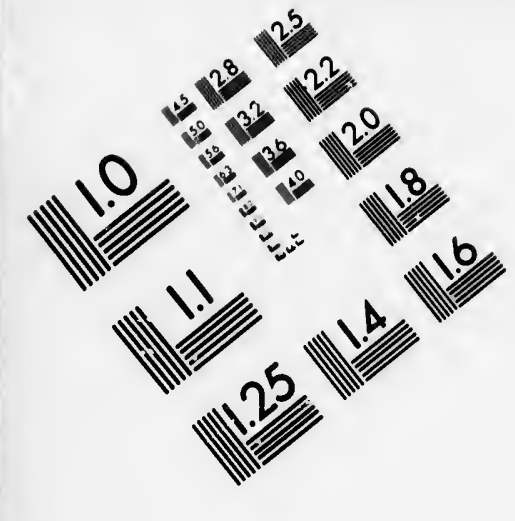

IMAGE EVALUATION

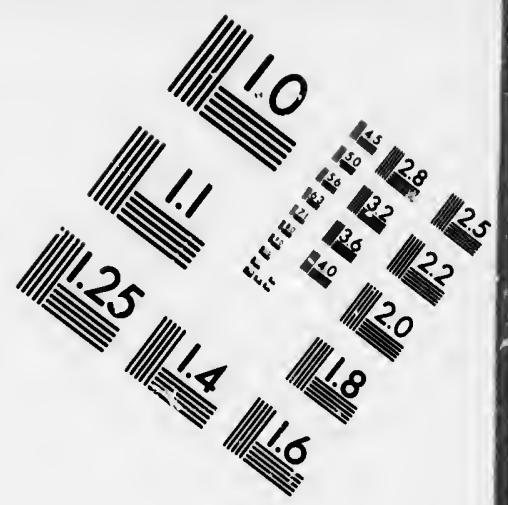

TEST TARGET (MT-3)
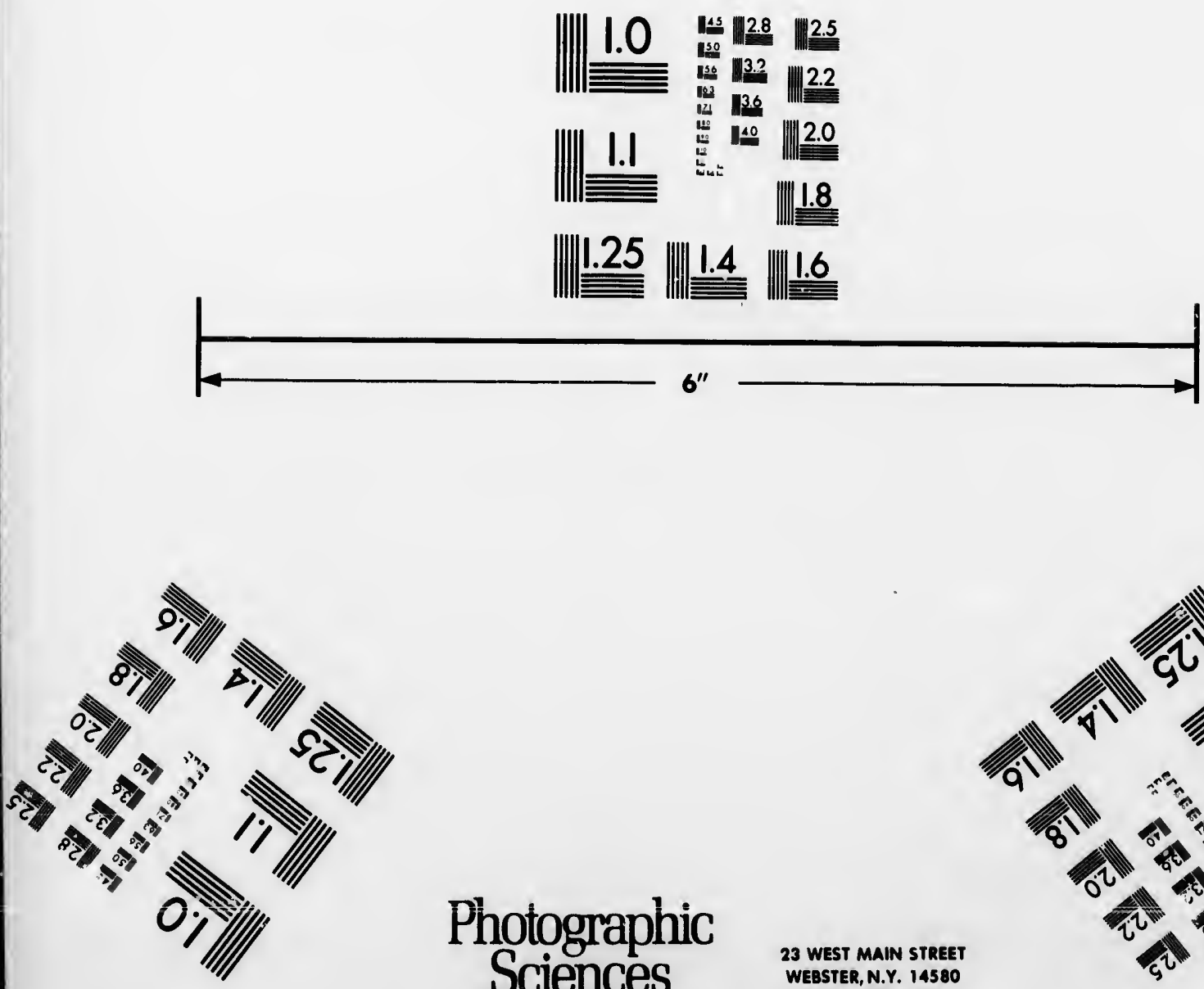

Photographic Sciences Corporation

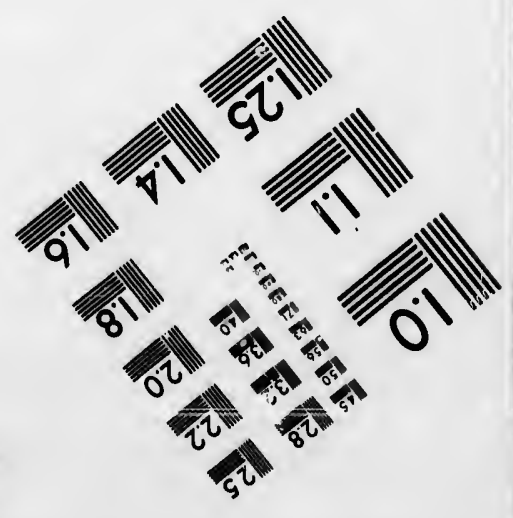


The Institute has attempted to obtaln the best original cepy available for filming. Features of this copy which may be blbliographlcally unique. which may alter any of the Images in the reproduction, or which may signiflcently change the usual method of fllming, are checked below.

Coloured covers/

Couverture de couleur

\section{Covers demeged!}

Couverture endommegde

Covers restored and/or laminated/

Couverture resteurbe ot/ou pelliculde

Cover title missing/

Le titre de couverture manque

Coloured meps/

Cartes géographiques en couleur

Coloured ink (i.e. other than blue or black)/ Encre de couleur (I.e. autre que bleue ou noire)

Coloured plates and/or illustretions/

Planches ot/ou lliustretions en couleur

Bound with other meteried

Relic avec d'autres documents

Tight bindling mey cause shedows or distortion along interior mergin/

La rellure serrb́e peut ceuser de l'ombre ou de le dlstorsion lo long de le marge intórieure

Blank leaves added during restoretion may appear within the text. Whenever posslble, these have been omitted from fllming/

II se peut que certaines peges blanches ajoutdes lors d'une restauretlon epparaissent dens le texte. mais, lorsque cela éteit posslble, ces peges n'ont pes été fllmíes.

Addlionel comments:/

Commentaires supplómenteires:
L'Institut a microfilmé le meilleur exemplaire qu'il lui a été possible de se procurer. Les détails de cet exemplaire qui sont peut-stre uniques du polnt de vue bibliographique, qui peuvent modifier une image reproduite, ou qui peuvent exiger une modiflcation dens la móthode normale de filmage sont indlqués ci-dessous.

Coloured peges/

Peges de couleur

Peges damaged/

Pages endommagóes

Peges restored and/or laminated/

Peges restaurbes et/ou pelllculdes

Pages discoloured, stained or foxed/

Pages décolord́es, tachetées ou piquées

Peges deteched/

Pages détachios

Showthrough/

Trensparence

Quelity of print veries/

Quellté inógele de l'Impression

Includes supplementery meterial/

Comprend du metériel supplémentaire

Only edltion evaileble/

Seule edition oisponible

Peges wholly or pertially obscured by errata sllps, tissues, etc., have been refilmed to ensure the best possible imsge/

Les pages totalemant ou partiellement obscurcies par un feuillet d'errata, une pelure. etc., ont été fllmés d nouveeu de façon à obtenir la mellleure image possible.

This item is fllmed at the reductlon ratlo checked below/

Ce document est filmé eu teux de róduction Indlqué ci-dessous.

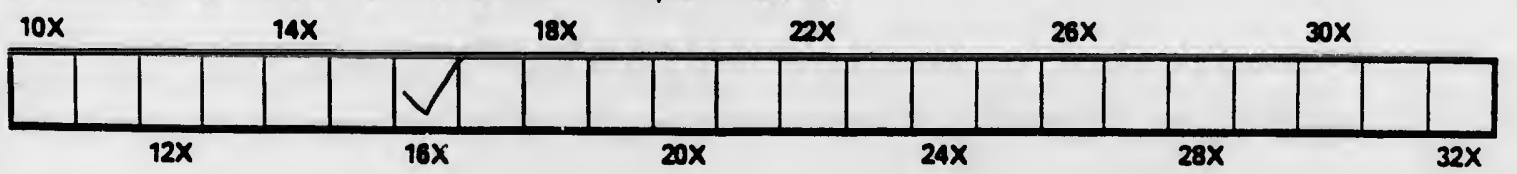


The copy filmed here has been reproduced thenks to the generosity of:

Metropolitan Toronto Library

Canadian History Department

The images appearing here are the best quality possibie considering the condlition end legibility of the original copy and in keeping with the filming contract speclfications.

Originai copies in printed paper covers are filmed beginning with the front cover snd ending on the last page with a printod or iliustrated impresslon, or the back cover when appropriete. Ali other original copies are fiimed beginning on the first page with a printed or iliustrated impression, end ending on the lest page with e printed or iliustrated impression.

The last recorded frame on each microfiche shali contain the symboi $\rightarrow$ Imeaning "CONTINUED"), or the symboi $\nabla$ (meaning "END"), whichever applies.

Maps, plates, charts, etc., may be flimed at different reduction ratios. Those too iarge to be entireiy included in one exposure are fiimed beginning in the upper left hand corner, left to right and top to bottom, as many frames as required. The foliowing diagrams lilustrate the method:
L'exempieire filmo fut reproduit grâce a la générosits do:

\section{Metropolitan Toronto Library Canadian History Department}

Les imeges suiventes ont b́t6 reproduites avec le pius grand soin, compte tenu de le condition et de la nettnté de l'exempieire filimb, ot en conformité avec les conditions du contrat de flimage.

Les exempiaires originaux dont ia couverture on papier est imprimbe sont filmb́s en commençant par ie premier piat ot en terminant soit par la derniare pege qui comporte une emprelnte d'improssion ou d'iliustretion, solt per ie second piet, seion ie ces. Tous ies autres exemplaires orlginaux sont flimés on commençent par ie premidre page qui comporte une empreinte d'impression ou d'iliustration ot en terminant par la derniere page qui comporte une teile empreinte.

Un des symboies suivants apparaître sur lo dernière image de chaque mlcrofiche, selon le cas: ie symbole $\rightarrow$ signifie "A SUIVRE", le symbole $\nabla$ signifle "FIN".

Les cartes, planches, tableaux, etc., peuvent être flimés des taux de réduction différents.

Lorsque ie document est trop grand pour être reproduit on un seui clichb, il est filimb d partir de l'angie supérieur gauche, de gauche d droite. et de haut en bas, en prenant ie nombre d'images nócessaire. Las diagrammes suivants iilustrent ia méthode.
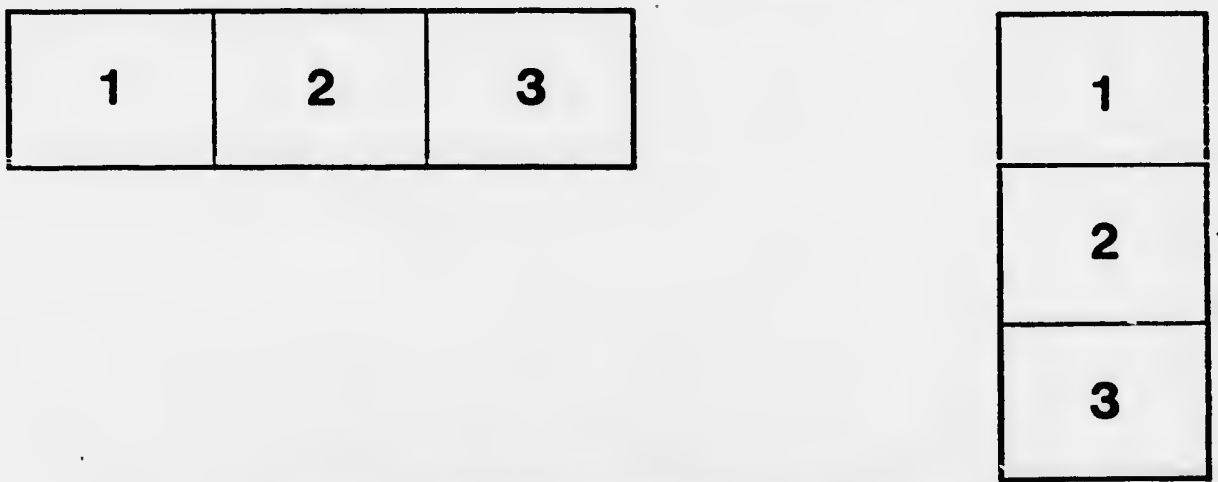

\begin{tabular}{|l|l|l|}
\hline 1 & 2 & 3 \\
\hline 4 & 5 & 6 \\
\hline
\end{tabular}





\section{T R A I T E \\ DU CASTOR,.}

DANS LEQUEL ON EXPLIQUE la nature, les proprietés \& l'ufage Médico-Chymique du Caftoreum dans la Médecine.

Par JeAN MARIUS, Médecin d'Aufbourg.

AUGMENTE DES OBSERV ATIONS de cet Auteur, \& de plufieurs áutres Médecins célébres i, de l'Hiftoire des Maladies dont on $n$ 'avoir point encore parlé, \& d'un grand nombre de découvertes, par JEAN FRANCUS.

Traduit par M. EIDOUS. A V ÉC FrgUREs.

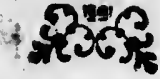

A PAR I S,

Chez David Fils, Quay-des Augufting; dụ côté du Pont S. Michel, au St Efprit.

M. D. C. C. X L V I.

Avec Approbation or Privilege du Ray: 
'Ardua res eft vetuftis novitatem dare; novis, auctoritatem; obfoletis, nitorem; obfcuris, lucem; faftiditis, gratiam; dubiis, fidem; omribus verò naturam, of natura fua omnia; itaque etiam non affecutis voluiffe abund's pulchrum of magnificum eft. Plinius. 


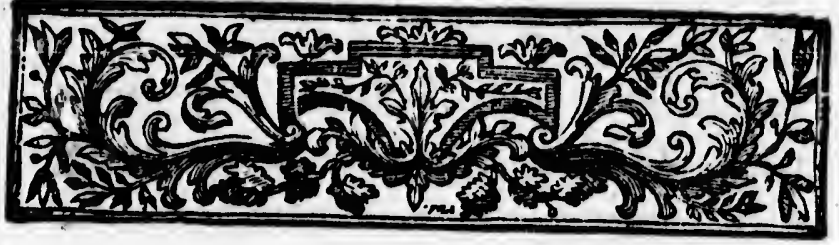

dare; novis,

P R E F A C E

DEFRANCUS.

; obfcuris, biis, fidem; a fua omnia; uiffe abunds inius. 
1)

$$
P R E F A C \text {. }
$$

jeuneffe à Jean Sculter, le premier Médecin \& le plus fameux Chirurgien de fon tems, fous la conduite duquel il fit de - fi grands progrès, qu'ils lui mériterent les honneurs du Doctorat. Aggrégé au College des Médecins de la ville d'Ulm, qui étoit porur lors le plus renommé après celui d'Ausbourg, il exerça pendant quelque tems la Médecine dans cette Ville; mais il paffa enfuite à Ausbourg où il mourut quelques tems après fans laiffer d'enfans.

Un grand nombre de perfonnes qui vivent encore, ont été témoins de fes fuccès dans la pratique, \& fileur témoignage ne fuffifoit point, le manulfcrit qu'il nous a laiffé, feroit plus que fuffifant pour nous en convaincre. Cet Ouvrage étant tombé, je ne fçai par quel hazard, entre les 
pre-

imeux

fous

de - fi nérite-

ctorat. Médei étoit é après ça pendecine affa enmourut $s$ laiffer

perfonont été sla pra. nage ne crit qu'il que fufivaincre. oé, je ne entre les

\section{PREFACE.} mains du célebre Jean Mayer, iij j'héritai , en qualité de difciple , d'un bien qui lui appartenoit, , ce qui me met en droit d'en faire part au Public. Si jaai ofé y joindre mes remarques, c'eft moins par oftentation \& par envie d'inf. truire des Demi-fçavans, que d'être utile à ceux qui fe deftinent à la Médecine, \& d'engager ceux qui ont en vûe l'utilité publique, de mettre au jour les Ouvrages qui n'ont point encore paru, \& qui peuvent contribuer à l'avantage de la Médecine.

C'eft-là le but que je me fuis propofé , \& qui ne me paroît pas tout-à-fait à méprifer. Je fçai bien qu'il n'a pas éte goûté de tout le monde; mais devois-je m'attendre à un avantage, dont Jupiter même n'a point joui \& que je n'ambitionne point : je me flatte cependant que quelques f̧̧avans

a $\mathrm{ij}$ 
iv

\section{P REFACE.}

approuveront mon deffein.

Je n'ai rien oublié de tout ce qui pouvoit contribuer à la perfection de cet Ouvrage ; jai rapporté, lorfque l'occafion s'en eft préfentée, les caufes prochaines des maladies dont $\mathrm{je}$ fais mention \& les ai accommodées aux loix de la circulation du fang. J'ai examiné à la rigueur ce qui m’a paru douteux, \& je me fuis fervi pour découvrir la vérité de la raifón auffi-bien que de l'autorité. J'ai recueilli avec tout le foin poffible, les découvertes qui ont été faites par les Médecins, \& furtout, par ceux d'Ulm \& de Memmingen, aufquelles jai joint celles du célebre Wedelins dont jai été difciple, dans la perfuafion que le Lecteur m'en fçaura gré.

Enfin jai eu foin de ne rien avancer de fuperflu, rien qui foir 


$$
P R E F A C E \text {. }
$$

étranger à mon fujet \& qui ne foit appuyé fur des preuves inconteftables.

Je prie le Lecteur de ne point condamner mon Ouvrage avane que de l'avoir lû, de le laiffer, fuppofé qu'il ne réponde point aux efpérances qu'il en avoit conçûes, ou de le corriger, fuppofé qu'il s'y foit gliffé quelques fautes; je ne lui en fçaurai point mauvais gré, pourvû qu'il évite les injures \& la fatyre, \& que $f_{a}$ critique foit fondee fur la raifon plutôt que fur le préjugé.

\& furde Memoint celins dont a perfuaen fçaura

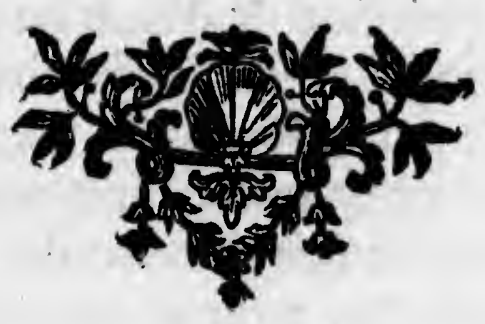

ne rien en qui foit 
$\nabla j$

\section{$L E T T R E$}

E X T R A I T

D'UNE LETTRE

DE M:SARR ASIN,

Médecin du Roi en Canada, touchant l' Anatomie du Caftor, écrite à $M^{\mathrm{r}}$. Pitton de Tour: nefort.

ES plus gros Caftors ont 3 ou I 5 . pouces de large au milieu de la poitrine \& d'une hanche à l'autre; ils pefent ordinairement depuis 40 jufqu'à 60 livres : $\grave{a}$ l'égard de leur vie, on ne croit pas qu'elle foit de plus de i 5 ou 20 ans. Ces animaux font ordinairement fort noirs dans le Nord le plus reculé : on y en trou- 
$D E M . S A R R A S I N$. vij ve auffi de blancs. Ceux du Canada font la plupart bruns; mais cette couleur s'éclaircit à mefure que les pays font plus temperés; car ils font fauves, \& inême ils approchent de la couleur de paille chez les Ilinois \& chez les Chaovanons.

Le Caftor dont on donne ici la defcription, étoit affez noir, quoique pris fur le bord d'un petit lac, à douze ou quinze lieues de Quebec : il ne pefoit que cinquante livres.

Cet Animal eft par-tout revêtu . de deux fortes de poils, excepté aux pattes, qui font couvertes d'un poil très-court : le poil de la premiere efpece eft long de 8 i 10 lignes jufqu'à deux pouces, \& diminize en approchant de la tête \& de la queue; c'eft le plus liifant, \& il donne la principalo couleur au Caftor. Si on confi- 


\section{viij $I E T T R E$}

dere ce poil avec un microfcope, on remarque dans fon milien une ligne beaucoup moins opaque que les côtés, ce qui fait conjecturer qu'il eft creux.

L'autre efpece de poil eft un duvet très-fin $\&$ très-ferré, long d'environ un pouce, qui garantit le Caftor du froid, \& qui fert d faire des Chapeaux \& des étoffes: Les peaux qui ont fervi d'habit ou de couverture de lit aux Sauvages, font les plus.recherchées, d'âtunt qu'elles ont perdu leur grand poil, \& que le duvet qui refte, étant devenu gras par la matiere de la tranfpiration, eft plus propre aux ouvrages \& fe foule beaucoup mieux.Ce duver, quand l'Animal eft en vie \& qu'il travaille, eft confervé \& garanti de la boue par le poil le plus rude $\&$ le plus long.

Il eft d'abord affez difficile de

c.

fe

o

o)

fo

m

le

cl

il

q

or

ef

m

de

dit

$\&$

re

m

di

to

de

cl

ce

d' 
$D E M . S A R R A S 1 N$. ix

nicrofins fon aucoup côtés, u'il eft

1 eft un é, long garantic i. fert d étoffes: d'habit ux Saurrchées; rdu leur uvet qui as par la ion, eft ges $\&$ fe e duvet, ie \& qu'il $x$ garanti plus rude ifficile de connoître fi le Caftor eft mâle ou femelle; on ne voit qu'une feule ouverture fous la queue, $\&$ cette ouverture eft deftinée pour la fortie de leurs differens excrémens; les parties qui diftinguent le fexe font cachées fous les mufcles; pour ne pas s'y tromper, il faut pincer plus que la peau qui eft entre l'os pubis \& cette ouverture; on y fent la verge qui eft dure, groffe \& longue comme le doigt.

On trouve fous la peau, un lit de graiffe épais ordinairement de de 8 ou i o lignes fous le ventre; \& qui s'étend depuis les machoires jufqu'à la queue; mais il diminue peu-à-peu en approchant dú dos où il n'y en a point du tout : on découvre un fecond lit de graiffe entre les deux mufcles obliques du ventre; mais cette graiffe n'a que 2 ou 3 lignes d'épais, les vifceres en font pref- 


\section{I $E T T R E$}

que dépourvûs; l'épiploon quoiqu'auffi grand que dans les autres animaux ne pele que 3 ou 4 onces.

Tous les mufcles du Caftor font extrêmement forts, \& femblent plus gros qu'ils ne doivent être par rapport a la grandeur de l'Animal; les fibres du mufcle peaucier ont des directions fort différentes; celles qui couvrent le dos depuis les cuiffes jufqu'au col, font droites \& fi groffes, que ce mufcle a dans cet endroit-la près d'un pouce d'épaiffeur ; les fibres qui font fituees à côté de celles-ci s'en écartent peu-à-peu $\&$ font un volume bien plus petit $\$$ elles décrivent prefque des demicercles, lefquels defcendant fur les mufcles pectoraux, fur le fternum, \& tout le long des mufcles droits, fe réuniffent par une aponevrofe, de telle forte qu'elles

Cr

d.

er

cc

$\mathbf{q}$

m

te

ro

di

fe

cc

te

d

ti

d.

il

uI

e

fo

21 


\section{$E$}

oon quoiles autres ou 4 on-

\section{du Caftor} , \& feme doivent andeur de lu mufcle tions fort couvrent s jufqu'au offes, que endroit-là iffeur ; les à côté de peu-à-peu plus petit edes demiendant fur fur lefterles mufcles ar une apote qu'elles

\section{DE M.SARRASIN. xj} enveloppent tout l'Animal : une partie de ces fibres vient embraffur les cuiffes, après quoi elles fe croifent fur l'os pubis, d'où elles defcendent \& forment un tiffu en maniere de natte; ce tiffu couvre, non-feulement un $\mathrm{pa}$ quet de fibres très-confidérables, mais auffi les fphincter de l'anus.

De la furface interne de la natte dont on vient de parler, environ I 2 ou I I lignes au-deffous de l'os pubis, fortent deux trouffeaux de fibres charnues gros comme le doigt, lefquels remontent à l'infertion des mufcles droits \& s'y attachent : de la partie de ces mufcles qui couvre le dos $\&$ dont les fibres font droites, il fe forme du côté de la queue une aponevrofe très-forte, qui enveloppe tout ce qui eft au-deffous des cuiffes; elle eft attachée aux apophyfes épineufes des ver- 
xij $\quad L E T T R E$

tebres qui font vers la queue, \& de diftance en diftance elle tient

m

br aux membranes des mufcles qui la font mouvoir.

L.e même plan de fibres étant parvenu aux premieres vertebres du dos, fe divife d'abord en deux parties qui forment plufieurs têtes, \& qui par différens principes s'inferent en differens endroits : il y en a une large d'environ deux pouces, qui monte jufqu'à la troifiéme vertebre du col, \& qui eft attachée fur le rhomboïde; une autre s'attache fur la crête de l'omoplate, une troifiéme, fur la partie poftérieure \& fupérieure du bras, fur le coude $\&$ fur la partie poftérieure \& inférieure de l'avant-bras : enfin la quatriéme fait un même tendon avec celui du très-large, \& de celle-ci, il s'en fait une cinquiéme, qui s'infere fur la partie 


\section{$D E M . S A R R A S I N$. xiij}

moyenne \& inférieure de l'avant bras.

Il n'y a rien de particulier dans les mufcles du ventre, fi ce n'eft que le petit oblique \& le tranfverfal font inféparables.

Le foye du Caftor eft rougebrun, divifé en fept lobes qui occupent également les deux hypocondres, en forte qu'ils couvrent l'eftomach de tous les cô. tés : la veffie du fiel eft attachée au plus gros de ces lobes, \& fe vuide ordinairement dans le duodenum. M. Sarrafin en a trouvé tune qui fe dégorgeoit dans le jejunum.

La ratte eft ronde, \& n'a gueres que 4 lignes de " " "ettre fur environ 3 pouces de long; elle eft plus ferme que celle des autrus animaux ; cinq ou fix vaiffaux fort courts l'attachent au fond de l'eftomac ; elle tient aufi par quel- 
xiv

\section{$L E T \tau R E$}

ques membranes aux reins, \& au colon : on apperçoit quelques glandes conglobées, groffes comme des pois, fituées vers fon extrêmité qui regarde l'eftomac, l'autre.

Les reins ont demi pouce d'épais fur deux pouces de long, \& fur prefque autant de large; les glandes renales font longues de 4 ou cinq lignes.

Le pancreas a du moins deux pieds de long, il forme un angle dont la pointe eft attachée aut gros lobe du foye par quelques petits filets : ce pancreas eft divifé en deux parties, l'une paffe fous l'eftomac \& vient s'attacher à la ratte $\&$ au rein gauche ; l'aultre defcend le long du duodenum \& du jejunum, dans lefquels il s'ouvre par plufieurs petits conduits.

unt ies I env rat fort At her ce i1 


\section{$E$}

reins, \& çoit quelées, groffes es vers fon l'eftomac, groffe que

pouce d'éde long, \& e large; les longues de

moins deux re un angle ttachée au ir quelques eas eft divil'une paffe it s'attacher unche ; l'audu duodeans lefquels s petits con-
DEM.SARR ASIN. XV L'éfophage eft intérieurement evêtu d'une membrane blanche, nii eft comme une efpece de loublure, que l'on détache aifément du canal fans la déchirer.

Le ventricule du Caftor eft une des parties des plus finguliees de cet Animal : ce ventricule I 2 ou 13 pouces de long fur nviron 4 de large du côté de la atte; il diminue peu-à-peu, enprte qu'après les deux tiers, il At rétreci de moitié par une faile de plus d'un pouce, qui avane dans fa capacité, après quoi s'élargit d'environ 3 pouces ers le pylore qui eft confidéraement relevé, arrondi \& avan- vers la ratte par une membrae attachée à l'éfophage par fon utre bout. L'évafement dont en thent de parler, femble faire un cond ventricule; mais il ne fert roprement qu'à retenir plus 
xvj

\section{ET T RE}

D

long-tems les alimens, \& fur tout, les plus folides, comme le bois dont il ne s'y fait qu'un extrait fort leger ; car il paffe prefque comme il a été avalé, au lieu que les herbes, les fruits, les racines, fe diffolvent parfaitement.

Les membranes du ventricule font fi minces, quc cette partie fe déchire pour peu qu'on la gonfle ; il n'y a que la membrane charnue qui s'epaiffit du côté du pylore \& le fortifie. On ne trouve aucunes glandes difperfées dans ce ventricule; mais en récompenfe, il eft garni d'environ cent veffies de deux ou trois lignes de long, lefquelles s'applatiffent du côté du ventricule, comme le font les grains de raifins qui font un peu trop preffés. Cette coutche de veffie eft attachée fur la membrane nerveufe, \& recou-

verte

verte

fa fit

la pa

l'éfop

une $e$

que ,

large

linté

glanc

licat

peu

tout

eurs

hean

arge

fur $q$ dans de l'.

pent

que 1

de $b$

d'ap!

que

mati 


\section{DEM.SARRASIN. xvij}

ur tout, le bois extrait prefque aur lieu. iits, les arfaite-

ntricule e partie a la gonembrane côté du ne trouifperfées is en rél'environ oislignes platiffent omme le qui font ette coulée fur la $x$ recouverte

verte de la charnue ; à l'égard de fa fituation elle fe trouve entre la partie droite du ventricule $\&$ l'éfophage: toutes ces veffies font une efpece de corps demi-fpherique, haut de 7 ou 8. lignes, \& large d'environ 3 pouces à fabafe. lintérieur de chaque veffie paroît glanduleux; mais elles font fi délicates, qu'elles crevent pour peu qu'on les preffe. Quoique toutes ces veffies ayent chacune leurs iffues, elles répondent peanmoins à $I 2$ petits orifices arges d'environ 2 lignes, rangés fur quatre colonnes qui s'ouvrent dans le ventricule. Après la mort de l'Animal ces veffies contienpent une matiere blanche, prefque fans odeur, \& de confiftance de bouillie; mais il y a beaucoup d'apparence qu'elle eft fuide lorfque l'Animal eft en vie. Cette hatiere eft fans doute le whol- 


\section{xviii $\quad L E T R R E$}

vant des alimens, qui, dans les Pays froids \& pendant l'hyver, ne font que de bois d'aune, de platane, d'orme, de frêne, \& de différentes efpeces de peupliers. Pendant l'été, les Caftors vivent de toutes fortes d'herbes, de fruits, de racines, fur-tout, de celles de différentes efpeces de nymphea.

Les inteftins de cet Animal font très-délicats, \& ont environ io pieds de long. Le cocum a la figure d'une faux ; il eft tenu dans cet état par deux ligamens qui rampent ; l'un, le long de fa partie cave; \& l'autre, fur la partie convexe : mefuré par la partie cave, il y a dix-huit pouces de long, \& plus de trente par la convexe. Sa largeur eft de 4 pouces dans fon gros bout , \& peut contenir s à 6 livres d'eau : le colon a. 4 pieds de long, \&.le rectum Is pouces. 
E

dans les l'hyver, aune, de Ene, \& de peupliers. ors vivent bes, de -tout, de fpeces de

Animal at environ ecum a la tenu dans mens qui de fa par- la partie la partie youces de par la con4 pouces peut con: le colon le rectum
DE M. SARRASIN. xix La veffie eft femblable à celle des chiens. Si l'on continue d'our. vrir cet Animal jufqu’à la racine de la queue, on découvre fort aifément les tefticules \& le paquet dont on a parlé dans la defcription du mufcle peaucier : ce paquet eft un mufcle creux qui renferme la verge $\&$ les bourfes. - Les tefticules font fitués dans les aînes, appuyés par leur bafe fur les parties latérales de l'os pu. bis, \& engagés dans la graiffe; ils font enveloppés de plufieurs membranes que le peritoine \& les mufcles du bas ventre leur fourniffent, fur-tout le mufcle crémafter, dont les fibres qui font circulaires, leur donnent la figure d'un cône ; ils reffemblent toutà-fair à ceux des chiens lorfqu'ils font développés.

Les vaiffeaux déferens, groffiffent confidérablement derriere ê ij 
$\mathrm{xx} \quad L E T T R E$

le col de la veffie ; mais ils diminueint avant que d'entrer dans luretre, oì ils ont leurs iffues fépàrées l'une de l'autre.

Les veficules féminales font tellement engagées fous l'os pubis, qu'on ne peuc les voir fans les féparer : elles ont ordinairement deux pouces de long fur un pouce de large vers le milieu; car elles font pointues parles deux bouts; leurs conduits s'ouvrent auffi féparément dans l'uretre, \&, vont aboutir ainfi que ceux des vaiffeaux déferens à une éminence charnue qui eft groffe comme un pois, \& qui eft une efpece de weru montanum : On voit à côté de cette é ninènce, plufieurs pevits orifices, des conduits excrétoires de quelques glandes, fituées au tour du col de la veffie, lefquelles font la fonction des proftrates, \& font remplies d'une

liqu

l'os

tent en $\mathrm{q}$ nes par un viro atta moj cen vert parl

F sib coul dep elle deu cle he cav ìć 


\section{$D E M . S A R R A S I N . \times x j$}

ils dimi-

rer dans urs iffues

sfont telos pubis, ans les félairement un pouce car elles ux bouts; t aufifi fé, \&, vont des vaiféminence

corsine efpece de it à côté fieurs peiits excréindes, fila veffie, ation des lies d'une liqueur blanche $\&$ huileufe.

Le mufcle creux eft fitué entre l'os pubis \& l'ouverture par où fortent les excrémens. Il reffemble en quelque maniere à ces anciennes gibecieres larges \& arrondies par le bas $\&$ retrécies par le haut : un corps tendineux, large d'environ un pouce, tient ce mufcle attaché à la lévre inférieure \& moyenne de l'os pubis d'où il defcend, en s'évafant jufqu'à l'ouverture commune dont on va parler.

En ouvrant cette efpece de gibeciere de haut en bas, on découvre vers fon milieu la verge, depuis.la racine jufqu'au balanus; elle partage cette capacité en deux cavités, après quoi le mufle creux fe repliant d'une certaihe maniere forme encore deux cavirés fituées fous les premieres à côté du balanus : c'eft dans ces 
xxij $\quad L E T F R E$

quatre cavités que font renfermées les bourfes qui contiennent le caftoreum ; mais avant que de paffer outre, il eft bon de parler de l'ouverture commune. C'eft une capacité d'environ deux pou* ces en tout fens, lorfqu'elle eft bien gonflée, dans laquelle aboutiffent les bourfes du caftoreum, l'uretre, l'anus \& le vagin dans les femelles; elle eft éloignée d'environ 3 pouces de la racine de la queue, \& de quatre pouces de l'os pubis, noirâtre \& bordée d'un poil affez fin, qui ne reffemble point à celui du refte du corps: la verge tient par fa racine a la lévre inférieure de l'os pubis : delà elle perce la membrane de la cloaque dans l'endroit où les bourfes fupérieures communiquent; cette membrane eft colée circulairement à l'infertion dubalanus, comme le diaphrag-

fer eft 
$E$

it renferntiennent nt que de de parler ine. C'eft deux pou* qu'elle eft elle abouaftoreum, ragin dans éloignée la racine tre pouces \& bordée nereffemrefte du ar fa racide l'os pumembra$s$ l'endroit ures commbrane eft l'infertion diaphrag-
DEM.SARRASIN. xxiij me l'eft à l'éfophage, la partie inférieure de la verge qui eft longue d'environ deux pouces $\&$ demi, eft contenue dans la cavité fupérieure du mufcle creux, dans l'endroit où il fe fépare en detux cavités, de forte que le balanus qui eft long de près de dix pouces \& demi, fe trouve tout-ar-fait dans la cloaque', fitué entre les iffues des bourfes, tant fupérieures qu'inférieures. Le Caftor approche la femelle par-devant, tant à caufe de la fituation de l'ouverture commune, qu'à caltde la longueur \& de l'inflexibilité de fa queue. Un Chaffeura affuré M. Sarrafin qu'il avoit tué d'un coup de fufil, deux Caftors, mâle \& femelle, accouplés dans cette fituation.

Le balanus qui eft tout-à-fait femblable à celui des chiens, eft couvert d'une peau chagrinée. 
xxiv $\quad L E T \boldsymbol{T} R E$

On découvre dans le corps dela

Ita verge, un os de figure piramidale, $\&$ dont la bafe eit attachée aux $\&$ corps caverneux, \& qui eft long d'environ is lignes.

Sous l'origine de la verge fe trouvent deux corps gros comme dé l'ầ on

fol une noix, attachés au corps caverneux; les deux corps font compofés de veficules fort délicates qui fe gonflent dains le tems de la copulation, par le moyen de plufieurs vaiffeainx fanguins, qui forment une efpece de capfule à l'uretre.

On trouve au même endroit

la bl. lap va po fer $\mathrm{da}$ deux glandes ovales, longues d'environ 10 lignes fur trois ou quatre lignes d'épais; leurs vaiffeaux excretoires qui font gros tet comme un ftilet ordinaire, \& $\mathrm{fl}^{\mathrm{u}}$ longs de plus de 12 ou I glignes, bn s'ouvrent dans l'uretre environ de un pouce dans la verge : la fubftance 
$E$

orps dela iramidale, achée aux it eft long

a verge fe os comme corps cacorps font fort délíans le tems moyen de guins, qui e capfule à

ne endroit , longues Cur trois ou leurs vaifi font gros linaire,$\&$ a 5 lignes, re environ ge : la fubftance

\section{DE M. SARRASIN. XxV} Aance de ces glandes eft ferme, \& contient une liqueur huileufe \& grifâtre, qui peut-être fert à défendre le canal de l'uretre de l'âcreté des urines. Les rats en ont de pareils, excepté qu'elles font rondes.

Les parties de la génération de la femelle du Caftor, font femblables à celles des femelles de lapins, de liévres, de rats; le vagin de celles du Caftor à cinq pouces de long; il n'eft pas ren-fermé non-plus que l'uretre dans la cavité fupérieure du mufcle creux, comme l'eft la verge du mâle; mais ce vagin a fon ouverure dans la cloaque.

On affure que les femelles portent 4 mois \& qu'elles font juflu'à $5,6, \& 8$ petits; cependant on ne leur en trouve jamais plus de 4. M. Sarrafin l'a vérifié dans celles qu'il a ouvertes.

$$
\text { i }
$$


$\operatorname{xxvj} L E T T R E$

Les Caftors femelles ont quât tre manmelles, deux fituées fur le grand pectoral, ainfi que celle des femmes entre la feconde \& 12 troifiéme des vrayes côtes, \& les deux autres au col environ quatre doigts plus haut que les premieres.

Les Anciens qui ne diffeguoient pas avec beaucoup de foin, ne s'appercevoient pas des tefticules du Caftor, parce quills font fort petits, \& qu'ils font fitués dans les aînes ; la groffeur, la fituation $\&$ la figure des bourfes leur en impofoit.

Les bourfes qui font contenues dans les cavités fupérieures du mufcle creux, \& que l'on appellera dans la fuite bourfes fit: perieurs, contienneitt une ma. tiere refineufe; mais celles qui fe trouvent dans les cavités infé. rieures , \& que l'on nommera

an pre ferr lus $a r$ 
ont quat: tuées fur que celle onde \& la es, \& les iron quae les pre-

ne diffeucoup de nt pas des arce qu'ils ils font figroffeur, des bour-

nt conteupérieures ue l'on ap. bourfes fitit une macelles qui avités infé.

nommera
DEM. SARRASIN. Xxvij pour cela bourfes inférieures, $y$ font affemblées par paquets, renfermées fous une membrane commune, \& remplies d'une ma. tiere huileufe : les fupérieures font doubles, \& reffemblent affez bien à une beface, dont chaque poche, qui ent d'environ trois pouces de long fur un poice $\& \mathrm{demi}$ de large dans le fond; fe trouve placée , l'une à droite, l'autre d gauche de la verge; ces bourfes décrivent un demi cercle en approchant de la verge, \& fe retréciffent peu-à-peu jufqu'à leurs ouvertures, lefquelles font d'environ un pouce $\&$ répondent dans la cloaque.

On remarque trois membranes ans la tiffure de ces bourfes ; la remiere eft fimple, mais trèsferme; la feconde eft beaucoup lus épaiffe, moëleufe \& fort arnie de vaiffeaux ; la troifiéme

i ij 
sxviij $L E T^{\prime} T R E$

elt particuliere au Caltor, elle cft féche comme un vieux parchemin : elle en a l'épaiffeur \& fe déchire de nitême; mais ellé eft tellement reptiée fur elle-mêne, qu'elle acquiert, quand on la dé-

f velope, trois fois plus de volume qu'elle n'avoit auparavant : cette membrane eft fort liffe en dehors, gris de perle, marquetée affez fouvent de taches brunes, quelquesfois rougeâtres; elle eft inégale en dedans, garnie de pe. tits filets aufquels la matiere refineufe eft fort adhérente.

Il femble que la premiere mem. brane ne fert qu'à contenir les bourfes dans leur jufte grandeur. Les vaiffeaux dont la feconde ef tapiffée, fourniffent la matiere ré fineufe mêlée avec le fang : cett membrane s'infere dans tous le replis de la troifiéme, comme pie-mere entre dans les anfractu p vi di pe ac fir or rec pl pa ra 4 , $d$ a of 


\section{$E$}

aftor, elle vieux paraiffeur \& fe ais elle eft He-même, ad on la déus de voluuparavant : fort liffe en marquetée hes brunes, res; elle eft arnie de pematiere refiente.

emiere mem contenir les fte grandeur: afeconde el la matiere ré le fang: cett dans tous le e, comme les anfractuo
DE M. SARRASIN. xxix fités du cerveaut. Pour la troifiéme il y auroit beaucoup d'apparence 'qu'elle doit fervir à filtrer la matiere refineufe, fi l'on pouvoit y découvrir des glandes, il faut lis fuppofer très-petites, \& peut-être que les filets dont on vient de parler en font les conduits excrétoires.

Cette matiere filtrée s'épaiffit peu-à-peu dans les bourfes, \& y cquiert la confiftance d'une raiGne échaufféc entre les doigts; on l'appelle communement caftoom ; elle conferve fa molleffe plus d'un mois après avoir été féarée de l'Animal, \& fent mauais dans ce tems-là, étant gritre en dehors, \& jaunâtre en edans; cnfuite elle perd fon deur, elle fe durcit \& devient able comme les autres raifines; ais il eft à remarquer qu'elle eft mbuitible en tout tems : les

I iij 
$\mathrm{Xxx}$

bourfes les plus groffes ne pefene qu'environ deux onces...

Les bourfes inférieures paroiffent d'abord doubles, l'une eft à droite, \& l'autre à gauche de Ja cloaque ; mais lorfqu'on a découvert la membrane qui les envelope, on en trouve quelquefois 2 ou 3 enfemble. Chaque paquet de ces bourfes eft long de deux pouces \& demi fur environ 14 ou 19 lignes de diametre. Les bourfes font arrondies par le fond, \& diminuent infenfiblement en approchant de la cloaque : la plus grande de ces bourfes occupe toute la longueur du paquet; mais elle n'a qu'environ 8 ou 10 lignes de diametre: la feconde qui n'eft pas toujours plus grande que la troifiéme, n'a pas ordinairement la moitié du volume de la premiere pour la troifiéme, elle êt le plús fouven

fe

m

la

d

co

no

ell

tér

glc

pa

tes

rie

ap

qu

so tre

dar

cell

bar

Gn

La

the hir 
ne pefene

es paroifl'une eft auche de i'on a déqui les quelquehaque pait long de ir environ diametre. dies par le infenfiblede la cloaces bourngueur du qu'environ ametre : la $s$ toujour's ifiéme, n'a moitié du re pour la lus fouvent
I' F. M.SARRASIN. $\mathbf{x x x j}$ moindre que les autres. Ces bourfes, outre leur membrane commune en ont chacune 3 propres; la premiere qui eft d'un tiffu fort d'́licat, eft parfemée de beancoup de vaiffeaux; la feconde eft non-leulement plus épaiffe, mais elle eft revêtue \& comme encroutée de glandes qui paroiffent conglomerées, \& ces glandes fe repandent par paquets de differentes groffeurs fur la furface extérieure de cette membrane : on apperçoit au milieu de ces paquets, certaines capacités qui souvrent les unes dans les autres; fçavoir, les plus grandes dans les plus petites; \& enfin. elles-ci, dans la bourfe même, ar des ouvertures d'une ou deux gnes.

La troifiéme membrane eft blanhe \& fi délicate, qu'elle fe déhire comme fi ce n'étoit qu'une 
xxxij $\quad L E T T R E$

crême épaiffie fur la furface intérieure de la feconde; elle eft percée aux mêmes endroits que celle-ci, afin de domner paffage à la liqueur filtrée dans les glandes.

La premiere membrane foutient les vaiffeaux fanguins, qui fourniffent la liqueur propre à être filtrée ; la feconde \& la troifiéme, fervent à la filtration. Les: glandes étant piquées, quoique très-légerement, laiffent échapper une liqueur huileufe, \& même celle qui eft dans la bourfe fe vuide facilement par cette ouverture pour peu qu'on preffe la bourfe ; cette liqueur eft jaunepâle, pleine de petits corps ronds femblables à ceux que l'on roit dans l'huile d'olive lorfqu'elle commence à fe figer : celle du Caftor devient parfaitement liquide \& de couleur d'ambre dans la fuite. pas 
$E$

rface intéelle eft perits que celpaffage à la $s$ glandes. brane foulguins, qui r propre ì e \& la tro:ration. Les: $s$, quoique ent échapufe, \& mêa bourfe fe c cette ouon preffe la reft jaunecorps ronds ue l'on roit lorfqu'elle : celle du aitement liambre dans
DE M. SARRASIN. xxxiij

On ne fçauroit affez admirer induftrie de la nature, qui pour empêcher que les petits conduits. des bourfes (lefquels fe dégorgent dans la cloaque à côte du balanus) ne fe bouchent par l'épaififfement de la liqueur, ou ne e deffechent par l'action de l'air; les a tous garnis d'un poil long d'environ demi pouce: il eft atta. ché par fa racine dans la bourfe même un peu au-delà du conduit; enfuite il en enfile la longueur, \& s'avance un peu dans a cloaque.

Toutes ces bourfes tant fupérieures quinférieures, ne communiquent point entr'elles; leurs conduits, comme l'on vient de die, aboutiffent dans la cloaque : on ignore l'ufage de ces liqueurs par rapport aux Caftors. Il n'eft pas vrai qu'ils s'en fervent pour exciter leur appétit lorfqu'il eft 


\section{xxxiv $\quad L E T T R E$}

languiffant. M. Sarrafin a nourri un de ces animaux pendant deux ans; mais il n'a pas pu en découvrir l'ufage : il eft faux que les Chaffeurs s'en fervent comme d'un appas pour attirer les Caftors dans le piége. On graiffe avec la liqueur huileufe, les piéges que lon tend aux animaux carnaffiers \& qui font la guerre aux Caftors, comme les Martres, les Renards, les Ours ; \& fur tout les Carcajoux, qui vont attaquer pendant l'hyver les Caftors dans leurs loges \& les brifent bien fouvent.

Les fenmes des Sauvages graiffent leurs cheveux avec l'huile des bourfes du Caftor ; mais elle fent mauvais, \& ne peut-être un appas que pour des Sauvages.

La poitrine des Caftors eft lon. gue d'environ s pouces, fort étroite par en haut, beaucoup

plus

parc

vraic

fept

font

qui

une

facil rétre peti tract pren L cing lage pour Les à dro autr dans ann font I deur 


\section{$D E M . S A R R A S I N$ XxxV}

nourri nt deux découque les comme les Cafiffe avec $s$ piéges aux carerre altx tres, les tout les attaquer ors dans oien fou-

ges graifc l'huile mais elle -être un vages. is eft lon. es, fort eaucoup plus large vers le bas, fermée par quatorze côtes i f̧̧avoir, fept vraies qui font fort courtes, \& fept fauffes, qui non-feulement font beaucoup plus larges, mais qui pardevant laiffent entr'elles une grande diftance; c'eft ce qui facilite au Caftor le moyen de fe rétrecir aifément; car elles fe peuvent rapprocher par la contraction des fibres circulaires du premier mufcle.

Le fternum eft compofé de cinq os aflez étroits : le cartillage xiphoïde eft large d'un pouce en rond \& fort fléxible. Les poumons ont fix lobes, trois à droite $\&$ deux à gauche, $\&$ un autre fort petit qui eft enfermé dans le médiaftin : les cartillages annulaires de la trachée artere font chacun d'une feule piece.

Le cour eft long d'environ deux pouces ; fa bafe a un peu 
xxxvj $\quad L E T T R E$

plus d'un pouce $\&$ demi de diamettre. Les ventricules en font égaux ; mais l'oreillette droite eft beaucoup plus petite que la gaulche ; cependant je ne crois pas pour cela, que la quantité de fang qui tombe dans ce ventricule foir moins proportionné à fa grandeur; car la veine cave inférieure eft dans cet endroit confidérablement évafée, \& forme une efpece de fac entouré de fibres charnues, long \& large d'environ un pouce \& demi de diametre : ce fac agit de concert avec l'oreillette droite pour rem: plir le ventricule droit : le nême fac eft plus étroit du côté du foye ou il eft fermé parcing valvules femblables aux figmoïdes qui permettent bien aul fang de pourfuivre fa route ordinaire, mais qui s'oppofent à fon reflix, lequel feroit à craindre, puifque

La've de $s^{\prime}$ par fac; de fe re à-fai vier rout rieu bran fous virir

mar tête

Le d plaq . 2 rieu re; rem nuc 
DE M.SAR R AS IN. xxxvij ni de dia$s$ en font la'veine-cave fupérieure, au lieu de s'ouvrir dans l'oreillette, paffe par derriere \& fe dégorge dans le fac ; de forte que le confluant de de cés deux colonnes de fang. fe rencontrent dans un fens toutà-fait oppofé, \& que la fouclaviere gauche, au lieu de finir fa route daus la veine-cave fupérieure, defcend (en paffant fur la branche inférieure de l'aorte) fous la bafe du cour, \& va s'ouvrir dans le fac dont on a parlé.

Voici ce que M. Sarrafin a remarqué de plus fingulier dans la tête du Caftor.

$I^{\circ}$. L'os occipital eft polé fur le derriere de la tête comme une plaque.

$2^{\circ}$. Il n'y a point de finus intérieur dans la faux de la dure-mere ; cette membrane divife légerement le grand cerveau, foutenu dans fa fituation par des offe- 
xxxviij $L E T T R E$

lets inferés dans fa propre fubftance, dont les uns ne font que des lames offeufes, très-folides quoique minces; \& les autres qui font ronds, ont line ligne de diametre fur deux ou trois lignes de long.

$3^{\circ}$. Le cerveau n'a aucunes anfractuofités fenfibles; on en fépare la pie-mere, comme fi elle étoit fimplement couchée fur un corps uni.

$4^{\circ}$. Le cervelet eft relevé de plufieurs tuberofités de différentes figures, qui font féparées les unes des autres par la pie-mere: il y en a deux qui fortent des côtés, \& qui ont 4 lignes en tout fens.

$5^{\circ}$. Les yeux font forts petits, l'ouverture des paupieres n'ayant qu'environ quatre lignes : la cornée eft ronde, \& l'iris d'un bleu. foncé.

com fitue 'œil qui déc décc Cont font deus les $\mathrm{i}$ du $n$ long celle pour Tupé dem férie fuive tes, prod bba gran 8 


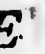

opre fube font que rès-folides autres qui jne de dia. s lignes de

a aucuines

$s ;$ on en mime fi elle hée fur un

relevé de de difféont fépares par la ix qui foront 4 li-

rts petits, -es n'ayant es : la cord'un bleu
DE M. SARRASIN. xxxix $6^{\circ}$. M. Sarrafin a remarqué comme une troifiéme paupiere, fituée dans le grand angle de 'œil ; c'eft comme un rideau qui couvre la cornée, ou qui la découvre au gré de l'Ánimal.

$7^{\circ}$. Les deux machoires qui font très-fortes \& prefque égales, font garnies chacune de 10 dents, deux incifives \& huit mollaires; les incifives. font fituées au bout du mufeau : celles d'en-haut font longues d'environ 8 lignes, \& celles d'en-bas ont environ un pouce de long: les racines des tupérieures ont deux pouces $\&$ demi de longueur, celles des inférieures en ont plus de trois, \& fuivent la courbure des machoires, ce qui leur donne une force prodigieufe; auffi les Caltors bbattent à coups de dents de grands arbres.

$8^{\circ}$. Comme ces Animaux vi- 
vent le plus fouvent d'alimens fort fecs, la nature leur a donné des glandes falivales d'une grandeur prodigieufe ; elles occupent tout le deffous de la machoire inférieure, le devant du col, \& defcendent jufques fur les clavicules: ces glandes font couvertes d'un mufcle adherant à la peau, compofé de deux plans de fibres charnues attachées à la $2,3 \& 4$ inféri puyé jufqu ufage abaifl prock mêm main: nour $\mathrm{La}$ vertebre ducol par un principe charnu large de 4 doigts ; l'un \& l'autre de ces plans prenant des routes oppofées, embraffent le col vers la trachée artere, fur laqueile ils croifent leurs fibres forme de natte: celui qui vient dit côté drōit va vers le gauche s'inferer par fon aponeurole au bras, au plis du coude, \& à l'avant-bras ; l'autre plan va par une route oppofée s'inferer de même dans l'autre bras: ce mufcle tient par 
DE M. SARRASIN. xlj limens donné - par en haut à toute la machoire inférieure, \& par en-bas il eft ap. puyé fur de la graiffe, '\&-defcend jufques fur les clavicules; fon ufage eft de preffer les glandes en abaiffant la machoire, \& en approchant les bras de l'Animal èn même-tems qu'il tient entre fes mains les alimens dont il fe nourrit.

La queue du Caftor n'a aucuin rapport avec le refte du corps; elle paroît approcher de la nature des poiffons ; car elle eft couverte d'une peau écailleufe, fous laquelle on trouve une graiffe ferme, qui reffemble affez à la chair du marfoin, ce qui pourioit fans doute, avoir le plus contribué d faire paffer le Caftor pour un amphibie; les écailles font exagones, épaiffes de demi-lignes fur environ trois ou quatre lignes de long, couchées les unes fur les autres?' par 
xlij $\quad L E T T R E$ jointes enfemble par une pellictrle fort délicate, enchaffée dans la peau dont elles fe féparent aifément après la mort de l'Animal: il fort d'entre chaque écaille, trois ou quatre poils longs d'environ 2 lignes, qui font plus fréquens dans les côtés de la queue qu'ailleurs.

Cetre queue eft mûe par un grand nombre de mufcles, dont les uns font grands \& les autres petits; les plus grands font appuyés fur les apophyfes, tranfyerfes de l'os facrum; leurs tendons font diftribués par paquets de 4 ou de 6 , enfermés dans des gaines qui les conduifent le long des vertebres de la queue; les petits mufcles ont leurs tendons collés \& confondus avec ceux des premiers.

Le Caftor étant deftiné à des ouvrages de maçonnerie, coupe

le boi gache pieds feule ge po il étoi leufe fieurs Le blabl qui, $\&$ qui entre rats, derri $\&$ ref de r mem comr canat pre à ger d du ne blabl 


\section{$D E M . S A R R A S I N . \times$ liij}

pellictrfée dans arent ai'Animal: écaille, ngs d'enplus fréla queue

e par un les, dont les autres font apes, tranf leurs ten$r$ paquets s dans des int le long ueue; les rs tendons avec cetix

Atiné à des. rie, coupe le bois avec fes dents, amollit \& gache la terre glaife avec fes pieds ; fa queue ne lui fert pas feulement de truelle, mais d'auge pour porter le mortier; ainfi il étoit neceffaire qu'elle fût écailleufe, garnie de graiffe \& de plufieurs mufcles.

Les pieds de devant font femblables aux pieds des animaux qui , comme lui, aiment à ronger, \& qui tiennent ce qu'ils mangent entre leurs pattes, comme les rats, les écureuils : les pieds de derriere n'y ont aucun rapport, \& reffemblene à cecix des oifeaux de riviere, qui font garnis de membranes entre les doigts, comme font ceux des oyes \& des canards. Ainfi le Caftor eft propre à marcher fur la terre \& à nager dans les eaux. Depuis le bout dı nez jufqu'aux cuiffes il eit femblable à un rat; mais depuis les ó ij 
xliv $\quad L E T T R E$

cuiffes jufqu'à la queue, il reffemble affez aux oifeaux de riviere qui ont les pieds plats.

Lorlque les grandes inondations font paffées, les femelles retournent à leurs logemens pour y mettre bas : les mâles tiennent la campagne jufqu'au mois de Juin \& de Juillet, \& ne reviennent chez eux que lorfque les eaux font tout-à-fait baffes; alors ils réparent les defordres que les inondations ont faites à leurs logemens, ou ils en font de nouveaux. Ils changent de lieu pour. trois principales caufes; lorfqu'ils ont confumé les alimens qui étoient à leur portée ; quand la compagnie eft trop nombreufe; quand les Chaffeurs les inquietent trop;

Pour établir leur demeure, ils choififfent un endroit abondant en vivres, arrofé d'une petite ri-

viere lac : i truire fuffifa qu'au mens rivier font 1 dans ! $\operatorname{dix} 0$ dans nuen où ment malux coup pas, parm ou ce puis ils le bout: fort leṣ en 


\section{DE M. SARR ASIN. xlv}

il refde rits.

inondaemelles ns pour iennent hois de revienque les ; alors que les à leurs de noueut pour. orfqu'ils ns qui uand la breufe ; inquie-

eure, ils oondant etite ri- viere, \& propre pour y faire un lac: ils commencent pary conftruire une chauffée de hauteur fuffifante pour élever l'eau jufqu'au premier lit de leurs logemens : fi le pays eft plat \& que la riviere foit creufe, les chauffées font longues \& moins élevées que dans les valons : ces chauffées ont dix ou douze pieds d'épaifleur dans leurs fondemens, \& diminuent peu-à-peu, jufqu'au haut où elles n'en ont ordinairement que deux. Comme ces Animaux ont une grande facilité à couper du bois, ils ne l'épargnent pas, \& le taillent ordinairement par morceaux gros comme le bras ou comme la cuiffe, \& longs depuis 2 jufqu'à 4 , 5 ou 6 pieds ; ils les enfoncent par. l'un des bouts fort avant dans la terre, \& fort proche les uns des autres, les entrelaffant avec d'autres mor- 


\section{xlvj $\quad L E T T R E$}

ceaux plus petits \& plus fouples, dont ils rempliffent les vuides avec de la terre glaife ; ils continuent à mefure que l'eau s'éleve, afin de pouvoir tranfporter plus aifément les matériaux. On arrête enfin ces fortes de digues, lorfque les eaux retenues peuvent atteindre le premier lit du logement qu'ils doivent faire : le côté de la chauffée quel'eau touche eft en talus, \& l'eau qui pefe fuivant la hauteur, preffe puif fammant contre terre; le côté oppofé eft à plomb : elles font affez folides pour foutenir les perfonnes qui montent deffus, \& ces Animaux ont grand foin de les entretenir; car ils reparent les moindres ouvertures avec la terre glaife. S'ils s'apperçoivent que les. Chaffeurs les obfervent, ils n'y travaillent que la nuit ou bien ils abandonnent leur demetre.

le bo titeif geme débo l'eau de la ne pu fois tiere fés de qu'ils ils en riaux les ch timer termi Les 1 deux leurs leurs bouts 
fouples, $s$ vuides Is contiI s'éleve, rter plus On arrêdigues, les peller lit du faire : le eau touqui pefe offe puifle côté lles font ir les periss, \& ces n de les arent les ec la tervent que ent, ils toubien metire.
$D E M . S A R R A S I N . \mathrm{xlvij}$ La chauffée étant finie, ils travaillent à leurs cabanes, qu'ils fondent toujours folidement fur le bord de l'eau, fur quelque petite ifle, ou fur des pilotis : ces logemens font ronds ou ovales, \& débordent des deux tiers hors de l'eau; mais ils ont la précaution de laiffer une porte que la glace ne puiffe pas boucher. Quelquefois ils bâtiffent la cabane entiere fur la terre, $\&$ font des forfés de 5 à 6 pieds de profondeur, qu'ils conduifent jufqu'à l'eau : ils employent les mêmes matériaux pour les bâtimens que pour les chauffées, excepté que les bâtimens font perpendiculaires, \& terminés en maniere de dôme. Les murailles ont ordinairement deux pieds d'épaiffeur : comme leurs dents, valent bien les meilleurs fcies; ils coupent tous les bouts de bois qui excedent les 
xlviij $L E T T R E$

murailles, \& y appliquent un enduit en dedans \& en dehors, quí eft une efpece de torchis fait avec la terre glaife $\&$ des herbes féches : c'eit bien dans cette occafion qu'ils fe fervent de leur queue pour mieux affermir cet endroit.

Le dedans de la cabane eft voûté en anfe de panier, \& propre pour loger huir ou dix Caftors. Hors d'oeuvres, cette maifon a 8 ou ro pieds de large, fur 10 ou 12 de long : fuppofé que la cabane foit ovale dans œuvie, elle a 4 ou 5 pieds de large, fur 5 ou 6 pieds de long : fil le nombre des Caftors eft de $\mathrm{I}$ s ou 20 , même de 30 , ce qui elt fort rare, le logement eft grand à proportion,\& même il y en a plufieurs les uns contre les autres. Quelques perfonnes ont affuré M. Sarrafin qu'on avoit trouvé 400 Caftors logés logés qui aux par retir elles paré oit il. ouve y ren Or ceux nes menc ouve avant ces $\mathrm{p}$ épaifl ou fi n'a de faut $p$ quoi quatr 
tun enors, quin fait avec rbes féte occade leur mir cet

bane eft , \& prodix Cafmaifon , fur 10 ofé que ouvie, rge, fur le nomoll 20, ort rare, proporicurs les uelques Sarrafin Cafturs logés

$D E M . S A R R A S I N . \quad x$ lix logés dans différentes cabanes, qui communiquoient les unes aux autres : elles font dilpofées par 'étages, afin de s'y pouvoir. retirer quand les eaux croiffent : elles ont auffi une ouverture féparée de leur porte \& de l'endroit ou ils fe baignent ; c'eft par cette ouverture qu'ils vont à l'eau pour y rendre leurs excrémens.

On appelle Caftors terriers, ceux qui fe logent dans des cavernes pratiquées dans un terrein élevé fur le bard de l'eau. Ils commencent leur logement par une ouverture qui va plus ou moins avant dans l'eau felon que les gla ces peuvent être plus ou moins épaiffes, \& la continuent de cinq ou fix pieds de long; mais elle n'a de largeur, qu'autant qu'il en faut pour y pouvoir paffer, après quoi ils font un lac de trois ou quatre pieds en tout fens, ou ils fé 


\section{$1 \quad I E T T R E$}

baignent quand il leur plaît ; enfuite ils coupent un autre boyau dans la terre, qui va toujours en s'élevant par étages, afin de s'y mettre aufec quand les eaux s'élevent. On trouve quelquefois de ces boyaux qui ont plus de roo pieds de long: ces Caftors couvrent les endroits où ils couchent avec de l'herbe ; en hyver ils font des copeaux qui leur fervent de matelas.

Tous ces ouvrages, fur-tout ceux des Caftors qui vivent dans les pays froids, font ordinairement achevés au mois d'Août \& de Septembre, qui eft le tems où il faut commencer à faire des provifions pourvivrependantl'hyver. Ils coupent donc le bois par morceaux, long depuis un ou trois pieds jufqua $\delta$ ou 10 ; les gros morceaux font traînés par plufeurs de ces Animaux ; les petits,

part

diffe

fer 1

tent tité

plac mier. piéce vifiol anim enfer fion 1 250 ou di bois . lui de d'une d'en leur $\mathrm{p}$ cetix avant coupe dans 1 couch 
laît ; enre boyau ijours en in de s'y eaux s'élquefois plus de Caftors ils couen hyver leur fer-

fur-tout ent dans rdinairel'Août \& tems où edes proitl'hyver. par morou trois les gros par plues petits;
$D E M . S A R R A S I N . \quad 1 j$ par un feul; mais par des chemins differens pour ne pas s'embarraffer les uns les autres. Ils en mettent d'abord une certaine quantité flotier dans l'eau, puis ils en placent de nouveaux fur les premiers qu'ils entaffent piéces fur piéces, jufqu’à-ce que leur provifion réponde au nombre des animaux qui ont deffein de loger enfemble ; par exemple, la provifion pour 8 ou ro Caftors eft de 25 ou 30 pieds en quarré, fur 8 ou dix pieds de profondeur. I.e bois n'eft pas entaffé conme celui de nos chantiers ; mais il l'eft d'une maniere qui leur permet d'en arracher les morceaux qui leur plaît; \& ils ne mangent que ceux qui tiempent dans l'eau: avant que de les manger ils les coupent menu, \& les apportent dans l'endroit de la cabane où ils couchent; s'ils les avoient cou$\tilde{\mathbf{u}} \mathrm{ij}$ 


$$
\text { L. ETTRE }
$$

pés avant que de les mettre dans lcur chantier, l'eau les auroit entraînés d'un côté $\&$ d'autre.

A. l'égard de la chaffe du Caftor, on la fair depuis les commencemens de Novembre, jufqu'au mois de Mars \& d'Avril, parce que ces Animaux font bien fournis de poil. On les tue à l'affut, on leur tend des piéges, ou on les prend à la tranche. L'affut eft 1a maniere la plus ennuyeufe \& la moins affurée ; la plus commune eftcelle de leur tendre des piéges. Quoique les Caltors ayent fait leur provifion, ils ne laiffent pas que d'aller de tems-en-tems dans, les bois chercher de notivelle nourriture. Les Chaffeurs mêmes qui fçavent qu'ils aiment mieux le bois frais que celui qui eft flotté , leurs en apportent tout près de leurs cabannes, \& leur dreffent des piéges femblables à cẹs.

qua

pou

fort

piqu delc

trav

viro.

quel bran sà une celle $\operatorname{tant}$ beau verfe pe la coût $\mathrm{Pr}$ che, la gla chan. qu'er Caftc nir à 
$D E M . S A R R A S I N$. liij quatre de chiffres dont on fe fert pour prendre les rats : on plante fort avant daus la terre plufieurs piquets de trois ou quatre pieds. delong, entre lefquels il y a une traverle fort pefante, élevée d'enyiron un pied \& demi , fous la.. quelle on met pour appas, une branche de peuplier, longue de 5 à 6 pieds, laquelle conduit à une autre branche fort petite: celle-ci répond à la traverfe avec. tant de jufteffe, que le Caftor a beau remuer la premiere, la traverfe ne tombe que lorfqu'il coupe la petite branche, \& il lui en coûte toujours la vie.

Prendre les Caftors à la tranche, c'eft faire des ouvertures à la glace avec des inftrumens tranchans, lorfque les glaces n'ont qu'environ un pied d'épais : les Caftors ne manqent pas de venir à ces ouvertures pour refpi-

$$
\widetilde{\mathbf{u}} \text { iij }
$$


liv

$$
\text { LETTRE }
$$

rer , \& c'eft-là où on les affomme à coups de hache. Il y a des Chaffeurs qui rempliffent ces trous avec de la bourre de l'épi de Jyphas, pour n'être pas vus par les Caftors, \& alors ils les attrapent par un pied de derriere. Sil y a quelque ruiffeau près des cabanes, on en coupe la glace en travers pour y tendre un filet bien fort, tandis qu'on va brifer la cabane pour en chaffer ces animaux, qui ne manquent pas de fe fauver dans le ruiffeau \& de donner dans le parizineau. 


\section{Iv}

Comme

sChaf-

$s$ trous épi de rus par les aterriere. rès des a glace un filet

a brifer ffer ces tent pas freau \& all.

\section{A NUSCR I TS}

Qui fe trouvent cités dans cet Ouvrage. $A_{\text {Medica. }}^{\text {Nonymi auctoris Experiment }}$

D. Jacobi Barneri, Cbemia Pbilosophica.

J. Sebaftiani Blofji, Ulmenfis praxis Medisa.

Seb. Bloffii, Pbyjici Ulmenfis practica.

Chriftophori Cellarii Pbifici Windsbeimen is $P$ alfionale Miedicum.

Caroli Eckoldi Ulm. Medicinalia biftorica.

Chriftophori Ebingeri Patricii Loimiatri Ulmenfis conflia Medicinalia of alia.

ũiiij 


\section{$1 \mathrm{v} j$}

Fr. Erhardi Monachi Ulmenfis scriptum.

Michaelis Ettmilleri PP. LipS. Dispp. Patbologice Collegium Chirurgicum, Chemicum \& praxis Medicie.

Chriftophori Fingerlini Loimiatri $U$ Imenfis praxis quotidiana.

: Salomonis Fifcheri, practica Medica.

J. Arnoldi Friderici, PP. Jenenfis Comment. ad praxis Jonston.

Danielis Fuchfii Pbys.Ulm. vifo-. tatio Febricitantium.

Friderici Fuchjii, Phys.Ulm. surationes.

Georgii Geigeri, Phylici Ulm. praxis.

Petri Hoeneri, Phyjici Wormacienfis experimenta.

. Joannis Harderi, Phyfici Geiflingenfis Fxpertus Rupertus.

Moy cbii $U i$

Joan Pbys. $L$ Lau $P h y \int \cdot C$ Sim gen $\int_{0} . C$ Joar praxis.

Joa? practici Geol PP.T praxin Joa Comm Annot Phar, Joa triaci

Ben Exper 
menfis

Lips.

Chi-

is $M e-$

imiatri

Mes

P. Je-

Jons-

mifi-

Ulme.

Ulm.

Worma.

ici Geif-
Moyjis Heldii, Medici Nofodocbii $V$ limenfis praxis.

Joannis Kelleri, dictus Berndin, Pbys. Ulm. cure of experimenta.

Laurentii Gualtber Kuchelii, Phyf.Ulm. praxis Medica.

Simperti Linfii Medici Mersimin-

gen $\int_{0}$ Cur.e.

praxis.

Joannis Melderi, Pbys. Ulm. practica.

Georgii Balthajari Mezgeri; PP. Tubingenfis Commentar ad praxim Jonftoni.

Joannis Michaelis, P P. Liplienf. Comment. ad praxim. Jonftoni, Annotationes, ad Chemiam Rolef. Pharmacop. Schroederi.

Joannis Micbelii, Medici Auftriaci opus practicusn.

Benedicti Milleri.à Taugendorf Experim. 
Iviij

Martini Neufarti, Phy. Ulm.

Dar Liber Medicus.

Georgii Noesfleri, PP. Altorf. Lectiones publ.

J. Wolfgaogi Rabi; Pbys. Ulm. Collectanea practica.

Georgii Renzii Medici Kirchbeim. tres decades medicinalium.

Guerneri Rolefincii, $P$ P. Jenen fi Formula Medicinales, \& de Jimplicibus. .

Joannis Sagittarii Medici Norici Experimenta medica.

Ioannis Schappleri, Phyf. Ulm Linea quotidiè ducta.

Joannis Sculteti, Phys. Ulmen fit praxis.

Joannis Stockeri, Medici Ulm Ulm. o praxis Medica.

Sebaftiani Stromaieri, Phyj Ulm. praxis Medica.

Auguftini T honneri, Pby $\int . U \mathrm{~lm}$ practica.

Mas Geor

Jenenfi. rum. D.

le. Lect.

$T \sim \sim$ in Ulm. Bar Elie mingen burg. b

Curatio Joan Ulm.pi Ulm. $p$ Joan 
$\int \cdot U l m$

Alforf

$y \int . U l m$ irchbeim

- Jenenfi de. fimpli

ici Norici

bys. Ulm

Ulmen/tu

dici $U l m$

, Pbyj Pbys.Ulm conditura cadaverum \& obfervan tiones medica.

Davidis Verbezii, Phys. Ulm. Curationes Ulmenjes. Ulm.praxis.

Joannis ReguliVillingeri, PhyS.

Joannis Vogtii Medici Loïmici, Ulm. pafionariume.

Elie Waldneri Medici Memmingenfis Calendarium medicum.

Jacobi Wald/chmidii, P P. Mafburg. hore publice ad Hartmanum. Georg. Wolfgangi Wedelii, PP. Jenenfis Comment. de morbis mulierum. De fimplicibus. Collegium Cafuan

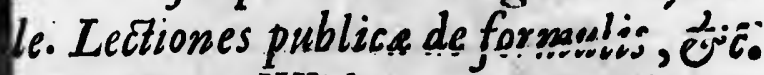
Jominnis Widemanni, Phyfocis Ulm. praxis.

Bartbolomai Wolfarti, Phyfici Ulm. opus practicum.

Marci Wolfarti, Medicis Memming. practica

Leonis Wolfarti, PhyS.Ulm. de

lix fiones medica. 
$1 x$

Jacobi Zacmanni, Phys. Ulm. praxis.

Adami $Z$ iwkeri Medici Memming. de Amphibiis of curationes medice.

Gabrielis $Z$ willingeii, diclus $D i d y m s u s$, repojitums medicum.

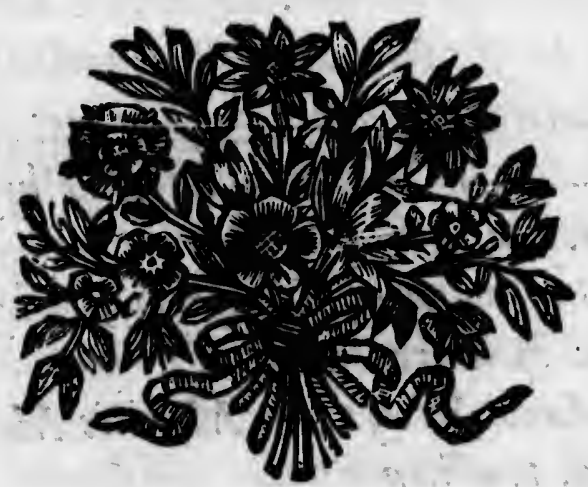

$D A \vee S$ la na Medi

AV

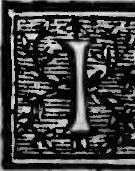

\& les fe product vie \& 'affiége 
$\iint \cdot U \operatorname{lm}$.

si Mem.

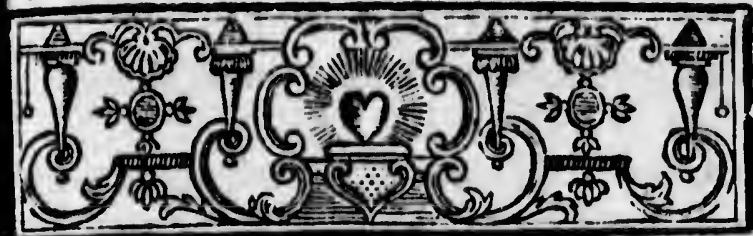

urationes

, dictus

T R A I T E

DU CASTOR,

DANS LEQUEL ON EXPLIQUE la nature, les proprietés \&o l'ufage Medico-Chimique de cette animal.

\section{AVA NT-PROPOS.}

TRAITE

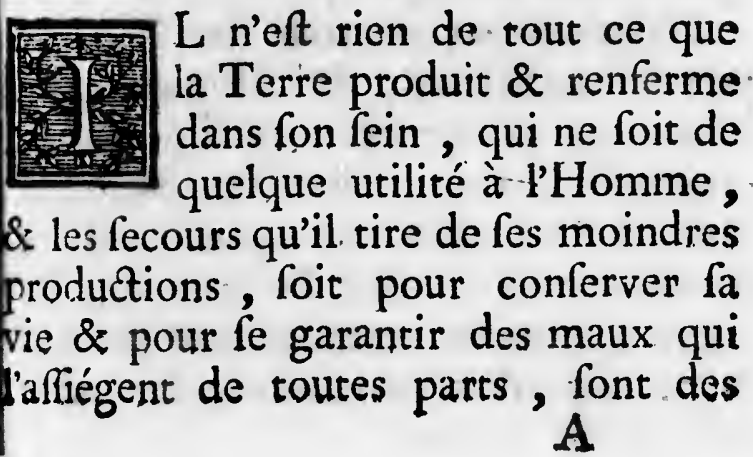




\section{T R A I T E'}

preuves fenfibles de la bonté infinie de l'Autcur de fon être.

Qu'y a-t-il de plus méprifable en apparence que la Pafquerette, qui eft d'une fi grande urilité dans la Cure des bleffures \& pour remcdier à l'intemperie du foye ? Le Chien-dent dont l'abondance diminue le prix, eft un remede excellent pour détruire les obftructions; \& la Mouffé terreftre dont on fait $f i$ peu de cas, poffede une qualité aftringente, dont on éprouve tous les jours les effers. L'Hifope, que le plus fage de tous les Rois met au rang des plus vils! vegetaux, eft le meilleur remede que nous connoiffions pour diffoudre le tartre des poulmons. Il n'eft pas jufqu'aux Champignons', \& aux autres excrémens de la Terre, qui ne foient de quelque utilité.

Nous éprouvons tous les jours la vertu des cailloux, du fable \& de la boue, que nous méprifons fi fort. Les crayes \& la chaux vive, ne font pas moins utiles pour être moins prifées, $\&$ nous en tirons tous les jours des fecours que nous attenderions inutilement des médicamens les plus rares. $\&$ les plus prétieux. 


\section{DU. CASTOR.}

Les grenouilles, \& les cloportes ne font pas d'un petit ufage dans la Medecine, \& un de mes Compatriotes a éprouvé l'été dernier les effers mer. veilleux des vers de terre dans la goutte vague fcorbutique.

Si des Plantes \& des Animaux tels que ceux dont nous venons de parler poffedent des proprietés fi merveilleules, quels fecours ne devons-nous pas attendre de la rhubarbe, de la contrayerve, du jalap, de la centaurée, de la chicorée, du romarin, des rofes, $\&$ des violettes. Peut-on ignorer, à moins que d'être tout-à-fait ftupide, l'ufage du vitriol, du nitre, du cinnabre dans la medecine? prefque toutes les parties du cerf, du lievre, du loup \& de la vipere entrent dans la compofition des remedes, \& il n'eft pas jufqu'au cochon, au chien, \& au chat, dont nous n'éprouvions tous les jours l'utilité. Le Caftor par fes proprietés admirables, fournit des remedes affurés pour la plûpart des maladies, \& il n'eft aucune partie dans l'homme qui n'ait fon ufage dans la. médecine; comme on peut s'en con- 
4

\section{T R A I T E'}

vaincre par la lecture des Ouvrages des plus célébres Naturaliftes. Il s'elt trouvé même des Auteurs qui ont découvert affez de proprietés dans la pierre de bozoar, le virriol, le cerf, l'ambre, l'écreviffe, le vin, l'opium, le géniévre, \& la fcorzonerre, le mufc, \&c. pour en compofer des traités où ils ne laiffent rien à défirer. On peut mettre de ce nombre le célébre Marius à qui nous devons l'ouvrage que je publie aujourd'hui. Il feroit à fouhaiter que Jean Mayer qui en étoit le poffeffeur eut pû lui-même en procurer l'édition ; mais la mort l'en ayant cmpêché, je me fuis chargé de ce foin avec d'autant plus de confiance,' que l'expérience que j'ai acquife dans la médecine, me met en étar de fuppléer à ce qui pourroit manquer à la perfection de ce Traité par mes propres obfervations, aufquelles j’ai jugé à propos de joindre les préparaicions de plufieurs fameux Medecins, qui en ont éprouvé eux-mêmes l'effet. Je prie le Lecteur de ne point tant s'attacher aux mots qu'aufens qu'ils renferment, \& de vouloir 


\section{DU CASTOR.}

ges des

it troudécoupierre l'amum, le mufc, ités où

is peut Marius que je uhaiter pofferarer l'é-

ant emce foin e, que dans la uppléer perfecres obpropos olufieurs éprouvé Lecteur ix mots de vouloir loir m'excufer s'il arrivoir que la difficulté du fujet m'empêchât de fatisfaire entiérement à ce qu'il a droit d'attendre de mes promeffes.

\section{ARTICLE PREMIER.}

Les grandes chaleurs de l'été m'ayàt obligé à difcontinuer pour quelque tems la pratigue de la Medecine, je réfolus pour n'être point oifif, de rechercher of d'examiner la nature $\&$ les proprietés du Caftor, dont les Auteurs anciens \& modernes ont rapporté plufieurs chofes, qui ne concernent pas moins la Phyfique que la Medecine, \& qui font aufji ntiles que propres à Jatisfaire la curiofité.

Pour éviter l'ennui que pourroit caufer an Lecteur une pareille recherche, je m'en acquitterai le plus brievement qu'il me fera pofible ơdiviferai mon? raité par articles. J'ofe me flatter que mon travail lui fera d'autant plus agréable, qu'il y découvrira plus de fimplicité dans le choix des matieres $\mathcal{\sigma}$ dans la maniere de les traiter. 


\section{ADDITION DE FR ANCUS.}

Si je joins ici mes Obfervations c'eft moins dans le deffein de parrager la gloire de mon Auteur, \& de le critiquer, que de rendre fon Ouvrage utile à ceux qui s'appliquent à l'étudo de la Medecine.

Quoiqu'il ne contienne rien de nouveau, ni de fort myfterieux, je tâcherai de faire enforte qu'on ne m'accufe pas de répéter ce qui a déja été dit avant moi. J'ai eu foin de citer dans les faits que je rapporte le nom de 1'Auteur \& du malade, aufi-bien que le jour \& l'année qu'ils fe font paffés, pour qu'on ne m'accufe point de vouloir en impofer au Lecteur.

On trouve peu d'Auteurs qui ayent parlé du Caftor, fi on en excepte Diofcoride, Sextius, Pline; Rondelet Bauhin, Gefner \& Jonfton; mais il $n_{c} y$ en a aucun qui ait compofé un Traité particulier fur cet Animal. J'ofe même avancer que Marius eft le premier qui ait traité ce fujet dans cetteHiftoire, qui a pour titre: Caftorewm Phyfice 0

Meo tué c trait

Caft dont

$L$ parce bords Aller àla Bibe

Le trêm que Caftc oì il l'orig mieu mot ] poin Le. ait d 


\section{DU CASTOR.}

Medice confideratum, auquel j'ai fubltiINCUS. tué celui de Caftorologia, parce qu'il y traite non-feulement de cette partie du Caftor, mais encore de toutes celles dont il eft compolé.

\section{A R T I L E I I.}

Les Latins ont appellé le Caftor Fiber; parce gu'il babite pour l'ordinaire fur les bords des Flewves of des Rivieres : les Allemands fe font contentés de fubfituer $\mathrm{B}$, à la place de l' $\mathrm{F}$, \& lui donnent le nom de Biber.

\section{$A D D I T I O N$}

Les Anciens appclloient Fibrum l'extrêmité ou le bord de quelque chofe que ce fût, \& l'on prétend que le Caftor tire fon nom des bords de l'eau oì il fe tient pour l'ordinaire; mais l'origine de ce nom ne me paroît pas mieux fondée que celle que l'on tire du mot Hebreu Peder, à caufe de l'embonpoint de cet Animal.

Les Modernes veulent qu'on ne lui ait donné ce nom, qu'à caufe de la $B$ ij

qui ayent cepte DiofRondelet n; mais if ompofé un nimal. J'ofe At lepremier tteHiftoire, m Phyfice os 
T R A I T E
facilité avec laquelle il ouvre \& fend les corps les plus folides; d'autres prétendent qu'il vient du mot Grec Phibros, parce que le Caftor a le poil très-fouple \& très-court. Je n'ai rapporté ceci qu'en faveur des Grammairiens ; mais j'avoue que cette derniere conjecture me paroît la mieux fondée.

\section{AR T I L E I I I.}

Les Grecs l'ont appellé Caftor, à caufe de la grandeur de fon eftomac. Les Géographes l'appellent aufic Canis Ponticus, parce quion le trouve fréquemment dans les rivieres du Pont, Province de l'Afie mineure.

\section{$A D D I T I O N$.}

Le nom que les Arabes lui donnent. vient d'un mot qui fignifie retrancher, à quoi peut avoir donné lieu la Fable des Anciens, que le Caftor fe prive lui-même de la partie pour laquelle on le recherche. Car l'on prétend que comme il f̧̧ait l'ufage que l'on fait de fes tefticules dans la Medecine, it fe

les arr aux $\mathrm{Cl}$ Mais 1 roîtra

D'a dérivé Parapl d'anim la mo: ma cos laiffe à moi , tion.

Le Italien verio lonnoi ger agr Allem $\mathrm{Je}$ tems obligé rappor pé à conno. Caftor geon Caftor 


\section{DU CASTOR.}

\& fend tres préPhibros, rès-fouorté ceci s ; mais njecture

I.

ftor , ̀̀ mac. Les nis Ponquemment ovince de

donnent rancher, la Fable fe prive quelle on tend que on fait de ine, il fe les arrache lui-même \& les abandonne aux Chaffeurs pour prix de fa rançon. Mais la fauffeté de cette opinion paroîtra par ce qui fuit.

D'autres veulent que fon nom foir dérivé du mot Hebreu Tfiim ; que le Paraphrafte Jonathan rend par celui d'animaux dont l'afpect eft affreux \& la morfure terrible, comme un Juif de ma connoiffance me l'a affuré; mais je laiffe à ceux qui en fçavent plus que moi, le foin de décider cette queftion.

Le Caftor eft appellé Bivaro par les Italiens, Buevre par les François, Biverio par les Efpagnols, Pobr en Polonnois, Hod en Hongrois, Abadger agraye en Anglois, \& Ten Beever en Allemand.

Je ne m'arrêterois pas plus longtems fur cette matiere, fi je n'étois obligé, pour contenter les curieux, de rapporter une homonymie qui a échapé à mon Auteur ; la voici. L'on connoît le frere de Pollux, appellé Caftor. On connoît auffi le gros Plongeon, auquel on donne le nom de Caftor ou de Fiber à caufe de l'avidité 
10

\section{T R A I T E'}

avec laquelle il fond fur les poiffons ; en quoi il eft femblable au Caftor. On donne auffi le nom de Caftor \& de Biver en Allemand à l'urine blanche \& épaille des Cachetiques, comme fi cet animal la troubloit dans la veffie urinaire.

\section{ARTICLE IV.}

'Le Caftor ou Bievre eft un animal amphibie, à quatre pieds, de la groffeur d'un chat, qui fe nourrit de fruits of d'ecorce d'arbres, particulierement de celle diormeau. Les pieds de devant refjemblent

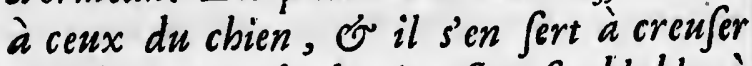
la terre, ceux de derriere font femblables à ceux du canard, \& il s'en fert comme lui pour nager.

Sa quene eft faite comme celle d'un poiffon, 'o il la tient prefque tonjours dans l'eau; car dès qu'elle vient à Jecher fon ventre l'obftrue, à caufe qu'il eft extrếmement chavid.

Il ne peut pas demeurer long-tims fous T'eau, parce qu'il cft obligé de prondrs fouvent Sa respiration, of lor gquil pasfe la riviere à la nage, il leve de tems en teras la tête fur l'enus. 


\section{DU, CAST OR. II}

oiffons ; ftor. On or \& de lanche \& me fi cet effie uri-

imal ama groffeur fruits of int de celle refjemblent a creuser mblables à comme lui d'un poifiours dans fecher fon extrême-

tiems fous cridrs fouasfe la rien terms la
Il conftruit fa demeure fur les bords des rivieres, avec les pieds de devant, elle eft difpofee par étages afin de pouvoir monter à mefure gue les eaux angmentent.

\section{$A D D I T I O N$.}

La tête du Caftor a la figure de celle d'un rat de montagne, il reffemble au blaireau par les oreilles \& par fes pieds de derriere, dont les doigts font attachés par une membrane, ce qui le met en état de marcher fur la terre, \& de nager avec beancoup de viteffe. Ils font couverts tous les deux d'un poil auffis fin que le duvet; mais il differe du Loutre en ce qu'il eft plus fort, qu'il a le ventre plus grand, le corps plus ramaffé \& plus maffif ; \& qu'il ufe d'une nourriture differente.

Sa queue a la figure d'un poiflon, elle eft plate, large de quatre travers de doigts, de couleur cendrée, fans poil, garnic d'écailles prefque creufes\& garnie d'un grand nombre de rides, ce qui lui a fait donner le nom de $B$ urfa rugofa.

Notre Auteur prétend que fon ven- 
tre eft fujet aux obftructions lorfque fa queue manque d'eau ; mais c'elt de quoi tout le monde ne tombe point d'accord. Quelques Auteurs ; \& entr'autres Zwiker ávancent avec plus de vraifemblance que cette féchereffe occafionne une contraction dans les poches de cet animal, qui arrête le cours de la matiere refineufe qu'elles contiennent.

Le Caftor fuivant Marius fe nourrit de feuilles \& d'écorces d'arbres, cependant comme il habite fur les bords des rivieres, il vit auffi de poiffons, d'é.creviffes, de grenouilles, quoi-qu'on en trouve qui rejettent cette efpece de nourriture. On peut donc dire que le Caftor reffemble en cela au Loutre, qui, comme jel'ai dit ci-deffus, ne laiffe pas de fe noarrir de fruits \& d'écorces d'arbres, quoi-qu'il foit fort friant de poiffon.

Il fe plaît dans les lieux déferts \& inacceffibles, parce qu'il s'y croit plus en fûreté contre les pourfuites des Chaffeurs. Il pratique dans fa cabane un chemin jufqu'à l'eau, ils la fait de trois ou quatre étages, \& les conftruit

avec proch ne pe

$P l_{n}$ chair $p \hat{u} m^{\prime} a$ dure, à cou qu'elle mets. $l_{6}$ meillen

Le tié po qu'aux dont i. jours $\varepsilon$

Un vendit Chartr rins, peau, fols àc 


\section{DU CASTOR.}

rfque fa de quoi accord. tr'autres de vraie occapoches cours de contien-

nourrit $s$, cepenords des ins., d'e... loi-qu'on Ipece de e que le Loutre, , ne laife d'écorces friant de

léferts \& croit plus dites des a cabane la fait de conftruit avec avec les bois qư'il coupe dans les forêts prochaines, avec tant d'artifice qu'on ne peut s'empêcher de l'admirer.

\section{A R T I LE.V.}

Plufieurs. Perfonnes font grand cas de la chair du Caftor, à laquelle je n'ai jamais pû̀ maccon̂tumer, car elle eft extrêmement dure, difficile à digerer $\&$ charge l'eftomac à coufe de la grande quantite de graiffe qu'elle contient. Sa queue paffe pour un des mets les plus délicats, of on la fert fur les meilleures tables.

$$
\text { ADDITION. }
$$

Le Caftor eft moitié chair \& moitié poiffọn. Sa partie fupérieure jufqu'aux cuiffes, eft de la chair véritable dont il n'eft permis de manger qu'aux jours gras chez les Catholiques.'

Un Pêcheur de tna connoiffance, vendit il y a quelques années à des Chartreux, pour la fomme de fix florins, un Caftor dont il avoit ôté la peau, \& dont il n'eût pas donné cinq fols à ce qu'il me dit. Ceux qui aiment 
14

\section{T R A I T E}

la graiffe s'accommodent de la chair de cet animal ; mais elle fait mal au cœur à d'autres, \& peut même caufer une diarrhée funefte, comme cela eft arrivé à un de mes compatriotes.

On apprête à la fauffe noire la partie inférieure, qui tient de la nature du poiffon, \& l'on fert celle de devant fur les meilleures tables, après l'avoir fait mariner pendant quelques jours dans du vinaigre, avant de la faire bouillir. On la met auff à la broche, \& on la pique avec du lard, du cloud de girofle $\&$ des morceaux d'écorce de citron.

Une Cuifniere que j'avois me fervit un jour une queue de Caftor qu'elle avoit apprêté de la maniere fuivante: après l'avoir dépouillé de fa premiere peau, elle la fit bouillir pendant deux heures avec des herbes pour pouvoir en ôter la feconde peali. Elle $y$ fit enfuite plufieurs incifions, \& la fricafla avec du vin blanc, du gingembre, du poivre; de la canelle, de petites paffilles, des amandes \& du fafran. 
la chair mal au e caufer cela eft tes.

la partie ature du devant s lavoir tes jours la faire broche, du cloud écorce de

me fervit or qu'elle fuivante : premiere dant deux ir pouvoir Elle $y$ fit la fricaffa embre, $d u$ setites paffafran.

\section{DU CASTOR.}

\section{ARTICLE VI.}

Cet Animal n'elt pas moins bideux gu'à craindre, à caufe de la longueur \& de la force de fes dents; avec lefquelles il perce tout ce quill trowve, abat des grands arbres \& les crenfe comine on pourroit le faire avec des cifeaux. Lorfqu'il vient à Saifir quelqu'autre animal it ne lache point prife gu'il n'ait brifé l'os, c'eft pourquoi on ne doit pas s'y fier. Son eftomac. eft fort grand, comme je l'ai déja remarqué ci-deffus.

\section{$A D D I T I O N$.}

Cet Animal eft non-feulement hideux, mais encore fi.cruel \& fi féroce, qu'on ne peut jamais l'apprivoifer, quoique quelques perfonnes prétendent en avoir vû d'auffi privés que des chats. On ne peut le prendre qu'en le faififfant par la queue, au moyen d'un noud coulant ou bien avec la main ; car comme il ne peut fe détourner pour venir mordre celui qui le tient, on le conduit où l'on veut. On le force encore, à ce que rapporte Zwiker, de 
16

\section{T R A I T E'}

même que les autres Bêtes fauvages.

Le Caftor eft fort timide \& ne s'écarte pas beaucoup de fa cabane pour aller chercher de quoi vivre, fice n'eft en hiver \& pendant la nuit, que tout eft tranquille. La caufe de cette timidité peut venir de la groffeur de fon cœur; ou ce qui paroît plus vrai-fem. blable, des parcies tartareufes \& fixes, dont fon fang eft rempli.

\section{ARTICLE VII.}

Le Caftor male on femelle a an bas de l'os pubis deux bourfes on poches dont l'une eft plus grande que l'autre, of d'ou il fort quelquefois, lorfque les veines viennent crever, une ligueur miellense que le Caftor l'che. Ces poches communiquent entr'elle ơ ont la groffeur d'un auf d'oye. On lew dnnne le nom de Caftoreum, of celui d. tefticules, quoique mal-à-propos.

Quoique les parties qui diftinguent $k$ deux fexes foient placées entre ces dew. parties, on ne s'apperçoit point cependar. qu'elles communiquent entr'elles autremert que dans les autres animaux. On appercal difinctement les tefticules du male
Sont $\int_{b}$

pubis,

cet ani

$\mathrm{La}$

mode

traire

on pev

Les

avec $\mathrm{b}$

poche:

Caftor

de ra

écrit $f$

de fai

ques

ouvras

Ada

manuf

lant du » $\mathrm{mal}$ squi , Chaf s2dont „.Méd 


\section{DU CASTOR.}

font fitués dans les aines of appuyés par.

uvages.

\& ne s'éane pour fice n'eft que tout cette timiur de fon vrai-fem. s \& fixes,

\section{I.}

- an bas do es dont l'une d'ouil fort s viennent que le Caftor ent entr'elles ye. On lew of celvi d: pos.

iftinguent le re ces dews nt cependam les autremert On apperça: male. i leur baf: fur les' parties latérales de l'os. pubis, comme je l'ai obfervé en diffequant cet animal.$$
A D D I T I O N
$$

La plûpart des Auteurs anciens \& modernes , font d'une opinion contraire à celle de mon Auteur, comme on peut s'en convaincre par ce qui fuit. Les Anciens qui ne diffequoient pas avec beaucoup de foin, prenoient ces poches pour les véritables tefticules du Caftor. Comme il feroit trop ennuyeux de rapporter ici tout ce qu'ils ont écrit fur ce fujet , je me contenterai de faire part à mon Lecteur de quelques paffages qui ont rapṕort à mon ouvrage.

Adam Zwiker dit dans fon Traité manufcrit fur les Amphibies, en parlant du Caftor. »s Le Caftor eft un Ani2o mal amphibie extrêmement chaud, »qui, lorfqu'il eft pourfuivi $\cdot$ par les „Chaffeurs's, s'arrache les tefticules sodont on fait un grand ufage dans la 2)Médecine. « 
I8:

\section{T R A I T E'}

,Je ne me fuis jamais trouvé, dit „„ Jean Harderus, dans.l'occafion d'é„, prouver fi les teftitules du Caftor ", appaifent la toux, comme on le pré" iend ; mais il certain qu'ils atte"nuent la pituite vifqueule qui eft "enfermée dans les broniches des pou"mons \& qui occafionne l'Afthme." Il eft de certains remedes cephaliques, , dit-il, dans un autre endroit, qui " caufent des douleurs à ceux qui n'y ", font point accoûtumés, tels font le ", fafran, la marjolaine, la rue, \& les „, tefticules du Caftor, dont l'odeur "portè à la tête. "6

Les remedes propres à appaifer les douleurs de la goutté, font à ce que que prétend Jean Schappler Médecin à Ulm, la graiffe de cochon, d'oye \& celle de l'homme, l'huile d'aneth, d'amandés douces, de camomille, de vers de terre, le fuc de fenouil, qu'on rendra encore plus efficaces en y ajoustant des tefticules du Caftor, où du camphre, fuppofé que lés douleurs tontinuent toujours.

On trouve quelques Auteurs qui donnent quatre tefticules au Câftor, ont

doit avoi: matr abba leur $\min$ chat parei leur font Sex quelc fentir mieu: Guill II a ble, , differ ferme placé fuivi dont thefe doute viens je me ne m les ra 


\section{DU CASTOR.}

ıvé, dit fion d'é-

Caftor i le préils attequi eft des pouAthme." haliques, oit, qui qui n'y $s$ font le ue, \& les

$t$ l'odeur

päifer les à ce que Iédecin à d'oye \& d'aneth, mille, de iil, qu'on in y ajour, ou du leurs con-

$s$ qui dons aftor, on doit, dit Chriftophe Ehinger, après avoir purgé la malade, en fortifier la matrice;, pour prévenir la fuffocation \& abbatre les vapeurs. Rien n'eft meilleur pour cet effet que la rue, le cumin, la coriandre, la fauge, l'herbe au chat, \&c. \& furtout les tefticules ap. parens du Caftor, que l'on découvre à leur odeur, car ceux qui font cachés ne font d'aucun ufage dans la Médecine.

Sextius \& après lui Diofcoride, \& quelques autres Médecins, font d'un fentiment contraire ; mais perfonne n'a mieux combattu cette opinion que Guillaame Rondelet de Montpellier. Il a prouvé d'une maniere inconteftable, que le Caitoreum eft entierement different des tefticules, \& qu'il eft enfermé dans des poches particulieres, placées dans les aînes , en quoi il a été fuivi par un granć nombre de fçavans, dont lautorité, en détruifant l'hypothefe des Anciens, ne permet plus de douter de la certitude de celle que je viens d'avancer. Comme les bornes que je me fuis preferites dans cet ouvrage , ne me permettent point de rapporter les raifons qui onc été alleguées de part

C iiij 


\section{0 \\ T R A I T E'}

$\&$ d'autre, je me contenterai d'établír comme une chofe certaine.

$I^{\circ}$. Que le Caftoreum fe trouve également dans les Caftors mâles \& femelles, \& qu'il eft enfermé dans une poche qui a la figure d'une bourfe, \& qui n'eft proprement, qu'un petit fac ridé dans lequel on trouve, après avoir féparé une peau affez épaiffe qui le forme, une matiere céracée, jaunâtre, d'une odeur forte \& pénétrante, lorfqu'elle eft nouvelle; mais qui devient séfineufe \& friable, lorfqu'elle eft féche. On en trouve quelquefois d'autres plus petits qui contiennent une matiere huileufe, cendrée, de mauvaife odeur \& toujours liquide. Chacun de ces facs eft couvert d'une membrane qui leur eft propre, fans compter la peau extérieure commune qui eft la plus épaiffe. On trouve de femblables poches dansle liévre, l'hiene \& quelques autres animaux, touchant lefquels on peut confulter les Auteurs:

$2^{\circ}$. Que les mâles cont, outre le Caftoreum, des tefticules fort petits, peu pefans \& de la groffeur de ceux d'un cocq, fans odeur \& fans faveur, fil'on

en $c$ font re, ont \& 0 la $\mathrm{m}$

Caf fait tout cont nes

com avec de cl dans faire com par que poin dans fperr de $V$ 


\section{i d'établir}

ouve éga$\&$ femeline poche e , \& qui fac ridé avoir féui le forjaunâtre, tre, lorfui devient ju'elle eft fois d'aunent une de maude. Chaune mem$s$ compter qui eft la emblables e \& quelne lefquels s.

tre le Cafetits, peu ceux d'un ur, fil'on

\section{DU CASTOR.} $2 \pi$

en croit Ehinger que j'ai déja cité. Ils font placés dans la capacité du bas venre, \& appuyés fur l'épine du dos. Ils ont chacun leurs vaiffeaux déferans, $\&$ on ne peut les arracher fans caufer la mort au Caftor.

$3^{\circ}$. Que la poche dans láquelle le: Caltoreum eft enfermé, eft tout-àfait differente des tefticules; quoique toute l'antiquité ait été d'un fentiment contraire. Car les Anatomiftes modernes ont démontré qu'elle n'a aucune communication avec les tefticules, ni avec la verge, outre que les conduits de ces poches ne fe dégorgent point dans la verge, comme il feroit neceffaire, \& aboutiffent à une ouverture communes, d'où l'on peut faire fortir par expreffion toute cette liqueur, ainfi que je l'ai remarqué ; ce qui n'arrive point dans les véritables tefticules, ni dans les circonvolutions des vaiffeaux fpermariques. Je fuis ici le fentiment de Wepler.

\section{ARTICLE VIIT.}

Lorfgue les Caftors veulent manger, its 
s'affient fur les pieds de derriere comme les Ecurenils, of fe fervent de cenx de devant pour tenir ce quils mangent. Ils font leurs petits an commencement de l'hyver, of les élevent avec un très-grand foin.

$$
A D D I T I O N \text {. }
$$

Les femelles s'accouplent au commencement de l'été , \& mettent bas leurs petits vers la $S$. Nicolas. Elles en font jufqu'à deux ou trois \& les élévent avec beaucoup de foin , jufqu'à ce qu'ils foicnt en état d'aller chercher eux. mêmes leur nourriture. Après qu'elles fe font accouplées avec leurs mâles, elles fe retirent dans leurs cabanes, où elles vivent des provifions qu'elles ont eu foin d'amaffer, \& d'où elles ne fortent que deux mois après.

Les Caftors fe battent à coups de dents, comme les cochons, \& fe font quelquefois des bleffures mortelles. Its ne jettent aucun cri, même dans les plus grands dangers. Ils marchent fur terre auffi lentement que les canards, \& nagent avec beaucoúp de viteffe. Comthe ils ont l'ouie fort fubtile; ils n'en- 


\section{DU CASTOR.}

comme les de devant font lours er, of les

au comttent bas s. Ellesen es élévent 'à ce qu'ils - eux.mêqu'elles. fe âles, elles $s$, où elles

es ont eu ne fortent

coups de $\&$ fe font telles. Its e dans les rchent fur anards, \& effe. Comils nen- tendent pas plutôt les Chaffeurs, qu'ils fe fauvent pour fe mettre à couvert.

On connoît l'âge du Caltor fuivant que les dents font plus ou moins émouffées. Il vit pour l'ordinaire trente à quarante ans. J'ai même appris qu'on en a nourri un jufqu'à l'âge de 78 ans, qui mourut de la morfure qu'un autre lui fic. Zwiker rapporte qu'il a foin d'ôter les fibres des feuilles dont il fe nourrit.

\section{A R T ICLE IX.}

On nous apporte ces Animaux de l'ller, du Danube, du Biber, qui pajfe près de Leipheim, où les Pếcheurs leur donnent la chajfe avec beaucoup de dextérité, ceux qui ont le poil noir font les plus eftimés. On en trouve de fort beaux en Pologne, où ils fontaprìis-commons.

\section{$A D D I T I O N$}

L'Iler fourniffoit il y a quarante à cinquante ans, un fi grand nombre de Caftor, qu'on en prit plus de 120 en moins de trois ans; mais on n'y en voit aucun aujourd'hui, ce qui vient, comme 
24

me l'a ąfuré un Pêcheur fort habile, de ce qu'on a pris les femelles qui étoient pleines. Il y a auffi quelques années qu'on en voyoit dans les foffés de notre Ville, où il n'en paroît plus aujourd'hui, non plus que dans le Danube, à moins qu'ils n'y, viennent de l'Autriche. Il y a toute apparence que la petite riviere Biber, qui coule au-deffous d'Ulm, à peu de diftance de la ville de Leipheim, \& qui fe jette dans le Danube, a tiré fon nom des Caftors qu'on y trouvoit ; il eft pourtant certain que les Vieillards du Pays ne fe Couviennent pas d'y en avoir vû.

On en prenoit autrefois en très-grand nombre aux environs de Riffa, près de Biberac, fi l'on en croit les relations ; mais ils y font très-rares aujourd'hui. Ceux que l'on prend dans le Rhône \& dans la Marne, font beaucoup meilleurs que les autres, tant à caufe de la bonté du climat, que de la nature des alimens dont ils s'y nourriffent. Gabriel Didyme, rapporre qu'on fit préfent en I 574 , à Gaudentius. Lefchenbrand d'un Caftor qui venoit du Aeuve Rha, connu aujourd'hui

fous

que

Mo

$\mathrm{Caf}$

qui

droi

rend

prét

de $n$ ce 1

le $\mathrm{C}$

Inde

gran

leur

II

s'arr

étoi

l'on

à lac

Pays

$J$ 'ind

quel

natu.

ce $\mathrm{q}$

part 
abile, de ii étoient es années de notre aujouranube, à l'Autrie la petiu-deffous e la ville dans le s Caftors tant cerays ne fe û.

ès-grand , près de elations ; ourd'hui. Rhône \& up meilcaufe de a nature urriffent. qu'on fit ius. Lefi venoit jourd'hui

\section{DU CAS TOR.}

fous le nom de Volga, ce qui prouve que cet Animal n'eft point inconnu en Molcovie.

On trouve une grande quantité de Caftors aux environs du fleuve Ruff, qui paffe en Suiffe, furtout dans l'endroit où il fe joint à l'Arole, pour fe rendre avec elle dans le Rhône. On prétend que la Viftule en fournit aufi de même que la Sana qui fe jette dans ce Fleuve, dains la Ruffie noire.

Les Caftors font très-communs dans le Canada \& les autres Provinces des Indes Occidentales, où l'on fait un grand commerce de leurs peaux \& de leurs poches.

Il ne feroit pas fort neceffaire de s'arrêter au choix du Caftoreum, s'il étoit plus commun chez nous, \& fi l'on n'avoit à craindre la falfification à laquelle celui qu'on nous apporte des Pays étrangers n'eft que trop expofé. J'indiquerai ci-après les marques auf. quelles on peut diftinguer celui qui eft naturel, d'avec celui qui ne l'eft pas, ce qui demande une attention toute particuliere. 
26

\section{T R A I T E' \\ A R T I C L E X.}

L'on recberche cet Animal à caufe de Sa pean, de fa graijse, de fon Jang, de fon poil, de fes dents, of furtout à caufe des poches ou tumeurs qui font placées dans fes aînes; car l'experience a fait vair qu'il n'y a aucune de ces parties qui n'ait fon utilité dans la Médecine, comme on pourra s'en convaincre par le détail que nous allons donner de leurs differens ufages.

\section{$A D D I T I O N$.}

Notre Auteur après avoir examiné le Caftor en qualité de Phyficien , s'attache à l'énumération des Parties de cet Animal qu'on employe dáns la Médecine. Nous éclaircirons ce qu'il en dit, par des faits anciens \& modernes, qui ferviront à conftater les proprietés des parties dont il traite, en commençant par la peau de cet Ánimal. 


\section{DU CASTOR.}

\section{ARTICLE XI.}

cauje de sang, de ut a caufe at placées ace a fait barties qui ine, comre par le de leurs

examiné ayficien,

S Parties

e dáns la s ce qu'il $x$ moder$r$ les proraite, en cet Ani-
La peau du Caftor eft d'une grande utilité dans lá colique, les douleurs de matrice ơ dans la manie, étant appliquée toute chaude, comme je l'ai éprouvé moimêmi fur un Habitant de.Wurtemberg, anquel je rendis la fanté, en lui appliquant fur la tête, après l'avoir rafe, la peaul d'un Caftor nouvellement écorché. Elle eft auffi très-efficace dans les jpafmes \& fur tout dans les douleurs de Paccouchement. Je lai appliquée avec fuccès fur l'eftomac pour le fortifier, pour remedier à latrophic des enfans, Fo pour guerir les ulceres des malades qui ont long-tems refté couchés. Un Juif de ma connoiffance étant venu me reridre vifite il y a quelque tems, Fo ayant $\iint_{\zeta} \hat{u}$ que je travaillois à cet ouvrage, me communiqua un fecret qu'il avoit appris de fes ancetres qui le tenoient euxmêmes de Salomon, qui l'avoit éprouvé. Il m'afjura donc qu'il fuffifoit pour acquévir une mémoire prodigieufe of pour ne jamais oublier ce que t'on a lu une fois, de porter un chapease de peau de Caftor, de fe frotter tous les miois la tüte ó l'épine du 
28

dos avec de Pbuile de cet Animal, of de prendre deux fois par an le poids d'un écu d'or de Caftoreum. Comme ce fait a beaucoup de rapport domon fujet, je n'ai pas voulu lobmettre. Je laiffe cependant à chacun la liberté d'en croire ce qu'il voudra.

\section{$A D D I T I O N$.}

La peau du Caftor eft fort utile dans toutes les maladies qui font caufées par le froid, étant appliquée extérieurement. Si l'on en croit Ehinger ; $\gg$ on „guérira infailliblement cette maladie $\Rightarrow$ (la foffocation de matrice) dit-il, sen appliquant une peau de Caftorfur sla region ombilicale, que la malade „saura foin de ne jamais quitter.

Le même Auteur rapporte qu'il vint à bout de guerir une colique flatueufe, en donnant deux fois par jour un lavement carminatif au malade, \& en lui appliquant fur le ventre une peau de Caftor qu'il eut foin de lier fortement. Je laiffe au Lecteur à décider fi la compreffion du ventre ne peut point avoir autani contribué à la guérifon du malade que la peau même. 


\section{DU CASTOR.}

La peau du Caftor n'eft pas moins efficace contre les'douleurs de la goutte , comme on peut en juger par l'exemple de Jean Bericht Parfumeur à Nuremberg, qui fut guéri des douleurs qu'il reffentoit depuis long-tems aux mains \& aux pieds, au moyen de gands \& de bottines de peau de Caftor, dont J. Sagittarius lui recommanda l'ufage.

On voit par-là de quelle utilité peuvent être les gants de peau de Caftor, que l'on trouve chez les Pelletiers, \& dont on fait un fi grand ufage. Quoique les parties de cet Animal foient d'un grand fecours dans la Médecine, il ne paroît pas croyable que fa peau ait la vertu d'augmenter la mémoire à un point fi prodigieux. D'ailleurs comme cette proprieté n'eft fondée fur aucune expérience, \& que ceux dont on tient ce fait ne méritent pas grande confiance, c'eft au Lecteur à s'en raporter s'il veut au témoignage du Juif dont j'ai parlé : Georgus Geiger Médecin à Ulm, affure que la peau du Caftor a tiré des parties, au tour defquelles on l'avoit attachée, les cloux $\&$ les autres corps qui y étoit entrés. 


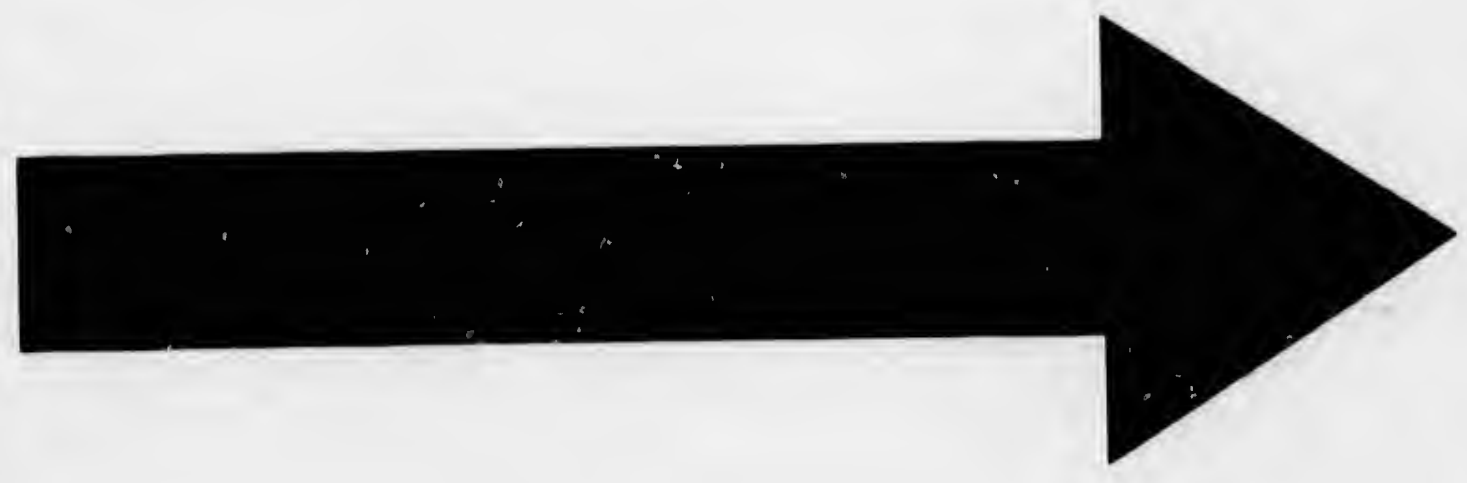




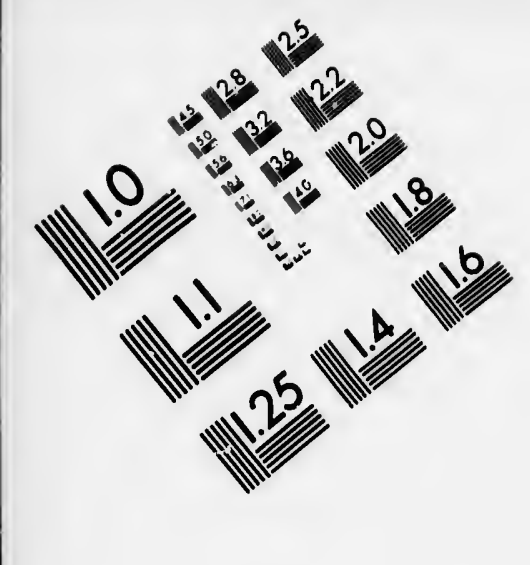

\section{IMAGE EVALUATION TEST TARGET (MT-3)}
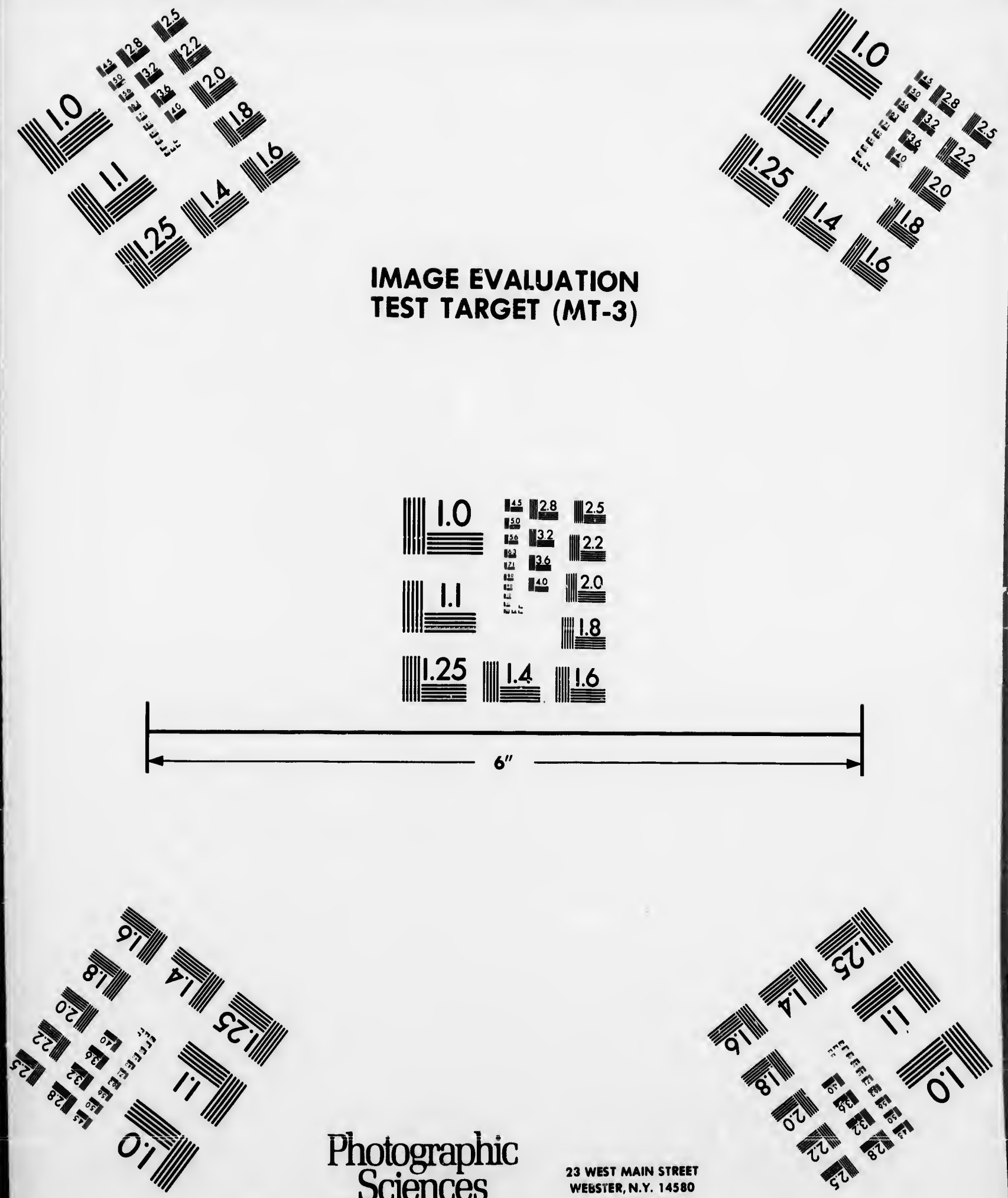

Photographic Sciences

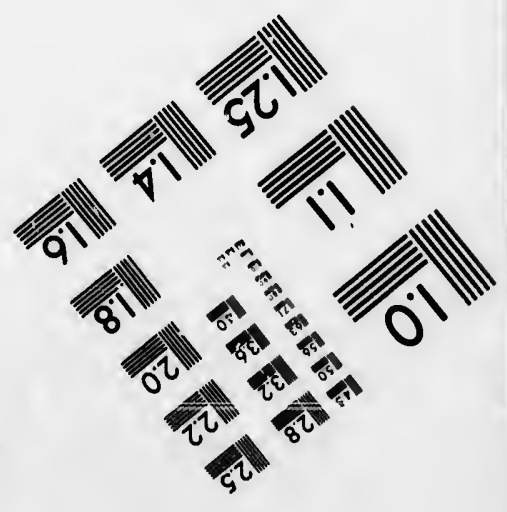
Corporation 



\section{TRA I T E'}

La graiffe du Caftor n'eft pas d'une moindre utilité dans la M'decine, of elle eft un remede efficace dans toutes les maladies qui ont leur fíge dans les nerfs, étant appliquée extérieurement toute chaude. Elle eft bonne contre l'épilepfie, elle prévieri. lapoplexie, elle empêche la lethargie, elle fait ceffer les fpafmes to les mouvemens convulfifs, elle fortifie of ramollit les nerfs qui font devenus immobiles, elle appaife les douleurs de matrice, of eft d'un puiffant fecours dans le vertige, le mal de dents, Cafthme, le vomiffement, les épreintes, la dyfenterie of les manx de reins.

Jai moi-même éprouvé la vertu de ce remede dans les douleurs des articles, (5) $c^{2}$ eft à lui que doit fa guérifon un Verrier dUlm, qui avoit fait une chute qui lui caufoit des douleurs extraordinaires dans Le côté gauche, contre lefquelles il avoit inutilement employé toutes fortes de remedes.

\section{ADDITION.}

L'Auteur prétend pasler felon toute appi que du C plus pous eft d la pe part: C'ef atter tueu puifl eu é phur qu'e! fume men les p aufi \& qu dans laiffé ples teurs étant I 573 trour 


\section{DU CASTOR.}

apparence, de cette matiore onçueufe que l'on trouve dans les petites beurfes du Caftor , \& que l'on doit retirer le

diune of elle mala, étant de. Elle révierir. rie, elle vemens lesnerfs appaife puiffant dents, ites, la

it de ce les, of Verrier qui lui es dans il avoit remedes.

in toute plus prornptement qu'il eft poffible, pour l'empêcher de fe corrompre. Elle eft differente de la graiffe qui eft entre la peau \& la chair qui correfpond à la partie huileule \& batireufe du lait. C'elt à quoi les Auteuris n'ont pas fait attention quoique cette partie onctueufe foic plus pénétrante, \& qu'on puiffe la divifer en graiffe \& en fain, eu égard aux particules volatiles, fulphurequfes qu'elle contient. De-là vient qu'elie attenue, qu'elle amollit, confume \& pénétre $\&$ quielle eft extrêmement propre à-fortifier les nerfs \& les parties nefveufes. Ceft ce qui fait aufi qu'on l'employe exterieurement, \& qu'elle produit de fi grands effets dans les maladies dont Marius nous a laiffé le détail. Vojei quelques exemples que jai puifés dans plufieurs Auteurs célébress.

La Veuve du Chancelier Schertel étant tombée en apopléxie le 4 Janvier 1573 , l'on me fit appeller, lui ayant crouvé quelques fignes de vie, je lui

D ij 


\section{TRAITE}

fis donner un fort lavement, ouvrir la veine cephalique, \& appliquer fur le crâne après l'avoir fait rafer, le Cérat fuivant :

Prenez Graine de Moutarde. de Fumeterre, ana deux fcrupules.

De la Chaux-vive, un gros. De Racine de Piretre. D'Euphorbe, ana demi gros. Noix Mufcade, demi gros. Maftic, quatre fcrupules. Gomme de Génévrier. Du Poivre, rond, àna demi fcrupule.

Clouds de Girofles. Cubebes, demi fcrupule. Sagapenum, un gros $\&$ demi. Safran, demi fcrupule.

Réduifez toutes ces drogues en poutdre féparément \& incorporés les avec une quanité fuffifante de graiffe de Caftor, de cire \& de puix pour en faire un Cérat. 


\section{DU CASTOR.}

Prenez Pillules forides, un fcrupule. Caftoreum, en poudre, fix grains.

Diagrede, deux grains.

ana

es.

gros.

gros.

gros.

es.

demi

On en formera des Pillules au nom. bre de 19. avec de l'Oxymel fimple, que l'on donnera au malacle vers la minuit.

Marc Wolfart, Médecin à Memmingen guérit, à ce qu'il rapporte Balthafar Funcken Cos, d'une léthargie caufée par le froid \& par l'humidiré , \& qui avoit refifté à toutes fortes de remedes, au moyende longuent fuivant.

Prenez Graiffe de Caftor.

Huile de Marjolaine, ana une once.

De Piretre.

pouravec fre de $n$ faire

De Sefaure, ana dèmi 1:i. dragme.

Gerofle en poudre, une dragme.

Cire blanche, une quantité fuffifante. 

oindrez la tête du malade le plus fouvent qu'il fe pourra, après avoir eu foin auparavant de la rafer.

Jean Stoker, Médecin à Ulm, donne dans fa pratique manufcrite, que j'efpere publier un jour; la compofition d'un onguent qu'il prétend être trèsefficace contre les douleurs des extrêmité des mains.

\section{Prenez de la graiffe de Chien. deVeau. de Caftoreum, ana demi livre.}

De l'huile de Laurier, trois onces.

Bayes de Laurier en poudre. Encens en poudre, ana trois onces.

Maftic en poudre, deux onces.

On mêlera ces drogues avec du Mercure éteint dans l'eau de vie, pour en faire un onguent, dont on oindra les Parties affligées, avant fe coucher. Je fouhaiterois qu'on fubftituaau Mercure de l'huile de jaune d'œuf, pour rendre ce remede plus efficace.
Le : manulc donne onces de la $n$ tion du trine,

Pren

On $\mathrm{m}$ tite qu: onguen confift: Cha bre Is colique

PreI 


\section{DU CASTOR.}

t vous us fouroir eu

donne que j'efsofition re très$s$ extrê-

oreum, mi livre. , trois poudre. ana trois , deux

du Merpour en indra les ıcher. Je Mercure ir rendre

Le même Auteut dans. fon Traité manufcrit de agritudinibus infantum, ordonne pour faire ceffer la toux, deux onces de Caffe en bâton, ou fix gros de la moëlle,fuivant lâge \& la difpofition du malade, auquel il oint la poitrine, avec la compofition fuivante.

\section{Prenez Huile de Violettes. Amandes douces, ana une once.}

Beurre frais, non falé. Graiffe de Caftor, ana une once \& demie. Safran, deux grains.

On mêlera ces drogués avec une petite quantité de cire, pour en faire un onguent, qui n'ait pas beaucoup de confiftance.

Charles Ekhold, guétit le 6 Septem: bre 1567. Samuel Faulhaber, d'une colique avec le lavement fuivant :

Prenez Menthe, trois poignées.

Origan.

Fleurs de Camomille, ana une poignée \& démie. 
Faites bouillir le tout dans une fuffifante quantité d'eau commune, dont on prendra dix onces, après l'avoir paffé, \& ajoutez $-y$ une once de graiffe de Caftor, pour en faire un lavement.

Auguftin Thonnerus, guérit le 30. Janvier I 647. Catherine Befingerin de douleurs utérines, caufées par des vapeurs corrompues, en lui appliquant au-deffous du nombril l'emplâtre fuivant, pour fuppléer aux remedes internes, qu'elle étoit hors d'état de prendre.

Prepez Galbanum choifi.

Gomme Tacamahaca, ana fix gros.

Graiffe deCaftor, deux gros.

Mêlez le tout \& en formez un emplâtre. La malade fut foulagée en trèspeu de tems de fes douleurs, \& je lui confeillai, pour prévenir une rechute d'ufer d'un vin médecinal, qui produifit l'effet que je fouhaitois.

La graiffe de Caftor eft très-efficace dans les maux d'oreilles, furtout lorfque la douleur eft violente.

Prenez 


\section{DU CASTOR.}

Prenez Lait d'une femme faine, une once. .

Opium d'Egypte, cinq grains.

Graiffe de Caftor, demi fcrupule.

Coulez la diffolution \& confervez la liqueur dans une bouteille de verre, pour en mettre quelques gouttes tiédes dans les oreilles, lorfqu'il en fera befoin.

Jean Michael, dans fon Commentaire manufcrit fur la pratique de Jonfton, recommande le mélange fuivant contre le tintement d'oreille.

Prenez Graiffe de Vipere, un fcrupule, de Caftor.

$$
\text { un gros, } \mathbf{M} \text {. }
$$

Il confeille encore le baume fuivant, comme propre à a ugmenter la femence $\&$ à exciter à l'a mour.

efficace ut lorf-

Prenez Huile de Fourmis, comp. deux gros.

Prenez

E 


\section{fix gouttes. \\ Graifle de Caftor, demi dragme.}

Incorporez ces drogues avec une quantité fuffifante de cire, pour leur donner la confiftance de baume.

Il fait encore beaucoup de cas du baume qui fuit, contre l'épilepfie.

Prenez Baume de Rue.

de Succin, ana demi dragme. Graiffe de Caftor, un fcru- pule.

On mêlera le tout, \& on s'en fervira au befoin.

Le célébre Wedelius fait entrer la graiffe du Caftor dans les onguens quil applique fur la région ombilicale, pour hâter la fortie du foetus qui eft mort dans la matrice. Il en recommande auffi l'ufage dans les affections des nerfs. Voici un onguent du même Auteur, contre la Paralyfie. 


\section{DU CASTOR.}

ana

demi

une

leur

as du

demi

fcru-

en fer-

trer la ns qu'il e, pour it mort de aufif nerfs. Auteur,

Prenez Onguent nervin, une once. Graiffe de Caftor, une dragme.

Huile de Laurier, fix dragmes.

Diftilée de Succin. de Poivre. deLavande, ana fix gouttes.

Mêlez toutes ces drogues, \& faitesen un onguent.

J'eus le bonheur l'année dernicre de guérir d'une Paralyfie, un Soldat appellé Jean Laupheimer, au moyen d'un Diaphorétique d'eau de Sureau, de Cinnabre diaphorétique, de Cinnabre minéral préparé felon l'art , \& de Rob deGeniévre.

L'Onguent Paralytique de Michael, eft très-propre au même effet.

Prenez Baume Paralytique de Michael, deux fcrupules. Graiffe de Caftor, une dragme, mêlés. 


\section{T R A I T E'}

$4^{\circ}$ 'Onguent fuivant a été très-falutaià un grand nombre de femmes fujettes aux fuffocations de matrice, quoique pluficurs ne s'en foient pas fí bien trouvées.

Prenez Huile de Laurier, deux dragmes.

de Menthe.

de Meliffe, ana demi dragme.

de Succin, vingtdeux gouttes.

Graiffe de Caftor, une quantité fuffifante ; on peut $y$ ajouter, fi l'on veur, une dragme \& demie de Bau- me du Pérou.

J'ai fouvent obfervé que les remedes dans lefquels il entre du Caftoreum, furtout lorfeu'ils font externes, incommodent aifément, à caufe de leur odeur, la plupart des femmes, furtout celles qui font rarement fujettes à la maladie dont nous venons de parler, ce qui fait qu'on ne doit employer qu'avec précaution les remedes qui ont une odeur forte. 


\section{DU CASTOR.}

Il arrive ordinairement, lorfque le

foetus eft d'une grandeur confidérable,
uoi-
bien
que le ventre dés femmes, furtout lorf-
qu'elles font délicates, demeure ridé
après l'accouchement. C'eft pour remé-
dier à ce défaut, que Wedelius, dont
deux
nous avons déja parlé, applique le

ujet-
uoi-
bien
que le ventre dés femmes, furtout lorf-
qu'elles font délicates, demeure ridé
après l'accouchement. C'eft pour remé-
dier à ce défaut, que Wedelius, dont
nous avons déja parlé, applique le

ujet-
uoi-
bien
que le ventre dés femmes, furtout lorf-
qu'elles font délicates, demeure ridé
après l'accouchement. C'eft pour remé-
dier à ce défaut, que Wedelius, dont
nous avons déja parlé, applique le

ujet-
uoi-
bien
que le ventre dés femmes, furtout lorf-
qu'elles font délicates, demeure ridé
après l'accouchement. C'eft pour remé-
dier à ce défaut, que Wedelius, dont
nous avons déja parlé, applique le

ujet-
uoi-
bien
que le ventre dés femmes, furtout lorf-
qu'elles font délicates, demeure ridé
après l'accouchement. C'eft pour remé-
dier à ce défaut, que Wedelius, dont
nous avons déja parlé, applique le

fojet-
uoi-
bien
que le ventre dés femmes, furtout lorf-
qu'elles font délicates, demeure ridé
après l'accouchement. C'eft pour remé-
dier à ce défaut, que Wedelius, dont
nous avons déja parlé, applique le Sparadraque fuivant :

ujet-
uoi-
bien
que le ventre dés femmes, furtout lorf-
qu'elles font délicates, demeure ridé
après l'accouchement. C'eft pour remé-
dier à ce défaut, que Wedelius, dont
nous avons déja parlé, applique le

demi qui fait emedes

reum,

incom-i odeur, it celles maladie précau-

e odeur

ingtquan, une e Bau-

\section{PrenezHuile de Lis blanc. de Violettes. de Camomille.
deLin, ana trois onces.
d'Oeufs, quatre onces.
la Cire, deux ou trois de Camomille.
deLin, ana trois onces.
d'Oeufs, quatre onces.
la Cire, deux ou trois de Camomille.
deLin, ana trois onces.
d'Oeufs, quatre onces.
la Cire, deux ou trois de Camomille.
deLin, ana trois onces.
d'Oeufs, quatre onces.
De la Cire, deux ou trois onces. \\ Blanc de Baleine. \\ Graiffe de Caftor, ana une demi once. demi once.}

Mêlez le tout. Ce remede eft encore très efficace pour appaifer les douleurs qui fuivent l'accouchement.

Voici un liniment dont le même Auteur fe fert dans les defcentes de matrice.

Prenez l'Huile de pomme de merveille.

E iij 

une once.

Graiffe de Caftor, une dragme.

Mêlez ces drogues :\& oignez - en I'Uterus, après les avoir fait chauffer, afin de le remettre dans fa place.

La graiffe de Caftor, eft un remedie excellent pour appaifer les maux de dents les plus fâcheux, \& qui font prefque incurables, comme l'éprouva dernierement la fille d'un Marchand, que la douleur obligea à fe faire arracher trois dents, fans qu'elle en fut foulagée, \& que je guéris avec le remede fuivant ;

Prenez Emplatre de Melilot, fix dragmes.

Gomme de Génévrier, deux dragmes.

\section{Tacamahaca.}

Maftic, ana demi dragme. Graiffe de Caftor, une fuffifante quantité. 


\section{DU CASTOR.}

ana

une

ez - en

auffer,

emedie aux de ui font prouva chand, ce arraen fut c le re-

ot , fix , deux dragme. une fufti-

Mêlez le tout, \& faites-en un emplâtre, que vous appliquerez fur le côté affligé.

Le Verrier dont nous avons déja fait mention, reçut fa guérifon de la graiffe du Caftor, mêlée avec d'autres drogues, à ce que rapporte mon Auteur, dans fa pratique manufcrite.

Prenez Onguent de Cynagloffe: Graiffe de Caftor, ana une once.

Huile de Laurier, demi once. Diftillée de Geniévre, deux dragmes.

Incorporez ces drogues avec quelque peu de cire, pour en faire un onguent.

\section{ARTICLE XIII.}

La fang du Caftor eft un remede efficace contre l'Epilepfie, car en ayant donné il y a trois femaines à un garçon mendiant, de $l$ 'ge de douze ans, qui ctoit tous les jours fujet aux accès de cette maladie, il en fut exempt pendant fix jours. Je lui en fis prendre une feconde fois, of je ne l'ai E iiij 
Not fang, pas diff le Caft fang $\mathrm{q}$ qui $f$. animal cules $\mathrm{h}$ les.

On metho fang d qui eft dies, qui fui Jean en 16 perdu que le promi le rem que ja

Pre 


\section{DU CASTOR.}

quil

auffl re les

nelles.

diffe-

$\mathrm{CaI}-$ indi-

int les préve. pour-

Caftor an feu un fel efoin ; huile, c le fel aucoup lans les es nerant fur 1 a tiré; rtu adat nous

Notre Auteur fubftitue à l'efprit de fang, celui du Caftoreum, qui n'en eft pas different à ce que je crois; puifque le Caftoreum n'eft autre chofe qu'un fang qui s'eft purifié dans les veficules qui font au-tour des bourfes de cet animal , \& qui eft compofé de particules huileufes, balfamiques \& volatiles.

On peut encore préparer, fuivant la methode de Van-Helmont, avec le fang de Caftor pulverifé, un remede qui eft fort eftimé dans plufieur, maladies, comme on peut en juger par ce qui fuit :

Jean Kneer, Tifferand, étant tombé en 1645 . d'une charette, \& ayant perdu la refpiration, à caufe peut-être que le fang s'étoit extravafé, je lui promis de le foulager , \& lui donnai le remede fuivant, qui eut tout l'effet que j’avois efperé.

Prenez Yeux d'Ecreviffes préparés. Sang de Caftor, ana deux fcrupules.

Eau de Cerfeuil, deux onces $\&$ demie. 


\section{TR A I T E'}

Mêlez ces drogues dans une quantité fuffifante d'Oxymel fimple, mêlez le tout \& faites-en prendre au malade.

J'ai tiré cette compofition de la pratique manufcrite de mon Auteur.

Elias Waldnerus, Médecin à Memmingen, guérit en I 600 . George Hirfichius, d'un point de côté, caufé par un fang extravafé, en lui donnant de ce fang dans du vinaigre.

\section{A R T I L E X I V.}

On employe le poil du Caftor non-fenlement pour faire des chapeaux, mais encore pour arrêter les bemorragies, de quelque espece quielles foient, comme je l'éprouvai dernierement après qu'un Chirurgien ent inutilement employé les ftypti. ques.

\section{ADDITION.}

Le poil de Caftor, comme on l'a dit ci-devant, eft cottoneux, très-fin , \& très-ferré à l'endroit de fon origine.

Il eft fi fortement enraciné dans la peau, qu'on ne peut l'arracher fans effort. Il eft formé d'une vapeur réche, 


\section{DU CASTOR.}

que la chaleur fait tranfpirer de la fubftance des parties, \& il reçoit par fes racines le fuperflu de la nourriture qui fert à fon accroiffément.

Il ne fert pas tant à garantir l'animal des injures de l'air, qu'à lui aider à nager; car outre qu'il eft creux, le Caftor a foin, avant que de fe jetter dans l'eau, de l'oindre avec la liqueur qui eft dans les poches pour pouvoir nâger avec plus de facilité ; c'eft donc fa porofité qui le rend propre à s'impregner de fang, \& fa froideur qui fait qu'il refferre la plaie, \& qu'il coagule lefang, ainfi que l'expérience le prouve.

\section{A R T ICLE XV.}

On attache les dents du Caftor au cou des enfants, pour faciliter la fortic des dents. On les réduit en poudre, $\sigma$ on les donne ainfi prépar'ce: dans la Pleurefie, avec beaucoup de $\hat{j}_{3}$ 'Elle garantit les enfans nouveaux nec a Epilepfie, étant prife dans du bouillon.

l'a dit fin , \& gine. dans la ter fans féche, 


\section{8 TRAITE?}

Pren

Les dents du Caftor ont une trèsgrande efficacité dans plufieurs maladies. Elles hâtent la fortie des dents aux enfans, lorfqu'on les leur attache au cou, enforte qu'elles touchent la chair ; mais je fuis perfuadé qu'elles produifent beaucoup plus d'effet, étant employées en forme de liniment.

\section{Prenez Miel vierge.}

Cervelle de Liévre, ana deux gros.

Poudre de dents de Caftor, un fcrupule.

Ces drogues étant mêlées enfemble ; appaifentmerveilleufement les douleurs des gencives que les enfans reffentent, ainfi que l'expérience le prouve.

Le Gargarifme fuivant que je tire des ouvrages manufcrits de Barthelemi Wolfart, eft un fecret que cet Aureur s'étoit refervé comme un remede admirable pour appaifer les maux de dents de quelque efpece qu'ils fuffent.

Faite vinaigr tiers; 1 vinaigr feuilles gardez du côté la fluxi s'en tro même font for tre l'E font fuj caufée la forti l'ufage qu'on 1 Michao tus dat \& dans 


\section{DU CASTOR.}

Prenez Sauge, une poignée. Hiflopé, demi poignée.

trèsmaladents ttache ent la u'elles étant

, ana

aftor,

mble ; oulewrs intent,

je tire thelemi Aureur admie dents
Piretre, deux dragmes.

Dents de Caftor pulverifées fubtilement, demi-once.

Faites bouillir ces drogues dans du vinaigre, jufqu'à la diminution du tiers; prenez enfuite une livre de ce vinaigre chaud, une once de firop de feuilles de chêne, mêlez le tout $\&$ gardez-en quelque peu dans la bouche du côté où fe fent la douleur. D'abord la fluxion augmentera, mais enfuite on s'en trouvera foulagé. Ces dents, de même que celles des autres animaux , font fouvent un excellent remede contre l'Epilepfie, à̀ laquelle les enfans font fujets, \& qui eft prefque toujours caufée par les douleurs inféparables de la fortie des dents. C'eft pour faciliter lufage de ces dents que Wedelius veut qu'on les réduife en poudre, à laquelle Michael attribue auffi de grandes vertus dans la Squinancie, la Pleurefie, $\&$ dans le débordement de bile. 
50

\section{T R A I T E'}

\section{ARTICLE X VI.}

On trouve au bas de l'os' pubis de cet Animal, deux pocbes ou tumeurs dans lefquelles eft renfermée la liqueur quion appelle Caftoreum, qui eft très-utile $\mathcal{O}^{\circ}$ tres - Salutaire dans un grand nombre de maladies, \& qu'on a fort prifee de tous tems à caufe de fes giandes proprietés, que lexpérience $n^{2} a$ jamais démenties.

\section{ADDITION.}

Ce feroit ici le lieu de parler des autres parties de cet Animal, de fon cerveau, de fes poumons, de fon foie, de fes excrémens \& de fon urine, auffibien que de l'ufage qu'on en peut faire dans la Médecine; mãis comme notre Auteur que nous prenons pour guide, n'en dit pas un mot, qu'il n'en eft point fait mention dans les ouvrages des Anciens, \& que la Médecine modernes nous fournit des remedes beaucoup plus efflcaces, je ne m’arrêterai pour le préfent, qu'à ce qui fait le fujet de cet ouvrage. 


\section{DU CASTOR. SI A R TICLE XVII.}

Le Caftoreum eft chand depuis le troifiéme jufquiau quatriéme dégré, de-là vient quil eft propre à diffiper, attenuer, deffeicher ơ attirer, auffi-bien qu'à réfoudre avec beaucoup de force les matieres froides $\mathcal{G}$ venteufes. Je. donnerai le détail des maladies particulieres pour lefquelles il eft propre.

\section{$A D D I T I O N$.}

er des de fon n foie, , aufiut faire notre guide, it point es des moderaucoup ai pour fujet de.

Nous voici maintenant arrivés à la Partie la plus noble \& la plus utile de cet Animal, fçavoir le Caftoreum, proprement dit, lequel devient friable lorfque l'air a diffipé les particules fereufes qu'il contient, \& dont la couleur varie à raifon de la grande quantité de parties heterogenes, dont il eft compofé ; car tantốt il eft jaune, tantôt d'un jaune tirant fur le rouge. Quelquefois il eft d'un rouge obfcur avec des veines $\&$ des rayes blanchâtres - mais le meilleur eft celui qui eft d'ws rouge tirant fur le noir. Quelques-uns veulent infé- 
52

\section{T R A I T E'}

rer de ces couleurs, que fa nature doit être chaude ; mais comme elles ne font qu'un pur accident \& que cette conféquence n'a rien de folide, il eft neceffaire de recourir à des meilleures preuves pour s'inftruire de fa véritable nature.

Si on l'approche de la langue, fes parties gommeufes ne feront pas plutât fondues que fes pointes s'infinueront dans fes pores; il s'en fuit donc que fa nature fera d'autant plus chaude que fon acrimoinie fera grande, \& il eft certain que l'amertume deffeiche à raifon des particules falées \& terreftres qui la caufent.

Son odeur n'eft point fuperficielle, mais elle eft répandue dans toute fa fubftance, \& comme l'orleur ne provient que des particules fulphureufes $\&$ volatiles, qui affectent l'organe de l'odorat, \& que le foufre eft chaud, il paroît indubitable que le Caftoreum doit l'être auffi.

On n'en doutera point fi on fait attention qu'il s'enflâme lorfqu'on l'approche du feu, \& que rien d'inflammable ne peut être froid de fa nature. Les

Les augmer fang, en ordinais fortus $\mathrm{q}$ prouver clure qu de fá na

Les $A$ le dégr affigner cenne, traire à une rou affez pu empoul peut, da miner, de féche jufqu'au dégré.

Il pa Caftore tilifer, des par fulphure \& terre

C'eft 


\section{DU CASTOR.}

Les effets même qu'il produit en augmentant les parties fulphureufes du fang, en chaffant les vents, excitant les ordinaires, \& en procurant la fortie du foetus qui eft mort dans la matrice, prouvent $\&$ nous donnent lieu de conclure que le Caftoreum eft fec \& chaud de fà nature.

Les Auteurs ne s'accordent point fur le dégré de chaleur qu'on doit lur affigner. Marius eft pour celui d'Avicenne, que je crois entierement contraire à la verité. Car quoiqu'il caufe une rougeur fur la peau, il n'agit point affez puiflamment pour y exciter une empoulle. It me paroit donc que l'on peut, dans une chofe fi difficile à déterminer, fixer fon dégré de chaleur \& de féchereffe depuis la fin du fecond, jufqu'au commencement du troifiéme dégré.

Il paroît fuivant ces principes que le Caftoreum eft apéritif \& propre à fubtilifer, diffiper \& fortifier, à caufe des particules gommeufes, réfineufes, fulphureufes, ballamiques, volatiles \& terreftres dont il eft compofé.

C'eft ce foufre volatil qui le rend

Les F 


\section{T R A I T E'}

ami des nerfs, propre à chaffer les maladies utérines, en corrigeant les particules irritantes, en réprimant les mouvemens déreglés de l'archée, en délayant la lymphe. C'eft lui encore qui le rend propre à appaifer les maux de tête, la colique, les douleurs vagues de la goute, \& celle des dents \& des autres parties nerveufes, à guérir le vertige, l'épilepfie \& l'apoplexie; proprieté que les Anciens lui ont accor. dées d'un fentiment unanime, comme il paroît par ce qui fuit :

Les refticules du Caftor, fi l'on-en croit Neufart, déféchent les humeurs fuperflues, \& guériffent les maladies qui ont leur origine dins les nerfs.

Le Caftoreum eft ger, pour les maladies des nerfs, furtout lorfqu'on l'employe après les purgati $\varsigma_{5}$. J'ai même oui dire autréfois au Docteur Martin , dont j’ai été difciple, qu'il agit avec beaucoup plus de force lorfque laLune eft dans fon plein. Je ne fçai fi cela elt vrai, à moins qu'on ne veuille parler du tems auquel on doit l'ôter à l'Animal.

Les telticules du Caftor, dit.Zwiker, 


\section{DU CAST OR.}

fe conlervent plufieurs années; \& font fort eftimés dans les maladies des nerfs.

Le Caftoreum féché à la fumée eft un remede admirable à ce que prétend Pierre Hæner , autrefois Médecin à Worm, contre la foibleffe d'eftomac,\& les maux de dents, à caufe de fa vertu déficative, les paffions hyfteriques, le mal caduc, l'apoplexie, la paralyfie; en un mot contre toutes les maladies des parties nerveufes.

Erhard, Religieux à Ulm, à compris en deux mots toutes les proprietés du Caftoreum : Caftoreum, dit-il, Colum petit fcilicet Micro cofmicum; nous parlerons de fon ufage particulier dans la Médecine.

\section{ARTICLE XVIII.}

Le Caftorcum eft un remede éprouvé contre les maladies des oreilles; il en appaife les douleurs of en fait ceffer lc bruit, le fifflement ơ le tintement. Il n'eft pas moins efficace contre la furdité ; pourvî griclle ne foit pas inveterée, of qu'elle ne $\mathrm{F} \mathrm{ij}$

it.Zwiker, 
$56 \quad$ TR A I T E'
Soit point caus'é par la superfluité des bromeurs ou par l'obftruction des nerfs.

Il diffipe les abcès étant appliquic extérieurement, ce qui fait quion lemploye avec utilit dansla compofition des onguens réfolutifs.

Le Caftoreum employé comme il faut, eft le remede le plus efficace que nous ayons contre les douleurs de la gouice.

Comme tous ces remedes ont une vertu bornée ơ peuvent même quelquefois devenir nuifibles, on ne doit pas être furpris $\sqrt{\mathrm{k}}$ le Caforeum ne produit pas toujours Peffet quion en attendoit, \& $f i$ fon ufage oft dangerenx aux femmes enceintes, griil fait avorter auffi-totot, comme cela arriva à une femme de ma connoifance, qui avoit une fuffocation de matrice, of qui pour avoir voulu y remedier par l'ufage interne o externe du Cafforeum, fit une fauffe conche o mit an monde un enfant qui n'avoit que treize femaines.

\section{$A D D I T I O N$.}

Le tintement d'oreilles eft pour l'ordinaire une maladie d'Hyver, qui occafionne dans l'organe de l'ouie, la

percept

\& l'em

qui le fi peurs ir pan, : 8 de rélo peut s'e fuivans. Il ne lorfqu'o nature differen dans le Jean a éprou fuivant lons, a dans l'c

Pren

On re poudre décocti 


\section{DU CASTOR.}

's bus-

perception d'un fon qui n'eft point réel, \& l'empêche d'être affectée par ceux qui le font. Elle eft caufée par des vapeurs internes qui agiffent fur le tympan, \& que le Caftoreum a la vertu de réloudre $\&$ de diffiper, comme on peut s'en convaincre par les exemples fuivans.

Il ne produit pas de moindres effets lorfqu'on Y'employe intérieurement en nature, que lorfqu'on le prépare de differentes manieres pour s'en fervir dans les maux d'oreilles.

Jean Micheli , Médecin Autrichien, a éprouvé autrefois l'effet du mélange fuivant dans la maladie dont nous parlons, ainfi qu'il le témoigne lui-même dans l'ouvrage qu'il nous a laiffé.

Prenez Caftoreum, demi dragme.
Oliban.
Myrrhe, ana demi fcrupule.
Racine de Cabaret, une
dragme.

On réduira toutes ces drogures en une poudre groffiere, pour les mettre en décoction dans une quantité fuffifante 


\section{T R A I T E'}

$5^{8}$ de vin. On coulera l'extrait, \& l'on en mettra une ou deux gouttes toutes chaudes dans l'oreille que l'on bouchera avec du cotton.

Le mélange fuivant dont on trouve la defcription dans le Commentaire manufcrit de Jean Michael, Profeffeur à Lipfick, eft encore très-efficace dans la mếme maladie.

Prenez Eau de Pies, avec le Caftoreum, trois gros. Effence d'Abfinthe, un gros. Melés :

Le mêlange fuivant, eft encore du même Auteur, qui s'en fert pour le même effet.

Prenez Effence d'Abfinthe. de Caftoreum. de Corne de Cerf, ana une dragme. Mêlés.

Mêl

Jeat

1621

comn

joint. mede fouha

Nous devons encore à cet Auteur la compofition d'une huile particuliere , dont le Caftoreum eft la bafe. 


\section{DU CASTOR: $59^{\circ}$}

Prenez Huile d'amande amere. de Fourmis. de Vers de terre, ana une once.

trouve entaire roferfficace

CaftoIn gros. core du pour le

m.

e Cerf, Mêlés.

uteur la culiere ,
Huile de Coftus. d'Abfinthe. de Caftoreum , ana demi once.

Diftilée de Laurier, un fcrupule.

de Marjolaine, demi fcrupule.

Mêlez toutes ces drogues.

Jean Schapper, ordonna le 5 d'Avril 1621. à Georges Vehen, qui étoit incommodé d'un tintement d'oreilles, jointrà un mal de tête violent, le remede fuivant, qui produifit l'effet qu'il fouhaitoit.

Prenez M. Pill. aurea.

Cochées.

Extrait de Rhubarbe, ana un fcrupule. de Caiftoreum, demi fcrupule. 
60

\section{TRAITE'}

On mêlera ces drogues avec de l'huile de Romarin diftillée pour en faire des Pillules.

Jean Sebaftien Bloffius, ordonna le même remede le 8 Décembre 1647 . à Vito Marchtaler, avec le même fuccès.

\section{Prenez Extrait Cathol. \\ Trochiques alhandal. \\ Diagrede, ana fix grains. \\ Huile de Marjolaine diftil- lée, deux gouttes.}

Faites-en des Pillules, au nombre de vingt-une, avec la teinture du Caltoreum.

Jacques Zcemann , ordonna en 1646. le remede fuivant à l'époufe de Jacques Scuter.

Prenez Feuilles d'Origan.

$$
\text { deSerpolet. }
$$

de Marjolaine, ana deux pincées.

Fleurs de Romarin, une pincée.

Pulpe de Coloquinte, un fcrupule \& demi.

On 1

feu len $\&$ le fi $\&$ apri fcrupu le tout fage $d$ Jean fils de fuivant dans 1 ' Pret

Mêl Caftoreum 


\section{DU CASTOR. $\quad 6 \mathrm{r}$}

l'huile

Caftoreum, deux fcrupules. Storax calamita, un fcrupule $\&$ demi.

Suc de Rue, nouvellement extrait.

Efprit de Vin, ana une once $\&$ demie.

Huile de Caftoreum.

ains. ana fix gros.

d'Amande amere,

On mettra le tout en coction, fur un feu lent, jufqu'à ce que l'efprit de vin, $\&$ le fuc des herbes loient confommés, $\&$ après l'avoir coulé, on y ajoutera un fcrupule \& demi de Pétrole ; on mêlera le tout, \& on le confervera pour l'ufage dans une bouteille.

Jean Regulus Villingerus, donna au fils de Georges Zechius, le remede fuivant, qui le guérit d'un battement dans l'orcille, dont il étoit affligé.

Prenez Huile d'Amande amere. de Caftoreum,

ana un gros. de Marjolaine , demi gros.

Suc d'Oignon, un gros.

Mêlez le tout, \& le gardez. aftoreum 
62

\section{T R A I T E'}

Il ordonna à la Baronne de Stadion, qui étoit tourmentée d'un mal d'oreille violent, le remede qui fuit.

Prenez Pilules d'Hiere \& d'Agaric ; un fcrupule \& demi.

Maftic.

Caftoreum, ana demi fcrupule.

Magift. de Racine de Mechoacan noir , fept grains. - On en formera avec de l'eau de Fenouil, des Pillules de grandeur ordinaire.

Prenez Huile de Coftus. de Caftoreum , ana deux gros. Suc d'Oignon, demi gros.

Mêlez le tout.

Une fille que j'avois, dit Jean Vogtius , \& qui étoit fort fujette à la pituitc, étant incommodée d'un tintement d'oreilles, je l'en délivrai au moyen des remedes qui fuivent, après l'avoir auparavant préparée.

Prenez Pillules aurea. Cochées. 


\section{U CASTOR. 6;} Aggregatives, ana un fcrupule.

Diagrede, trois grains.

Jonc odorane.

Caftoreum, ana deux grains.

On mêlera ces drogues, \& on en formera des Pillules, au nombre de onze.

Prenez Huile do Moutarde, demi once.

Caftoreum, quatre grains. Mufc, deux grains.

Melez lo tout.

grains. de Fear ordi-

1, ana

ni gros.

In Vogla pituiintement 1 moyen s l'avoir

On verfera ce mélange goutte à goutte dans l'oreille.

Barthelemi Wolfart guérit en r 57r. la veuve de Thomas Lebzelter, qui étoit incommodée d'une furdité caufée par des humeurs froides \& épaiffes, au moyen des compofitions fuivantes.

Prenez Pilules cochées.

Trochiques d'Agaric.

Caftoreum, ana demi dragme.

$$
G \text { ij }
$$




\section{T RA I T E'}

64 mêlera ces drogues avec de l'Oxy. mel, pour en faire des Pillules au nombre de dix, dont la malade en prendra deux tous les matins, avant le jour.

Prenez Solution de vinaigre de Caftoreum., deux dragmes. Huile de Geniévre , une dragme. Suc de Rue, autant que l'on voudra.

Après que toutes ces drogues feront parfaitement incorporées, on en mettra dans loreille, avec une mêche de cotton.

Le mêlange fuivant n'a pas produit un moindre effet dans une femblable circonftance.

Prenez Huile de Caftoreum, demi dragme. diftillée d'Hyfope. de Marjolaine, ana fix gouttes. de bois de Saffafras, trois gouttes. 


\section{DU CASTOR. 65}

Oxy-

es au

de en

rant le

eCafigmes.

, une

ue l'on

s feront

en metêche de

produit mblable

, demi

Cope.

arjolaine,

is de Safuttes.

Après avoir mêlé ces drogues, on en ufera comme ci.devant. Ce mélange étant pris intérieurement, ranime les efprits \& leve promptement les obftructions.

Chriftophe Ehinger, guérit la fille de Jean Habfafti Ehinger, d'une furdité dont elle étoit affligée depuis quatre femaines, au moyen de la compofition fuivante.

Prenez Huile de Laurier. de Rue. de Caftoreum.

Suc d'Abfinthe. de Sabine.

Miel de Romarin, ana demi once.

Ellebore, une dragme.

On fera bouillir enfemble ces drogues jufqu'à faturation, \& lorfque le malade fera fur le point de fe coucher on lui en mettra fix gouttes toutes chaudes dans l'oreille, ce qui ne manquera pas de lui procurer un prompt foulagement.

Le Caftoreum appliqué extérieurement eft propre à réfoudre, à ou- 


\section{TR A I T E'}

vrir les pores \& à meurir ; comme nous l'afure Michél Ettmiller dans fa Chirurgie manufcrite. On le mêle avec du Galbanum \& du Geniévre, lorqu'on veut diffiper quelque tumeur odematcufe, ou une enflure caulée par l'hydropifie, comme l'a pratiqué Neufart, qui guérit la femme ciu Licentié Schittben, d'une tumcur molle \& indolente de cette efpece, avec l'emplâtre fuivant.

\section{Prenęz Galbanum. \\ Sel Ammoniac, ana demi once. \\ Caftoreum. \\ Mirrhe , ana deux dragmes. Huile de Chanvre, une quantité fuffifante.}

On fera de ces drogues un emplâtre qu'on appliquera tout chaud.

Je guéris en peu de jours, au moyen de l'emplâtre fuivant MagdelaineMayerin , d'une tumeur qu'clle avoit au pied gauche.

Prenez Emplâtre Dyächilon, avec les gommes, demi once.

Mêlé gardés.

Bart l'emplât puftilen

Pren

On e

Le C remedic tions, autres $\mathrm{r}$ pour cet foient difent lo 


\section{DU CASTOR.}

Gomme de Lierre.

mme

ins fa

avec

lorf-

meur

éc par

Neucentié $\&$ inmplâ-

demi

agmes.

, une

emplâ-

moyen Mayeau pied

avec ii once.
Caftoreum, ana une dragme. Huile Philofophique, une quantité fuffifante.

Mêlés fuivant les regles \& l'art , \& gardés.

Barthelemi Wolfart, fe fert de l'emplâtre fuivant pour les tumeurs puftilentielles \& malignes.

Prenez Suie.

Mithridate.

Caftoreum.

Sel commun.

Fiante de Pigeon, ana une once.

Huile de Scorpion, demi once.

Du Miel Rofat \& de la Cire, autant qu'il en faut.

On en fera une Emplâtre.

Le Caftoreum eft excellent pour remedier aux douleurs des articulations, \& il eft au-deffius de tous les autres remedes que l'on peut employer pour cet effer, quelques efficaces qu'ils foient d'ailleurs. Ecoutons ce qu'en difent les Auteurs.

Giiij 
Villingerus, guérit autrefois Martin Georges Lavinganum, de douleurs vagues qu'il reffentoit aux articles, avec le remede fuivant.

Prenez Huile de Vers de terre. de Coltus.

de Renard, ana demi once.

de Caftoreum.

de Poivre, ana deux dragmes.

Eau de vie, une dragme \& demie.

Mélez ces drogues \& faites en ufage.

Il ordonna, après les préparations convenables, le mêlange fuivant au R. P. Sebaftien, Religicux à Soflingen, qui reffentoit la même incommodité.

Prenez Eau d'Hirondelles, avec le Caftoreum, ana une once \& demie.

Archritique d'Aufbourg, deux onces.

de Sauge, une once. Mêlez ces drogues \& faites en ufage.

Le : dont $n$ jufqu'à moins

Pre

Mế

Plu goutte remed affure. Mo de l'F avec 1 Glafe: afflige ordor $\&$ des 


\section{DU CASTOR.}

69

Martin uleurs ticles,

e.

a demi

deux

gme \&

nufage.

arations

vant au

Sollincommo-

, avec le une once

urbourg,

e once. en ufage.

Le mêlange Antarthritique fuivant dont notre Auteur s'eft réfervé le fecret jufqu'à la fin de fes jours, n'elt pas moins efficace.

Prenez Efprit de Geniévre.

de Vers de terre, ana deux onces.

Cephalique, une once. Camphre, demi once. Effence de Caftoreum, trois

Opium d'Egypte, diffous dans de l'ESprit de vin; demigros.

Mêlez ces drogues.

Plufieurs Perfonnes attaquées de la goutte, ont éprouvé la vertu de ce remede, comme Marius nous en affure.

Moyfe Heldius, Medecin ordinaire de l'Hêpital d'Ulm, guérit en 1645 , avec la compolition fuivante, Barbe Glaferin, qui depuis long-tems étoit affligée de la goutte, après lui avoir ordonné auparavant l'ufage des Bains $\&$ des Tifanes. 


\section{0

Prenez Huile de Camomille. de Rue. de Caftoreum, ana demi once. Térébenthine diftlllée, deux gros.

Mêlez ces drogues \& faites en ufage.

Jean Oeltrichius Aubergifte, à l'Enfeigne duBœuf d'or, fut délivré des douleurs cruelles que lui caufoit la goutte, par le moyen de la compofition fuivante, dont Jean Sebaftien Bloffius lui prefcrivit l'ufage.

Prenez Eau d'Hirondelles, avec du Caftoreum, deux onces. Eau de vie, une once. Efprit de Muguet. de Ceriles noires, ana eux dragmes.

de Sang de Cerf, une once \& demie.

Mêlez ces drogues \& faites-en ufage.

Chriftophe Stuberus, Supérieur du Monaftere de Edelftatten, après avoir

Mêl 


\section{DU CASTOR. $\quad 7 \mathrm{~T}$}

inutilẹment employé differens remedes contre la goutte, fit appeller Jean Melder, qui le délivra par le remede ana deux ufage.

'Endououtte, uivani pref-

Prenez Sirop de Betoine. de Stæchas, ana deux onces.

d'Hyfope, une once $\&$ demie.

de Pivoine, demi once. Miel de fleurs de Romarin, deux onces.

Eau de Primevere, demi livre.

de Sauge. de Romarin. de Betoine. de Lavande, ana deux onces.

Effence de Cáftoreum, un fcrupule.

Eau de Canelle, demi once. Mêlez ces drogues.

$f$, une ufage. leur du $s$ avoir

Prenez Pilules d'Hiere, avec l'Agaric. 


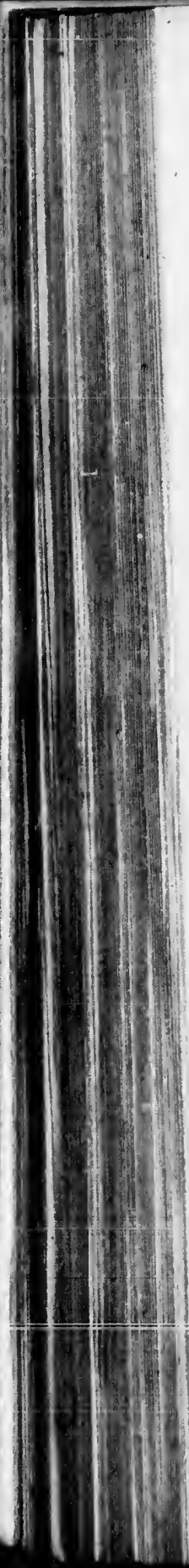

72

\section{T R A IT E'}

Extrait de Pilules cochées;

- ana deux fcrupules.

'Trochifques alhandal', cinq

Pren Efrains.

Huile de Fenouil diftillée, quatre gouttes.
Syrop-de Stæchas, autant qu'il en faur.

On mêlera ces drogues, \& on en formera des Pilules au nombre de vingt-cinq. .

\section{Prenez Eau de Lavande. de Sauge. de Fleurs de Tilleul. de Muguets, ana y compris le vin, demi livre. d'Hirondelles, avec du Caftoreum.de Küchel. Arthritique d'Aurbourg, ana deux onces. \\ Efprit de Muguets, une once.}

- Mêlez ces drogues , \& donnez en un verre aumalade. 


\section{DU CASTOR. 7s}

Prenez Conferves de Rofes.

cinq

, trois

Tillée ,

autant

on en

bre de

illeul.

ana $y$

ni livre.

, avec

Küchel.

arg, ana

ne once.

ez en un de Bourrache.

de Sauge.

de Betoine.

de Romarin, and

fix dragmes.

d'Ivette.

de Muguets.

de Primevere.

de Lavande, ana

demi once.

Racine d'Aunée, confite.

Ecorce de Citron, confite.

Calamus Aromaticus, confit, ana demi once.

Efpeces Diarrhodon.

Aromatiques Rofat, completes, ana une dragme.

de Diambra.

de Diamochi dulcis,

ana demi dragme.

Succin blanc préparé, une dragme \& demie.

Corail rouge préparé, une dragme.

Emeraude préparée, un fcrupule. 


\section{T R A I T E'}

Poud're de Gui de Chêne ; deux dragmes.

Semence de Pivoine.

Mufcade, ana une dragme.

Cardamome.

Cubebes, ana un fcrupule. Extrait dc Caftoreum, demi fcrupule.

Syrop d'écorce de Citron. Suc de Bourache, ana trois onces.

On mêlera parfaitement toutes ces drogues \& on en fera un Electuaire de moyenne confiftance, en y ajoutant d'huile de Succin, de Canelle, ana dix gouttes, de Citron, fix gouttes. On les mêlera de nouveau, \& on les mettra dans un grand vaiffeau. On gardera cette préparation pour l'ufage.

Il donna auffi au malade les Pilules Arthritiques d'Aufbourg, après les avoir réformées de la maniere qui fuit.

Prenez Poudre d'Ivette Arthetiques.

de Fleurs de Stxchas d'Arabie, ana une 


\section{DU CASTOR. $\quad 75$}

once \& demie. de Betoine. de Primevere, ana une dragme. de Romarin. de Lavande, an demi dragme.

Hermodacte mondée.

Trochique d'Agáric.

Rhubarbe choilie.

Turbith blanc \& gommeux, ana deux dragmes.

Trochiques alhandal.

Diagrede corrigé avec l'huile de Fenouil, ana une dragme.

Calamus Aromaticus.

Canelle.

Noix Mufcade, ana demi dragme.

Cubebes.

Gingembre.

Gerofles, ana demi fcrupule: Spica d'Inde.

Sel Gemme.

Safran.

Caftoreum, ana demi fcrupule. 
76

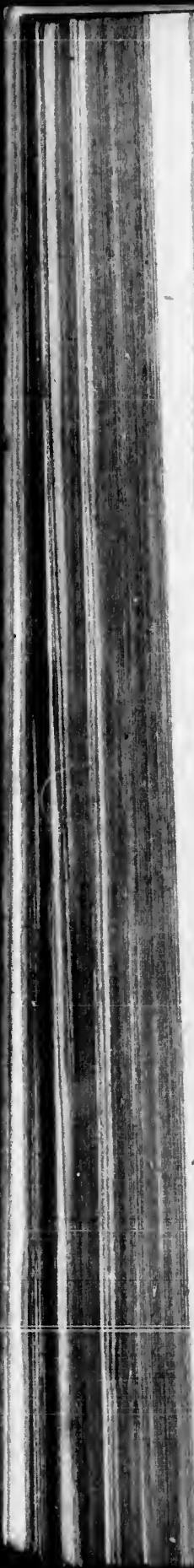

Sel Ammoniac.

Opopanax.

Sagapenum, ana demi drag. me.

Aloes Succotrin, demi once. Extrait d'Ellebore noir , demi dragme.

de Tithimale, un fcrupule.

de Regliffe, un fcru, pule \& demi.

Suc d'Ivette, \& Eau de la même, extraite par la coction, une quantité fuffifante.

On fera de toutes ces drogues, une maffe, que l'on oindra avec de l'huile d'Anis, \& que l'on gardera dans une boëte, dans un lieu convenable, après l'avoir enveloppée d'une peau. Il donna anfi au malade des Pilules d'Ivette, compofées de la maniere fuivante.

Prenez Pilules d'Ivette, deux dragmes.

Huile diftillée de Sauge, quatre gouttes.
Mêlc

Pilules envelor moschi a

Pren

On avec ur trente ] dans $d \epsilon$ tique $\mathbf{r}$ le mal: remede Mon Compa appelle 


\section{DU CASTOR.}

Mêlez ces drogues \& formez en des

emi drag.

emi once. noir ,

ale, un

, un fcrus

Eau de la

e par la quantité

sues, une de l'huile dans une ble, après 1. Il donna d'Ivette, ivante.

leux drag-

Sauge ,

Mêlez
Pilules au nombre de trente, que vous envelopperez de poudre d'efipeces Diamofchi dulcis.

\section{Prenez Pilules Affaieret.}

\section{Alxphangines.}

Trochiques d'Agarie, ana une dragme.

Maftic choifi, un fcrupule. Efpeces Diambra completes, demi fcrupule.

Ambre vrai, trois grains. Baume de Fenouil, huit grains.

Effence de Caftoreum, trois gouttes.

On formera de toutes ces drogues avec une dragme de Syrop de Stxechas trente Pilules, que l'on enveloppera dans demi dragme de Poudre A romatique rofat complette. Dentur ad Scat. le malade guérit par l'ufage de ces remedes.

Monfieur Chriftophe Weber, mon Compatriote, me fit dernierement appeller, fe trouvant tourmenté de 


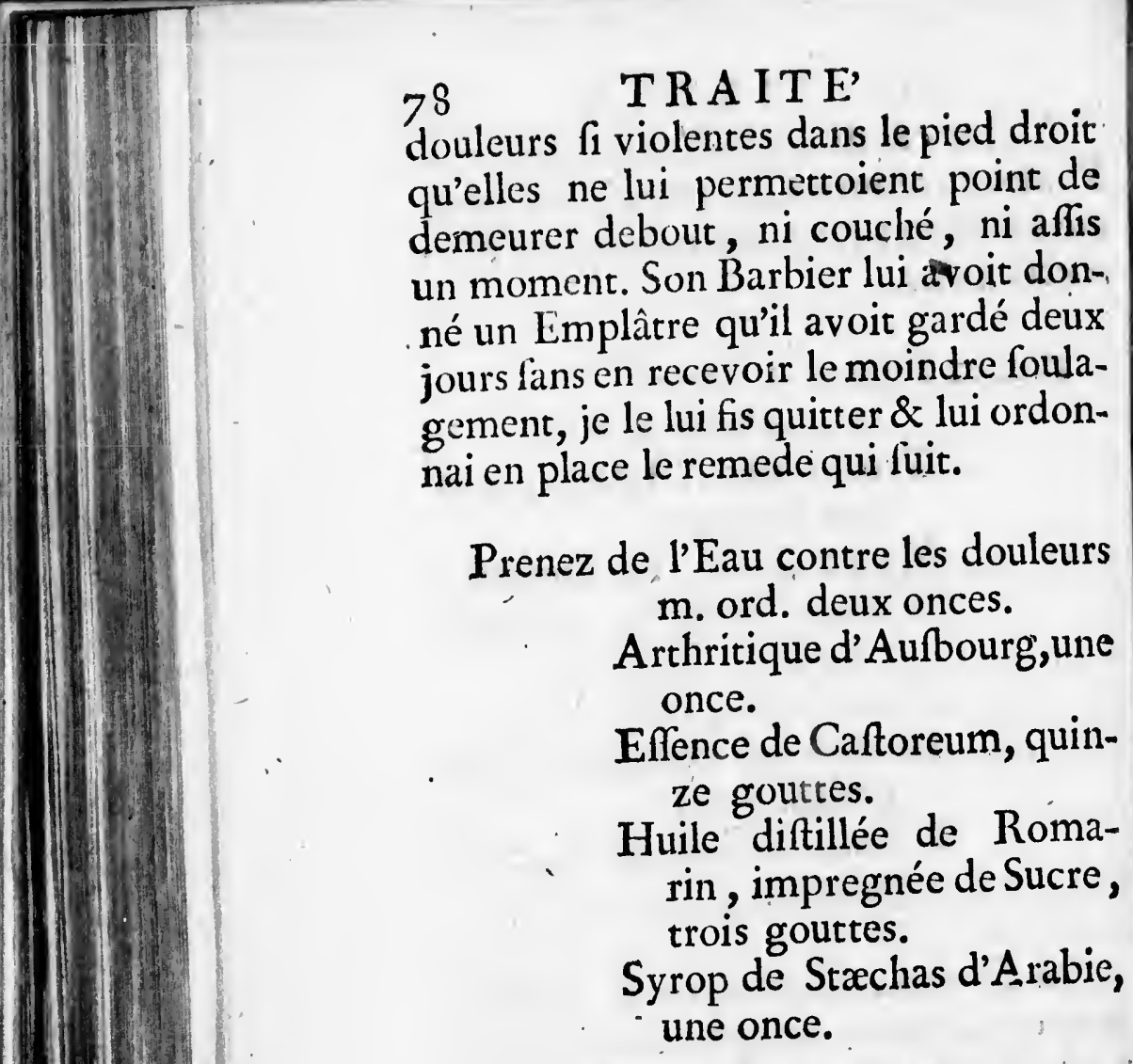

Mêlez ces drogues \& donncz en d'une heure à l'autre une cuillerée au malade.

Prenez Eau d'Hirondelles, avec le Caftoreum, deux onces. Efprit de vers de terre, demi once,
Mêl

Le des, $c$ fe tro reveil.

Les les feu. reum $\mathrm{C}$ nos $\mathrm{A}$ propris même jetté de familie

L'A ces de ún grai lefquel: $\&$ don douleus froid o uns.

Pren 


\section{DU CASTOR.}

Sel Ammoniac, une dragme \& demie.

ni affis

it dondé deux e foulaiordon-

louleurs es.

urg, une

n, quin-

RomaeSucre,

l'Arabie,

onnicz en llerée au

, avecle ix onces. e terre,

\section{Mêlez ces drogues \& faites-en ufage.}

Le Malade ayant ufé de ces remedes, comme je le lui avois ordonné , fe trouva entierement guéri à fon reveil.

Les Medecins modernes ne font pas les feuls qui ayant employé le Caftoreum dans les maladies des articles, nos Ancêtres qui en connoiffoient les proprietés s'en font auffi fervis dans la même occafion, \& ne l'ont point rejetté des compofitions qui leurs étoient familieres dans ces fortes de maladies.

L'Auteur Anonyme des expériences de Médecine manufcrites, décrit ún grand nombre de médicamens dans lefquels il fait entrer le Caltoreum , \& dont il vante l'efficacité dans lés douleurs des articles, caufées par le froid ou le chaud. En voici quelques uns.

Prenez Onguent Martiatum.

$$
\begin{aligned}
& \text { Aregon, ana demi } \\
& \text { once. }
\end{aligned}
$$

$\mathrm{Hij}$ 
80

\section{T RAIT E'}

Huile de Caftoreum. d'Euphorbe. Petrole. de Geniévre, ana deux dragme. Poudre d'Euphorbe. de Galanga. de Poivre long, ana un fcrupule.

Cire, demi once.

Mêlez toutes ces drogues, pour en faire un onguent.

Prenez Eau de vie, deux livres. Poivre long.

Caftoreum.

Cocognid.

Semence de Roquette.

Graine de Paradis, ana une once deux gros.

Fai livres à la

Mêlez ces drogues, comme cideffus.

Onguent du Docteur Balthafar de Herden, pour les articles.

Prenez de la Racine de Salfepareille, deux onces. de Piretre, une once. 


\section{DU CASTOR. $8 \mathrm{r}$}

Feuilles de Rue. de Sauge. d'Iverte. d'Auronne. de Pouliot. de Primevere. d'Abfinthe. de Germandrée. de Mille-pertuis. de Spica-nard, ana deux poignées.

pour en

res.

Graines de Geniévre, demi poignée.

Girofles.

Canelles.

Galanga, ana demi once.

Faites cuire ces drogues dans quatre livres de bouillon ảe Poule , \& ajoutés à la colature :

ana une

nme cithafar de

Eau de vie.

Vin blanc, ana une livre.

Huile de Tartre.'.

- de Laurier. de Caftor eum. de Vers de terre, ana trois onces. 
Myrrhe choifies.

Aloës Hepatique.

Oliban.

Opopanax.

Bdellium,

Galbanum.

Sel Ammoniac.

Maftic.

Storax calamita liquide , ana demi once.

Laudanum, diffous dans du vin.

Terebenthine, ana dix gros. Gomme Elemi, trois dragmes. de Lierre, deux dragmes.

d'Euphorbe , une dragme.

Graifle de Renard. de Blaireau. d'Oýe. de Poule.

Axonge de Cochon, ana une once.

: Faites bouillir ces drogues jufqu’à confomption de Phumidité \& ajoutés. 


\section{DU CASTOR. Safran, trois dragmes. Cire, quatre onces.}

Mêlez \& faites-en un onguent, comme ci-devant.

On peut ufer de ce mêlange fuivant avec d'autant plus de confiance, que j’en ai éprouvé les effets.

Prenez Eau de magnanimité. Efprit de Vers de terre volatil, ana fix gros.

Sel Ammoniac, trois gros. Effence de Succin, deux

deux

une gros.

de Caftoreum, demi gros. $\&$ demie.

de Pin, une dragme

ix gros.

$s$ drag-

,

n, ana

Mêlez \& donnez-en uñ verre au malade.

Jean Keller, dic Berndein, ordonna le liniment fuivant à Gafpard Burkärd de Klingenftein , qui reffentoit des douleurs vagues aux articles, lefquelles étoient une fuite de l'impureté totale des liqueurs.

jufqu'à ajoutés. 


\section{TRAITE'}

Prenez Onguent Nervin, une once. Huile de Caftoreum. de Mille-pertuis. de Geniévre. Axonge de Chien. de Blaireau. de Chat fauvage. de Cicogne , ana demi once.

Mêlez ces drogues.

Le Docteur Didyme, qui s'eft fervi de l'Arcane fuivant pour appaifer des douleurs violentes aux articulations, nous avertit qu'on ne doit en ufer que dans un extrême befoin, parce qu'il peut rendre les membres immobiles.

Prenez Huile de Camomille. de Gaftoreum:

Lait de femme, ana une once.

Opium, fept grains.

Mêlez ces drogues, \& faires en un liniment.

Il fait beaucoup de cas de l'huile du fils fils Z: dans $c$ donne

Pre:

Met dans u

Geo chhein fuccès Eifeng berg, articul Pret 


\section{DU CASTOR.}

85

fils Zacharie, approuvé par Mefué, dans ces fortes de douteurs, \& il en donne la compofition fuivante.

\section{Prenez Coftus.}

Fuphorbe.

Poivre, ana une once.

Safran, deux gros.

Caftoreum ; demi once. Huile de Camomille. de Vers de terre. de Coftus, ana troisonces. .

'eft fervi aifer des lations, ufer que rce quil obiles.

le. um:

ana une

S.

tes en un

l'huile du fils

Mettez ces drogues en décoction dans un vaiffeau verniffé.

George Renzius, Médecin à Kirchheim, ordonna avec beaucoup de fuccès le remede fuivant à Balthafar Eifengrinius, Confeiller de Würtemberg, qui étoit affligé de douleurs aux articulations.

Prenez Agaric préparé.

Caftoreum.

Maffe de Pilules alumineufes

- de Nicolas, ana un fcrupule. 
86

\section{T R A I T E'}

Mêlez \& faites avec du Syrop do Stæchas des Pilules au nombre de quinze.

Prenez Onguent Aregon.

Huile des Philofophes. de Caftoreum. de Vers de terre. de Renard, ana une once.

Mêlez ces drogues.

On peut mettre dans la claffe des remedes dont nous parlons les Trochiques de Barthelemi Wolfart, qui ne fon pas moins efficaces contre les douleurs de la goute que dans la fupprefion des ordinaires. Il les donne dans une décoction de Baies de Geniévre.

Prenez Amidon fec.

Myrrhe Troglodite.

Noix Mulcade.

Spica-Nard.

Maftic.

Caftoreum.

Storax, ana une dragme.

Gomme Arabique.

Safran, ana demi dragme.

On 1

gues a adraga:

Prer

Faitc tant de lc inala Wol de Pili Krafft la gout pieds $\mathrm{d}$ Jean toreum 'eft pa des fem ntẹ́rieu a fuffo 
Syrop do mbre de

phes.

im.

terre.

, ana une

claffe des $s$ les Troolfart, qui contre les lans la fup. les donne ies de Ge-

lite.

dragme. ue. ni dragme.
DU CASTOR.

On fera des Trochiques de ces drogues avec le mucilage de la Gomme adragant fait avec l'eau de Lavande.

Prenez Gomme Adragant.

Arabique, ana demi

Oliban.

Myrrhe Troglodite.

Amydón.

Caftoreum.

Safran , ana un fcrupule.

Opium d'Egypte.

Faites de ces drogues, en y ajoutant de l'Eau Rofe, trente Pilules, dont le inalade en prendra trois dans la nuit. Wolfart donne à ces Pilules le nom de Pilules Krafft, parce que Louis Krafft s'en fervoit très-fouvent contre la goute en fcarifiant auffi la plante des pieds du malade.

Jean Widmann prétend que le Caftoreum caufe l'avortement, mais cela 'elt pas toujours-vrai , car j'ai connu des femmes enceintes qui l'ont employé ntérieurement \& extérieurement dans a fuffocation de matrice fans s'en

$$
\text { I ij }
$$


88

\section{T R A I T E'}

trouver mal. J'ai auffi connu une fille qui prenoit très-fouvent du Caftoreum par dragmes, dans le deffein d'avorter \& qui a été fruftrée de fon attente.

Ce n'elt pas tant le Caftoreum qui fait avorter les femmes qui en ufent, que les vapeurs virulentes dont l'uterus eft rempli.

Je pole donc pour principe, que le Caftoreum peut bien à la verité caufer cet effet, lorfque les femmes ont de la difpofition à l'avortement ; je veux dire, lorfque les vaiffectux de la .ma* trice font lâches \& que le fortus eft extrêmement foible ; \& qu'au contraire lorfqu'on l'employe comme il faut, il fortifie non-feulement le ton de l'uterus, mais lès met encore à couvert de l'atteinte des maladies. Les bons effets qu'il a produit dans les femmes enceintes aufquelles j'en ai donné dans les affections hyfteriques, prouvent la vérité de ce que j'avance.

\section{A R T IC LE X I X.}

Le Caftoreum eft un remede très-utill dans les maladies de la tête, caufées par des

bumeurs

o de di

Il n'ej

fie, pon

Cenx

tranchée

comme

déliurai

depuis 9

dre $d u$

Un

m'ayant dont il prendre reum, $q$ Les jei grand $u f$ fouvent

Le C contre 1 qu'ils $f$ acres, d'adouci s reum, strès-gr 
une fille ittoreum d'avorter ente.

reum qui n ufent, it l'uterus

je, que le ité caufer ; ont de la je veux le la .ma tus eft excontraire il faut, il in de l'uteà couvert Les bons les femmes donné dans prouvent la

I X.

ede très-utill ancees par des

\section{DU CASTOR.}

89 bumeurs froides, qu'il a la vertu $a^{\text {ta attenuer }}$ \& de diffoudre.

Il n'eft pas moins efficace dans l'Epilepfie, pourvî qu'on l'employe fur le champ. Cevx qui font fujets à la colique \&o aux tranchées, en reçoivent du foulagement, comme l'a éprouvé un Tifferand que je délivrai des douleurs dont il étoit tourmenté depuis quelques jours, en lui faifant prendre du Caftoreum.

Un jeune bomme de vingt-trois ans m'ayant confulté fur une colique violente dont il étoit affligé ; je lui confeillai de prendre pendant quelques jours du Caftoreum, qui le guérit prefque tout-à-fait.

Les jeunes Femmes doivent éviter le trop grand ufage du Caftoreum, car il empêche fouvent la conception \&o caufe la fterilité.

$$
A D D I T I O N \text {. }
$$

Le Caftoreum eft un remede efficace contre les maux de tête, furtout lorfqu'ils font caulés par des humeurs acres, qu'il a la vertu de détourner, d'adoucir \& d'abforber. s. Le Caftosreum, dit Jean Melderus, eft d'une strès-grande utilité dans les maux de

$$
\text { I iij }
$$




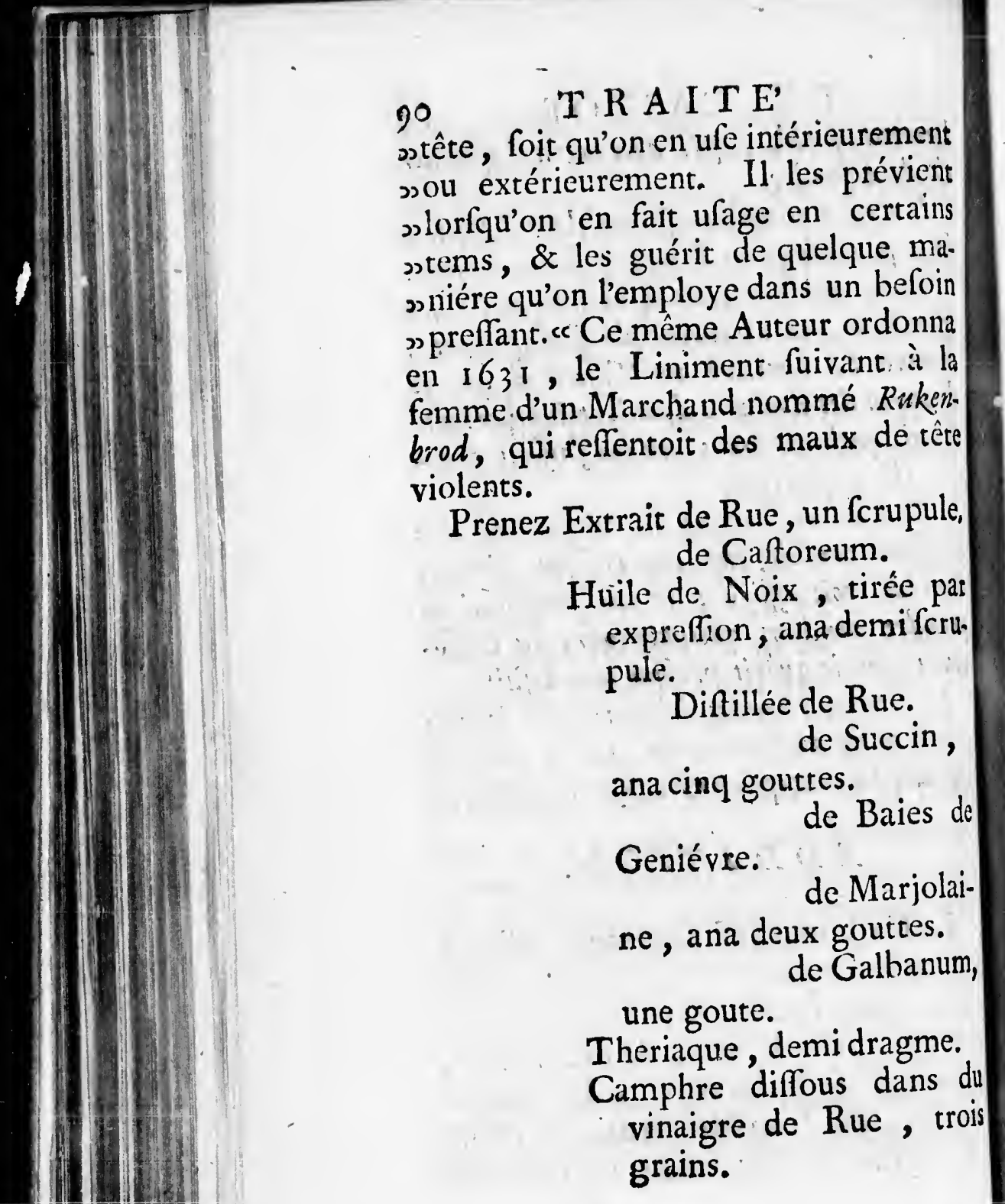

Mề

Linin

Jea 1644 . de têt remec fuite $c$

Pre violents.

Prenez Extrait de Rue, un fcrupule, Huile de Noix , tirée pas expreffion, ana demi fcru. pule.

Diftillée de Rue. de Succin, de Baies de

l'efpri dorée: Jea 1621 des $m$ caufoi au mo

$\operatorname{Pr}$ 
DU CASTOR. $9 \mathrm{r}$

eurement prévient certains elque maun befoin r ordonna vant ì la né Ruken. ux de tête

n fcrupule, eum.

tirée pat demi fcru.

e Rue.

Succin, es.

e Baies de

c Marjolaigouttes. Galbanum,

ii dragme. us dans du Rue, trois
Mêlez ces drogues pour en faire un Liniment.

Jean Scultet guérit le 19 Novembre 1644 . l'Abbeffe de Soflingen, des maux de tête dont elle étoit affligée, avec le remede fuivant, dont elle ufa dans la fuite deux fois par an.

Prenez Extrait d'Agaric.

de Pilules dorées. de Caftoreum, ana un fcrupule.

Magiftere de Mechoacan noir, fept grains.

Huile de Succin, deux gouttes.

On fera de toutes ces drogues avec l'efprit de Matricaire de petites Pilules dorées.

Jean Schappler guérit le 24 Mars I62I , la femme de Jacques Binders, des maux de tête continuels que lui caufoir la fuppreffion de fes ordinaires, au moyen du remede fuivant.

Prenez Pilules cochées. de Caftoreum.

Catholiques deTheoph. Iiiij 


\section{2}

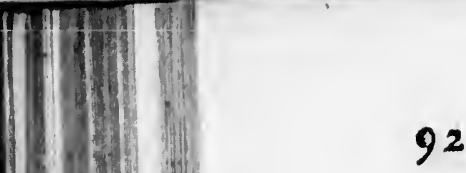

\section{.}




\section{DU CASTOR.}

$1, \operatorname{deux}$

e quan-

prefque point differentes de celles dont nous venons de parler, appaifent entiérement les maux de tête qui proviennent de la mauvaife difpofition de l'Uterus, \& les particules balfamiques \& volatiles du Caftoreum, font qu'on Pilules peut lẹs donner avec le même fuccès aux hommes qui font fujets aux maux de tête. C'eft à elles que la fille unique d'un Sénateur d'Ulm dût fa guérifon, quoiqu'elle n'en eut pris qu'une feule dore.

Prenez Pilules de Succinčzde Craton Caftoreum, du meilleur, ana fix grains.

Réfine de Jalap.

Tartre vitriolé, ana trois grains.

Trochique alhandal, deux grains.

Mêlez ces drogues \& faites-en avec de l'Elixir de propriété des Pilules au nombre de vingt-une.

C'eft par le moyen des Pilules fuivantes que Villengerus, délivra le Baron de Welden, des, violens maux de tête dont il étoit tourmenté.

c de l'eau e grolfeur 


\section{TRA I T E' \\ Prenez Pilules d'Aloes, d'Aquapen- dente, unfcrupule. de Caftoreum , demi fcrupule. Magiftere de racine de Me- choacan noir, dix-huit grains. \\ Huile de Romarin, trois grains.}

Faites de ces drogues avec de l'Efprit Céphalique d'Anhalton complet, des Pilules au nombre de dix-neuf.

Le Caftoreum n'eft pas moins efficace étant appliqué extérieurement fur le front, \& c'eft en l'employant de cette forte que Bloffius délivra en 1649. la fille de Frédéric Ehinger d'un mal de tête qu'elle avoit.

Prenez Eau d'Hirondelles avec du Caftoreum, demi once. Efprit de Muguet.

de Cerifes noires, ana deux dragmes.

Mêlez ces drogues \& faites en ufage. 


\section{DU CASTOR.}

95

juapen-

reum ,

de Melix - huit

, trois

de l'Er:omplet, neuf.

oins effiment fur $t$ de cette 1 649. la mal de

avec du ni once.

noires , hes.

en ufage.

Wedelius applique, dans le cas dont nous parlons, fur le front du malade de l'Efprit de Caftoreum reformé avec l'Eau d'Anhalt. Une femme de condition appellée Sufanne Minfingerin, âgée de cinquante ans, fut attaquée en 1678 , de maux de tête violens, accompagnés de vertiges \& d'uneStupeur des fens, qui ne lui donnoient aucun relâche, \& qui avoient refifté à tous les remedes qu'elle avoit employé. Elle me fit appeller le 27 Août, $\hat{x}$ je fus. affez heureux que de la guérir avec le remede fuivant :

Prenez Eau de Fleurs de Romarin, une once. vin. de Sauge, tirée avec le de Meliffe, tirée avec le vin, ana demi once. Efprits de Muguets. de Cerifes noires, ana deux dragmes.

Effence de Caftoreum, une demic dragme.

Syrop de Stæchas d'Arabie, une demi once. 
96

Mêlez ces drogues \& faites-en uf́lge.

\section{Prenez Extrait de Caftoreum. de Sauge.}

Cinnabre minéral bien préparé, ana un fcrupule. Vitriol de Mars, huit grains. Huile de Lavande. de Camphre, ana deux gouttes.

Mêlez ces drogues \& faites-en des Pilules au nombre de trente-trois.

Nicolas Beringer, Greffier de cette. Ville, ayant été attaqué vers le mois de Juin $\mathrm{I} 575$, de violens maux de têté, Ehinger lui ordonna de fe faire rafer la tête, \& d'en oindre les futures avec le Liniment fuivant :

Prenez Huile de Nenuphar. de Pavots. de Rofes, ana une dragme.

Caftoreum en poudre, une dragme.

Safran; une demie dragme.
On un pe guent gatio dont

Or mêm form fuiva

Pr

O. les ar depu drag la ve

L cont 


\section{DU C A S T O R.}

On mêlera toutes ces drogues avec un peu de Cire pour en faire un onguent, qui précedé d'une légere purgation, procura la guérifon du malade dont nous venons de parler.

On peut encore employer dans les mêmes cas les Pilules de Nicolas, réformées par Jean Stoker, de la maniere fuivante:

Prencz Aloës, quatre dragmes. Myrobolans Citrius.

Chebules.

Embics.

Judiens.

Maftic.

Diagrede.

Cabaret.

Rofe, ana une demi once. Safran, une dragme. Caltoreum, trois dragmes.

On formera de ces drogues des Pilules avec du fuc de Choux. La dofe eft depuis une demie dragme, jufqu'à une dragme \& demie, \& on en a éprouvé -la vertu dans les douleurs invéterées.

Le Caftoreum eft un remede efficace contre l'Apoplexie. Il débaraffe le cerdragme. 
98

\section{T R A I T E'}

veau de tout ce qui peut lui nuire, \& les pores, auffi-bien que l'origine de la moëlle Epiniere des particules groffieres qui y caufent des obftructions, \& rétablit le ton des parties, ainfi que l'expérience le prouve.

Wolfart fit revenir un homme d'un accident d'apoplexie dans lequel il étoit tombé en lui faifant fleurer le mêlange fuivant :

\section{Prenez Huile de Caftoreum, une once. \\ Vitriol, deux dragmes. Mêlez ces drogues.}

Une femme qui étoit mariée depuis environ un an, après avoir fenti pendant trois femaines des vapeurs froides qui fe portoient vers le côté gauche, tomba tout d'un coup en pamoifon plumant des Aloüetres, fon mari l'ayant relevée elle fe coucha fur la tête, fe plaignit d'un vertige \& d'un tremblement dans le bras gauche, le mari lui donna du vin ; ce qui ne l'empêcha pas d'être attaquée peu de tems après du même accident. 
Les amies qu'elle avoit fait appeller prenant cet accident pour une fuffocation de matrice, fe fervirent dans un befoin auffi preflant de tout ce qu'elles purent imaginer, de papier brouillard, de Caftoreum, de Succin allumé, de plumes de Perdrix, de Vin \& autres chofes femblables ; mais fans aucun fuccès. Cependant comme la malade alloit toujours de mal en pis, l'on me fit appeller vers le minuit. Je la trouvai paralyeique d'un bras \& d'une jambe, ne reffentant aucune douleur, balbutiant un peu, uniquement incommodée d'une perte involontaire d'urine.

Le froid, ce qui mérite d'être ree depuis nti pens froides gauche, samoifon on mari a fur la \& d'un che, le ne l'emde tems marqué, s'étoit tellement emparé du côté gauche, qu'elle vouloit qu'on le lui coupât, comme une partie morte $\&$ qui ne lui appartenoit plus.

Je ne voulus point qu'un autre Médecin qu'on vouloit appeller partagea avec moi une cure, du fuccès de laquelle je l'affurai , \& fans employer les lavemens, la faignée, les cautéres \& les ventoufes, qu'on employe communément en pareil cas; je me fervis de Pilules, d'infulions nervines, \& d'un 


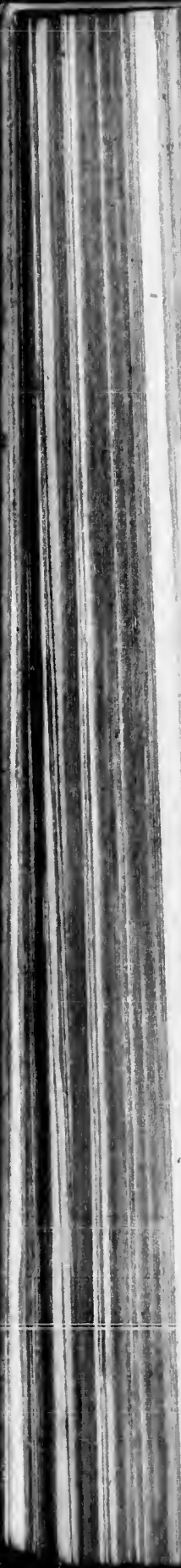

\section{TRAITE'}

100 onguent fingulier, avec tant de fuccès, qu'au bout de trois femaines la malade commença à remuer fes doigts les uns après les autres, affez doucement à la verité, \& qu'elle fut en étar de vaquer à fes affaires au bout de huit femaines.

L'on trouvera ce fait rapporté avec toutes fes circonftances dans la Pratique Clinique, que je compte mettre bientôt au jour.

De tous les remedes que j'employai au foulagement de la malade, l'onguent fuivant fut le plus efficace.

Prenez Graiffe de. Chien. de Chat fauvage, ana une once.

d'Homme. de Caftor. de Vers de terre, ana demi once $r$

Huile de Laurier.

d'Euphorbes.

de Fourmis, ana deux dragmes.

de Geniévre, une demi once.

Diftillé de Spica d'Italie, 


\section{DU CASTOR. IOI}

fuccès, malade $s$ les uns ient à la e vaquer naines. orté avec Pratique tre bienemployai l'onguent

vage, ana terre, and

S.

, ana deux

e, une deSpica d'Italie,
Mêlez ces drogues.

talie, demi dragme. de Sauge, un fcrupule.

Sebaftien Stromaier, eut auffile bonheur de guérir de la maniere fuivante, un Tifferand nommé Jean Bucher, qui étoit tombé en apoplexie.

Prenez Theriaque d'Andromachus, deux fcrupules.

Extrait de Caftoreum, demi fcrupule.

Huile diftillée d'Anis, quatre gouttes.
de Girofles, deux gouttes.

Mêlez ces drogues, \& faites en un liniment pour la langue.

Prenez Galement.

Origan.

Marjolaine.

Rue.

Sauge, ana une poignée.

Semence de Carvi. de Fenouil.

K 

un nouet, une dragme. Ellebore blanc, une dragme.

Faites boullir ces drogues dans l'eau commune jufqu'à la diminution des deux tiers.

Prenez Une livre de Colature, ajoutez-y Electuaire benedicto laxative.

Diaphænic.

Diacolocinthidos, ana deux dragmes. Miel anacardin.

Huile de Caftoreum, ana une once.

Sel gemme, une dragme. Faites un lavement.

Prenez Conferve de Romarin. de Sauge. de Marjolaine,ana une once.

Caftoreuin préparé, un fcrlpule.

Huile de Girofles, quatre gouttes. 


\section{DU CASTOR. 103}

Efprit de Cerifes noires, deux dragmes.

Miel de Komain, une quantité fuffifante.

Faites un Electuaire, dont on prendra la groffeur d'une Châtaigne, le plus fouvent que l'on pourra. Le Docteur Michael ordonne le clyftere fuivant.

Prenez Feuilles de Rue.

d'Origan. de Romarin. de Cabaret.

Fleurs de Stæchas d'Arabie. de petite Centaurée. de Muguets, ana une poignée.

nænic.

olocinthi-

ragmes.

um, ana

Iragme.

Racine d'Ariftoloche ronde. d'Impératoire. de Pirethre, una demi once.

Agaric blanc, une dragme $\&$ demie.

Semence de Cartame, dans un nouet, fix dragmes.

Pulpe de Coloquinte, dans un nouet, un fcrupule.

$\mathrm{K}$ ij 


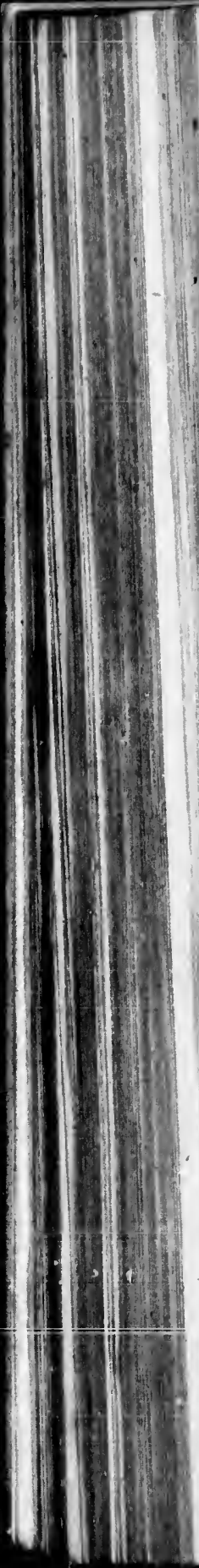

104

\section{T R A I T E'}

Mettez toutes ces drogues en décoction dans une quantité fuffifante d'eau compofée, coulez. Prenez huit onces de Colature, dans laquelle vous ferez diffoudre Electuaire Hiere-picre, avec 1'Agaric, Benedicta Laxativa, ana demi once. Suc de Rue épaiffi, demi dragme. Extrait de Caftoreum fix grains. Faites un lavement. Il donne après l'accès les Pilules fuivantes, dans lefquelles il fait entrer le Caftoreum.

Prenez Extrait Diacarthami, un fcrupule.

Trochique Alhandal , deux grains.

Cafţoreum, trois grains.

Mêlez ces drogues avec de l'huile de Marjolaine, pour en faire des Pilules.

Le Lecteur ne fera pas fâché de trouver ici la compofition de l'Emplâste Céphalique de Wedelius.

Prenez Cerat Céphalique, une once. Caftoreurn.

Styrax liquide, ana demi dragme. 


\section{DU CASTOR. 105}

décoc-

e d'eau inces de rez difavec

a , ana

i, demi eum fix 1 donne es, dans reum.

ni , un

, deux

rains.

l'huile de Pilules. fâché de '́Emplâ-

une once. ana demi
Encens.

Gomme de Geniévre, ana un fcrupule.

Malaxez avec l'huile Rofat, en quantité fuffifante.

L'Onguent que Chriftophe Cellarius ordonna à un Payfan de Degersheim, qui avoit eu une attaque d'apoplexie, n’eft point du tout à méprifer.

Prenez Onguent Aregon. de Mars, ana une once. once. d'Agrippa , demi Huile de Coftus,

de Renard, ana demi dragme.

de Rue.

de Vers de terre, ana demi once.

de Caftoreum, demi dragme.

Poudre de petite Sauge. de Romarin. de Betoine. de Poivre, ana un fcrupule. 

demi fcrupule.

Racine d'Acorus, deux fcru= pules.

Cire, autant qu'il en faut pour un onguent.

Bloffius fecourut un Apoplétique avec le Cataplafme fuivant.

Prenez Vieux Levain, une once \& demie.

Ambre jaune, trois dragmes. Noix Mufcades.

Cubebes, ana demi dragme. Mente frifée.

Girofles, ana un fcrupule.

Caftoreum.

Bois d'Aloës véritable, ana demi fcrupule.

Mêlez ces drogues \& donnez leur la forme de Cataplafme avec l'efprit Céphalique d'Anhalt \& le Vinaigre.

Jacques Zæmann, guérit l'Enfant d'un des premiers Commerçans de

cette $\mathrm{V}$ ques vi en lui a un Cata Caftore avec d Docter fuivant

Prer

Met dans ur mune. $\&$ ajou Hieregrains $\&$ faite Jean extraor moins d'en fa. 


\section{DU CASTOR.}

cette Ville, de Convulfions Epileptiana

ux fcrue

en faut

plétique ques violentes, aufquelles il étoit fujet, en lui appliquant fur la plante des pieds un Cataplafme d'eau d'Hirondelles, de Caftoreum, ana une once \& demie, avec de la Rue nouvelle pilée. Lé Docteur Michael fe fervit du lavement. fuivant avec un pareil fuccès.

Prenez Fleurs de. Tilleul. de Muguets, ana

once \&

dragmes.

dragme. rupule.

able, ana

nnez leur ec l'efprit inaigre.

t l'Enfant erçans de trois pincées.

Racine de Pivoine, trois dragmes.

Feuilles de Senné, deux dragnes.

Mettez ces drogues en décoction dans une quantité fuffifante d'eau commune. Prenez trois onces de Colature \& ajoutez-y trois dragmes d'Electuaire Hiere-Picre avec l'Agaric, \& quatre grains d'extrait de Caftoreum. Mêlez $\&$ faites un Lavement.

Jean Stokerus fait mention d'une cure extraordinaire que je vais rapporter, moins dans le deffein de l'admirer que d'en faire voir le ridicule. Voici fes 


\section{DU CASTOR.}

de Bouraché \& de Buglofe, une demie livre, de la Mufcade \& de la Canelle, ana deux dragmes.

Le même Auteur ordonna, avec beaucoup de fuccès, la poudre fuivante à un homme $\&$ deux femmes fujettes à l'épilepfre, après avoir auparavant employé les remedes généraux.

Prenez deux jeures Corbeaux du mois de Mars, renfermez les dans un pot qui 'n'aît point encore fervi, faitesles brûler jufqu'à ce qu'ils foient réduits en cendres, \& donnez en deux ou trois fois la fémaine âu malade dans du vin dans lequel on aura 'mís du Caftoreum en décócetion.

périences

ffers adcheffe de prie. En

ombre de

L'eau d'Hirondelles fuivante, qui eft dela compofition de Stupan, eft encore un remede admirable dans les convulfron épileptiquies a da que prétend cet Auteur.

Prenez des Fleurs de Muguets, une livre.

fufer pendes. Fleurs de

de Pivoine. de Lavande. L 


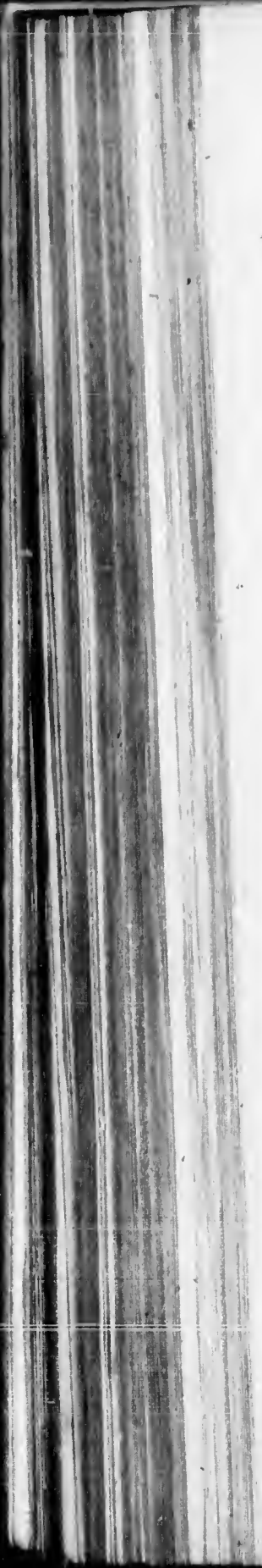

110

TRAITE'

de Betoine.

de Tilleul.

de Chicorée.

de Bouitlon blanc.

d'Oeillets.

Sommités de toutes les efpeces de Meliffes, fechées à l'ombre, ana deux onces.

du vir enfuite

Racines de; Pivoine. d'Aunée. de Distame. d'Ariftoloche lon-

gue.

d'Angelique a a demi once. de Chicoree, ana une once.

Guy de Chêne dix dragmes: Canelle, fix dragmes.

Caftoreum une once.

Strechas d'Arabie, ffx drag. mes.

Racine de Pirethre. de Souchet blanc; ana cing gros. Semence de Pivoine mon-

On bouteil

Seba enfans décoct garanti yoit $\mathrm{m}$ effet. C dela $\mathrm{R}$ la Betc Nou pece d Une 


\section{DU CASTOR.}

dée, deux onces.

C. B. une once.

Cubebes.

Poivre long, ana une once.

les efpechées à onces.

he lon:

ie

nRoland. ée, ana

dragmes: mes.

ince.

fix drag:

e.

t blanc;

oine mon-
Mettez ces drogues en infufon dans du vin de Malvoifie, \& ajoutez-y enfuite,

de la Theriaque vieille excellente, quatre onces. du Mithridate, deux onces. Trochifque de Viperes, trois dragmes.

On gardera cette infufion dans une bouteille bien bouchée.

Sebaftien Blofluus faifoit prendre aux enfans nouvellement nés, un bain d'une décoction de Caftoreum , pour les garantir de l'épilepfie, ce qui ne pouyoit manquer de produire un très-bon effet. On peut y ajouter, fi l'on veut, de la Racine de Pivoine, de la Rue, de la Betoine, de la Sauge, \&c.

Nous parlerons ailleurs de cette efpece dẹ Bain.

Une femme de ce pais âgée d'un $L$ ij 


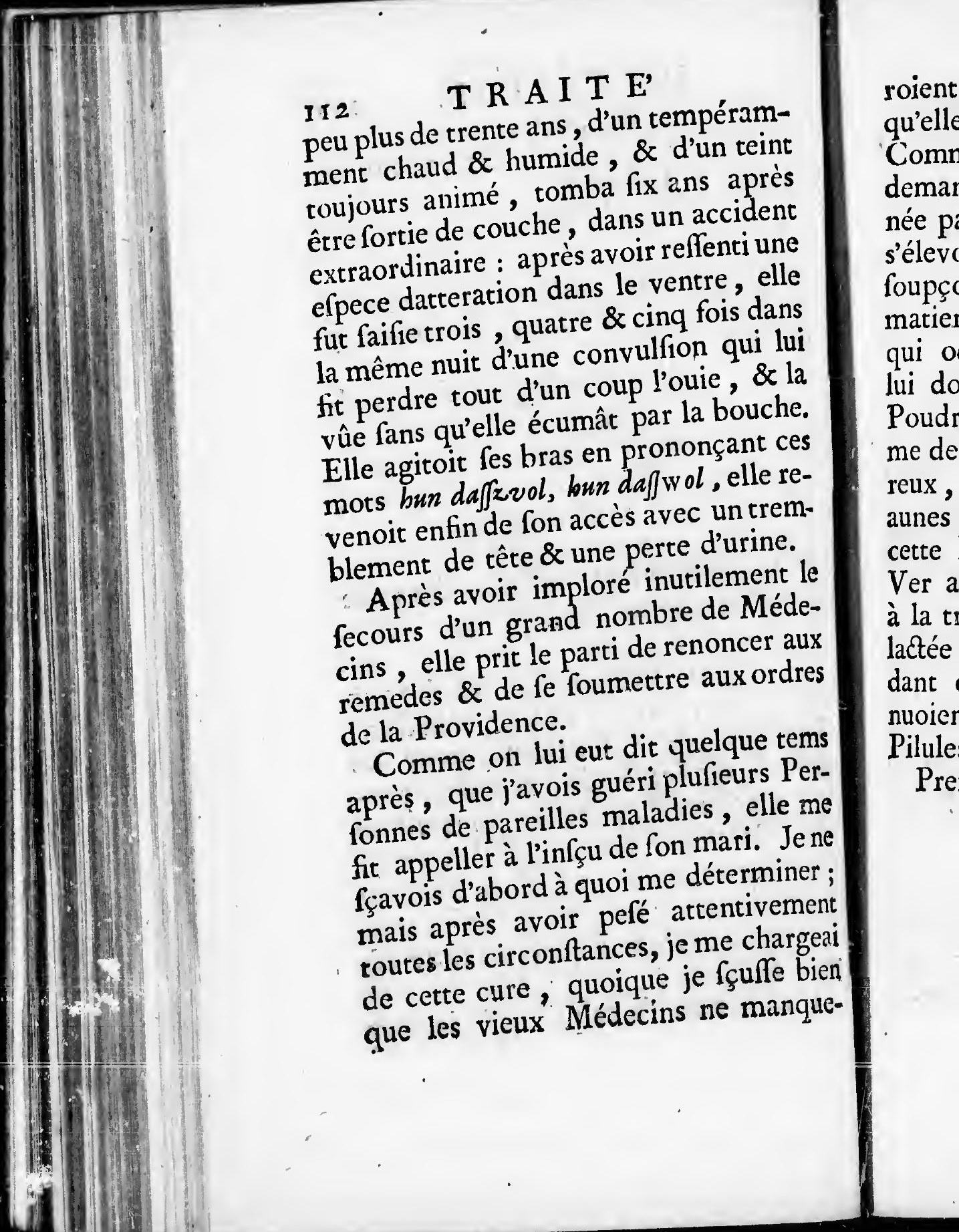




\section{DU CASTOR.}

113

roient pas de me blâmer, fuppofé qu'elle n'eut pas un heureux fuccès. Comme la malade fentoit une grande demangeaifon dans le nez, occafionnée par des vapeurs mordicantes qui s'élevoient des parties inférieures, je foupçonnai qu'il pouvoit y avoir une matiere vermineufe dans les inteftins qui occafionnoit ces fymptômes. Je lui donnai donc pour l'évacuer une Poudre purgative de Gialap, de Crêmede. Tartre, de Dyagrede fulphureux, qui lui fít rendre un Ver de deux aunes de long. A la leconde dole de cette Poudre, elle rendit un fecond Ver avec plufieurs de fes particules; à la troifiéme elle rendit une-matiere lactée, mais fans aucun Ver. Cependant comme les fymptômes continuoient toujours, je lui ordonnai les Pilules fuivantes.

Prenez du Cinnabre minéral, préparé felon l'art. de l'Extrait de Sauge, ana demi fcrupule. de Romarin. feize grains. de Pivoine, ana L iij

lque tems ieurs Per, elle me nari. Je ne terminer ; entivement ne chargeai fçuffe bien e manque-

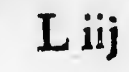




\section{T R A I T E'}

de Muguets.

de Caftoreum,

ana fix grains.

Pilules de Succin, demi fcrupule.

Laud. Opiat. un grain \& demi.

Huile de Fleurs de Romarin diftillée.

de Succin, ana deux gouttes. de Cubebes,

une goutte.

Mêlez ces drogues, \& faites-en des Pilules avec de l'efprit de Noifettes.

La Cure réuffit comme je l'avois efperé , \& les fymptômes cefferent pour la plus grande partie. Je lui ordonnai pour les diffiper entiérement le mêlange fuivant, dont elle ufa tous les matins, \& qui la guérirent tout-à-fait. Je lui confeillai cependant d'aller prendre les eaux.

Jean Keller, dit Berndein, ordonna le 2 i de Juillet 1607 , à la fille d'Albert Schleicher, la compofition fuivante, comme un préfervatif contre l'épilepfie. 


\section{DU CASTOR.}

Prenez Huile de Rue.

uets.

oreum,

mi fcru-

grain \&

Romarin

uccin

Jubebes,

es-en des

ifettes.

je l'avois cefferent Je lui orrement le fa tous les ut-à-fait. aller pren, ordonna fille d'Alfition fuiatif contre de Vers de terre. de Laurier. de Caftoreum, ana trois dragmes.

Mêlez toutes ces drogues, avec quelque peu d'eau de vie.

Le Frere Benoît Miller, guérit un garçon de quinze ans, qui ćtoit fujer à l'épilepfie, avec la poudre fuivante.

Prenez de la grande Berce. du Caftoreum. du Sang de Dragon.

Corne de Cerf brûlée, ana fept grains.

Os de cocur de Cerf, trois grains.

Ongle d'Elan calcinée, huit grains.

Guy de Chêne, vingt grains. Crâne humain antérieur.

Fraxinelle, ana vingt grains. Fleurs de Mille-pertuis. de Lavande.

Racine de Tormentille, ana quatré grains.

L iiij 

ana deux grains \& demi. Stæchas Arabique.

Perles préparées, ana vingtcinq grains.

Feuilles d'or très-fin, als nombre de trois.

Réduifez toutes ces drogues en poudre.

Jean Fuchfius avoit une fille âgée de 19 ans, qui étoit très-fujette à l'Epilepfie, \& qui à l'approche de l'accès, étoit faifie d'une douleur d'eftomac \& d'une difficulté de refpirer, fes mois étant d'ailleurs très-reglés. Le Pere m'ayant confulté le 9 OAtobre I 679 , je lui ordonnai les remedes fuivans qui produifirent un fi bon effet, qu'elle n'a jamais reffenti depuis la moindre atteinte de ce mal.

Prenez Crâne humain, une dragme. Guy de Noifettier.

Caftoreum préparé.

Ongle d'Elan préparé.

Cinnabre minéral préparé, ana demi dragme. Vitriol de Mars, huit gout-

M poud J'a perfo plus 1 mala tion tes. 


\section{DU CASTOR.}

Pivoine demi.

a vingt-

in, au

gues en

ille âgée te à l'El'accès, tomac \& nois étant m'ayant , je lui qui proelle n'a jare atteinte e dragme.

é.

saré.

préparé, ne.

huit gout-
Laud. opiat. deux grains. Huile de Marjolaine. de Lavande, ana deux gouttes.

Mêlez ces drogues \& réduifez-les en poudre.

Prenez Eau de Pivoine.

de Fleurs de Tilleul. de Rue , ana une once \& demie.

Epilepf. de Langius. d'Hirondelles avec du Caftoreum, ana demi once.

Efprit Corylin, demi dragme.

de Sel Ammoniac, demi fcrupule.

Syrop de Betoine, demionce.

Mêlez ces drogues \& réduiiez-les en poudre.

J'ai vu l'eferet de ces remedes fur cing perfonnes de ma connoiflance qui n'ont plus reffenti la moindre atteinte de cette maladie jufqu'aujourd'hui.

On trouve dans Mezger la compofition des fuppofitoires fuivans. 


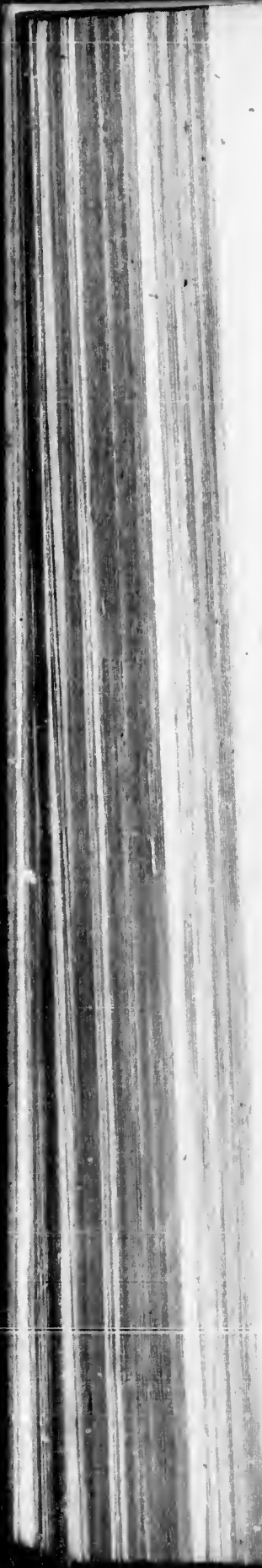

118

\section{T R A I T E -}

Prenez Electuaire Hiere-Picre.

Crottes de Souris, ana une dragme.

Fiel de Bœuf épaiffi, demi dragme.

Miel Anthofat, une quantiéé fuffifante.

On en fera un fuppoítoire que l'on oindra avec de l'huile de Rue \& de Caftoreum.

Il n'eft rien de meilleur contre la colique que les remedes, \& fur tout les lavemens dans lefquels ón fait entrer le Caitoreum, qui ont la vertu de chalfer des inteftins les matieres qui les picottent. Celui qui fuit eft de la compofition du Docteur Michael.

Prenez Fleurs de Camomille Romaine.

Sommités d'Aneth.

Mercuriale, ana une poignée.

Baies de Laurier, fix drag- mes.

Racine de Zédoạire, une once.

Met une qu

Pre laquel Baies Caftor Rue neth, clyfter comp

Pre

Mê

$\mathrm{Da}$ $18 \mathrm{Ar}$ fur $\mathrm{d}$ 


\section{DU CASTOR.}

cre.

ana une

i, demi

quántité

que l'on ue $\&$ de

contre la ur tout les entrer le de chais qui les e la com-

nille Ro-

une poi-

fix dragaire, une
I 19

Ecorce d'Orange, demionce.

Semence de Cumin.

Carvi.

d'Aneth, ana

une dragme \& demie.

Mettez ces drogues en coction dans une quantité d'eau fuffifante.

Prenez de Colature une livre dans laquelle vous ferez diffoudre Elect. de Baies de Laurier, une once $\&$ demie, Caftoreum demie dragme, Huile de Rue diftillée, de Camomille, d'Aneth, ana quatre gouttes : Faites-en un clyftere. Harderus fait grand cas de la compofition fuivante.

Prenez Succi morfi gallin; deux dragmes.

Caftoreum, deux fcrupules. Vin d'Efpagne.

Eau diftillée de Menthe, ana demi-once.

Mêlez ces drogues.

David Mindler ayant confulté , le 18 Août 1671. le Docteur Eckold, fur des douleurs qu'il reffentoit dans 
l'eftomac, \& dans le dos, jointes à une conftipation de deux jours, \& à des naufées, il lui ordonna le remede fuivant.

Prenez de la Manne. de la Mauve.

Mercuriale. Melilot.

Camomille, ana demi poignée.

Graine de Lin. de Senegré, ana une once.

Figues, au nombre de fix. Fleurs de Melilot, trois pincées. Mettez ces drogues en coction, dans une quantité d'eau fuffifante.

Prenez Colature, une livre.

Electuaire benedicte laxative.

Diaphenic.

Huile de Lys.

Caftoreum, ana une once. Sel foffile, quelque peu.

Mêlez toutes ces drogues pour en faire un lavement. 


\section{DU CASTOR.}

es à une

à des ede fui-

demi

ana une

de fix.

, trois

n, dans

te laxa-

e once.

peu.

pour en
Prenez Huile de Camomille.

mes.

Laurier.

Caftoreum, ana une once.

Geniévre, trois drag-

Mêlez ces drogues, \& oignez-en la partie affligée.

Jacques Zæemann, ordonna en 1644 le remede fuivant, au fils de Louis Schmid, qui fouffroit de la colique.

Prenez Huile de Lys.

Camomille, ana une once.

Caftoreum, demi-once.

Mêlez ces drogues \& faites-en ufage.

Plufieurs Perfonnes qui avoient la même incommodité, en ont été délivrées par le mêlange fuivant.

Prenez Eau de Menthe.

Vin de Malvoifie, ana une once.

Effence de Caftoreum, vingt-fix gouttes.

Huile d'Anis impregnée de 
122

\section{TR A ITE'}

fucre, quatre gouttes. Syrop de Menthe, demi- once.

\section{Mêlez ces drogues.}

Un grand nombre de Perfonnes ont été heureufement délivrées de la colique, en prenant quelques gouttes $\mathrm{du}$ mêlange fuivant.

Prenez Efprit de Tartre, quinze gouttes.

de Camomille rom. une dragme.

Effence de Caftoreum, demi dragme.

Mêlez ces drogues \& faites-en ufage.

Prenez de l'Eau carminative R. deux onces.

Contre les douleurs M. Ord, une once.

Extrait de Caftoreur. 1, trois grains.

Syrop de Menthe, demionce.

Mêlez ces drogues.
J'ai , dition, au mo

Pre:

Mề Pilule:

Un Schefo differe coliqu ordon fa ent toit,

$\mathrm{Pr}$

$M$ 


\section{DU C ASTOR.}

$123:$

J'ai connu un homme de baffe con-

es.

demi-

ines ont

la coliuttes du

quinze

lle rom.

Im, demi

en ufage.

ative $R$.

douleurs ce.

ur. 1 , trois

, demi- dition, qui a été guéri de la colique au moyen des Pilules fuivantes.

Prenez Extrait de Caftoreum, trois grains.

Laud. Opiat. un grain.

Huile d'Anis , une goutte.

Mêlez ces drogues \& faites-en des Pilules, au nombre de quatre.

Un de mes Parens appellé Michel Schefolt, ayant inutilement employé differens remedes contre une violente colique qui le tourmentoit, je lui ordonnai le remede fuivant, qui appaifa entiérement les douleurs qu'il reffentoit, au bout de deux heures.

Prenez Eau contre les douleurs. M. Ord. une once.

- Huile de Cumin impregnée de fucre, fix gouttes. Effence de Caftoreum, trois gouttes. Syrop de Menthe , demionce.

Mêlez ces drogues. 


$$
\rightarrow
$$




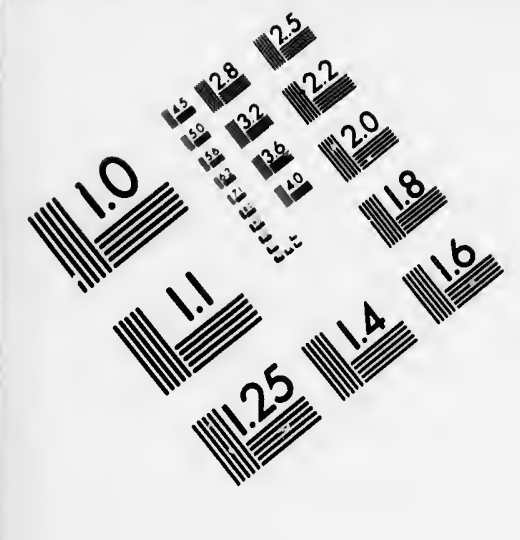

IMAGE EVALUATION

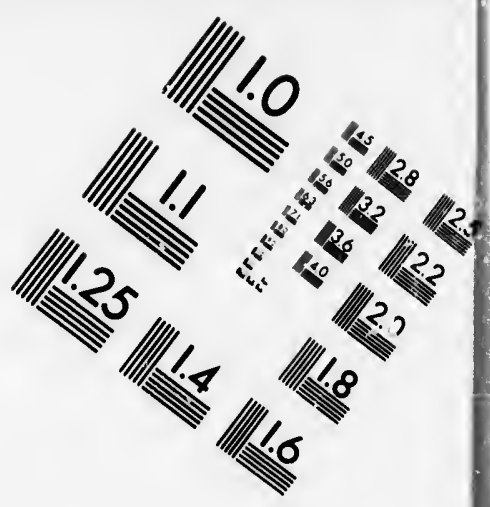

TEST TARGET (MT-3)
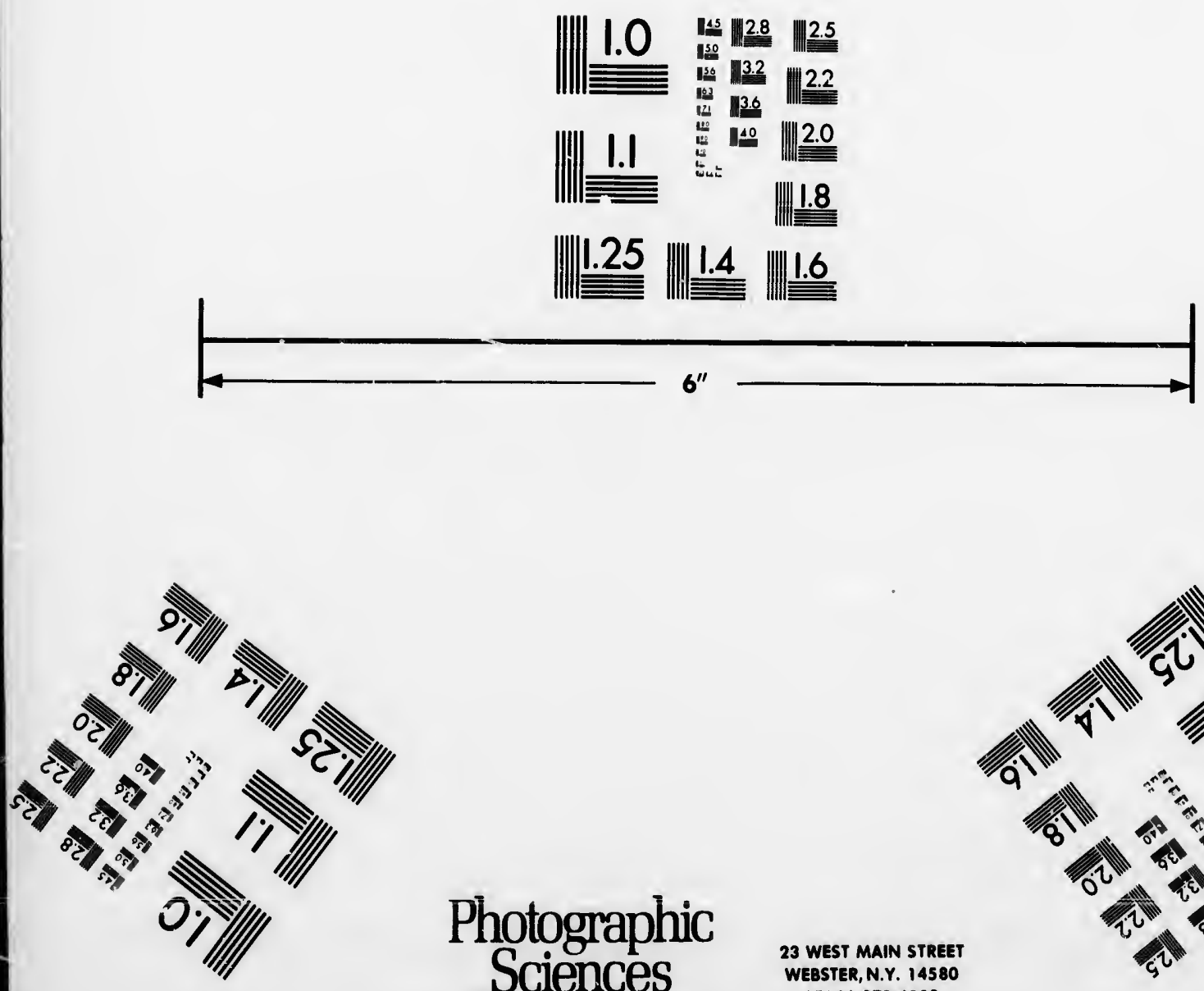

Photographic Sciences Corporation

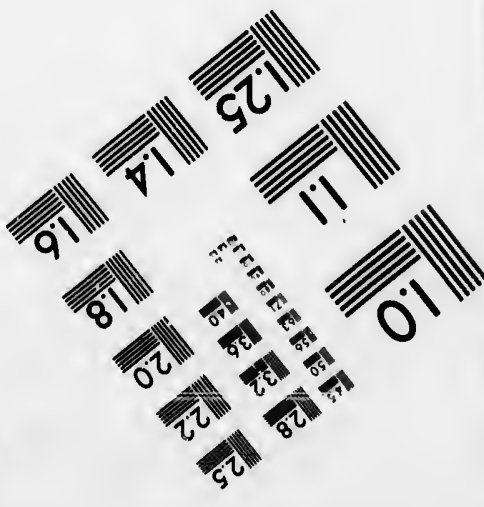




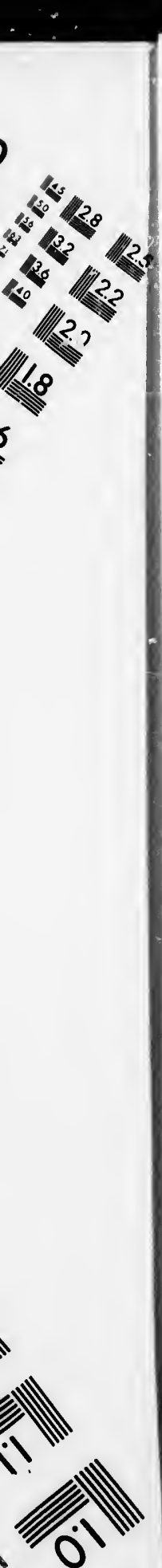




\section{T R A I T E}

124 Poudre fuivante prife dans du, vir, a guéri un de mes Compatriottes d'une colique violente \& continuelle.

Prenez Caftoreum ,' demi fcrupule. Poudre d'écorce d'Oranges. ins de Graines de Cumin, ana un forupule.

Mêlez ces drogues.

Mon efprit Phyfogone, que je mêle quelquefois avec d'autres drogues, ne laiffe pas d'avoir fon utilité étant pris tout feul dans du vin.

Prenez Racine d'Impératbire, trois' onces.

de Zedoaire, une once.

d'Angelique, demionce.

Feuilles de Menthe velue. de Rue. de Vérónique.

Sommités de Camomille , ana quatre poignées. Semence de Pimprenelle. d'Anis. 
DU CASTOR.

de Cumin.

dans du. apatriotconti-

Ccrupule. Oranges. de $\mathrm{Cu}$ pule.

ie.je mêle gues, ne tant pris ire, trois , une e, demivelue.

ue. nomille , nées. enelle. de de Sefame.

Ecorce de Coftus. d'Oranges.

Caftoreum, ana une once. Canelle acut. deux onces. Baies de Laurier, une once $\&$ demie.

Mêlez \& écrafez toutes ces drogues: $\&$ les mettez en digeftion pendant quelques femaines, dans une quantité fuffifante de yin, prenez enfuite la partie la plus fubtile \& gardez-la pour l'ufage.

On a vu ci-devant que le Caftoreum caufoit la fterilité, mais ce n'eft que par l'excès qu'on en fait, comme je l'ai prouvé dans une Differtation fur la fterilité des femmes. D'ailleurs fon odeur n'eft point affez agréable, pour les engager à en faire un trop grand ufage.

\section{ARTICLE XX.}

Le Caftoreum eft un remede efficace contre le mal de dents, parce quiil diffipe la matiere morbifique, vifcide of catbar.

M 


\section{T R A I T E'}

reufe qui le caufe. Je confeille donc aux perfonnes qui y font fujettes d'en faire. ufage.

$$
A D D I T I O N \text {. }
$$

On peut mettre l'Odontalgie au nombre, \& même au-deffus des douleurs les plus cruelles, elle jette dans le defefpoir ceux qui y font fujets, elle n'épargne aucun âge, \& eft fi fréquente qu'on pourroit la regarder avec raifon c mme une maladie épidémique \& héréditaire. Perfonne n'ignore combien l'homme \& la femme peuvent contribuer à la naiffance \& à la propagation de cette douleur, lorfque l'un \& l'autre $y$ font fujets. L'influence des Aftres y contribue aufi, comme. Wedelius le prouve dans fes Thematologies manufcrites.

* On fait beaucoüp de cas de l'Eau contre les douleurs des Dents, dont on trouve la compofition fuivante dans Schupplerus.

Prenez Racine de Piffenlit. (x) dragmes.

de Dictame. 


\section{DU CASTOR.}

Ecorce de Raifort.

donc aux d'en faire

talgie au $s$ des doujette dans ujets, elle if réquente ivec raifon émique \& e combien ent contriropagation n \& l'autre es Aftresy Vedelius le ies manuf-

is de l'Eau ents, dont ivante dans

lit.

re, ana deux

me.
d'Acacia.

de Pin, ana demi dragme.

Caftoreum. Maftic, ana demi fcrupule. Girofles, au nombre de trois.

Coupez'\& pilez ces drogues, \& les mettez en infufión pendant the nuit, dans du vin rouge, d'eau de Morelle? ana cinq onces. Le lendemain matin après le premier bouillon, prenez de la Colature huit onces, Diámoron deux onces 'mêlez le tout \& le confervez dans une phiole bien bonchée, pour vous en laver la bduche le plus fouvent que vous pourrez, après avoir fait chauffer ce mélange.

L'Auteur Anonyme des Expériences de Médecine, a guéri "en peu de tems plufieurs Perfonnes, qui avoient des doüleurs de dents viblentes, avec les Trochiques fuivans.

Prenez Poivre blanc.

Semence de Jufquiame, ana une dragme.

$M$ ij 
Opium, demi dragme. Safran, demi fcrupule. Lavande, trois grains. Pirethre.

Caftoreum, ana demi fcrupule.

Mêlez ces drogues, avec du Miel écumé, pour en faire de petits Trochiques.

Simpert Linfus, Médeçin à Memmingen, prétend que le vin dans lequel on a mis de la Racine de Pirethre \& du Caftoreum en décoction, appaife le mal de dents.

Didyme a éprouvé la vertu des Pilules fuivantes dans les douleurs que caufent les Dents cariées.

\section{Prenez du Meilleur Ladanum. du Caftoreum. delOpium, ana trois grains.}

Faites-en des Pilules, dont on en mettra une fur la dent cariée. L'Emplâtre fuivant dont cet Auteur donne la defcription n'eft pas moins efficace.

Prenez Poudre de Melilot. 
me.

ale.

ins.

mi fcru-

du Miel rits Tro-

à Memans lequel thre \& du ippaife le des Piluleurs que

num.

o

ont on en e. L'Emeur donne is efficace.

\section{DU CASTOR.} dragmes. d'Origan, ana deux

Caftoreum, demi dragme. Thériaque, cinq dragmes.

Faites-en une Pâte, avec du fort Vinaigre, \& l'appliquez fur le côté affligé.

J'ai guéri des douleurs de dents violentes avec le Baume dental fuivant.

Prenez Huile del Scoto, deux dragmes. de Nicotiane. de Caftoreum. d'Opium d'Egypte , ana un ferupule. Extrait de Bois de Giaiac. de Sauge, ana autant qu'il en faut.

Mêlez ces drogues, \& faires-en un Baume, dont vous oindrez la gencive affligée.

$$
\text { A R I I L XXI. }
$$

Le Caforeum remedie aux cbûtes du fondement, comme l'a éprouré une femme 
130

\section{T R A I T E'}

à qui une conftipation trop. opiniatre avoit cause'e cet accident. Un Profeffeur fort. connu n'employoit point d'aútre remede que celui-là, ¿ơ s'en trouvoit cxtrêmement foulagé.

$$
A D D I T I O N \text {. }
$$

Po

Les chûtes de fondement peuvent avoir plufieurs caufes, mais les principales font un tres-grand effort, le froid, la lubricité , \& une chûte violente. Rien n'eft meilleur dans tous ces cas que les remedes dans lequel il entre du Caftoreum, parce qu'ils refferrent, échauffent \& fortifient les nerfs \& les mufcles, qui après la fortie des excré. mens fervent à remettre, l'anus dans $f_{2}$ place. Wolfart, guérit en 1570 Simon Eilberg, Miniftre à Junginfen, d'une pareille incommodité, en humectant la partie avec une décoction de Tormentille, de Sumac, \& de Semence de Plantain, \& la Saupoudrant enfuite avec la Poudre fuivante:

\section{Prenez Pierre Ponce. Myrthe, åna une dragme. Câftoreum.}




\section{DU CASTOR.}

iniâtre avoit rofeffeur fort e remede que cxtrêmement

$N$

Baume de Judée, ana demi dragme.

Capul.glandium, demi fcrupule.

Mêlez ces drogues \& faites-en une Poudre.

Cette maladie ( la Dyfenterie) dit. Frederic Fuchfius, eft fuivie d'une autre incommodité, fçavoir de la chûte du fondement, qui caufe de trèsgrandes douleurs; on peut cependant y remedier par le fecours de la Chirurgie , \& du liniment fuivant.

Prenez Bol d'Armenie.

Plomb brûlé.

Caftoreum.

Myrthe.

Tutie, ana deux dragmes.

Huile de Myrthe, demionce.

Suc de Plantain.

Vin rouge, ana demi-once.

Faites bouillir ces drogues jufqu'à ce que le fuc \& le vin foient confommés, $\&$ ajoutez à la colature une quantité fuffifante de Cire. Reduifez le refte en 


\section{2}

\section{TRA IT E}

Poudre \& faites-en un onguent dans un mortier de plomb.

Il n'eft point de remede plus efficace dans la chûte du fondement que lo Caftoreum diffous dans du Vinaigre, que l'on applique tout chaud avec une éponge fur la partie aftligée, comme nous en affure Laurent 'Gadtier Kuchelius.

Marius nous affure que la femme de Sigifmond Biekhard, qui fouffroit d'une pareiile incommodité , en fut délivirée par le remedefuivant, \& qu'elle nes'en eft plus reffentie.

Prenez Huile de Myrthe, une once. Noix de Galles concaflées, deux dragmes.

Safran de Mars aftringent, une dragme.

Caftoreum, demi dragme. Cire, une dragme \& demie.

Mêlez ces drogues \& faites-en un ongüent.

$$
\text { A R T I CLE XXII. }
$$

Cotmme le Caftoreum caufe avortement, ox pent, à mon exemple, l'employex pour bâter 
nt dans un

us efficace que lo Cafaigre, que une éponmme nous uchelius. femme de froit d'une it délivírée elle nes'en

une once. oncaflées;

ftringent,

i dragme. \& demie.

ites-en un

I I I.

vortement, oloyex pour bâter
D U*CASTOR. biter la fortie du foetus, dans guelque état quill foit. Co fût à ce remede que la femme d'un Soldat nommé Martin Scheiner, dî̀ fa délivrance, après avoir été long-tems dons les douleurs de l'accouchement, l'enfant étant mort dans fon fein.

$$
\text { ADDITION. }
$$

Lorfque les Parties qui fervent à l'expulfion du foetus, font dans un état convenable, on peut employer en toute fûreté le Caftoreum, après avoir murement pefé toutes les circonftances.

Je me fers dans de pareilles occafrons du mêlange fuivant, dont j'ai plufieurs' fois éprouvé l'effet.

Prenez Efprit de Suie.

Matric. fcult.

Effence de Caftoreum, ana demi dragme.

Huile de Sabine diftillée, cinq gouttes. de Canelle, deux gouttes.

Mélez ces drogues \& faites en ufage.

$\mathrm{N}$ 


\section{T R A I T E:}

I 34 Kuchelius, donna le 8 Avril 1579 . à la femme de Michel Muldel, qui étoit depuis trois jours dans les douleurs de l'enfantement, for Arcane qui la fit accoucher le lendemain.

\section{Prenez Canelle choifie, deux drag- mes. \\ Corne de Cerf brûlée. Caftoreum. \\ Cendres de Vers de terre : ana demi dragme. \\ Sucre candi, demi-once.}

Faites-en une poudre, dont vous prendrez une dragme dans de l'eau de Cerfeuil \& d'Armoife, \& oignez-le bas ventre du malade avec l'onguent fuivant.

Prenez Axonge de Poules, deux onces.

Huile de Lys.

de Vers de terre, ana une once.

de Caftoreum.

d'Aneth, ana une once. de Jafmin.

de Myrrhe, ana deux dragmes. 
vril 1579 : fdel, qui $s$ les douir Arcane aain:

deux dragâlée.

de terre; se.

ii-once.

dont vous de l'eau de oignez-le l'onguent

les, deux

terre, ana

im.

la une once. , ana deux

\section{DU CASTOR.}

Mêlez ces drogues \& faites-en un onlguent.

La Poudre fuivante, dont on trouve la compofition dans les expériences de Médecine d'un certain Auteur Anonyme, facilite extrêmement l'accouchement \& appaife les douleurs qui le fuivent.

Prenez Succin citrin, un fcrupule. Safran, demi fcrupule. Os de cœur de Cerf, trois grains.

Caftoreum, cinq grains. Perles préparées, deux

Mêlez ces drogues, \& faites-en une Poudre très-fubtile.

Mart. Neufart fait beaucoup de cas des Pilules fuivantes dans les accouchemens difficiles.

Prenez Bdellium, une dragme.

Caftoreum.

Trochifque de Myrrhe.

Storax calamita, ana un fcrupule.

Faites-en avec du Syrop de Rofes

$$
\mathrm{Nij}
$$


136 T R A I T E'

laxatif des Pilules du poids d'une dragme, \& donnez en fix à la malade. L'Auteur rapporte que la femme de Barthelemi Dullenkopff, accoucha le 2. Juin 1576 , de deux enfans, fans beaucoup de peine pour en avoir ufé. Eckold fut appellé le 6 Janvier I569, pour voir la femine de Marc Wolfgang Raufchnabel, qui étoit depuis fix jours en travail. Elle avoit I'haleine puante, le vifage pâle \& défiguré, \& ne fe plaignoit d'autre chofe que d'une douleur dans la région ombilicale, \& d'une froideur dans le ventre. Votre enfant eft mort, lui dit Eckold ,\& commence à fe pourrir, ne négligons donc rien pour en hâterla fortie, de peur qu'il ne pourriffe la matrice, \& n'occafionne plufieurs autres fâcheux accidents. Je vous confeille de prendre la groffeur d'une noix de l'Electuaire fuivant.

Prenez Safran. Myrrhe.

Caftoreum.

Storax, ana demi once. Macis. 


\section{DU CASTOR.}

Sabine.

ooids d'une

la malade. femme de accoucha le nfans, fans n avoir ufé.

6 Janvier ie de Marc qui étoit deElle avoit pâle \& déd'autre chofe région omeur dans le nort, lui dit pourrir, ne r en hâterla pourriffe la plufieurs atlvous confeille l'une noix de

Canelle, ana deux dragmes. Miel, une quantité fuffifiante.

Faites en un Electuaire.

\section{Prenez Ellebore. \\ Myrrhe, ana demi-once. Caftoreum, une dragme.}

Mêlez ces drogues avec du Suc de Pouliot, \& faites en un peflaire de la longueur de huit travers de doigts \& d'un pouce d'épaiffeur.- Trois heures après qu'il eut été introduit dans la matrice, il en fit fortir le foetus.

Jean Stokerus fait beaucoup de cas du remede fuivant.

\section{Prenez Caftoreum, un fcrupule. Affafoetida, demi fcrupule.}

Mêlez ces drogues \& donnez les. dans de l'Eau de Sabine.

Ces remedes font encore propres à chaffer les Moles. 


\section{8 \\ T R A I T E' \\ A RTICLE XXIII.}

J'ai gueri avec le Caftoreum, trois bommes à la fois de la gonorrbée, en ujant de quelques autres remedes.

Je me fuis fervi très fouvent du Caftoreum, pour gu'rir cette forte de maladie; mais je ne vois pas que les autres Médecins l'ayent employé à cet uJage.

\section{$A D D I T I O N$}

Dans le flux de femence, dit Wolfart, dans le manulcrit que nous avons déja cité , qui eft caufé par des humeurs froides, \& lorfque le malade eft d'une mauvaife compléxion, rien n'eft plus utile qu'un Cataplafme de Caftoreum avec le Suc d'A gnus Caftus, \& quelque peu de Vinaigre. Mais il faut auparavant purger le malade.

Chriftophe Cellarius guérit en 1622. Leonard Munzer, Sacriftain à Wintthem, d'une Gonorrhée avec l'onguent fuivant, après avoir auparavant employé les remedes généraux. 


\section{DU CASTOR.}

I I I.

reum, trois orrbée, en des.

nt du Caftode maladie; es Médecins

, dit Wolnous avons es hameurs le eft d'une a n'eft plus Caftoreum $\&$ quelque ut aupara.

it en 1622. in à Wintl'onguent avant em-
Prenez Huile de Maftic, demi-once. de Rue, deux dragmes.

Caftoreum en poudre, demi fcrupule.

Menthe pulverifée, une dragme.

Noix Mufcade pulverifée , un fcrupule.

Mêlez ceśs drogues \& faites-en un onguent.

Un de ceux dont nous avons parlé ci-devant, que guẻrit notre Auteur, étoit un jeune libertin qui partageoit fon tems entre l'Amour \& les Livres ; \& qui fut affez heureux pour êtréguéri de cette honteufe maladie, au moyen du remede fuivant.

Prenez Yeux d'Ecreviffes.

Gomme Arabique, ana une dragme.

Sang de Dragon.

Trochifque d'Alkekenge en poudre, ana un fcrupule. Caftoreum, demi fcrupule. $\mathrm{N}$ iiij 
Huile de Térébenthine diftillée, quatre gouttes.

Mêlez ces drogues \& faites-en une poudre.

Un Curé d'une Paroiffe, dont je tais le nom, d'une taille replette \& d'un tempéramment bilieux, âgé d'environ quarante-cinq ans, étoit incommodé depuis fix femaines d'une gonorrhée. Comme il n'ofoit'fe confier à aucun Médecin de fa Ville, il me confulta par Lettres, \& je le guéris avec le remede fuivant, après l'avoir auparavant purgé.

Prenez Teinture de Fleurs de Millepertuis.

Efprit de Térébenthine, ana une dragme.

Effence de Cafioreum, un fcrupule.

Mêlez ces drogues.

\section{A R T ICLE XX I V.}

$J$ ai mployé très fouvent le Caftoreum avec fuccès contre la Migraine, \& j aiété furpris de la promptitude avec laquelle il l'a fait ceffer. 


\section{$E^{\prime}$}

nthine diftilouttes.

faites-en une

, dont je tais lette \& d'un gé d'environ incommodé gonorrhée. fier à aucun confulta par ec le remede avant purgé. ars de Milleenthine, ana Toreum, un

X I V.

le Caforeum ze, \& jaieté ec laquelle it

\section{DU'CASTOR.}

Le Caftoreum ramollit auffi la dureté du Foye, étant appliqué extérieurement, ainfi que jai occafian de m'en convaincre tous les jours.

\section{$A D D I T I O N$.}

L'ouverture de la veine céphalique eft d'une grande utilité dans la maladie dont nous parlons, \& Frédéric l'approuve beaucoup dans fon Commentaire fur la pratique de Jonfton. Le Caftoreum produit auffi de très-bons effers, foit qu'on l'employe feul à l'exemple d'Harderus, qui nous affure avoir guéri une migraine, en le donnant tous les matins deux heures avant le jour, en forme de Pilules, foit qu'on le mêle avec d'autres drogues, fuivant les formules que les Auteurs nous ont laiffées. J'en rapporterai quelques-unes qui ont śr fuivies dans le Siécle précédent.

Chriftophe Ehingerus, guérit en I575, Sebaftien Salzmani, Gouverneur de Wengens, d'une Migraine avec l'Emplâtre fuivant. 


\section{2

Prenez Galbanum diffout dans du Vinaigre, fix dragmes. Cire jaune, demi once. Poix , deux dragmes. Moutarde, une dragme. Huile de Caftoreum, une quantité fuffifante. Cérat.

Mêlez ces drogues, \& faites-en un

Didyme rapporte que George Veiel, fut guéri en 1574 , de la même incommodité, au moyen du mêlange fuivant.

Prenez Huile Mufcade, dans laquelle on aura fait bouillir des Baies de Laurier, une once.

de Caftoreum, deux dragmes.

de Rue diftillée , trois gouttes.

Mêlez ces drogues \& frottez-en légérement la partie affligée.

La femme de Samuel Faulhaber vint me confulter (Ekold.) le i4 Décembre I 568 , fur une douleur quelle reffentoit

fe

ne

me le 1 nés de du fait ave con 
$E^{\prime}$

Fout dans du fix dragmes. emi once. agmes. ie dragme. toreum, une ffante.

faites-en un

George Veiel, même incommêlange fui-

le , dans la. ra fait bouillir Laurier, une

reum, deux

ftillée, trois frottez-en léaulhaber vint 14. Décembre elle reffentoit

\section{DU CASTOR.}

depuis depuis long-tems dans le côté gauche de la tête, toutes les fois qu'elle y touchoit, \& qui lui donnoit du relâche par intervale. Votre maladie, lui dis-je, eft une Migraine, caufée par la lézion des nerfs qui tapiffent le crâne, \& je vous ordonne de frotter la partie affligée avec l'huile fuivante.

Prenez Huile de Marjolaine. de Caftoreum , ana demi once. mes. de Rue, deux drag-

Opium, demi fcrupule.

Mêlez ces drogues.

L'an I 645 , Marguerite Müntherin, fe trouvant incommodée de la Migraine , \& ayant inutilement ufé des remedes que fon Médecin ordinaire, \& le Docteur Ofwald, lui avoient ordonnés, je la guéris enfin avec fix grains de mon Sél volatile de Caftoreum dans du Syrop de Pivoine. Ce même Sel fait beaucoup de bien lorfqu'on le mêle avec de l'efprit diftillé de Caftoreum, comme nous en affure Barnerus. 
144

\section{T R A I T E'}

La dureté du Foye ne vient que de fon obltruction, \& l'on doit y remedier promptement, fi l'on ne veut qu'elle ne dégénere en Squirrhe, autrement elle caufe une Hydropifie, dont la mort eft fuivant la fuite. Barthelemi Wolfart, fe fert pour cet effet de 1'Emplâtre fuivant.

\section{Prenez Gomme Ammoniaque, une dragme \& demie. Bdellium, une once.}

Jucifez groffiérement ces drogues; $\&$ après les avoir fait infufer pendant vingt - quatre heures dans une demionce de Vinaigre de Squille, \& fix dragmes d'Huile de Maftic, ajoutez-y la poudre fuivante, pour en faire une Emplâtre d'une confiftance convenable.

Prenez Caftoreum, trois dragmes. Maltic, deux dragmes. Labdanum, une dragme.

Mêlez ces drogues, \& faites-en une poudre.

Notre Auteur fait beaucoup de cas de la compofition fuivante. 
ient que de loit y reme'on ne veut irrhe, autreopifie, dont te. Barthelecet effet de

niaque, une mie.

once.

ces drogues; fufer pendant is une demile, \& fix dragajoutez-y la faire une Emonvenable.

ois dragmes. dragmes. ne dragme. faites-en une aucoup de cas inte.

\section{DU CASTOR.} Prenez Graiffe de Caftor. de Canard. Mucilage de femences de Fenugrec. de Lin, ana deux dragmes.

Huile de Camomille. de Caftoreum. de Melilot. de Rue.

Moèlle de Bœuf, ana une dragme.

Mêlez ces drogues, \& oignez-en la partie affligée, après les avoir fait chauffer.

$$
\text { ARTICLE XXV. }
$$

La Femme d'un Ravaudeur étoit tellement incommodée de la Sciatique, quielle ne pouvoit trouver ancun repos dans quelque fituation quielle fût, ce qui me faifoit craindre une fauffe couche, $j$ eus cependant le bonbeur de la guérir avec le Caftoreum.

$$
A D D I T I O N \text {. }
$$

Le Caftoreum eft propre à appaifer les, douleurs Sciatiques, à caufe de fes 


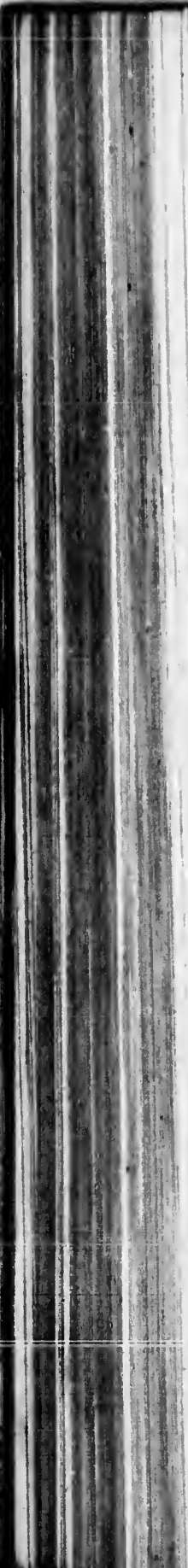

146

\section{TR A I T E'}

parties fulphureufes \& balfamiques, qui ont la vertu de diffiper les particules étrangéres, âcres \& humides, qui adhérent aux parties nerveufes \& aux pores des articulations, comme il feroit aifé de le prouver par le témoignage des Médecins, anciens \& modernes; mais conme cette douleur eft fixe \& qu'elle ex:ge la même Cure que la goutte, nous indiquerons quelques remedes dont on peut ufer extérieurement, après avoir employé les remedes internes.

La femme de Daniel Wicland, fut faifie en I 579 , pendant fa grolfeffe d'une douleur fciatique, dont Jean Wolfgang Rabi, la délivra au moyen de cet onguent.

Prenez Huile de Vers de terre, fix onces.

Moëlle des pieds de Bœuf,

- deux onces.

Vin de Malvoifie, une once $\&$ demie.

Fleurs de Lavande. de Romarin. de Sauge, ana deux pincẻe. 


\section{DU CASTOR.}

Sommité d'Ivette.

miques, qui

$s$ particules , qui adafes \& aux nme il feroit cémoignage modernes; $r$ eft fixe \& ure que la quelques extérieureré les reme-

icland, fut fa groffeffe dont Jean a au moyen

le terre, fix de Bouf,

; une once inde. arin. , ana deux de Marjolaine, ana une pincé.

Bois de Geniévre. Caftoreum, ana une dragme.

Mettez ces drogues en coction, jufqu’à ce que le vin foit confumé, \& oignez-en la partie douloureufe.

Kuchel, a employé très-fouvent avec fuccès le remede fuivant, comme il paroît par differens paflages de fon manufcrit.

Prenez Opopanax diffout dans du vinaigre, une once. Huile de Camomille,Caftoreum, Cire, une quantité fuffilante.

Faites en un Cérat.

L'emplâtre fuivant, à ce que prétend Wolfart eft admirable dans la fciatique.

Prenez une Maffe d'emplâtre Oxycroceum , une once. Caftoreum, demi-once. 
Malaxez ces drogues avec de l'huile Nardin, \& faites-en une Emplâtre.

Ekold fut appellé le 17 Juillet I 595 , chez Barthelemi Rehm, dont la fille fe plaignoit d'une douleur violente dans la cuille droite, qui d'ailleurs n'étort ni enflée, ni enflammée. Comme il connut que c'étoit une douleur fciatique, caulée par une Pituite mêlée avec quelque humeur bilieufe, qui affectoit la veine de la cuille, il lui ordonna le remede fuivant, qui l'appaifa entiérement.

Prenez Pilules d'Hermodactes. $:$

Cochées, ana un fcrupule.

Dorées.

Calloreum, ana demi fcrupule.

Faites-en des Pilules médiocres, avec du Syrop de Betoine.

$\therefore$ Prenez Huile de Coftus, une once. de Vers de terre. de Caftoreum, ana demi-once.

Onguent Aregont. dragmes. de Mars, ana deux Mêlez 


\section{DU CASTOR.}

ec de l'huile mplâtre.

uillet I 595 , dont la fille iolente dans lleurs n'étoit Comme il uleur fciatie mêlée avec , qui affecil lui ordonqui l'appaifa odactes.

es, ana un

S.

na demi fcru-

$s$ médiocres, e.

us, une once. de terre. coreum, ana gont. Mars, ana deux Mêlez
Mêlez ces drogues \& faites-en un onguent.

Jacques Zxemann , guérit en 1645 , un. Payfan des environs d'Ulm, de cette maladie avec l'huile fuivante.

Prenez Huile de Vers de terre. de Caftoreum, ana fix dragmes.

d'Iris.

de Rue , ana demionce.

Mêlez ces drogues \& faites-en ufage.

Jai guéri, en I 679 , la femme de Zimprecht Oftertag, de douleurs fciatiques violentes avec l'onguent fuivant, après avoir auparavant employé les remedes généraux.

Prenez Onguent Nervin, une once. Anodin.

Dialth. ana deux. dragmes. Huile de Caftoreum. de Laurier, ana trois dragmes.

Diftillée de Geniévre, 


\section{T R A I T E' \\ demi dragme.}

Mêlez ces drogues \& faites-en un onguent.

La femme de Daniel Henning, fut attaquée il y a quelques années, fix femaines avant d'accoucher d'une douleur fciatique $f i$ violente, qu'elle ne pouvoit trouver aucun repos. Elle me fit appeller apris avoir vainement employé un grand nombre de remedes, $\&$ je lui ordonnai le remede fuivant.

Prenez Cinnabre mineral préparé.

Caftoreum choifi, ana fix grains.

Opiate de Laudanum, un grain \& demi.

- Mêlez ces drogues \& faites-en dés Pilules, au nombre de onze, avec de l'huile d'Anis.

Prenez Emplâtre de baies de Laurier, une once.

Gomme de Geniévre, deux dragmes.

Galbanum, diffout dans du Vinaigre, une dragme. 
aites-en un

enning , fut innées, fix d'une douqu'elle ne os. Elle me nement emle remedes, fuivant.

l préparé. ifi, ana fix

danum, un

faites-en des zze, avec de

ies de Laue.

aiévre, deux um, diffout laigre, une

\section{DU CASTOR. ISI Caftoreum, demi fcrupule.}

Mêlez \& malaxez ces drogues avec quelque peu d'huile de Caftoreum $\&$ faites-en une maffe.

La malade n'eût pas plutôt ufé de ce remede, que les douleurs cefferent, fes forces revinrent \& elle accoucha trois jours après d'un garçon.

Le Baume Arthirique dont je parle Art. 28. eft excellent dans le cas dont il s'agit, \& je ne l'ai jamais employé fans effet.

\section{ARTICLE XXVI.}

Rien n'ef plus vraique ce qu'à dit un Auteur, quil eft très-difficile de tirer un Léthargique de fon asfoupiffement, ie puis cependant me vanter d'avoir beureufement guéri cette maladie avec le Caftoreum, Sans craindre que le Vieillard gui on a reffenti les effets démente ce que javance.

Perfonne n'ignore combien la Ratte peut occafionner des maladies dans le corps bumain par fon enflure of $\int a d u-$ reté, que jai fouvent diffipée avec ce même remede.

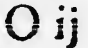


On peut encore donner du Caftoreum aux Nourrices pour augmenter leur lait.

$$
A D D I T I O N \text {. }
$$

Le Caftoreum eft le remede le plus efficace que l'on puiffe donner aux Léthargiques, foit en forme de Magiftere ou d'Effence, car il entre dans les vaiffeaux \& ouvre les pores du cerveau, ce qui ne peut manquer de les faire revenir de leur affoupiffement.

Michael dans fon Commentaire manufcrit, fur la pratique de Jonfton, fait beaucoup de cas des remedes fuivans.

Prenez Caftoreum en poudre, un fcrupule.

Scam. Sulphureufe, demi fcrupule.

Mêlez ces drogues \& faites-en une poudre que vous donnerez au malade dans du vin.

P'renez Extr. hydragogue un fcrupule. Faites le diffoudre dans une quantité fuffifante d'Eau de vie,\& ajoutez-y

Syrop de Betoine, trois dragmes. 


\section{DU CASTOR. IS,}

Mêlez ces drogues. dragme.

Prenez Extr. hydragogue, un fcrupule.

iede le plus ner aux Lée Magiftere e dans les lu cerveau, les faire re-

entaire mae Jonfton, emedes fuioudre, un eufe, demi faites-en une au malade

ue un fcruns une quan\& ajoutez-y ine, trois

Trochifque alhandal, trois grains.

Caftoreum, fix grains.

Faites en avec de l'Effence de Cafto: reum des Pilules, au nombre de vingt $\&$ une.

Prenez Pilules d'Agaric, un fcrupule. Extrait de Caftoreum, fix grains.

Trochifque alhandal, trois grains.

Faites-en avec de l'Oximel Scillitique des Pilules, au nombre de vingt \& une.

Prenez Feuilles d'Origan.

$$
\text { de Rue. }
$$

Fol. dift. Afar. ana une poignée.

Fleurs de Muguets.
Stæcas Arabique.

Semences de Cartame, fix dragmes. 
Pulpe de Coloquinte, dans un nouet, deux dragmes.

Mettez ces drogues en coction dans une quantité fuffifante d'Eau compofée. Prenez une livre de Colature dans lav quelle vous ferez diffoudre Extrait de Caftoreum, demi fcrupule. Fiel de Bouf épaiffi, deux dragmes. Huile diftillée de Rue, fix gouttes. Un Jaune d'œuf. Mêlez \& faites-un lavement.

Prenez Spec. dialunæ $M$, trois drag. mes.

Magiftere de Caftoreum, deux fcrupules.

Huile diftillée de Rue, frix gouttes.

Mêlez \& divifez-en fix portions égales.

Prenez Eau de Rue, quatre onces. Oxymel Scillitique, deux onces.

Vinaigre benedict. Vitriolique, trois dragmes.

Effence de Caftoreum, deux dragmes.

La dofe eft de deux petites cuillerées à caffé. 


\section{DU CASTOR.}

Prenez Feuilles d'Ache, trois pincées.

Semences de Nielle. dragme.

de Rue, ana une

Caftoreum, une dragme \& demie.

Faites- en un nouet que l'on flairera.

Prenez Vinaigre de Rue, deux dragmes \& demie. une once.

Benedicte diftillé ,

Suc de Rue récent, demiv once.

Effence de Caftoreum, deux dragmes.

Mêlez ces drogues.

Prenez Poudre de Cantharides, un fcrupule. grains. d'Euphorbe, douze quatre onces. itique, deux edict. Vitriolidragmes. Iftoreum, deux etites cuillerées de Caftoreum, un fcrupule.

Levain bien aigre, demionce.

Mêlez ces drogues. Rabi fe fert du remede fuivant pour 
I 6 TR A I T E

diffiper la vapeur Narcotique, \& pour faire revenir le malade à lui-même.

Prenez Rapure d'os de Bœuf, demionce.

de Corne de Cerf, demi dragme.

Caftoreum, deux fcrupules. Affa fætida.

Myrthe.

Sagapenum.

Galbanum.

Bois de Geniévre, ana un fcrupule.

Sucre, deux dragmes.

Pilez \& reduifez ces drogues à la groffeur d'un grain de Chanvre, \& fairesen une poudre, dont on jettera une pincée fur des charbons ardens, pour en recevoir la fumée.

Georges de Naefler , défaprouve extrêmement ces fortes de fumigations, dont l'odeur eft capable de fuffoquer.

Neufart, veut que l'on fomente la: partie pofterieure de la tête du malade avec l'épitheme fuivant. 
que, \& pour ui-même.

Bœuf, demine de Cerf, ux fcrupules.

vre, ana un lragmes.

gues àla grofre, \& faitestera une pinens, pour en

léfaprouve exfumigations, e fuffoquer.

n fomente la: te du malade

Prenet

\section{DU CASTOR.}

Prenez Racine d'Afphodele. de Piretre. mi-once.

d'Ellebore, ana deCamomille. Serpolet. Origan.

Feuilles de Laurier, ana une pincée.

Faites cuire ces drogues dans une quantité fuffifante d'eau de Pouliot, jufqu'à la diminution du tiers, \& ajoutez à la colature

Poudre de Caftoreum, un fcrupule.

Moutarde.

Euphorbe, ana demi fcrupule.

Suc de Marum, une once.

Faites bouillir ces drogues encore un? pau \& faites-en un Epitheme.

Michel Frank, étant tombé le I 6 Octobre I 579 dans une Léthargie, Kuchel le guérit avec le remede fuivant.

Prenez Suc de Beterave cuite. de Rue, ana cinq onces. 
Hiere de Logadius, deux dragmes.

Huile compofée, deux dragmes.

Miel anthofat, une once \& demie.

Sel, une dragme.

Caftoreum, un fcrupule. Mêlez \& faites-en un lavement.

Prenez Rhubarbe en poudre. Spec. Dianth. un fcrupule. Suc de Rue, demi-once. Caftoreum, un fcrupule. Diaphænic, demi-once. Eau de Betoine, une quantité fuffifante.

Faites une potion purgative.

On voit par-là que le Caftoreum eft d'une grande utilité dans toutes les maladies affoupiffantes, \& que ce n'eft point fans fujet que Michel fait un fi grand cas de fon effence, dans laquelle il entre.

On doit, dit Wolfart, mettre tolljours quelque peu de Caftoreum dans les remedes quel'on donne aux Lethar:' 
us, deux deux dragne once \&

fcrupule. ement.

adre.

in fcrupule. emi-once. frrupule. ii-once.

, une quan-

ative.

aftoreum eft outes les maque ce n'eft hel fait un fi dans laquelle

, mettre toll-: ftoreum dans e aux Lethar:
DU CASTOR.

159

giques, parceque nos Ancêtres ont remarqué qu'il a guéri un grand nombre de malades de cette efpece. On peut fe fervir pour cet effet de fternutatoires compofés de Caftoreum, d'Ellebore, de Poivre \& de Noix Mufcade, d'un Cérat digeltif, compofé d'une égale quantité d'huile de Rue \& de Cire, que l'on fera fondre dans un por verniflé, \& qu'on appliquera fur la tête du malade, après y avoir ajouté du Suc de Marum \& quelque peu de Caftoreum. Rien n'elt meillcur pour détruire la caufe morbificue que les médicamens compofés de Caftorcum \& de Scam. nionée.

Il n'eft point, dit Harderus, de remede comparable au Caftoreum, pour fa vertu pénétrante, comme jo l'ai appris d'Aléxandire'Mafrária, dont j’ai été Difciple , \& j'ai même éprouvé depuis peu fes effets fur un Vieillard très-riche, que je guéris avec la fotion purgative fuivante.

Prenez Feuilles de Séné, une dragme \& deinie.

Eptilyme.

$P$ ij 
160

\section{TRA I T E'}

Myrobolans Citrins, ana une dragme.

Feuilles de Betoine, une pincée.

Semences de Fenouil, une dragme \& demie.

Mettez ces drogues en infufion dans une quantité fuffifante d'Eau de Serpolet, exprimez-en le fuc, dont on prendra.

quatre onces \& demi. Agaric en forme de paftilles. Rhubarbe choifie \& pulverifée, ana deux fcrupules $\&$ demi.

Caftoreum, deux fcrupules. Lavande, fix grains.

Mettez ces drogues en infufion pendant une nuit, $\&$ ajoutez aufuc que vous en tirerez

Elect. in d. major. trois dragmes,

Miel anthofat, diffous.

Mêlez \& faites-en une potion.

Je finirai par une obfervation que i'ai faite le I I Août 1679 , à l'occaz 


\section{DU CASTOR. $16 \mathrm{r}$}

rins, ana

oine, une

ouil, une ie.

fufion dans I de Serpont on pren-

$\&$ demi. de paftilles. ie \& pulveri$\mathrm{x}$ fcrupules

ix fcrupules. rains,

nfufion penfuc que vous

major. trois

diffous. potion.

fervation que 79 , à l'occag

fion de la femme de Jean Kettinger, d'Herfelfingen, dans le Territoire d'Ulm. Cette femme qui avoit environ quarante ans \& qui étoit d'un tempéramment colérique, étoit fujette depuis quelques mois à un accident qui la prenoit deux fois par jour, principalement fur le midy, \& qui la rendoit tour d'un coup immobile, comme une itatuë; elle reftoit avec les yeux ouverts \& fans mouvement dans l'état que l'accès la prenoir, fans qu'elle lentit aucune douleur dans la tête, ni dans aucune autre partie du corps, avant ni après l'accès. A près lui avoir fait ôter l'écume qui l'empêchoit de refpirer, je lui ordonnai les remedes fuivans, qui produifirent un très-bon effet.

Prenez Jalap réfineux, un fcrupule. Scam. fulphureufe, fix grains. Trochifque alhandal, trois grains.

Caftoreum, deux grains. Huile diftilée de Lavande, une goutte.

Mêlez ces drogues, \& faites-en une poudre.

$$
\text { P iij }
$$




\section{2

Prenez Caltoreum choifi, une dragme.

Cinnabre naturel préparé, un licrupule.

Pierres d'Ecrevifes préparées, domi dragme.

Mêlez \& faites une poudre.

Prenez Onguent Nervin. Axonge de Chien, ana demionce.

Huile de Caftoreum. dragme. d'Euphorbe, ana une

Mêlez \& faites un liniment.

Je lui ordonnai enfuite pour prévenir de femblables accidens \& pour conforter les efprits animaux, l'Efprit de Sel Ammoniac , impregné de Caftoreum, qu'elle prit goutte à goutte, \& la guérit entiérement.

Marius parle fouvent dans fa pratique manufcrite du remede fuivant, dont il prétend avoir éprouvé les effets dans les douleurs \& l'enflure de la ratte.

Prenez Emplâtre d'Ammoniac. 
fi, une drag-

el préparé,

iffes prépaIragme.

dre.

in.

en, ana demi-

reum.

rbe, ana une

ent.

pour préve\& pour con-

l'Efprit de né de Caftoà goutte , \&

lans fa pratiede fuivant, uvé les effets re de la ratte.

nmoniac.

\section{DU CASTOR. 16;}

Onguent fplenique, ana demi-once.

Mirrhe, deux dragmes.

Caftorcum.

Safran, ana demi-dragme.

Faites-en un emplâtre avec du fuc de Creffon \& quelque peu de Térébenthine.

Fuchfius guérit, en I 571 , Wolfgang Stamler d'une enflure de ratte, avec l'onguent luivant.

\section{Prenez Huile de Rue, fix dragmes. d'Iris. de Laurier, ana trois dragmes. \\ Onguent de Guimauve, deux dragmes.}

Suif de Chef, une dragme. Poudre de Caftoreum.

Fleurs de Souci.

de Thym, ana un fcrupule.

Cire, une quantité fuffifante.

Mêlez ces drogues \& faites-en un onguent fans employer le feu.

Les Pilules fuivantes font très-eff-

$P$ iiij 


\section{TRAITE'}

caces, pour réfourdre les enflures de la ratte, pour ouvrir les vaiffeaux \& pour purgerle corps de ce qu'il y a de fuperflu. Je les ordonnai, dit Marius dernierement, f̧̧avoir le 6 Avril I645, avec beaucoup de fuccès à Marie Majerin de Giengen, qui étoit affligée d'une parẹille maladie.

Prenez Pilules d'Ammoniac, deus fcrupules.

de Tartre, un ferupule.

Extrait d'Ellebore noir, demi fcrupule. de Caftoreum, deux grains.

Diagrede, trois grains.

Huile de Fenouil, quatre grains.

Faites-en des Pilules au nombre de trente-fept avec de l'Eau de Scolopendie.

Les Pilules Domeftiques fuivantes, ne font pas moins efficaces dans ces fortes de maladies, elles font purgatives \& digeftives.

Prenez Racine de Fougere mâle. de Ronce. 
nflures de la eaux \& pour $y$ a de fuperMarius derAvril 1645 , Marie Matoit affligée

sniac, deus re, un fcrubore noir, e.

oreum, deux $s$ grains. louil, quatre u nombre de de Scolopen-

des fuivantes, aces dans ces $s$ font purgagere mâle. ce.
DU.CASTOR. 165 de Chiendent, ana $\&$ demie.

Polypode.

Ecorce de Tamaris, ana fix dragmes.

de Caprier , trois dragmes.

Herbe hépat. nob.

Fraizier.

Pafquerette, ana deux poignées.

Caftoreum choifi, demionce.

Semence de Genet d'Efpagne, une once.

Canelle, trois dragmes. Baies de Laurier. Galanga, ana deux dragmes.

Faites-en une Poudre fur laquelle vous verferez une quantité fuffifante d'Efprit de vin rectifié , pour en faire un Extrait.

Prenez Extrait ci-deffus. Scam. fulphureufe.

Trochifque alhandal, ana fix grains.

Huile diftillée d'Aneth, fept gouttes. 
Faites-en avec de l'Eau Carminative R. des Pilules au nombre de dix-neuf.

Rabus prétend que l'Emplâtre fuivant a la vertu de diffiper l'enflure de la ratte, \& que l'ayant une fois appliqué fur cette partie, elle en diffipa aufftôt la douleur \& l'enflure.

Prenez Diachylon, une once.

Mucilage de racine de Guimauve, fix gros.

Huile de Cappres, fix gros. Galbanum.

Sel ammoniac, diffous dans du vinaigre, ana trois dragmes.

Graiffe humaine.

Onguent de Bdellium M. ana une once.

Poudre de Caftoreum.

d'Ariftoloche ronde. de Sel gemme, ana une dragme.

Quelque peu de cire.

Mêlez \& faites-en une Emplâtre.

Je fuis perfuadé que le Caftoreum augmente le lait en dilatant les vaif- 


\section{DU CASTOR.}

167

feaux par fa qualité fulphureufe, \& en diffipant le fang épais qui réfide dans ceux qui aboutiffent aux mammelles, pour qu'il puife y affluer. De-là vient que Wolfart ordonne pour cet effer le Caftoreum diffous dans du vin.

\section{A R T ICLE XXVII.}

e once.

cine de Gui. gros.

res, fix gros.

, diffous dans

, ana trois

1e.

Bdellium M. e.

Atoreum.

oloche ronde. yemme, ana

e cire.

Emplâtre.

le Caftoreum tant les vaif-

Ce que j'ai rapporté ci-devant d'un Juif' qui m'avoit alfuré que le Cafioreum augmentoit la mémoire, mérite confirmation; mais je puis affurer, comme une chofe vraie, qu'une fille à qui une fiévre maligne l'avoit entierement fait perdre, la recouvra de nouveau avec le fecours du Caftoreum, au grand étonnement de fes parens qui m'en firent mille remercimens.

\section{$A D D I T I O N$.}

Notre Auteur a donc raifon de recommander, avec Avicenne, l'ufage du Caftoreum pour fortifier la mémoire, car il diffipe, fépare \& anéantit les particules qui lient les efprits animaux, afin que devenant plus fubtils ils puiffent fervir avec leurs promptitudes ordinai- 


\section{TRAIT Es}

res aux fonctions aufquelles ils font déftinés: c'eft pour cette raifon qu'Ehinger, ordonne à ceux qui veulent fortifier leur mémoire d'oind ? leurs temples avec de l'huile Rofat ix du Caftoreum.

Si ces remedes ne fuffifoient pas (dit Fuchfius) on doir y ajourer du Caftoreum, qui eft très propre aux efprits animaux ; par exemple, on s'oindra la tête avec le liniment fuivant qui a forsvent produir des effets admirables.

\section{Prenez Euphraife, demi dragme. Verveine, un fcrupule. Meliffe, une dragme.}

Noix mufcade, deux fcrupules.

Encens, un fcrupule.

Coriande préparée, demi dragme.

Canelle, deux fcrupules. Zédoaire, un fcrupule.

Incifez, pilez \& mettez ces drogues en infufion dans -

Huile de Lys, trois onces. d'Aneth, 


\section{DU CASTOR. Axonge d'Ours, ana demi- once.}

Eau de Betoine, neuf onces.

Mettez ces drogues pendant quatre heures dans un lieu chaud, enfuite faites les bouillir jufqu'à ce que l'Eau de Betoine foit confumée, \& après en avoir expriméle fuc, ajoutez-y

Caftoreum, une dragme. Bois d'Aloës en poudre, demi dragme,

Mêlẹz , ajoutez-y de la Cire, s'il en eft befoin, \& faites-en un liniment.

Marius fait beaucoup de cas de l'efprit urineux du Caftoreum, dont il donne la compofition. Les Pilules fuivantes qu'il ordonna à Marie Mauchterin, font très-propres à fortifier la mémoire,

Prenez Pilules de Caftoreum, deux fcrupules.

rupule. arée, demi

crupules. crupule.

ces drogues

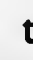

- Sine quibus. demi fcrupule.

Alephangines, ana Magiftere de Jalap , fix grains. 


\section{0 \\ T R A I T E'}

Faites-en avec de l'Eau de Fenouil des Pilules, au nombre de vingt-une.

Prenez Eau de fleurs de Romarin, deux onces. de Canelle.

Epileptique deLangius. Efprit de Caftoreum, ana demi-once.

Rot. Dianth. trois dragmes.

Mêlez ces drogues \& donnez-en un verre.

On doit avant que d'employer un remede, examiner exactement quelle eft la maladie qui affecte le cerveau, car autrement on court rifque de faire plus de mal que de bien au malade, fur tout lorfque la chaleur domine, il eft done plus fû́r de garder un certain milieu $\&$ 'd'ufer, fuivant le befoin, de remedes fecs \& humides, qu'on peut employer extérieurement. Le Lixivium $\int_{a}$. pientix de Michel, nous fervira d'exemple.

Pren ez 'Racinesd'Oeillet. de Piretre. $\mathrm{de}^{\prime}$ Róndelle, ana une once. 
de Fenouil e vingt-une. e Romarin, e deLangius. reum, ana ois dragmes. onnez-en un

imployer un ment quelle le cerveau, fque de faire au malade, lomine, il eft a certain miCoin; de remeon peut emLixivium Javira d'exem-

et.

re.

delle, ana

\section{DU CASTOR. $\quad$ I r}

Guy de Chêne. Oliban.

Succin , ana demi-once.

Feuilles de Romarin.

de Marjolaine.

de Sauge.

de Rue.

de Meliffe.

d'Origan.

de Laurier, ana deux dragmes.

Fleurs d'Afpic.

de Roles rouges.

de Pivoine.

de Betoine.

de Primevere.

de Camomille Ro: maine, ana une dragme.

Faites bouillir ceś drogues dans une leffive douce \& gardez-les pour l'ufage.

Villinger ordonne l'onguent fuivant pour fortifier la mémoire, il veut qu'on en oigne la partie pofterieure de la tête, après une lotion. .

Prenez Huile Nardin.

- de Caftoreum, ana fix dragmes. 


\section{T R A I T E'}

Species Dianth. demi dragme.

Huile de Canelle exprimée, deux frupules.

Diftillée de Lavande, quatre gouttes. de Gerofles , deux gouttes.

Cire, trois dragmes. Mêlez \& faites un onguent.

On trouve plufieurs autres formules, outre celles que nous venons 'de rapporter, que le Caftoreum rend d'une grande utilité à ceux qui ont la mémoire affoiblie. On l'employe dans les Electuaires pour qu'il fortifie les efprits avec plus d'efficacité. C'eft dans cette vûe que Melder prefcrivit l'année 16:9. la formule fuivanteà Marc Wollaibius.

Prenez Conferve de Betoine. de. Romarin. de Sauge.

Myrob. emb. cond. Ecorce de Citron confite, ana deux dragmes. Cubebes.

fat
na
re
pe
l'e
effe

l'bo

lad

ince

tiol

ven

épa

Semences 
demi drage exprimée, S.

e Lavande, s.

de Gerofles ,

rmes.

dent.

res formules, lons 'de rap. a rend d'une ont la méloye dans les ifie les efprits eft dans cette l'année 1629. c Wollaibius.

toine. omarin. tuge. ond.

ron confite, gmes.

Semences

\section{U CASTOR.}

Semences de Bafilic.

Maniguettes, ana demi fcrupule.

Caftoreum préparé. Maftic, ana un fcrupule. Syrop de Betoine, une quantité fuffifante.

Faites-en un Electuaire.

Le Caftoreum préparé comme il faut \& mêlé avec des drogues convenables, n'eft pas moins efficace pour redonner la mémoire à ceux qui l'ont perdue, \& j'ofe même affurer qu'on ne l'employe jamais fans en éprouver les effets.

\section{ARTICLE XXVIII.}

Le Caftoreum corrige la puanteur de Thaleine, qui eft fouvent une fuite des maladies, ce qui ne. laiffe pas que d'itre fort incommode.

$$
A D D I T I O N \text {. }
$$

Lorfque par un vice de conformation, les procès mammillaires $\mathrm{fe}$ trouvent obftrués par une matiere craffe \& épaiffe, \& que la membrane intérieure 
du nez, auffi-bien que fes petites fibres font afrectées par des particules étran. geres, l'odorat s'affoiblit de telle forte, que les particules fulphureufes, huileufes \& volatiles qui s'exhalent des corps, n’ont plus la liberté de pénétrer jufqu'aux ventricules antérieurs du cerveau, pour $y$ affecter les efprits animaux, qui ne peuvent plus en faire la diftinction. Il eft donc befoin de détruire le plus promptement que l'on peut les caufes morbitiques au moyen des remedes que les Auteurs ont eu foin de nous indiquer. Marius n'en connoît aucun qui foit plus efficace que le Caftoreum, qu'il a raifon de regarder comme une Panacée, car il pénétre dans les vaiffeaux à caufe de la petiteffe de fes parties, il en ôte les obftructions en diffipant les matieres craffes qui s'y étoient fixées, \& fortifie les nerfs \& les efprits animaux, par fa vertu balfamique, de quelque maniere qu'on l'applique.

Ce font ces proprietés ( dit Chrifto. phe Ehinger ) qui m'ont engagé à ordonner à ceux qui ont perdu l'odorat, de remedier à cette incommodité, par 


\section{'E'}

petites fibres ticules étrande telle forte, eufes, huileuent des corps, pénétrer jufieurs du ceres efprits anilus en faire la foin de détruique l'on peut moyen des reont eu foin de en connoît auque le Caftogarder comme nétre dans les petiteffe de les biftructions en craffes qui s'y les nerfs \& les vertu balfamiere qu'on l'apiés ( dit Chriftont engagé à orserdu l'odorat, ommodité, par

\section{DU CASTOR.}

l'odeur du Caftoreum qui produit de très-bons effets.

Neufart rapporte qu'il s'eft toujours fervi avec fuccès de l'Errhine fuivant, pour fortifier l'odorat.

Prenez Suc de Velar, demi-once.

Eau de Marjolaine, fix dragmes.

Caftoreum, fix grains. Elaterium, trois grains.

Mêlez ces drogues \& oignez-en le dedans du nez avec le dojgt ou avec une plume.

Jean Keller ordonna, en 1581, 'Errhine fuivant à Jacques Miller $\mathrm{Au}$ bergifte, à l'Enfeigne de la Croix d'or.

Prenez Suc de Poirée blanche, une once.

Huile de Rue, demi-once.

Caftoreum, deux grains.

Euphorbe, fix grains.

Mufc, un grain.

Mêlez ces drogues \& oignez-en le nez avec une plume, de deux en deux jours.

Ce même Auteur, applique fur le front le mêlange fuivant, en forme $Q$ ij 


\section{T R A I T E}

d'Epithême, pour diffoudre la matiere vifqueufe.

Prenez Suc de Poirée blanche, une once.

Oxymel Scillitique, demionce.

Huile de Sureau , deux drag. mes.

Poudre de Marjolaine, une dragme.

de Myrrhe, demi dragme.

de Caftoreum, un fcrupule.

Mêlez ces drogues:

\section{A R T I C L E X X I X.}

Le Caftoreum fait beaucoup de bien aux Phrenetiques, $\mathcal{F}$ il feroit feulement à foubaiter quel'on trouva le moyen de corriger Sa mauvaife odeur. Ceux qui font attaqués de la Pleurefie, en éprouvent tous les jours les effets, quelque peu quion leur en donne.

$$
A D D I T I O N \text {. }
$$

bl:

Lorfque l'on employe le Caftoreum 


\section{DU CASTOR.}

e la matiere

anche, une

que, demi-

, deux drag-

olaine, une rhe, demi

oreum, un

X I X.

up de bien aux ulement à fouien de corriger i font attagues at tous les jours leur en donne.

$N$ le Caftoreum dans laPhrenefie, c'eft moins dans lavûée d'appaiferl'inflammation des efprits animaux \& des Meninges, en attirant les particules fulphureules au dehors, qu'afin de les diffoudre \& de les détourner de la tête où elles fe font portés, pourque les pores du cerveau puiffent fe refferrer de nouveau, \& que le malade éprouve les bons effets du fommeil, qui eft prefque le meilleur remede que l'on connoiffe, comme nous en affure Waldfchmid.

De-là vient que Marius ordonne lẹs remedes fuivans à ceux qui ont de trop longues infomnies, en employant auparavant la faignée du front \& les autres fecours neceffaires.

Prenez Caftoreum, quatre grains. Opiate de Lodanum, trois grains.

Faites-en avec de l'Eau de Pavot blanc des Pilules, au nombre de trois.

Lorfque les Pilules précédentes ne produifent aucun effet, il fe fert le lendemain de celles qui fuivent.

Prenez Extrait de Caftoreum. 


\section{T R A I T E。}

Spec. Diamarg. frig. ana demi fcrupule.

Opiate de Laudanum, trois grains.

Mêlez \& faites avec de l'Eau de $\mathrm{Pa-}$ vot blanc des Pilules, au nombre de onze.

Simpert Linfius, Médecin à Memmingen, n'employe dans la Phrenefie qu'un feul Epithême, compofé de Caftoreum, \& de quelques autres ingrédiens. Il a une vertu diffolvante \& rafraichiffante.

Prenez Eau de Rofes, trois onces. Vinaigre rofat, une once \& demie.

Huile de Rofes, deux onces.

Caftoreum, une dragme.

Mêlez \& faites. en un Epithême.

Les particules du fang venantà s'extravafer \& à fe gliffer dans les rameaux de la veine azigos, ou dans les mufcles intercoftaux, fe figent \& caufent la pleurefie, des tumeurs, des inflamma. tions, \& le déchirement de la pleure.

On doit remedier le plus promptement que l'on peut à cette maladie, \& 


\section{DU CASTOR.}

E。

g. frig. ana le.

danum, trois

l'Eau de Pau nombre de

ecin à Mem. is la Phrenefie npofé de Cafautres ingréolvante \& ra-

trois onces.

, une once \&

$s$, deux onces, ne dragme. Epithême.

venantà s'exas les rameaux ans les mufcles \& caufent la des inflammade la pleure. plus promptete maladie, \&
179

confulter les Auteurs qui en ont écric fur la pratique. Quani à moi, je me contenterai d'indiquer au Lecteur les avantages que l'on retire du Caftoreum lorfqu'on a foin de le préparer \& de l'employer comme il faut.

Barthelemi Wolfart ordonna, en I 569 , le remede fuivant à Burthelemi Petelhauben, qui avoit un point au côté gauche.

Prenez Electuaire Diatragacanthe, une once.

Diacaftoreum,demi dragme. Huile d'Amandes, une once. Décoction d'Orge \& de Regliffe, une quantité fuffifante.

Mêlez ces droguss.

Jean Harderus ordonna, en I 600 , le remede qui fuit, à un homme qui avoit une douleur de côté.

Prenez Sel C. B. deux fcrupules. Sucre candi blanc, une dragme.

Caftoreum, huit grains. 
180

\section{T R A I T E'}

Mêlez \& faites une Poudre, que vous donnerez dans de la tifane de Paffilles.

Wolfart, dont nous avons parlé cidevant, guérit en 1576 , Ulric Schermaier, d'une Pleurefie en obfervant les loix du régime.

Prenez Diatragacanthe froide. Sucre Violat.

Penides, anā trois dragmes.

Suc de Regliffe.

Rad. ir. Flor pulv. ana un fcrupule \& demi.

Caftoreum.

Gomme Arabique, ana demie dragme.

Semences de Xiphion. de Mauve , ana un fcrupule.

Pilez ce qui doit l'être \& faites-en un Eclegme, avec du Syrop d'Althæa.

Le I 2 Septembre 1678 , un Soldat nommé Conrad Wernerus, s'étant extrêmement échauffé en démoliffant les ramparts d'un Faubourg, \& ayant bû de l'eau avec excès, fut faifi d'un point 


\section{DU CASTOR. I8r}

oudre, ques a tifane de ns parlé ciUlric Scherbfervant les

froide.

anā trois

oulv. ana un emi.

ue, ana deiphion. lauve, ana

$\&$ faites-en op d'Althæa.

8 , un Soldat us, s'étant démoliffant $\mathrm{rg}, \&$ ayant fut faifi d'un point
- point au côté droit. Son urine étoir rouge, il avoit une toux violente, il refpiroit a vec peine, \& fes crachats étoient peu abondans. Je lui ordonnai le remede fuivant, qui lui fit rendre au bout de trois jours une matiere d'un verd noirâtre, accompagnée de crachats fanglants \& de la celfation totale de la fiévre.

Prenez Eau C. M.
de Scorzonerre.
de Cerfeuil, ana trois
onces.
Cord. H. S.deux onces, Caftoreum dans un nouet, une dragme. Syrop C: B. une once.

Mêlez \& faites une potion dont le malade prendra une cuillerée de trois heures en trois heures, jufqu'à ce qu'il vomife.

Il n'y a pas long-tems qu'une femme qui avoit un point au côté, accompagné de la fuppreffion de fes ordinaires, dut fa guérifon au remede fuivant.

Prenez Efprit de Suye, une dragme. R 

fcrupule.

Mêlez ces drogues.

\section{A RTICLE XXX.}

Le Caftorcum n'eft pas moins utile dans la Paralyfie que dans la Goutte, comme ien fuis convaincu par une infinité d'exemples, of ce feroit perdre le tems que de repéter ici ce que jai dit de fes differens u jages or de fon utilité dans la premiere de ces maladies. Il Suffit que le Lecteur Sache quil peut être d'un grand fecours aux Perfonnes goutteufes, comme un Miniftre d'une Paroiffe des environs de cette Ville, peut en rendre témoignage.

Le Caftoreum eft auffi fort utile dans les maladies qui affectent la Poitrine, comme nous en afjurent les Awteurs anciens of modernes.

\section{ADDITION.}

Nous éprouvons tous les jours la vertu qu'a le Caltoreum de fortifier les nerfs, en corrigeant \& en confumant, au moyen du foufre pénétrant qu'il contient, les férofités fuperflues \& les 


\section{DU CASTOR.}

parties hétérogenes qui relâchent \& qui picotent les nerfs \& caufent des douleurs exceffives. Les Anciens n'ont

X X.

ins utile dans utte, comme finité d'exemems que de relifferens ufages -emiere de ces eur facbe quil s aux PerfonMiniftre d'une te Ville, pent

$t$ utile dans les itrine, comme inciens \& mo-

$N$.

les jours la de fortifier les n confumant, énétrant qu'il iperflues \& les point ignoré cet effet, comme il paroît par ce paffage de $Z$ wicherus.' $L e s M^{\prime}$ decins font tellement convaincus de l' efficacité du Caftoreum pour fortifier les nerfs, quils l'employent prefgue toujours dans les remedes quiils ordonnent.

„Le Caftoreum eft extrêmement sfalutaire, dit Fuchfius, à ceux dont »les nerfs font relâchés \& affoiblis par wdes humeurs vifqueufes \& groffieres „qu'il diffout $\&$ diffipe, pour redonner „à ces parties la force dont elles étoient "privées. " Nous fçavons même par expérience, continuê cet Auteur, quelques lignes plus bas ; $s$ qu'il eft extrêsmement propre à exciter les ordinaisses, à faciliter l'accouchement \& à sfortifier les nerfs, ce qui fait que nous sl'employons fréquemment à cet ufasge.

Je trouve à propos de joindre aux authorités précédentes, celle de Wolfart, qui guérit le 16 Juin 1569. la fille du Docteur Rabi, qui étoit fujette aux fluxions fur les parties mufculeufes 
184

\section{T R A I T E'}

d'une paralyfie du pied droit, qui avoit réfifté à differens remedes, au moyen du fuivant.

Prenez Pilules dorées.

Sine quibus, ana demi dragme.

Caftoreum, demi fcrupule.

Faites-en avec du Syrop de Suc de Fenouil, des Pilules au nombre de dixneuf, que l'on prendra cinq heures avant le dîner.

Prenez Serpolet, une pincée.

Sauge, demi pincée.

Bois de Geniévre.

Caftoreum.

Pirethre, ana une dragme.

Maftic, deux fcrupules.

Huile de Coftus, dans la. quelle on aura mis des

Fleurs de Romarin, trois onces.

Vin excellent, deux onces.

Faites bouillir le tout, jufqu’à ce que le vin foit confommé, \& faites-en un onguent, dont vous oindrez le pied malade deux fois par jour auprès du feu. 
it , qui avoit

, au moyen

us,ana demi

mi fcrupule.

op de Suc de mbre de dixcing heures

pincée. incée.

vre.

une dragme. crupules. Aus, dans la. ura mis des omarin, trois , deux onces. , jufqu'à ce que $\&$ faites-en un indrez le pied jour auprès du

\section{DU CASTOR.}

C'eft ici le lieu de parler d'une Poudre, dont un Moine communiqua le fecret à Nicolas Stokerus, \& qui produit des effets admirables dans la Paralyfie. Il paroît que le Cinabre eft en ufage dans la Médecine, depuis deux cent ans.

Prenez Caftoreum. Cinabre.

Pivoine, ana un fcrupule. Mufc, deux grains.

\section{Mêlez ces drogues.}

On donnera ce remede dans une décoction de Germandrée. Celle d'Ivette eft préférable à toutes autres, comme je l'ai fouvent éprouvé.

Ce même Auteur recommande l'Emplâtre fuivant dans la Paralyfie des nerfs \& dans la Goutte fciatique.

Prenez Ràine d'Acorus. Coftus amer. Ariftoloche ronde. Lys célefte, ana une once. Feuilles ou Suc de Primevere. Sel commun, 
Lavande.

Ivette.

Mufcade, ana demi-once.

Poivre blanc.

Moutarde.

Pirethre.

Euphorbe.

Caftoreum, ana trois dragmes.

Squinant.

Maftic.

Coquo.

Sel Ammoniac préparé, ana une once \& demie.

Narciffe, demi-once.

Térébenthine, une once \&

- demie.

Laudanum.

Cire, ana cinq onces.

Mêlez ces drogues \& faites»en un Emplâtre.

Je fus appellé, dit Eckold, le 14 Novembre 1580 , chez le Docteur Wolfart, dont la fille ne pouvoit plus marcher. Elle reffentoit des douleurs violentes dans le dos, \& fes ordinaires 


\section{DU CASTOR. 187}

avoient ceffé depuis neuf femaines. Comme ce n'étoit autre chofe qu'un relâchement des nerfs, qui avoit fa caufe dans la matrice, je lui ordonnai le remede fuivant, qui produifit tout l'effet que je m'en étois promis.

Prenez Pilules foetides, un fcrupule \& demi.

trois drag-

préparé, ana demie.

ii-once.

une once \&

onces.

faiteseen un

ckold, le i4 le Docteur e pouvoit plus des douleurs fes ordinaires

Caltoreum, demi dragme. Trochifque alhandal, trois grains.

Faites des Pilules de groffeur médiocre, avec du Suc de Rue.

Prenez Safran, une dragme.

Aloës, demi-once.

Mirrhe, deux dragmes.

Caftoreum.

Canelle, ana deux fcrupules. Semences de Fenouil. de Perfil.

de Marjolaine, ana demi dragme.

Bois d'Aloës.

Caffia lignea.

Corne de Cerf, ana un fcrupule.

Riiij 
Rhubarbe choifie \& pulverifée.

Racine de Couteurrée.

Epithyme, ana une dragme. Feuilles de Sené , trois dragmes.

On pulverifera ces drogues \& l'on en fera une maffe avec du Syrop de Betoine, dont on prendra une dragme une fois par femaine, après lui avoir dónné auparavant la forme de Pilules médiocres.

Pierre Bitterlin, ayant été attaqué d'un racourciffement de nerfs, Geiger l'en guérit par le fecours des frictions, avec du Caftoreum, de la Semence d'Anis \& du Soufre.

Le 3 Juin I $58 \mathrm{I}$, Jean Plebft, ayant été privé tout d'un coup du mouvement des yeux, Kuchel le guérit de cette incommodité avec l'Onguent fuivant, dont il lui oignit la moëlle épiniere, après avoir ufé auparavant des remedes convenables.

Prenez Graiffe d'Heriffon. Beurre frais. Huile Rofat.

de Rue, ana quatre onces. 
\& pulveri-

euvrée.

ne dragme. trois drag-

es \& l'on en $\mathrm{p}$ de Betoiragme une avoir dónné ules médio-

été attaqué ifs , Geiger es frictions, la Semence

lebft, ayant 1 mouvement érit de cette tent fuivant, lle épiniere, des remedes

Ton.

ana quatre

\section{DU CASTOR. $\quad 189$}

Caltoreum, une dragme. Encens, demi dragme. Térébenthine, deux onces.

Mêlez \& faites-en un onguent.

Heldius délivra en 1649 , la femme de Jean Akermann, des douleurs vagues qu'elle reffentoir dans les pieds, avec longuent fuivant, après lui avoir ordonné auparavant l'ufage des tifanes.

Prenez Onguent ne vin, une once $\&$ demie.

Suif de Cerf, une once.

Huile de Camomille. de Lys blanc. de Caftoreum, ana.

Mêlez ces drogues.

Le 7 Août de la même année, Villingerus ordonna le Topique fuivant à Walpurge Gailbacherin, qui reffentoit des douleurs dans les bras \& dans la nucque.

Prenez Eau dorée de Langius, une once \& demie.

d'Hirondelles, avec du Caftoreum, deux onces. 
de Lavande, ana une once \& demic.

Efprit de Muguet, fix gros. Mêlez ces drogues.

Prenez Huile de Caftoreum, fix dragmes. de Rue.

de Vers de terre, ana demi-once.

Ce fut avec ces trois Huiles exactement mêlées, que Jacques Zæeemann, delivra le fils d'un Soldat de cette Ville, nommé Langius, des douleurs cruelles qu'il reffentoit dans les pieds.

Le s Seprembre 1646 , George Tonner, Laboureur à Altheim, tombafur fon dos d'un lieu fort élevé. : $U n$ Chirurgien à qui il s'adreffa lui ayant ordonné un Emplâtre pour appaifer les douleurs qu'il reffentoit dans le bras droir, il produifit un fi mauvais effet, qu'il le mit hors d'état de s'en fervir. Zaemann, qu'il fitappeller, ayant mûrement examiné la chofe, lui ordonna de s'oindre l'épine du dos avec l'Onguent fuivant, qui le guérit parfaitement. 
de, ana une let, fix gros:

oreum, fix

le terre, ana

Iuiles exactes Zaemann, e certe Ville, leurs cruelles eds.

6 , George theim, tomrt élevé. :Un ffa lui ayant our appaifer $t$ dans le bras zauvais effet, de s'en fervir. $r$, ayant mû, lui ordonna s avec l'Onéric parfaite-
D U C A STOR. IgI Prenez Huile de Vers de terre. de Caftoreum. de Renard, ana une once.

Mêlez ces drogues.

Le Topique fuivant eft admirable pour fortifier les parties \& leur rendre le mouvement qu'elles ont perdu.

Prenez Bayes de Geniévre, deux poignées.

Sommités de Romarin.

de Marjolaine.

de Sauge, ana une poignée.

Caftoreum, fix gros.

Mettez ces drogues en infufion au Soleil, pendant trois jours, dans huit onces d'Efprit de vin rectifié \& après en avoir exprimé la liqueur, ajoutez-y :

Eau de Magnanimité, dêux onces.

Efprit de Vers deterre, une once \& demie.

Camphre, une dragme.

Mêlez ces drogues. 


\section{2 \\ T RAITE'}

Prenez Vers de terre , trois onces. Racine de Patience rouge. de Pivoine, ana une once.

Feuilles de Germandrée. de Rue. de Bouillon blanc:

Fleurs de Lavande, ana une poignée.

Sommités de Marjolaine, trois poignées. Semences de grande Ortie ; deux gros. Bayes de Laurier, deux pugiles. de Geniévre ， demi livre.

Huile de Caftoreum. de Geniévre. de Vers de terre, ana une quantité fuffifante.

Mettez ces drogues en digeftion pendant quatorze jours dans un lieu chaud, exprimez les, \& ajourez à la colature :

de la Moëlle de jambe de Bœuf, trois onces. 


\section{DU CASTOR.}

ois onces:

ce rouge.

ie, ana une

zandrée.

llon blanc.

de, ana une

Marjolaine ,

inde Ortie ;

$r$, deux pu-

re , demi

eum.

re.

e terre, ana uffifante:

igeftion penilieu chaud, $z$ à la colatu=

le jambe de onces.
Graiffe humaine, cinq onces.

Huile de Pétrole.

Maftic.

Mirrhe, ana une once.

Mêlez ces drogues felon l'art, \& gardez ce Baume Arthritique pour l'ulage.

Il eft impoffible de donner à ce Baume les louanges qu'il mérite, c'eft pourquoi je laifle le foin au Lecteur d'en faire l'expérience. Je puis cependant affurer que j'ai guéri avec lui un grand nombre de perfonnes de la Gcutte, \& des douleurs cruelles qu'elles reffentoient dans les Articles.

Rien n'eft plus efficace que le Caftoreum dans l'Afthme, qui eft caufée par les vents, \& dans les convulfions occafionnées par des particules âcres , qui irritent les nerfs \& les"membranes.

Marius qui n'ignoroit point fes bons effets, ordonna à une femme extrêmement âgée \& fujette à l'Afthme, des Pilules compofées d'un Extrait de Caftoreum, de Safran \& d'Huile d'Anis, qui eurent tous le fuccès qu'il s'en étoit promis.

Celles qu'Eckold ordonna en I 575 ; 
à Leonard Huterus, qui étoit incommodé de la toux, font à peu près les mêmes.

Prenez Trochifque d'Agaric récent, diffous dans de l'Oxymel, demi dragme.

Caftoreum en poudre, demi fcrupule.

Maftic, fix grains.

Safran, huit grains.

Huile d'Anis, extrait felon les regles de la Chimie, trois gouttes.

Mêlez ces drogues enfembles, \& formez-en des Pilules ordinaires.

Martin Neufart guérit, en I 569 , Ottilie Neuthardin, d'une oppreffion de poitrine, avec le Topique fùivant.

Prenez Huile d'Iris, une once.

$$
\text { d'A neth. }
$$

Axonge de Poule, ana deux dragmes.

Sel Ammoniac, diffous dans du Vinaigre de Squille, une dragme.

Caftoreum en poudre, un fcrupule. 


\section{DU CASTOR.}

Ajoutez à ces drogues un peu de Cire pour leur donner la confiftance d'un onguent mol.

J'ai fouvent éprouvé l'effet du remede fuivant dans l'Afthme caufé par un fang flutueux qui retournoit des hypochondres op de l'uterus par les veines dans les fuumons.

Prenez Emplâtre du fils de Zacharie.

Dia Sulphuris R. ana une quantité fuffifante.

Malaxez ces drogues avec une quantité fuffifante d'Huile de Caftoreum , \& ajoutez Huile diftilée d'Anis, fix gouttes.

\section{A R T I C L E XXXI.}

Le Caftoreum rieft pas moins utile pour detruire les Landes of les Pous qui viennent à la tête of fur les autres parties du corps. Les enfans ne font pas les Senls qui ayent éprouvé l'effet de ce remede, os je me fouviens d'avoir délivré une femme de ces infectes dont elle avoit été long-tems in- commodée.
, diffous dans de Squille, poudre, un ule, ana deux

t, en I 569 , oppreffion
e füivant.

ine once.

ins. ains.

extrait felon la Chimie,

nbles, \& forires. 


\section{I96 TRAITE \\ $A D D I T I O N$.}

Adam Zwicker, attribue au Caftoreum la vertu de tuer la vermine. » On sconnoit, dit cet Auteur, les Ani»maux qui s'engendrent fur le corps ss humain, \& qui deviennent quelque. „) fois fi incommodés qu'ils rendent la s) vie infuportable. Le Caftoreum a la »vertu de les détruire de quelque masniere qu'on l'employe, furtout lorfsqu'on en faupoudre la partie, après „l'avoir réduit en poudre.c

Neufart employe le Caftoreum avec l a fa foetida, en forme de fumigation pour tuer les Pous, \& l'on ne doit point rejetter fa methode.

Schappierus fe fert du remede fuivant pour le même effet.

Prenez Savon de Venife, trois dragmes.

Camphre.

Caftoreum.

Oliban, ana quinze grains.

Ajoutez à ces drogues une quantité fuffifante

fuf

$\mathrm{Vi}$

UI

un

bail

foi

il $\mathrm{F}$

dit

nai

unt

qu'

yet

qui

me

plu da fe:

bât

orc

ma

per

par

ver

des

vol

me 


\section{DU CASTOR.}

fuffifante de fuc de Balfamine \& de

$O N$.

ue au Caftoermine. » $\mathrm{On}$ ur, les Anifur le corps hent quelqueils rendent la aftoreum a la quelque ma, furtout lorpartie, après .ce.

aftoreum avec de fumigation $\mathrm{n}$ ne doit point

remede fuivant

enife, trois

quinze grains.

es une quantité fuffifante
Vin brulé pour faire un liniment.

Jean Vogtius, autrefois Médecin à Ulm, regardoit le Caftoreum comme un fpecifique dans la maladie pedicukaire. Il s'en eft même fervi plufieurs fois avec beaucoup de fuccès, comme il paroît par l'exemple fuivant.

J'ai connu il y a environ trente ans, dit cet Auteur, un homme fexagenaire, extrêmement riche, qui avoit une fi grande quantité de Pous, qu'il ne pouvoit plus faire ufage de fes yeux. Ils ne s'étendoient pas plus loin que les épaules \& rempliffoient tellement les oreilles, qu'on n'y diftinguoit plus aucune cavité. Il ne reffentoit d’ailleurs aucune autre incommodité \& fe promenoit dans fa maifon avec un bâton. Son Medecin ordinaire lui ayanț ordonné des remedes contraires $\grave{a} . \mathfrak{f} \dot{a}$ maladie, ces infectes fe répandirent peu à peu par tout fon corps, \& s'emparérent d'abord de la poitrine, du ventre, du dos, des jambes \& enfin des pieds. Il devint auffi extrêmement vorace, \& ufoit d'une quantité d'alimens prefque incroyable. Je le guéris. $\mathrm{S}$. 
enfin en peu de tems avec du Mufc \& du Caftoreum, après l'avoir purgé auparavant.

Voici la compolition de l'Onguent dont Marius fe fervic pour guérir la Dame dont j'ai parlé, de cette fâcheufe maladie.

Prenez Vieille Axonge, demi-once. Térébenthine.

Huile de Laurier, ana deux gros.

$$
\begin{aligned}
& \text { Diftillée de Lavande. } \\
& \text { d'Abfinche , }
\end{aligned}
$$
ana un gros.

Caftoreum, quatre fcrupules.

Mirrhe, un fcrupule.

Mêlez ces drogues \& faites-en un onguent.

Melderus vante beaucoup l'onguent fuivant, qu'il prétend être tr ès-efficace pour détruire les Pous qui ulcérent la tête.

Prenez Onguent Rofat M. fix gros. Inucilage de Semence de Lin Extrait avec de l'Eau de Lavande, demi-once. Huic d'Abfinthe. 
Mufc \& du purgé aupa-

e l'Onguent ur guérir la ette fâcheufe

, demi-once. r, ana deux de Lavande. d'Abfinthe ,

uatre fcrupu-

crupule.

faites-en un

oup l'onguent e tr ès-efficace ui ulcérent la

it M. fix gros. emence de $\mathrm{Lin}$ ec de t'Eau de demi-once. the.
DU CASTOR. 199 de Laurier, ana deux gros.

Semence de Staphifaigre.

Caftoreum, ana un fcrupule. Cire blanche, autant qu'il en faut.

Faites un onguent.

Jean Stokerus ordonne dans fa pratique manufcrite le Caftoreum, nonfeulement pour la maladie pediculaire, mais encore pour la teigne.

Prenez Soufre vif, deux onces. Ellebore blanc \& noir. Chaux vive. Mercure éteint. Caftoreum, ana une once, Litharge, deux onces.

Pilez \& criblez ces drogues \& incorporez-les avec de l'axonge de Cochon, pour en faire un onguent.

Il eft encore à propos de s'oindre la tête avec de l'Eau d'Hirondelles \& du Caftoreum. J'ai fouvent éprouvé l'effes dece remede. 


\section{0 \\ T R A I T E' \\ ARTICLE XXXII.}

Le Caftoreum eft encore très-efficace pour lever les obftructions des Reins, comme jele prouve dans ma pratique manufcritte.

$$
A D D I T I O N \text {. }
$$

Marius recommande le Caftoreum dans les obftructions des Reins, comme un remede dont il a éprouvé les effets. Il ne paroît point par fon manufcrit qu'il l'ait eruployé intérieurement, mais il affure que le Liniment fuivant eft très-efficace.

Prenez Onguent de Dialthea. Graiffe d'Oye , ana trois dragmes. Huile de Camomille. de Scorpion, ana une dragme.

Blanc de Baleine, un fcrupule \& demi.

Caftoreum, demi fcrupule. Mêlez ces drogues. On en oindra la region des Reins. 


\section{DU CASTOR. 20.r}

Wolfart ordonne un femblable remede pour cette maladie.

Prenez Graiffe de Poule, une once. Caftoreum en poudre, une dragme.

Safran, un fcrupule.

Baies de Genevrier, demionce.

Huile de Sefame, fix dragmes.

Mêlez ces drogues.

L'Huile de Caftoreum Térébentinifée eft auffi utile que la compofition en eft facile, \& l'on ne peut mieux faire que de s'en fervir. On ne doit point. rejetter l'effence de Caftoreum extraite. avec de l'Efprit Térébentinifé.

Le Topique fuivant eft de la compofition de Geigerus.

Psenez Huile de Melitot.

de Caftoreum, ana. demi-once.

Sel de Geniévre, une dragme.

Mêlez ces drogues.

ion, ana une

he, un fcrupu.

emi fcrupule. des Reins. 


\section{T R A I T E'}

J'ai guéri dernicrement avec cet onguent un enfant de douze ans, d'une douleur dans le rein droit, accompagnée d'une fuppreffion d'urine ; après lui avoir fait prendre les bains \& donné une potion altérante. La douleur ceffa $\&$ il rendit une pierre tranfparente du poids de fix grains.

On trouve dans Didyme, la compo. fition d'un remede interne pour les obftructions des Reins, dont le Caftoreum fait la bafe. Chriftophe Reifer, Marchand Libraire, s'en eft fervi avec fuccès.

Prenez Semence de Millet bis.

Térébentine féche.

Pepins de Nefles, ana une once.

Diacaftoreum, une dragme. Yeux d'Ecreviffes, demi dragme.

Corail rouge.

Coques d'oufs, ana une dragme.

Hermodacte, deux fcrupules.

Sucre Rofat en tablettes, fix onces. 


\section{DU CASTOR. 203}

ne avec cet ze ans, d'une it , accompaIrine ; après ains \& donné douleur ceffa nfparente du

e, la compopour les obfle Caftoreum Reifer, MarIt fervi avec

illet bis. che.

fles, ana une

une dragme. viffes, demi

is, ana une deux fcruptn tablettes, fix
Mêlez ces drogues \& faites-en une Poudre, dont vous donnerez deux dragmes foir \& matin au malade.

Il eft inutile que je m'arrête plus long-tems fur cette matiere, car perfonne n'ignore que ces effets font une fuite de la vertu qu'a le Caftoreum, d'appaifer les irritations du genre nerveux, de délayer \& de diffoudre la férofité qui féjourne dans les Parties.

\section{A R T ICLE XXXIII.}

Le Caftoreum eft un excellent Stomachique ơ a fouvent été d'une grande utilité : il fait ceffer le Hoquet, il eft bon contre les Spafmes, la Céphalalgie of l'A Afoupifsement.

Tiré pä le nez il fait éternuer א. purge lecerveau; il appaife \& fait ceffer le Coma ó fa fumée provoque le fommeil, comme je laifouvent éprouvé.

\section{ADDITION.}

Le Caftoreum eft d'un grand fecours dans les maladies du ventricule, furtout 


\section{T R A I T E'}

dans le Hoquet qui eft caufé par des particules âcres \& malignes qui picotent \& déchirent fon orifice fupérieur, \& le Diaphragme. Il poffede même une vertu ballamique $\&$ un fel volatil huileux , qui le rend propre à remedier aux contractions \& aux tenfions des nerfs.

Delà vient que les Auteurs le regardent comme un remede efficace, ainfi qu'il eft aifé d'en juger par les exemples qui fuivent.

L'An I 549, Simper Linfius, ordonna à Jean Stebenhaber, qu'un Hoquet opiniâtre empêchoit de dormir, d'ufer matin \& foir de la confection fuivante à la dofe de la groffeur d'une noix, ce qui lui rendit la fanté.

Prenez Coings confits.

Enule confite, ana cinq dragmes.

Ecorce d'Oranges confites. Racine de Paftenaque confite, ana demi-once. de Pimprenelle confite , cinq dragmes. Calamus Arom, confit, trois dragmes. Ecorce: 
aufé par des es qui picoe fupérieur, flede même n fel volatil e à remedier tenfions des

urs le regarficace, ainfi les exemples

Linfius, or, qu'un $\mathrm{Ho}$ de dormir, a confection roffeur d'une anté.

, ana cinq nges confites. tenaque confini-once. prenelle confiigmes. a, confit, trois Ecorce:

\section{DU CASTOR.} Ecorce de Citron confite,
deux dragmes.

Acacia , confit.

Zingembre I. confit, ana demi-once.

Conferves de Rofes. de Menthe. de Racine d'Acorus, ana deux dragmes. Species Dialangal, une dragme.

Caftoreum pulverifé, demi dragme.

Canelle, un fcrupule.

Jucifez groffierement les Aromates \& les Contitures \& mêlez les enfemble pour en faire un Electuaire.

Le même Auteur ordonna en I 554 l'Electuaire fuivant à Louis Fifchacher, qui avoit la même incommodité, \& l'effet n'en fut pas moins prompt.

Prenez Conferves de Rofes, trois onces.

d'Ozeille.

de Bourrache, ana demi-once. 


\section{T R A I T E'}

Caftoreum choifi, une dragme.

Species Arom. Ror. une dragme \& demie.

Mêlez ces drogues.

Il donna en 1560 , le Bol fuivant à Jacques Schelder, qui étoit incommodé du Hoquet.

Prenez Electuaire des trois Santaux, deux dragmes.

Diacordium.

Hiere fimple, ana une dragme.

Hiacinth. quatre fcrupules. Species Diacaftoreum, un . fcrupule.

Mêlez ces drogues \& faites-en un Bol.

Jean Keller guérit en 1 582 , André Stromaier du Hoquet, avec le remede fuivant.

Prenez Syrop de Menthe, fix dragmes.

de Canelle.

d'Aigre de Citron. de Gelée de Coings, ana demi-once. 


\section{DU CASTOR.}

, une drag-

\section{Rof. une} mie.

3ol fuivant à toit incom-

ois Santaux,

Eau de Menthe. d'Hyfope. de Canelle, ana deux onces.

Caftoreum choif, un frupule.

Mêlez ces drogues.

Il oignit la région de l'eftomac avec le liniment fuivant.

Prenez Huile de Maftic. de Menthe. once. d'Abfinthe, ana une

Poudre de Caftoreum. de Labdanum. de Myrrhe, ana une dragme.

Civette, cinq grains. Eau de Vie, demi-once. Mêlez \& faites un liniment.

Melderus délivra en 1628 , Jean Ulric Fliker Orfévre, d'un Hoquet dont il étoit affligé depuis environ quatre mois avec les remedes fuivans.

\section{$T$ ij}




\section{T R A I T E'}

Prenez Syrop de Myrrhe, deux dragmes. de Menthe, demionce.

Confection alkermes, un fcrupule.

Caftoreum, trois grains. Eau de Vie Matth. demionce.

Mêlez ces drogues \& faites-en une potion.

Prenez Poudre de Caftoreum, demie dragme. Térébenthine, une dragme. Emplâtre de Maftic, demionce.

Huile de Coing, \& de la Cire, une quantité fufffante.

Mêlez \& faites un Cérat.

Il guérit auffi le 16 Août 1632 , un Tailleur, nommé Jean Sontag, d'un Hoquet opiniâtre, avec ces Pilules.

Prenez Extrait de Caftoreum, fix gouttes.

Civette, une goutte.

de

M 


\section{DU CASTOR.}

Laud. Opiat. deux gouttes.

Mêlez \& faites des Pilulss.

he, demi-

ermes, un

is grains.

latth. demi-

faites-en une

Le Docteur Michel recommande uniquement le Caftoreum, fur tout fon Extrait \& fon Effence, pour le Hoquet.

Wedel a obfervé que le Cafto reum, en Effence, fait ceffer les Hoquets les plus opiniâtres.

Je guéris il y a un an avec l'Effence de Caftoreum mêlée avec de l'Eau de Maftic Guernerus Menfinger, d'un Hoquet très-incommode, caufé par la graiffe d'une chair endormic, après lui avoir donné auparavant un Emétique convenable.

Je ne dois point laiffer ignorer au Lecteur la vertu qu'a le Caftoreum pendu à un fil, en forme d'amulette pour faire ceffer le Hoquet, fans qu'il foit befoin d'obferver l'heure \& les autres cérémonies fuperftitieufes. J'en ai éprouvé l'effet fur une jeune fille, ce qui fait voir qu'on peut ajouter foi à cet efpece de remede.

oût 1632 , un Sontag, d'un c ces Pilules.

Caftoreum, fix

Le Caftoreum contribue beaucoup à faire ceffer les Spafmes, en altérant \&. diflipant les particules rudes, aufteres, T iij 


\section{T R A I T}

âcres \& étrangéres qui les caufent. Ekold avoit coutume de le donner pour cet effet en forme de Pilules, mêlé en quantité égale avec l'efpece de Hiere Piere.

Chriftophe Ehinger ordonna avec fuccès à la Veuve de Eberhard Ungelterus, qui étoir fujette aux Spârnes un Liniment d'huile de Caftoreum, dans laquelle on avoit fait bouillir des Grenouilles vertes.

L'an 1587. Marc Wolfart, Médecin à Memmingen, fit ceffer des convulfions, caufées par les vers, avec de l'Eau d'Hirondelles, de Rue \& de Caftoreum, maceré dans du vin, diftillée \& mêlée àvec quelques gouttes. d'eau de Fleurs de Tilleul, de Muguets \& du Sucre.

Jean Keller fait beaucoup de cas des remedes fuivans avec lefquels il délivra la femme de Jacques Wilhalm, des convulfions aufquelles elle étoit fujette, après avoir auparavant ufé de préparatifs convenables.

Prenez Caftoreum choifi, une drag: me. 


\section{DU C A S T O R.
Syrop de Strechas, une once.
Décoction de Sauge, d'A-
neth \& de Betoine, une
quantité fuffifante pour \\ DU C A S T O R.
Syrop de Strechas, une once.
Décoction de Sauge, d'A-
neth \& de Betoine, une
quantité fuffifante pour \\ DU C A S T O R.
Syrop de Strechas, une once.
Décoction de Sauge, d'A-
neth \& de Betoine, une
quantité fuffifante pour \\ DU C A S T O R.
Syrop de Strechas, une once.
Décoction de Sauge, d'A-
neth \& de Betoine, une
quantité fuffifante pour \\ D U C A S T O R.
Syrop de Strechas, une once.
Décoction de Sauge, d'A-
neth \& de Betoine, une
quantité fuffifante pour} une gorgée:

lonna avec ard Ungelaux Spâmes. Caftóreum , bouillir des

fart, Médefier des convers, avec de Rue \& de lu vin, diftilques gouttes. al, de $\mathrm{Mu}$ up de cas des uels il délivra Vilhalm, des e étoit fujette, ufé de prépa-

ifi, une drag:

es caufent.

onner pour e de Hiere

Prenez Huile de Renard. de.Vers de terre. de Caftoreum, ana demi-once.

\section{Onguent Dialth. de Bdellium, ana} deux dragmes \& demie.

La folution faite, oignez-en la partic affligée deux fois par jour.

Ce même Médecin ordonna le liniment fuivant à Jean Haripronner, Marchand extrêmement riche, qui étoit fujet à des Spâmes frụ́ ýlens.

Prenez Huile de Caftoreum. de Vers de terre, ana deux dragmes. de Geniévre, une dragme.

Vin fublimé, demie dragme. Mếlez ces drogues. 


\section{T RAIT E'}

Chriftophe Mangius Libraire à Aufbourg, revenant de prendre les aigrelettes, fut faifi d'une fiévre violente \& de convulfions Spâmodiques dont $\mathrm{Da}$ vid Verbez le délivra le 6 Septembre I 6 I 3 , avec les remedes fuivans.

Prenez Thériaque d'âge moyen, une dragme.

Extrait de Caftoreum , demi fcrupule.

Eau de Chardon bénit, trois onces.

Syrop de Fumeterre, une once.

Mêlez \& faites une potion fudorifique.

Prenez Huile de Renard. de Coftus. de Vers de terre, ana une once \& demie.

Fleur Anthos. -

Sommités de Sauge. de Betoine, ana une pugille.

Caftoreum.

Styrax.

Encens, ana une dragme. 


\section{DU CASTOR.}

213

Eau de Betoine.

Vin blanc, unequantitéfuffi-

fante.

Mettez ces drogues en décoction \& coulez-les pour un liniment.

On trouve dans les Ouvrages de $\mathrm{Mi}$ chel, une autre remede pour les Spâmes, compofé d'Huile de Vers de terre, de Caftoreum, d'Euphorbe, d'Huile diftillée de Sauge, de Romarin \& de Lavande.

Wedelius fait beaucoup de cas de l'effence \& de l'efprit de Caftoreum, dans. les Spâmes des Femmes qui font en travail, lorfqu'on en oint les jointures, fuivant la direction des nerfs.

Les Anciens mettent le Caftoreum au nombre des fternutatoires, à caufe de l'âcreté, de la volatilité \& de l'inégalité de fes particules qui le rendent propre à irriter la tunique du nez. On ve s'en fert plus aujourd'hui, parce que fon odeur eft trop défagréable ; je ne laifferai pas cependant de rapporter quelques exemples des bons effers qu'il produit. Le Docteur Eckold prife beau. coupla Poudre fuivante. 
Mêlez.

$$
\begin{aligned}
& \text { T R A I T E } \\
& \text { Prenez Poudre de Marjolaine: } \\
& \text { d'Ellebore. } \\
& \text { de Pyrethre, ana de. } \\
& \text { mie dragme. } \\
& \text { de Poivre. } \\
& \text { de Caftoreum. } \\
& \text { de Nielle, ana un } \\
& \text { fcrupule. }
\end{aligned}
$$

Verbez s'eft fervi avec fuccès du remede fuivant dans les Fluxions, fur la. Gorge \& les Poumons.

\section{Prenez Poudre de Muguets. de Racine de Velar, ana demie dragme. de Caftoreum, demi} fcrupule:

Feuilles de Nicotiane.

Poivre blanc.

Gerofles, ana un fcrupule. Mufc, quatre grains.

Mêlez ces drogues \& faites-en une Poudre que vous tirerez par.le nez.

Jean Melderus ordonna en 1631 , le remede fuivant à Paul Nagelin, natif d'Außbourg.. 


\section{DU CASTOR. 2 rs}

Prenez Caftoreum, demi fcrupule. Racine de Pirethre, fix

e.

hre, ana der

e.

reum.

, ana un

uccès du reuxions, fur la.

uets.

ne de Velar, ragme.

reum, demi

otiane.

in fcrupule.

rains.

faites-en une

ir le nez.

a en 1631 ,

1 Nagelin,

\section{grains. \\ Cubebes. \\ Macis. \\ Lavande, ana trois grains.}

Mêlez ces drogues \& faites-en une. Poudre.

Chriftophe Cellarius ordonna pareillement le remede qni fuit, à Georges Eccard, qui avoit une obftruction de. cerveau.

Prenez Fleurs de Lavande, deux. dragmes.

Origan , une dragme.

Marjolaine.

Semence de Sermont: ine:

de Pivoine, ana.

deux dragmes.

Racine d'Ellebore blanc, demi dragme.

Caftoreum, dont l'odeur foit: forte, une dragme.

Réduifez ces drogues en poudre \& mêlez les avec de la Térébenthine \&: de la Cire pour en faire des fternutatoi:res àe forme pyramidale. 


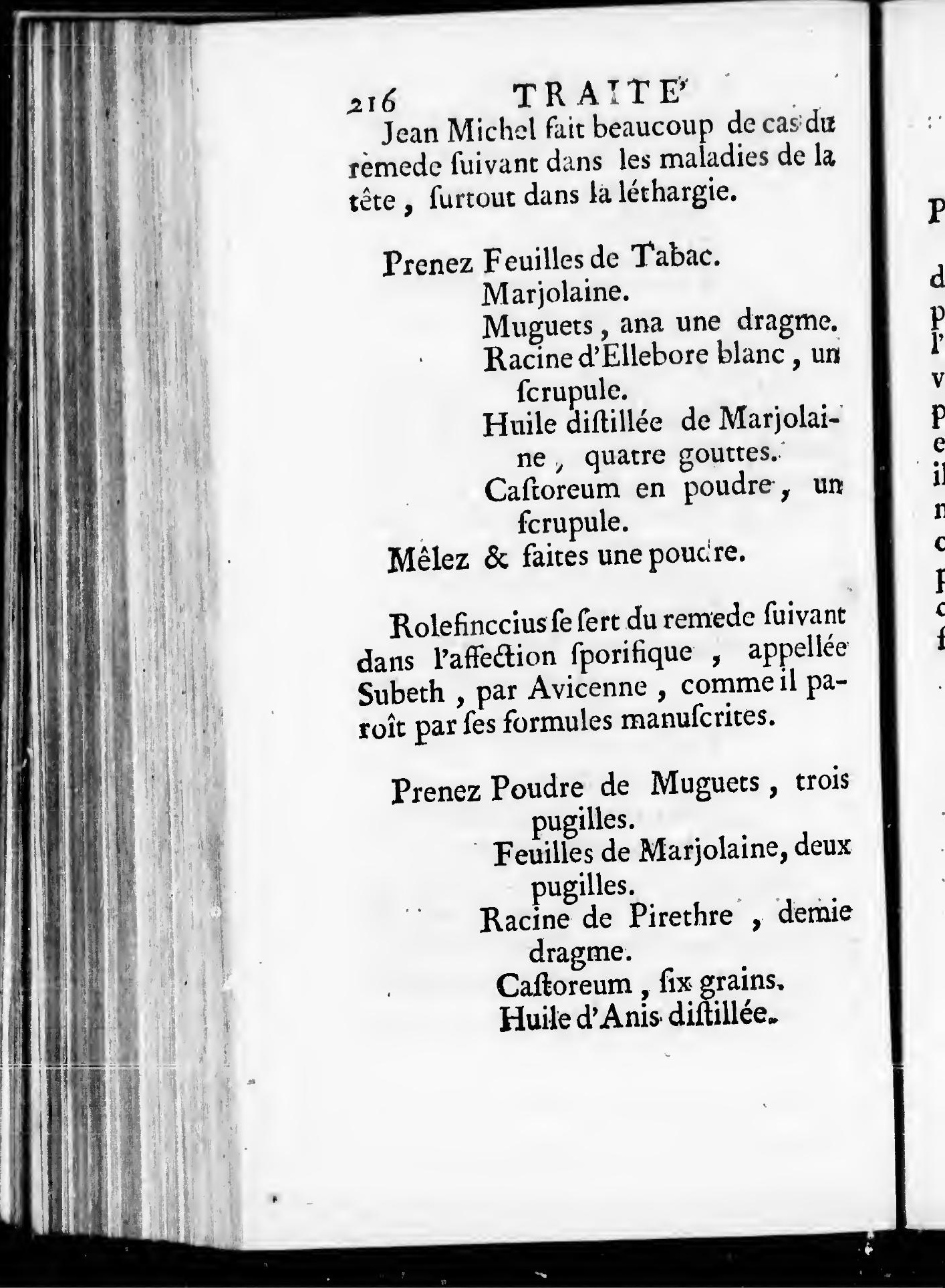




\section{DU CASTOR. de Succin, ana deux gouttes.}

ladies de la rie.

c.

ne dragme. e blanc, un

e Marjolaiouttes.

oudre, un

cire.

nede fuivant , appellée omme il pacrites.

guets, trois olaine, deux are, demie grains. tillée.

Mêlez ces drogues \& faites-en une Poudre.

On fouffle cette Poudre dans le nez des Perlonnes qui tombent en léthargie pour exciter les efprits animaux, où lon fe contente de leur en faire recevoir l'odeur pour rétablir leurs forces, pour difliper les heterogeneités, \& les eccentricités, afin qu'étant en liberté ils purffent exercer leurs fonctions ordinaires \& s'infinuer dans la machine du cœur. C'eft ce que j'ai pratiqué depuis peu avec beaucoup de fuccès à l'égard d'une fille de cette Ville, à qui je fis flairer la compofition fuivante :

Prenez Effence de Caftoreum', de-: mie dragme.

Efprit de Sel ammoniac. de Suye, huit gouttes.

Mêlez ces drogues.

Le Caftoreum procure le fommeil aux perfonnes qui ont des inquiétudes, en liant $\&$ appefantiffant les efprits, furtout étant mis fur des charbons ar- 


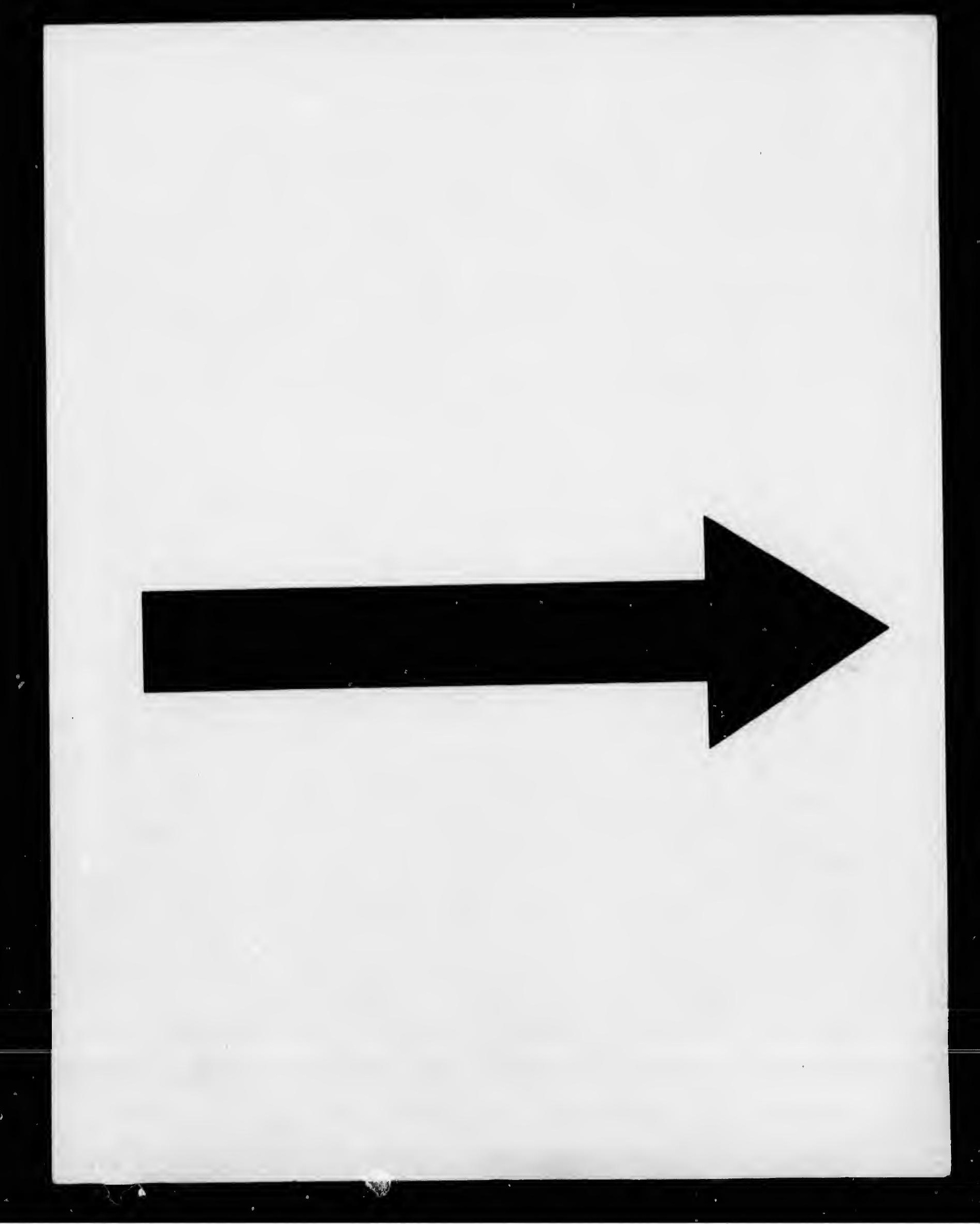




\section{IMAGE EVALUATION TEST TARGET (MT-3)}
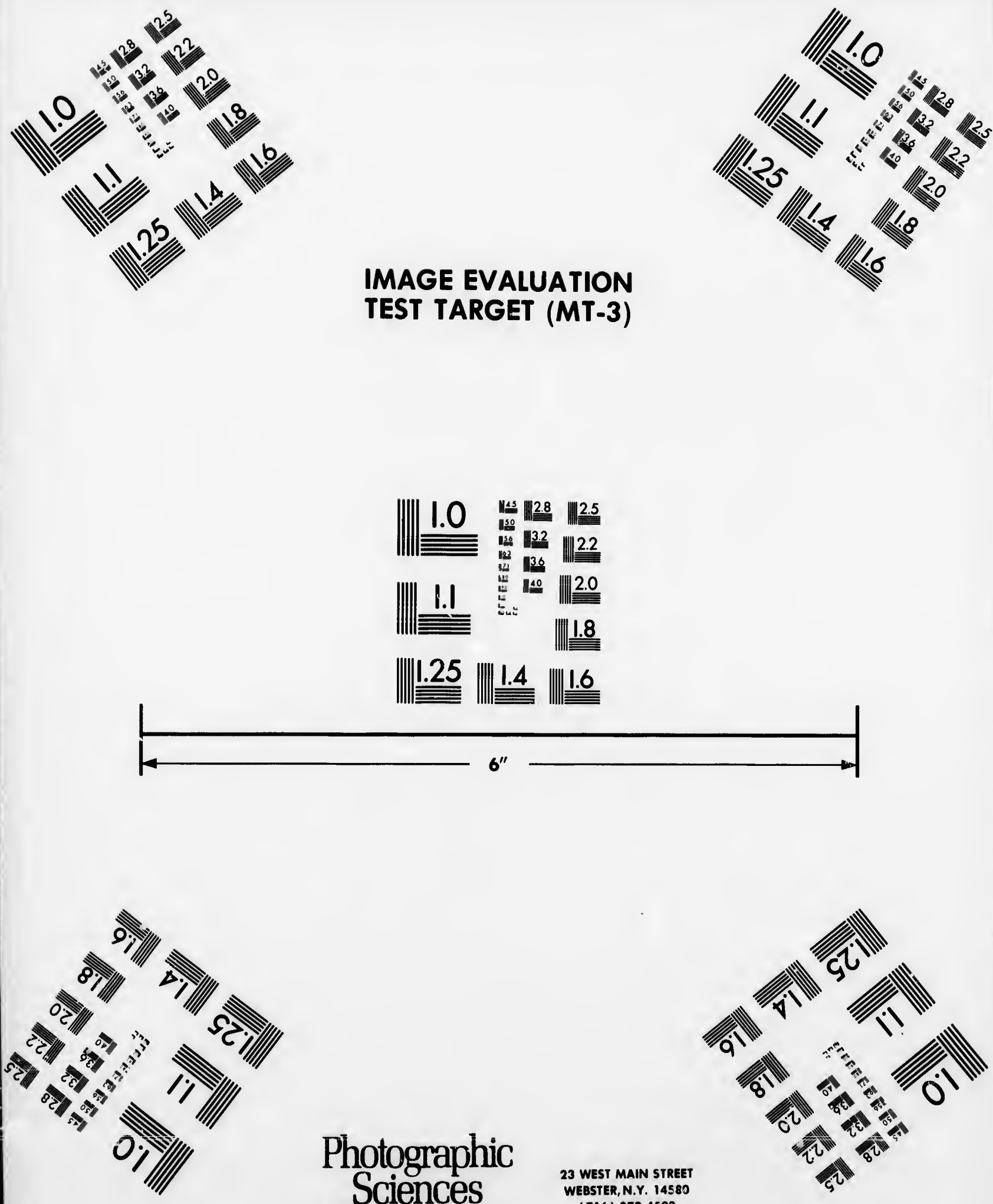

Photographic Sciences Corporation
23 WEST MAIN STREET WEBSTER, N.Y. 14580

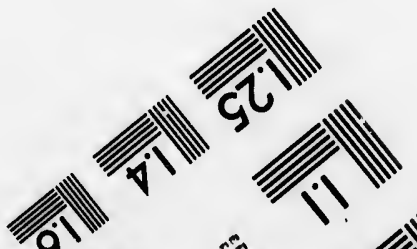

i

8. - 10 (716) 872.4503 


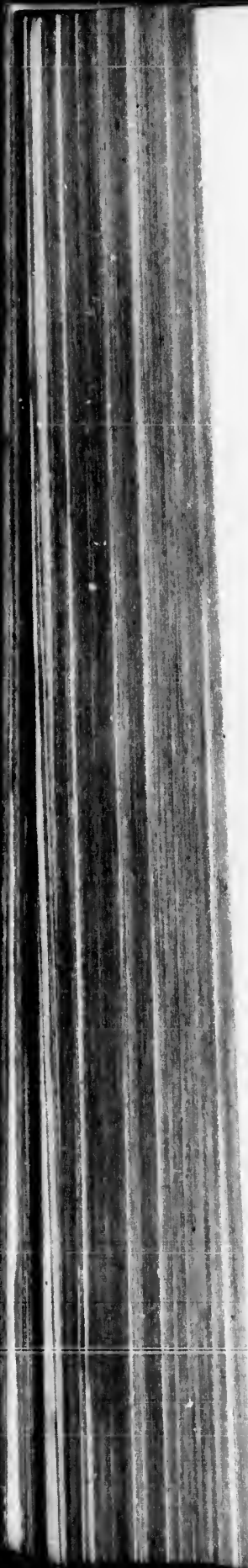

$21 \%$

\section{T R A I T E'}

dens , comme le pratiquent tous les jours nos femelettes à l'égard de celles qui ont une fuffocation de matrice. $L_{a}$ fumée venant à remplir les pores $\mathrm{du}$ cerveau, elles s'affoupiffent, s'appaifent $\&$ ne fe mettent plus en peine de ce qui fe paffe au-dehors.

L'ovum a beaucoup de rapport à cette maladie, mais comme la cure eft la même que celle de la migraine, dont nous avons déja parlé, nous y renvoyons le Lecteur, pour éviter les répétitions inuriles.

Je crois de même qu'il eft inutile de parler de l'engourdiffement, c'eft-àdire ; de cette perception émouffée de fentiment, puifque nous en avons traité ci-deffus, dans l'article de la Paralyfie.

\section{A R T ICLE XXXIV.}

Le Caftoreum eft très-cfficace pour exciter les ordinaires, pour faciliter la fortic de $l$ arricre faix ơ remedier à la Jiffocation de la matrice, comme plufieurs exempiles en font foy. 
tous les de celles matrice. pores du s'appaiine de ce

apport à cure eft ne, dont nvoyons pétitions

inutile de c'eft-àouffée de ons traité Paralyfie.

IV.

e pour exer la fortic la eiffocaeurs exem-

\section{$A D D I T I O N$}

Lorfque l'orgafme du fang vient à ceffer ou que les vaiffeaux de l'uterus fe trouvent obftrués par des particules étrangeres qui furmontent \& enveloppent les balfamiques, les ordinaires ceffent ou diminuent. Le Caftoreum eft propre à remedier à cet accident par fa vertu pénétrante \& digeftive, furtout lorfqu'on le donne à propos, quoique Wedel le croye beaucoup plus efficace dans les maladies de l'uterus, qui afrectent le genre nerveux, que dans les fimples obftructions des vaiffeaux.

Ce que je viens de dire eft confirmé par ce paffage de Gabriel Sivilling , parmi les remedes qui attenuent \& fondent le fang, qui augmentent fa chaleur \& fon âcreté, \& qui relâchent les orifices des vaifleaux, les principaux font le Caftoreum, la Myrrhe, la Racine de Chardon Roland, l'Áriftoloche, l'Herbe au Chat, l'Armoife \& le Pouliot.

De-là vient auffi que l'on trouve dans les Auteurs differentes formules pro- 


\section{T R A I T E'}

220 p̀ ces maladies, dont le Caftoreum fait la bafe. On peut mettre de ce nom-

* bre la potion fuivante avec laquelle Marc W olfart Médecin à Memmingen guérit en I 574 , la femme de Barthelemi Mozen, à la troifiéme dofe.

\section{Prenez Syrop des cinq Racines, une} once \& demie.

Eau de Pouliot.

d'Armoife.

de Menthe fauvage, ana une once.

Caftoreum choifi, un fcrupule.

Mêlez \& faites-une potion pour une dofe.

Le 1o Novembre 1579 , Jean Wolfgang Rabus, ordonna les Pilules fuivantes à la Servante d'Euftache Sunfpurgers, qui étoit Afthmatique, \& dont les ordinaires avoient ceffé depuis quatorze femaines, quatre jours avant le tems du période ordinaire, à caufe que l'effort que fait alors la nature hâte extrêtmement l'effet du remede.

Prenez Pilules foetides. 
Caftoreum e ce nomc laquelle emmingen Barthelefe.

cines, une

fauvage , , un fcru-

n pour une

Jean WolfPilules fuiItache Sunfmatique, \& ceffé depuis jours avant re, à caufe a nature hâte hede:

Myrrhe
Myrrhe, ana demi fcrupule. Caftoreum, un fcrupule. Eau d'Armoife, une quantité fuffifante.

Faites des Pilules compofées.

Stokerus ordonne dans un pareil cas une égale quantité de Caftoreum, d'Acorus, de Semences d'Anis, \& d'Ache en forme de potion, dans du vin trempé , ou en forme de pilules.

\section{Prenez Hiere Picre de Galien, une} dragme.

Pilules forides, deux dragmes.

Agaric.

Coloquinte, ana demi fcrupule.

Faites-en avec du vin de décoction d'Agaric \&-de Caftoreum, trente-quatre Pilules, dont la dofe fera depuis trois jufqu'à cinq.

Trois Pilules faites d'un fcrupule de Caftoreum, ont la vertu de provoquer les ordinaires.

La femme d'un Luthier, nomméJean Sturmius, ayant eu fes ordinaires fup- 
primés enfuite d'une couche, Barthelemi Wolfart lui donna en I 579 , le remede fuivant, avant le tems ordinaire, qui defobftrua les vaiffeaux , corrigea la mauvaife qualité du fang occafionnée par des humeurs craffes \& provoqua fes ordinaires.

PrenezElectůaire d'herbes auxPuces. de Turbith, avec de la Rhubarbe, ana demi-once.

Caftoreum en poudre, demie dragme.

Décoction des Fleurs, de Fruits \& de Feuilles de. Sené, une quantité fuffi: fante.

Mêlez ces drogues.

Chriftophe Fingerlin, ordonna avec fuccès les Pilules fuivantes à la Servante du Licentié Louis Pocken, dont les ordinaires tardoient trop à reprendre leur cours.

Prenez Gomme Sagapenum, diffoute dans du Vinaigre Scillitique , une dragme \& demie. 


\section{DU CASTOR. 223}

, Bartheen I 579 , le ems ordinaiffeaux , corlu fang occaaffes \& pro-

jes auxPuces. urbith, avec be, ana deoudre, demie

Fleurs, de e Feuilles de. quantité fuffi:

ordonna avec. s à la Servante. en, dont les p̀̀ reprendre senum, diffoute naigre Scillitiagme \& demie.
Species de Turbith, avec Rhubarbe,demie dragme. Caftoreum choifi, un fcrupule.

Myrrhe, demi fcrupule. Safran, demi fcrupule.

Faites-en avec de l'Eau d'Armoife, des petites Pilules.

Une Religieure de Sofflingen, nommée Didica Weikmannin, dont les ordinaires n'étoient point affez abondans, fut guérie en 1646 , par le Docteur Willinger, qui lui ordonna la Poudre fuivante.

Prenez Feuilles de Calement. d'Armoife. de Pouliot. de Sabine. Semence Ammeos. de Levefche. de Perfil. de Cumin, ana demi fcrupule.

Baies de Laurier.

Caftoreum. Myrrhe. 
Caffia Lignea, ana un fcrupule \& demi.

Poivre.

Noix Mufcade, ana deux fcrupules.

Sucre blanc, une once \& demie.

Réduifez toutes ces drogues en poudre extrêmement fubtile.

J'ai éprouvé l'effet des Pilules Aloëtiques, Marocoftines, réformées avec le Caftoreum, \& le Safran de Mars de Wedel,dans l'obftruction inveterée des Mois , c'eft pourquoi j'en recommande l'ufage.

Prenez Pilules Marocoftines, une dragme.

Safran de Mars apéritif vitriolé , un fcrupule.

Caftoreum, demi fcrupule.

Mêlez ces drogues \& faites-en avec de l'Elixir de proprieté, des Pilules. que la malade prendra de tems à autre.

Lorfque le retour périodique des ordinaires eft accompagné de douleurs, 


\section{DU CASTOR.}

le Caftoreum produit des effets admirables , comme carminatif, outre qu'il a la vertu de fortifier avec fes particules ana deux he once \& ues en pou-

ilules Aloëormées avec de Mars de nveterée des ecommande

ftines , une apéritif virupule. emi fcrupule.

faites-en avec des Pilules tems à autre. díque des orde douleurs, huileufes \& balfamiques, le genre nerveux \& la fubftance nerveufe: de l'Ute. rus.

Prenez Galbanum diffous dans du: Vinaigre \& épaiffi , trois dragmes.

Huile de Mufcade.

Baume du Perou, ana un fcrupule.

Caftoreum, demi fcrupule. Huile de Succin ou Carminatif, trois gouttes.

Mêlez ces drogues.

J'ordonnai dernierement avec fuccès les Pilules fuivantes, à une jeune fille de très-bonne maifon, dont les ordinaires étoient fupprimés.

Prenez Gomme Sagapenum préparée avec du. Vinaigre, demie dragme.

Extrait de Dictamne. de Sabine.

Tartre vitriolé, ana unfcrupule. 
226;

\section{TRA IT E}

Myrrhe rouge.

Caftoreum choifi, ana fix grains.

Safran d'Autriche, demi forupule.

Huile diftillée d'Aneth, huit gouttes.

Faites-en avec de l'Efprit de Muguet des Pilules, au nombre de quarante, que vous donnerez à la malade avec la groffeurd'un pois dé Fecules de Raçine, de pied de Veau. La dofe eft de cing. Pilules pour une fois.

J'ai délivré un grand nombre de Filles \& de Femmes de cette fâcheufe incommodité, avec les préparations altérantes \& confortatives fuivantes, en ayant égard à la difpofition de la malade, au tems \& l'homogenité du: liquide.

Prenez Effence d'Abfinthe. de Caftoreum, ana une dragme.

Efprit de Sel Ammoniac, demi fcrupule.

Mêlez \& ufez de cette mixtion digeftive. 


\section{DU. CASTOR.}

Prenez Efprit apéritif Penot, deux dragmes.

de Matricaire deSculter une dragme.

e, demi fcru-

Aneth, huit

it de Muguet

e quarante, alade avec la es de Racine, le eft de cinq

Extrait de Caftoreum, fept. grains.

Mêlez ces drogues.

Prenez Efprit de Suye.

de Myrrhe, ana une dragme.

Effence de Caftoreum, un: fcrupule.

Mêlez ces drogues.

Prenez Safran de Mars apéritif.

Trochifques de Myrrhe, ana une dragme.

Caftoreum choifi, demie dragme.

Huile de Sabine diftillée, trois gouttes.

Mêlez ces drogues \& rédüifez-les en poudre.

Prenez Extrait Panchymagogue de Crollius,

Caftoreum. 
Scam. Sulphureufe.

Trochifque alhandal, ana fix

grains.

Huile diftillée de Sabine, quatre gouttes:

de Canelle,

quatre gouttes.

Faites-en des Pilules.

Le Caftoreum eft d'un ufage admirable, \& d'un fecours infaillible dans la fuffocation ou étranglement de matrice., car il réfout ; attenue \& diflipe au moyen du fel volatil qu'il contient ce miafme âcre \& malin. De-là vient que les Femmes qui font fujettes à cette incommodité, n'ont point recours à d'autres remedes, \& que Jean Schaplerus recommande le Caftoreum dans prefque toutes les maladies de l'Uterus, fans avoir égard aux faifons.

Chriftophe Ehinger prife beaucoup. les Pilules fuivantes, dans la fuffocation de matrice.

Prenez Caftoreum très-pur, unfcrupule.' Myrrhe. 


\section{DU CASTOR.}

dal, ana fix

e Sabine,

Canelle,

fage admilible dans la. tt de matri\& diflipe au coneient ce là vient que $s$ à cette incours à d'auSchaplerus dans prefe l'Uterus, s.

fe beaucoup s la fuffocapur, unfcruAfa
Affa foeida, ana demi fcrupule.

Storax, un fcrupule.

Faites-en des Pilules au nombre de vingt-cinq a vec de l'Oxymel.

L'Elixir uterin de Charles Eckold, corrige la froideur de la matrice, en fait cefler la fuffocation, \& excite les ordinaires.

Prenez Meliffe.

Armoife, ana deux onces.

Brioine.

Zédoaịe, ana fix dragmes. Angelique.

Valeriane, ana trois onces. Rhubarbe Monach. Fuchf. Dictame blanc.

Baies de Laurier, ana deux onces.

Diacalement, une once \& demie.

Ecorces d'Oranges, demie dragme.

Semence de Bafilic. d'Anis. de Fenouil. 
Maniguette.

Gingemibre, ana demi fcrupule.

Caitoreum.

Huile de Geniévre, ana une once.

Noix mufcade.

\section{Gerofles.}

Safran, ana une dragme. Lavande, demie dragme.

Pilez \& contufez ces drogues \& faites les macerer comme il faut dans de l'Eau de vie, pendant quelques jours \& quelques nuits.

Le 16 Février 1632, Melderus ayant été appellé chez un Tailleur, nommé Jean Sontag, dont la fille étoit fujette aux fuffocations de matrice, il lui ordonna les Pilules fuivantes, après le Paroxifme , qui la délivrerent pour toujours de cette fâcheufe maladie.

Prenez M. de Pilules d'Hiere, avec Agaric.

Extrait, ana un fcrupule \& demi.

Pilales aromatiques, demi fcrupule. 


\section{DU CASTOR. Pulv. Sir. \\ Trochifque Alhandal, ana deux grains.}

re, ana une

dragme. ie dragme.

rogues \& fai1 faut dans de elques jours \&

Ielderus ayant lleur, nommé lle étoit fujette ice, il lui orntes, après le erent pour tounaladie.

d'Hiere, avec

un fcrupule \& natiques, demi

Mêlez ces drogues \& faites-en avec de l'eau de Meliffe des Pilules au nombre de trente-cinq.

On peut auffi fe fervir pour le même effet des Pilules fuivantes, dont j’ai éprouvé la vertu, après Sibelius, qui les prifoit beaucoup.

Prenez Effence d'Opium de Langitus, demi-once.

Extraitde Caftoreum. de Safran, ana demie dragme.

Cinạbre d'Ántimoine. préparé.

Bezoar d'Etain, ana une dragme \& demie.

Mêlez \& faites trente Pilules de démie dragme:

Jean Michel a laiffé differentes for$\mathrm{X}$ ij 


\section{T R A I T E'}

232 de remedes propres pour la fufmules de de matrice, dont je crois defocal faire part au Lecteur, à caufe de voutilité dont ils font dans le Paroxifme, auffi bien qu'après.

Prenez Eau d'Hirondelles avec le Caftoreum, deux onces. de Meliffe. de Matricaire, ana une once.

Fecules de Brioine, une dragme.

Magiftere de mere de perles, deux fcrupules.

Magiftere d'Etaim , un fcrupule.

Mêlez ces drogues \& faites-en ufage,

Prenez Species Dia-Stagni M. deus dragmes.

Fecules de Brioine, une dragme. Magiftere de Caftoreum, un fcrupule.

Mêlez ces drogues \& faites-en unt Poudre, dont la dofe eft depuis demi 


\section{DU CASTOR.}

$E^{\prime}$

es pour la fufont je crois deIr, à caufe de le Paroxifme,

idelles avec le deux onces. fre.

ricaire, ana une

Brioine, une

emere de perles, pules.

Etaim , un fcrl-

faites-en ufage,

-Stagni M. deus

Brioine, une

de Caftoreum, un

\& \& faites-en ung eft depuis demi fcrupule, demie dragme, jufqu'à deux fcrupules.

Prenez Poudre hifterique A. deux dragmes.

Fecules de Brioine, deux dragme.

Bezoar d'Etaim, un fcrupule.

Magiftere de Caftoreum, fix grains.

Mêlez ces drogues.

Prenez Eau d'Hirondelles, avec Caftoreum. de Carbunc, ana deux onces.

Effence de Caftoreum, une dragme.

Mêleż ces drogues \& faites-ẹn ufage, après les avoir reduites en une poudre, que l'on peut auffi tirer par le nez.

Prenez Feuilles de Mercuriale. de Matricaire. de Rue. de Meliffe, ana une poignée.

Racine de Brioine.

$\mathrm{X}$ iij 
ana une once.

Agaric, dans un nouet, trois dragmes.

Baies de Laurier,demi-once,

Faites bouillir ces drogues dans une quantité d'eau fuffifante.

Prenez Six onces de Colature dans laquelle vous ferez diffoudre.

Electuaire diHiere Picre, avec Agaric, une once. Caftoreum, un frupule. Jaune d'ouf, un.

Mêlez pour un Lavement.

-Prenez Emplâtre utęrin d'Aurbourg, une quantité fuffifante.

Malaxez-le avec de l'Huile de Caftoreum, dans la forme ufitée.

On peut-l'appliquer vers la nuit après le Paroxyfme.

Prenez Pulv. Cathol. noftr. un fcrupule. 


\section{DU CASTOR. $\quad 235$}

Tche.

loche ronde; e.

$\mathrm{n}$ nouet, trois

r,demi-once,

ues dans une

Colature dans ferez diffouliere Picre, , une once. nfcrupule.

un.

nent.

in d'Aurbourg, fuffifante.

Iuile de Caftotée.

rs la nuit après

noftr. un fcru-
Fecules de Brioine, fiz grains.

Vitriol Hermaphrod, quatre grains.

Extrait de Caftoreum, trois grains.

Mêlez ces drogues.

Prenez M. de Pilules fatides, un fcrupulc.

Scam. Sulphureufe. Refine de Jalap, ana cinq grains.

Faites-en avec de l'Effence de Caftoreum des Pilules que vous faupoudrerez avec de la Fecule de Brioine.

L'Elixir fuivant de Michel, eft aufi fort utile.

Prenez Feuilles de Meliffe. d'Armoife. de Pouliot. de Romarin. de Matricaire. situge. de Mercuriale. de Rue. de Marjolaine, ana 'deux poignées. 
Fleurs Cheir. une poignée.

Calend.

de Mille-pertuis.

de Sauge.

de Lavande, ana trois pugiles.

Racines de Brioine. de Levefche. d'Ariftoloche ronde. de Pivoine, ana deux pnces.

de Dictamne, une once.

de Garence des Teinturiers.

d'Angelique, ana une once \& demie.

Fleurs Anthos, trois dragmes.

Baies de Laurier, deux onces.

Caffia lignea véritable, une once \& demie.

Safran d'Orient, demie once. Semences de Paftenaque, trois dragmes.

Caftoreum, trois onces. 


\section{DU CASTOR.}

poignée.

pertuis.

nde, ana

ine.

efche.

oloche ron-

ine, ana deux

tamne, une

ce des Tein-

elique, ana lemie.

trois dragarier, deux éritable, une ie.

$r$, demie once. Paftenaque, les.

rois onces.
Jucifez ces drogues \& arrofez les avec de l'Elprit Hermaphrodite tiré du Fer $\&$ du Cuivre, infufé dans de l'EFprit de Vin, tiré de Plantes utérines, ou de l'Efprit de Meliffe \& de Pouliot.

Les remedes de Wedel font trèsefficaces, furtout fon Elixir urérin, compofé d'Effence de Succin, de Caftoreum, de Myrrhe, de Baume fimple, \& d'un peu de Camphre. On peut y ajouter, dans un befoin preffant, de l'Affa fatida. J'ai fauvé la vie à un grand nombre de Perfonnes avec ce remede, dont l'effet eft auffi certain que celui de la Poudre fuivante.

Prenez Magiftere de Succin. de Caftoreum. d'Etaim.

Fecules de Brioine. Julor. de Noix. Affa fretida, ana fix grains. Poudre anodine céphalique, dix grains.

Mêlez \& faites une Poudre.

L'Opiate de Labdanum mêlé avec le 
Caftoreum, a rendu la fanté à un grand nombre de femmes.

La Poudre fuivante n'clt pas à méprifer.

Prenez Semence de Pivoine, un fcrupule.

de Zédoaire, fix grains.

Caftoreum, trois grains.

Mêlez \& faites une poudre que vous donnerez à la malade dans du Vin de Malvoifre.

- Jacques Zxemann ordonna, le 17 Janvier 1644 , le remede fuivant à la Baronne d'llerdiffen, qui avoit une tuffocation de matrice.

Prenez Eau d'Hirondelles avec le Caftoreum, trois onces. admirable de Langius. Efprit de Matricaire de Scult. une dragme, demi fcrupule.

Opiat de Labdanum in $M$. S. diffol. demi fcrupule.

"Mêlez ces drogues. 


\section{DU CASTOR.}

à un grand

pas à méne, un fcruaire, fix s grains.

re que vous du Vin de

inna, le I 7 uivant à la voit une luf-

les avec le rois onces. de Langius. ire de Scult. demi fcru-

num in $M$. fcrupule.
Les Pelotes utérines font ici fort utiles pour exciter les efprits animaux , \& abattre les vapeurs qui s'élévent de la matrice. On enferme communémene pour cet effet des efpeces convenables. dans un noud d'étofie de foye rouge, $\&$ on les porte au nez. Le Pomum matricale que Zxeman ordonna à la Dame dont nous venons de parler nous fervira d'exemple.

Prenez Galbanum.

Caftoreum, ana deux fcrupules.

Feuilles de Meliffe.

Citrar, ana deux

pugiles.

Mêlez ces drogues, \& faites-en une pelote avec du Syrop folutif de Rofes.

Berndin ordonna à la femme de Rothius, la pelote matricale fuivante.

Prenez Caftoreum intérieur, une dragme.

Affa fæetida, demie dragme.

Feuilles $d \epsilon$ ue. d'Aurones, ana deux pugiles. 


\section{T R A I T E'}

Semence de Rue, une dragme.

Pulverifez ces drogues \& faites-en une pelote avec un morceau d'étoffe rouge.

Jean Stokerus ordonne le remede fuivant dans un pareil cas.

Prenez Caftoreum, deux dragmes. Sagapenum. Affa fretida.

Soufre, ana demi-once.

Incorporez ces drogues enfemble avec du Vinaigre, \& faites-en une pomme.

Jean Melderus envoya autrefois la balle fuivante à une femme fujette aux paffions hifteriques.

Prenez Caftoreum, quatre fcrupnles.

Affa fretida, un fcrupule. Galbanum, demi fcrupule.

Faites-en une pomme avec une quantité fuffifante de Cire.

La Pomme matricale que Villingesus ordonna à la femme de Matthieu 


\section{DU CASTOR. 24I}

une drag-

faites-en

au d'étoffe

e remede.

dragmes,

ii-once.

enfemble

es-en une

tutrefois la fujette aux

ttre fcrupu-

Ccrupule. i f crupule.

c une quan-

e Villinge-

e Matthieu
Faulhaber, fert au même ufage.

Prenez Affa fatida, un fcrupule. Caftoreum, un fcrupule \& demi.

Galbanum, deux fcrupules. Feuilles de Marjolaine. d'Armoife. de Pouliot, ana de. mi pugile.

Faites-en avec un morceau d'étoffe rouge, une Pomme degroffeur raifonnable.

Ce même Auteur ordonna avec fuccès un Emplâtre utérin avec le Caftoreum à Elifabeth Wolffterin, Religieu* fe dans le Monaftere de Soflingen.

Prenez Galbanum choifi.

Gomme Tacamaqué , ana demi-once.

Poudre de Caftoreum. Affa færida, ana un fcrupule \& demi.

Mêlez ces drogues \& après les avoir étendues fur un morcean de peau de la largeur de la main, enfermez-les dans un morceau d'étoffe rouge. 


\section{T R A I T E'}

2422 Wedel propofe une autre Emplâtre.

Prenez Emplâtre de Galbanum, une once \& demic.

Sel de Jupiter, demic dragme.

Affa færida, une dragme.

Huile de Caftoreum, une quantité fuffifante.

diftillée de Rue, quatre gouttes.

Mêlez pour une Emplâtre.

Voici une Huile qui fait beaucoup de bien aux femmes Hifteriques lorfqu'on a foin de leur en oindre fouvent la région ombilicale.

Prenez Huile de Caftoreum. de Laurier, ana une dragme.

Diftilée de Geniévre, demie dragme.

- de Succin, fix gouttes. de Galbanum, deux gouttes.

Mêlez ces Hựiles. 


\section{DU CASTOR.}

On peut auffi fe fervir pour le même

Emplâtre.

Janum, une

emic drag-

dragme.

eum, une

ante.

Rue, qua-

re.

it beaucoup eriques lor $[-$ adre fouvent

eum.

- ana une

e Geniévre ,

le.

, fix gouttes. um, deux effer de l'Emplâtre fuivant de Wilhelme Rafcalion, dont il eft parlé dans l'Auteur anonyme, qui le prife beaucoup, dans la fuffocation de matrice.

Prenez Poix navale.

Colophone, ana fix dragmes. Gomme Ammoniaque. Bdellium, ana demi-once. Galbanum, fix dragmes. Myrrhe, une dragme. Storax calamita, quatre fcrupules.

Térébenthine, une once. Savin.

Armoife, ana deux dragmes. Meliffe.

Pouliot, ana une dragme \& demie.

Caftoreum.

Racine de Valeriane. de Biftorte, ana deux fcrupules.

Semences de Carrote fauvage.

de Fenouil tortu. Cim., in. ana une dragme. 
244

\section{T R A I T E'}

Electuaire de Baies de Lau; rier, demi-once.

Huile de Rue, une once \& demie.

de Menthe, une once.

Cire, fix onces.

Gornme diffoute dans du

Vinaigre.

On en fera, comme ci-devant, un Ecuffon Matrical.

Jean Keller, dit Berndin, vante beaucoup les Pilules fuivantes dans les maladies hifteriques.

Prenez Semences de Levefche.

de Sermontaine. de Dancus Creti-

cus.

de Pivoine, ana demie dragme.

Racine de Zédoaire.

de Calamis aromaticus.

d'Angelique, ana un fcrupule \& demi. Afla ufærida, demi fcrupule. Caftoreum. Myrrhe, ana demie dragme. Sel 


\section{DU CASTOR. 245 Sel d'Armoife. d'Abfinthe, ana demi fcrupule.}

Faites avec du Syrop d'Ecorces de Citrons, des Pilules de la groffeur d'un Pois, que vous envelopperez d'une Feuille d'or.

Les Pilules hyfteriques, que Berndin ordonna à une Religieufe d'Ulm, nommée Barbe Kraftin, ont la même vertu.

Prenez Caftoreum intérieur , un fcrupule. Huile de Succin diftillée, une goutte.

Eau d'Hirondelles, une quartité fuffifante.

Faites-en deux Pilules, que vous envelopperez dans des Feuilles d'or.

\section{ARTICIE XXXV.}

ngelique, ana \& demi. demi fcrupule. demie dragme. Sel

Le Caftoreum eft fort utile dans les tremblemens, il chaffe aufji le fommeil.

Il fortifie la viue oo guérit les vertiges. infi que ie l'ai éprouve dernierement. 


\section{T R A I T E'}

Un Théologien, que tout le imonde connoît, étoit $f i$ fujet aux Vertiges, quil ne pouvoit vaguer an Service divin. Il en fut cependant délivré par l'ufogge du Caftoreum.

\section{$A D D I T I O N$.}

Perfonne n'eft mieux en état d'expliquer ce que c'eft que le Tremblement que celui qui a la févre: car les efprits animaux ne pouvant s'introduire en affez grande quantité dans les fibres nerveufes, la partie s'éleve ; mais le défaut d'efprits animaux, fait qu'elle s'affaiffe auffi-tôt, ce qui eft l'avantcoureur de la Paralyfie dans les Perfonnes qui fe portent bien, \& de la fanté dans les Paralytiques. De-là vient que les Médecins font entrér le Caftoreum dans les remedes qu'ils employent contre les Tremblemens. C'eft ainfi que le Fameux Thonnerus ordonna le remede fuivant à un Prêtre, qui avoit un tremblement de main.

Prenez Onguent nervin, deux dragmes.

Huile de Caltoreum, deux 
DU CASTOR. dragmes \& demie.

le inonde coniges, quill ne divin. Il en ufnge du Caf-

$N$.

état d'expliTremblement car les efprits atroduire en ins les fibres leve; mais le fait qu'elle eft l'avantdans les Perien, \& de la es. De-là vient ntrér le Caftoiils employent s. C'eft ainfi. rus ordonna le être, qui avoit

in, deux dragtoreum, deux: de Laurier.

de Renard.

Nardin, ana trois dragmes.

Mêlez \& oignez-en l'épine du dos.

Martin Neufart guérit, en 1569 , Michel Faftnacht, d'un tremblement de tête.

Prenez Electuaire Diaphænic, une once.

Faites-le diffoudre dans une quantité fuffifante d'Eau de Betoine \& ajoutez-y fix grains de Caftoreum, pour une potion.

Prenez Huile de Laurier, une once. de Rue. de Vers de terre, ana une dragme. de Caftoreum, demionce.

Ajoutez-y un peu de Cire, \& faitesen un liniment pour l'Epine du dos.

Le Docteur Michel vanie l'Effence \& l'huile de Caftoreum, comme d'excellens Antitrymiques. Un Berger d'Al$\mathrm{Y}$ ij 
tenmuher ayant fait une chute, étoie incommodé depuis cinq ou fix jours d'un tremblement, Chriftophe Cellarius ordonna de lui appliquer fur la partie affligée du vin de Malvoifie chaud, mêlé avec du Caftoreum, avec des linges pliés en double, ce qui lui sendit la fanté le i4 Avril I 652. On a parlé fort au long de la vertu qu'il a de caufer l'infomnie, en traitant de la Léthargie, \& l'on peut voir dans I'Article XXXII. la maniere dont il opére. Il eft donc inutile de répéter ici ce qui a été déja dit, \& ce que nous avons à dire dans la fuite fur ce fujet.

L'ufage du Caftoreum eft encore admirable dans les maladies des yeux, furtout lorfque les nerfs optiques font couverts de nuages qui empêchent l'impreffion des rayons vifuels, il agit en diffipant ces obftacles, en rarefiant les efprits \& en fortifiant ceux qui font foibles \& languiffants, lorfqu'on le mêle avec d'autres remedes de la maniere fuivante.

L'an I 699. Leonard Huterus, dont la vue étoit extrêmement foible, ayant confulté le Docteur Eckold, celui-ci. 


\section{DU CASTOR.}

hute, étoit I fix jours ophe Cellaquer fur la Malvoifie reum , avec ce qui lui 652. On a tu qu'il a de aitant de la voir dans iere dont il de répéter ce que nous fur ce fujet.

eft encore es des yeux, ptiques font pêchent l'imIs, il agit en a rarefiant les eux qui fone lorfqu'on le es de la ma= uterus, dont foible, ayane old, celui-ci. qui connut que cette incommodité ne venoit que du défaut d'Efprits animaux, lui ordonna le remede fuivant qui produifit un très-bon effet.

Prenez Aloes lot. un fcrupule. Maffe de Pilules Luc. ana demi fcrupule. Cochées ; Caftoreum, un fcrupule. Diagrede, deux grains.

Faites-en des Pilules au nombre de vingt-cinq, avec du Syrop de Stæchas.

Prenez Feuilles d'Euphraife, trois dragmes.

Racine de Valeriane, une dràgme.

Semences de Fenouil, deux dragmes.

Sermontaine, une tragme \& demie.

Caftoreum, deux fcrupules. Coriandre, deux fcrupules. Canelle, deux dragmes. Macis, demie dragme. Galanga, un fcrupule. 


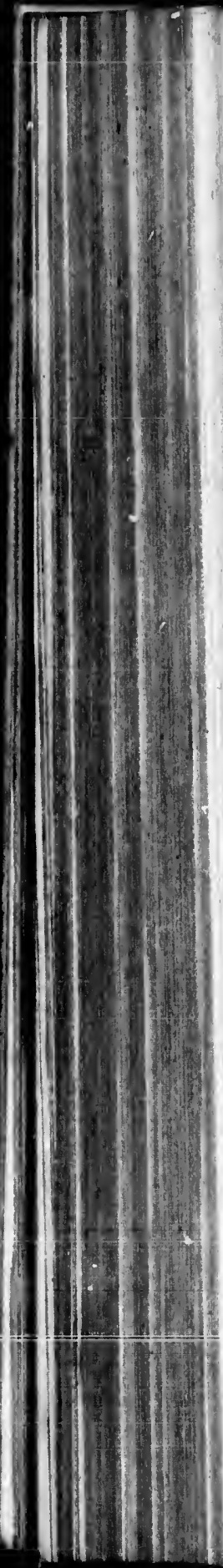

\section{T R A I T E'}

250

Mêlez ces drogues \& faites-en une Poudre, à laquelle vous ajouterez Species Dianthos, deux fcrupules. Sucre une quantité fuffifante. Mêlez \& faitesen un Trochifque.

L'an 1580, Marc Wolfart ordonna 1a Poudre fuivante à Pierre Kuchlin, qui avoit la vue extrêmement foible.

Prenez Semence de Fenouil réduite en poudre fubtile, une once.

Feuilles de Marjolaine. d'Euphraife , ana deux dragmes.

Caftoreum, demie dragme. Sucre blanc, une quantité fuffifante.

Mêlez \& faites une Poudre que l'on donnerà matin \& foir au malade dans du vin blanc.

L'an 1621 , Jean Schapplerus ordonna la compolition fuivante à Marguerite Veherin ; qui étoit affligée du mal de tête \& d'une ophţhalmie. 


\section{DU CASTOR.}

- Prenez Pilules cochées.

aites-en une is ajouterez ipules. Sucre lez \& faites-

fart ordonna re Kuchlin, ent foible.

nouil réduite ubtile, une

rjolaine.

raife, ana es.

mie dragme. une quantité

udre que l'on malade dans

plerus ordonite à Margueffligée du mal Imie.
Lucis.

Dorées, ana un fcrupule.

Caftoreum préparé.

Extrait d'Ellebore, ana de-: mi fcrupule.

Formez-en des Pilules médiocres avec de l'Eau de Fenouil.

Voici les Pilules que Salomon Fif-: cher ordonna le 29 Septembre $164^{6}, \grave{a}$ la fille de M. Riedlin qui avoit une: pareille incommodité.

Prenez Huile rofat, demie dragme. Lapis lazuli préparé. Succin préparé.

Gaftoreum choifi, ana un fcrupule.

Diagrede ; deux fcrupules. Extrait de feuilles de Sené, une dragme.

de Valeriane, un fcrupule.

Huile de Fenouil , cinq grains. 
252 Mêlez \& faites des Pilules de la groffeur d'une Lentille, que vous donnerez au malade.

Des Médecins célébres nous ont laiffé plufieurs remedes, tant internes qu'externes, propres pour le vertige, qui produifent certainement de trèsbons effets, mais ils deviennent beaucoup plus efficaces par leur mélange avec le Caftoreum, qui a la vertu de diffiper ces vapeurs, qui font engendrées par des crudites, \& qui fe communiquent par les veines \& les arteres aux ventricules du cerveau, \& de réduire les efprits animaux dans l'ordre dont ils fe font écartés.

\section{Prenez Euphraife finement pulveri- fée, une once. \\ Racine de Pivoine. \\ de Valeriane, ana une once \& demie.}

Faites de ces drogues une mixture, en les faifant cuire à petit feu, avec une quantité fuffifante de Miel Anthofat, \& la coction étant finie, ajoutez- 


\section{DU CASTOR.}

lules de la vous don-

y de la Semence de Coriandre préparée, deux dragmes.

Caftoreum choifi, un fcrupule.

Canelle, deux frupules.

Mêlez ces drogues.

François Lofchenbrand Tréforier, fe fervit en I 577 , avec fuccès, de cette compofition contre les vertiges, aufquels il étoit fujet, par ordre de Barthelemi Wolfart.

L'Auteur Anonyme a éprouvé la vertu de la poudre fuivante, dans le vertige qui eft caufé par la foibleffe de l'eftomac.

Prenez Species Diagalang Diacimini.

ne.

eriane, ana demie.

une mixture, it feu, avec Miel Anthonie, ajoutezdine.

Confection anacar-

Racine de Pimprenelle.

Baies de Laurier, ana demi dragme.

Caftoreum, demi fc rupule. Mêlez \& faites-une poudre. 


\section{T R A I T E'}

254 J'ai ordonné avec fuccès les Pilules fuivantes dans le vertige, accompagné d'une grande pefanteur de tête, de douleurs d'Eftomac caufées par. les viandes, de la rougeur du vifage, \& du tremblement des lévres.

Prenez M. de Pilules de Succin. C. Extrait d'Ellebore, ana douze grains. Suc de Cerfeuil épaiffi, de. mi fcrupule. Sel de Tartre. Diagrede Sulphureux, ana trois grains.

Faites-en une Maffe de Pilules au nombre de trente, avec de l'Effence de Caftoreum, \& enveloppez-les dans une Feuille d'or.

Charles Ekold ordonna, en 1570 ; avec beaucoup de fuccès les Pilules fuivantes à la veuve de Barthelemi Rhemius, qui étoit fujette aux vertiges.

Prenez. Aloes Hepatique.

Valeriane.

Cubebes. 
$s$ les Pilules ccompagné ête, de douar. les vianage, \& du le Succin. C. bore, ana 1 épaiffi, de. hureux, ana de Pilules au le l'Effence de z-les dans une 1a, en 1570 ; les Pilules fuithelemi Rheaux vertiges.

que.

\section{DU CASTOR.} Maniguctte.

Calamus Aromaticus.

Canelle.

Gerofles, ana deux dragmes. Semence de Coriandre. Noix Mufcade. Macis, ana un fcrupule.

Faites-en des Pilules de la groffeur d'un Pois, avec du Suc de Fenouil.

Barthelemi Wolfart, appliqua en I57I, avec fuccès, le fachet fuivant, fur la tête de la veuve de Thomas Lebzelter, qui avoit une extrême répugnance pour les remedes internes.

Prenez Caftoreum, deux fcrupules. Romarin.

Serpolet, ana une dragme. Meliffe, demie dragme. Succin, un fcrupule. Lavande, une dragme. Noix Mufcade, demi fcrupule. Ambre, deux grains.

Jucifez ces drogues \& enfermez-les

$$
\mathrm{Z} \text { ij }
$$


256
dans un fachet de lin, que vous aurez foin de piquer.

Le liniment fuivant que Wolfart ordonna, en 1578 , à un Ouvrier en Parchemin, nommé David Sturzel, n'eft pas moins efficace.

Prenez Huile de Geniévre.

de Lavande, ana demionce.

Caftoreum, demie dragme. Maftic, un fcrupule.

Mêlez pour oindre l'épine \& le fommet de la tête.

Il y a quelques femaines qu'un Ouvrier de ce Pays, qui aimoit extrêmement les Oignons, ayant mangé avec avidité un gâteau, où il $\mathrm{y}$ en avoit une très-grande quantité, fut faili d'un mal de tête violent accompagné d'un vertige qui ne lui permit point de quitter fon fiége. 'Apres avoir inutilement employe differens remedes, il me fit appeller, \& je lui donnai après l'émétique ordinaire, la poudre fuivante , pendant trois jours, qui le guérit parfaitement. 


\section{DU. CASTOR.}

Prenez Cinnabre minéral préparé. Caftoreum choifi.

Ongle d'Elan préparée, ana fix grains.

Ambre gris, un grain.

Huile diftillée de Coriandre,

deux gouttes.

Mêlez \& faites une poudre.

\section{A R T I C LE XXXVI.}

Le Caftoreum ouvre les conduits urinuires, o fert a plufeurs autres ufages.

\section{ADDITION.}

On employe le Caftoreum dans la Colique néphretique, non-feulemente pour diffoudre \& délayer la ferofité qui croupir dans le réfervoir qui lui eft deftiné ; mais encore pour fortifier de genre nerveux, qu'elle irrite par fon trop long féjour.

Le paffage qui fuit fait très-bien à notre fujet. $\gg \mathrm{La}$ fuppreffion d'urine \& sles donleurs des reins, dit Jean Har»derus, font des fymptômes trèsscruels, que l'on peut appaifer avec $\mathrm{Z}$ iij 


\section{T R A I T E'}

2sdifferends remedes, fur-tout avec „l'Opium, le Caftoreum , \& l'Huile »d'Amandes douces. "c

Un Foulon, nommé Pierre Neubronnerus, étant affligé en' 1579 , de cette incommodité , Laurent Gauthier Kuchel , l'en guérit avec ce remede.

Prenez Semences de Guimauve, un fcrupule.

Succin.

Safran.

Myrrhe.

Caftoreum, ana demi fcrupule.

Opiate de Labdanum, trois grains.

Incorporez ces drogues avec du Vin de Malvoifie, \& mêlez-les long-tems dans un mortier, que vous aurez foin de faire auparavant chauffer avec fon pilon. La dofe eft de trois ou quatre grains.

L'an $157^{8}$, Euftache Gunzpurger étant affligé des douleurs Néphretiques violentes, accompagnées d'infomnie , Wolfgang Rabus l'en guérit avec le remede fuivant. 
$r$-tout avec

, \& l'Huile

?ierre Neun* 1579 , de ent Gauthier :e remede.

uimauve, un

aa demi fcru-

danum, trois

$s$ avec du Vin

les long-tems us aurez foin iffer avec fon ois ou quatre

e Gunzpurger urs Néphretignées d'infom'en guérit avec

\section{DU CASTOR. \\ 259}

Prenez Caftoreum.

Pierre d'éponge, ana demi fcrupule. Syrop de Pavot. Eau de fleurs de Camomille. de Fraizier. de Perfil, ana

une once.

Mêlez pour une verrée.

Marfilius nous a laifé la defcription de Pilules particulieres dans lefquelles il entre du Caltoreum, qu'il prétend être bonnes dans les douleurs nephretiques, de quelque nature qu'elles foient.

Prenez Térébentine, cinq dragmes. Semences de Concombres mondées.

$$
\text { d'Ache, aná deux }
$$
dragmes.

Yeux d'Ecreviffes, une dragme \& demie.

Caftoreum, demi dragme.

Arrofez ces drogues, après les avoir réduites en poudre avec de l'eau d'Alkekenge, \& faites-en des Pilules de

$$
\mathrm{Z} \text { iiij }
$$


260

\section{T R A I T E'}

feize à la dragme, avec du fuc de Regliffe.

Nous voici bien-tôt arrivés à la fin de notre Ouvrage ; mais comme Marius a paffé fous filence un grand nombre de maladies aufquelles le Caftoreum eft propre, nous en dirons un mot fans nous y arrêter qu'autant que notre fujet le demande.

Voyons d'abord quelle eft la vertu du Caftoreum dans les fiévres intermittentes.

Fuchfius nous affure qu'il eft fort $\mathfrak{f}$ lutaire dans ces fortes de fiévres en ces termes : byc etiam facit aliquid, abfinthium, Caftoreum ơ gentiana quac obftructiones anferunt cum robore.

On trouve dans la pratique manufcrite d'Ettmiller les Piiules fuivantes.

Prenez Myrrhe. . .

Caftoreum.

Grande Berce.

Gentiane.

Abfinthe, anà un fcrúpule.

Faites-en des. Pilules au nombre de vingt-cinq, avec du Mithridate. Voici comment je les corrige. 
fuc de Revés à la fin omme $\mathrm{Ma}$ rand noms le Caftodirons un 'autant que eft la vertu es intermit-

left fort faévres en ces. iquid, abfina que obftruicique manuffuivantes.

nà un fcrú-

nombre de ridate. Voici
DU CASTOR. $\quad 26 x$ Prenez Extrait de Gentiane. de petite Centaurée. de Caftoreum, ana fix grains. Huile diftillée de Girofles, trois gouttes. Opiate de Laudanum, une goutte \& demie.

Mêlez \& faites des Pilules au nombre de dix-neuf, que vous envelopperez d'une feuille d'or, pour le donner deux heures avant le Paronyfme, lorfque le ferment commencera à s'agiter. Les fiévres ayant regné le Printemps dernier dans la Ville d'Ulm \& réfilté à tous les remedes qu'on avoit employés contr'elles, j'eus le bonheur de guérir un grand nombre de Perfonnes avec f ces Pilules.

: Le Caftoreum produit auffi des effets admirables dans les affections hypochondriaques, lorfqu'on apprehende une fuffocation \& une enflure d'eftomac, fi on a foin d'en faire précéder l'ufage par un lavement $\&$ une potion adouciffante, comme je l'ai dernierement éprouvé à l'égard d'une jeune Demoifelle que je guéris avec ce remede. 


\section{2 \\ TR A I T E:}

Prenez Vitriol de Mars, fept grains. Safran de Mars apéritif, deux dragmes.

Safran d'Autriche, une dragme.

Caftoreum choifi, un fcrupule.

Huile diftillée de Succin, trois gouttes.

Mêlez \&. faites-en une Poudre que vous diviferez en fept parties égales.

Prenez Effence de Caftoreum.

Efprit de Camomille Romaine, ana une dragme. Efprit de Sel Ammoniac, un fcrupule.

Mêlez, la dofe eft de quarante gouttes.

Il r'eft pas moins utile dans le Scor-l but, qui a beaucoup de rapport à la maladie précédente, furtout lorfqu'il eft accompagné de la difficulté de refpirer, d'une fauffe Paralyfie, de contractions dans les articles \& d'une laffitude générale. Nous avons parté fort au long de toutes ces differentes maladies dans les articles qui leur conviennent. 
fept grains. apéritif,

e, une drag-

un fcru-

le Succin,

Poudre que es égales.

reum.

omille RoIne dragme. Immoniac,

le quarante

lans le Scor-1 rapport à la tout lorfqu'il culté de reffie, de cond'une laffias : parté fort rentes malaeur convien-

\section{DU CASTOR. 263}

Ettmiller attribue les fleurs blanches ou gonorrhée batardes des femmes à une férofité qui par le défaut de digeftion des premieres voyes, palfe en abondance de la maffe du fang dans l'Utérus. Le Caftoreum eft très-propre pour les faire ceffer.

Prenez Racine de Tormentille. de grande Confoude, ana deux dragmes.

Caffia lignea, un fcrupule. Ofteocolle, un fcrupule. Caftoreum, demi fcrupule.

Faites-en une Poudre.

Eckold guérit, en 1569 , avec ce remede, la femme de David Mrelin , qui étoit fujette à cette incommodité.

Wedel fait grand cas de la Poudre fuivante.

Prenez Caftoreum préparé.

Yvoire.

Succin préparé, ana deux fcrupules.

Corail, un fcrupule. Huile de Canelle, dcux gouttes. 


\section{T R A I T E \\ Mêlez \& faices-une poudre.}

On l'employe très-fouvent dans les chutes, parce qu'il a la vertu de fortifier, de réfoudre \& d'incifer les grumeaux de fangl qui s'arrêtent aux environs des nerfs. In cafu, dit Zwikerus, bona eft rubrica, bona eft marga, bona rad. rub. tinct. Sed omnium optimum CaStoreum, quod ex proprietate i Sanguinem concretum refolvit.

Un Berger d'Altenmuhr ayant été faiff d'un tremblement enfuite d'une chute, Chriftophe Cellarius ordonna de lui appliquer chaudement, fur la partie affligée, du Vin de Malvoifie, mêlé avec du Caftoreum.

Le 17 Juillet 1625 , le Gouverneur d'Heidenhaim, nommé Feift, eut le malheur étant fou, de tomber de fon cheval près de Veftheim. On fit appeller Cellarius , qui le guérit avec la potion fuivante.

Prenez Poudre contre les chutes, une dragmie.

Racine de Pimprenelle, deux fcrupules.

Caftoreum d'une odeur forte, fix grains. 


\section{DU CASTOR. 265}

Eau de Cerfeuil. de Flevrs de Tilleul, ana une once.

Vinaigre rofat, demi-once. Mêlez ces drogues \& faites-en ufage.

er les grunt aux enZwikerus, arga, bona timum CafSanguinem ayant été uite d'une $s$ ordonna ent, fúr la Malvoifie ,

Souverneur ift, eut le ber de fon In fit appelit avec la chutes, une ènelle, deux odeur forte,

On peut le donner intérieurement ${ }^{2} \&$ extérieurement à ceux qui tombent en foibleffe pour les faire revenír, \& l'employer avec d'autres remedes en forme de fternutatoire, ainfi que nous l'avons déja dit.

Je me fers ordinairement pour mettre les efprits en mouvement de l'Errhiné que voici.

Prenez Effence de Caftoreum.

Efprit de Suye, ana demie dragme.

Mêlez \& flairez ces drogues quatre fois par jour.

Wedel fait beaucoup de cas de l'EFprit de Caftoreum pour lever l'obftruction des nerfs qui font autour du cœur, \& pour mettre les efprits en mouvement. Une femme de ce Pays étoit fujette à tomber en défaillance à la moindre peur qu'elle eut, ayant pris un verre de Vin impregné de Caftoreum, 


\section{T R A I T E'}

elle fut tout-à-fait guérie de cette incommodité.

Le Caftoreum a tant de vertus dans la petite Verole \& la Rougeole, qu'il pouffe fans peine du centre à la circonférence, ce venin qui fixe fa réfidence auprès du cœur, \& en facilite l'excrétion à travers les pores de la peau, fur la furface de laquelle il s'éleve un millier de putules, au grand foulagement du malade. De-là vient que Melderus fe fervoit de la mixtion fuivante, dont il proportionnoit la dofe à l'âge de fes malades.

Prenez Eau de Fumeterre, trois onces.

Cordiale, une once. Effence de Caftoreum, une dragme.

Sucre perlé, demi-once.

Mêlez ces drogues.

Ettmuller dans fa pratique manufcrite regarde le Caftoreum \& fa teinture comme des remedes fpecifiques dans ces fortes de maladies; je crois en effet què le Caftoreum eft propre à 


\section{DU CASTOR.}

267

hâter l'éruption des exanthemes, en appaifant la douleur, \& en réfiftant au venin, pourvâ que fon odeur ne répugne point aux jeunes gens \& qu'on puilfe le leur en faire prendre.

Il eft auffi fort propre à chaffer les Vers, en tant qu'il réfifte à la corruption par fes particules ameres. De-là vient qu'Eckold prife beaucoup les $\mathrm{Pi}$ lules fuivantes, dont il a éprouvé l'effet.

\section{Prenez Pílules de Ruffus.}

Rhubarbe choifie, ana une dragme.

Caftoreum, un fcrupule. Coloquinte préparée, demi fcrupule.

Formez-en des Pilules médiocres ne once. reum, une ni-once. que vous donnerezau nombre de douze $\&$ plus, fuppofé que la premiere dofe lne foit pas affez forte.

Urfule Maierin m'ayant confulté il y a fix ans dans le mois de Juin, fur des douleurs qu'elle reffentoit dans le cœur, dansle dos \& dans la tête, accompagnées des fyncopes fréquents $\&$ de démengeaifons dans le nez, je lui ordonnai les Pilules précédentes vers le déclin 


\section{T R A I T E'}

de la Lune, après les avoir ainfi réformées.

Prenez M. de Pilules de Ruffus, quinze grains.

Extrait de Caftoreum. de Rhubarbe.

Trochifque alhandal, ana deux grains.

Huile diftillée d'Abfinthe,

quatre gouttes.

Mêlez ces drogues \& formez-en des Pilules au nombre de vingt-une.

Ces Pilules lui rendirent le ventre fi libre, qu'elle rendit un nombre infini de Vers par morceaux, avec une matiere laiteufe. Ses ordinaires lui revinrent, ce qui m'empêcha de continuer l'ufage des purgatifs ; mais au bout de trois jours je lui ordonnai la Poudre fuivante.

Prenez Racine de Dictamne.

de Gentiane.

de Contrayerva , ana une dragme.

Corne de Cerf brûlée, demie dragme.

Caftoreum choifi, un fcrupule. 


\section{DU CASTOR.}

ainfî réfor-

Huile diftillée d'Abfinthe, autant qu'il en faut, pour e Ruffus , qu'elle conferve la forme d'un Poudre très-fubtile.

La malade en ayant pris de tems à reum. rbe. ndal, ana l'Abfinthe,

rmez-en des -une.

le ventre fi mbre infini ec une mares lui revinde continuer $s$ au bout de la Poudre

mne.

iane.

aycrva, ana brûlée, deifi, un fcruHuile autre, rendit fans aucun effort, un Vers en vie, qui avoit foixante aunes de long \& n'a plus été fujette depuis à ces fortes d'incommodités.

Le Caftoreum préferve les corps morts de la corruption \& des atteintes des Vers, à caufe des particules aromatiques \& balfamiques qu'il contient, comme les Auteurs nous en affurent. Je me contenterai d'appuyer ce que j'avance de l'autorité de Leon Wolfart : „On doit employer pour les embaume„mens tout ce qui eft capable de refifster à la corruption \& de conferver les schairs. On prétend que la Myrrhe eft foxcellente pour cet effet ; on peut $y$ sjoindre le Storax, la Colophane, la "Menthe, l'Abfinthe , l'Aloes, la Noix „Mufcade, le Caftoreum, le Benjoin , sle Maftic \& plufieurs autres drogues sdont on s'eft fervi, il y a quelques »années, pour embaumer le corps de ${ }_{2}$ Fréderic III. Electeur Palatin. A a 


\section{0 \\ A R TICLE XXXVII.}

Quoique les Auteurs qui ont écrit fur les Animaux venimeux, mettent le Caftoreum au nombre des Poifons, on ne laijfe pas de Temployer en qualité $d$ Antidote dans la Theriague d'Andromachus, of d'en ufer contre ll Aconit, le Guy, la Pigueure des Scorpions, des Araignées \& de la Tarentule, les maurais effets de POPium of contre. la Pefte même.

\section{$A D D I T I O N$.}

Les tefticules du Caftor fe confervent pendant huit ou neuf années, dit Zwikerus, pourvu qu'on ait foin de les tenir dans des boetes bien fermées. Car quoiquelles contiennent une grande quantité de particules balfamiques, fulphureufes \& volatiles, elles ne peuvent point fe diffiper fi promptement à caufe des parties gommeufes, réfineufes \& terreftres qui les enveloppent ; mais lorfque les premieres font une fois diffipées, le Caftoreum n'eft plus bon à rien. 


\section{DU CASTOR.}

27r

XXII.

at écrit fur les. te Caftoreum ne laifje pas de idote dans la of d'en ufer a Pigueure des de la Tarenpium \&o contre.

$N$

tor fe conferIf années, dit $\mathrm{n}$ ait foin de bien fermées. ent une granbalfamiques, elles ne peuromptement à ufes, réfineuenveloppent ; $s$ font une fois 'eft plus bon à

Les caufes qui peuvent concourir à le dépouiller de fes vertus, font la trop grande torrefaction, qui diflipant fes parties les plus volatiles, ne laiffe que les plus groffieres, \& le défaut d'humidité qui le fait devenir rance.

Je confeille auffi de n'en point pulverifer une trop grande quantité à la fois, parcequeles particules fulphureufes venant à s'exhaler, il devient plus fujet à fe corrompre.

L'on trouve fouvent des Impolteurs qui vendent les Reins du Caftor deffechés pour du véritable Caftoreum. Souvent ce à quoi ils donnent ce nom, n'eft qu'un mêlange de plufieurs drogues foetides, de Sel Ammoniac, de Sagapenum, de grande Berce, d'Affa Færida, de fang \& de graiffes de Caftor, mais dépouillé des fibres \& des pellicules dont le véritable Caftoreum eft entrelaffé, ce qui eft une preuve infaillible de leur mauvaife foi. C'eft ce Caftoreum mal préparé, ou tout-àfait alteré, que les Anciens ont mis au nombre des Poifons.

Au refte, le Caftoreum eft entierement oppofé à tout ce qui eft capable A a ij. 


\section{T R A I T E'}

$27^{2}$ dirriter les genres nerveux, de refferrer les pores du cerveau, \& de figer les particules fulphureufes \& volatiles , car il leve les obftructions, met les efprits en mouvement, \& ranime, pour ainfi dire, l'archée: De-là vient l'antipathie qu'on remarque entre l'Opium \& le Caftoreum, \& qui eft une fuite de la difference de leur foufre.

Perfonne n'ignore que le Caftoreum réfifte à la contagion, \& les Auteurs tant anciens que modernes, qui lui accordent unanimement cette vertu, le mettent au nombre des drogues qui tiennent généralement le premier rang parmi les principaux Alexipharmaques, fçavoir de la Theriaque célefte, que quelques-uns mettent au-deffus de tous les autres remedes, \& de la Terre Bézoardique, en tant qu'il refifte à la corruption par fés particules ameres ; balfamiques \& aromatiques \& conferve le Craffe du fángl Mais comme Pexpésience eft au-deffus du raifonnement, \& que je n'ai jamais éprouvé fa vertu contre la pefte, 'jaime mieux m'en rapporter -au témoignage de ceux qui font au fajt de cette matiore, quede décows 


\section{DU CASTOR.}

de refferle figer les atiles , car les efprits pour ainfi antipathie ium \& le fuite de la

Caftoreum es Auteurs s, qui lui tte vertu, drogues qui remier rang lexipharmaqque célefte, au-deffus de de la Terre il refifte à la llesiameres, s \& conferve mmé lexpéifonnement, uvé fa vertu. eux m'en rapceux qui font quede dérow vrir mon peu d'expérience dans les raifons que je pourrois alléguer.:

\section{ARTICLE XXXVIII.}

Voilà quelle eft l'utilité du Caftor dans la Médecine. J'ai été témoin moi-mème de la plîpart des effets dont jai parlé , \& je ne lui donne aucune louange qu'il ne mérite. D'autres que moi en ont connu l'efficacité , of les Médecins d'Aufbourg l'ont employé trente fois dans les meilleures compofition de leur Pbarmacopée. Si le Lecteur trouve quelque faute dans mon $\mathrm{On-}$ vrage, qu'il fe fowvienne que je fuis homms ऊ. que mon $\int$ çavoir eft imparfait, of s'il $y$ découvre quelque chofe d'utile, qu'il en rende grace à celui de qui nous tenons toutes nos connoiffances.

!

\section{$A D D I T I O N$}

Je pourrois ajoûter encorc un grand nombre de chofes à ce qu'a dit Marius; mais comme il eft impoffible de traiter de toutes les maladies aufquelles le Caftoreum eft propre, je bornerai ici ma carriere. Si quelqu'autre vouloit 


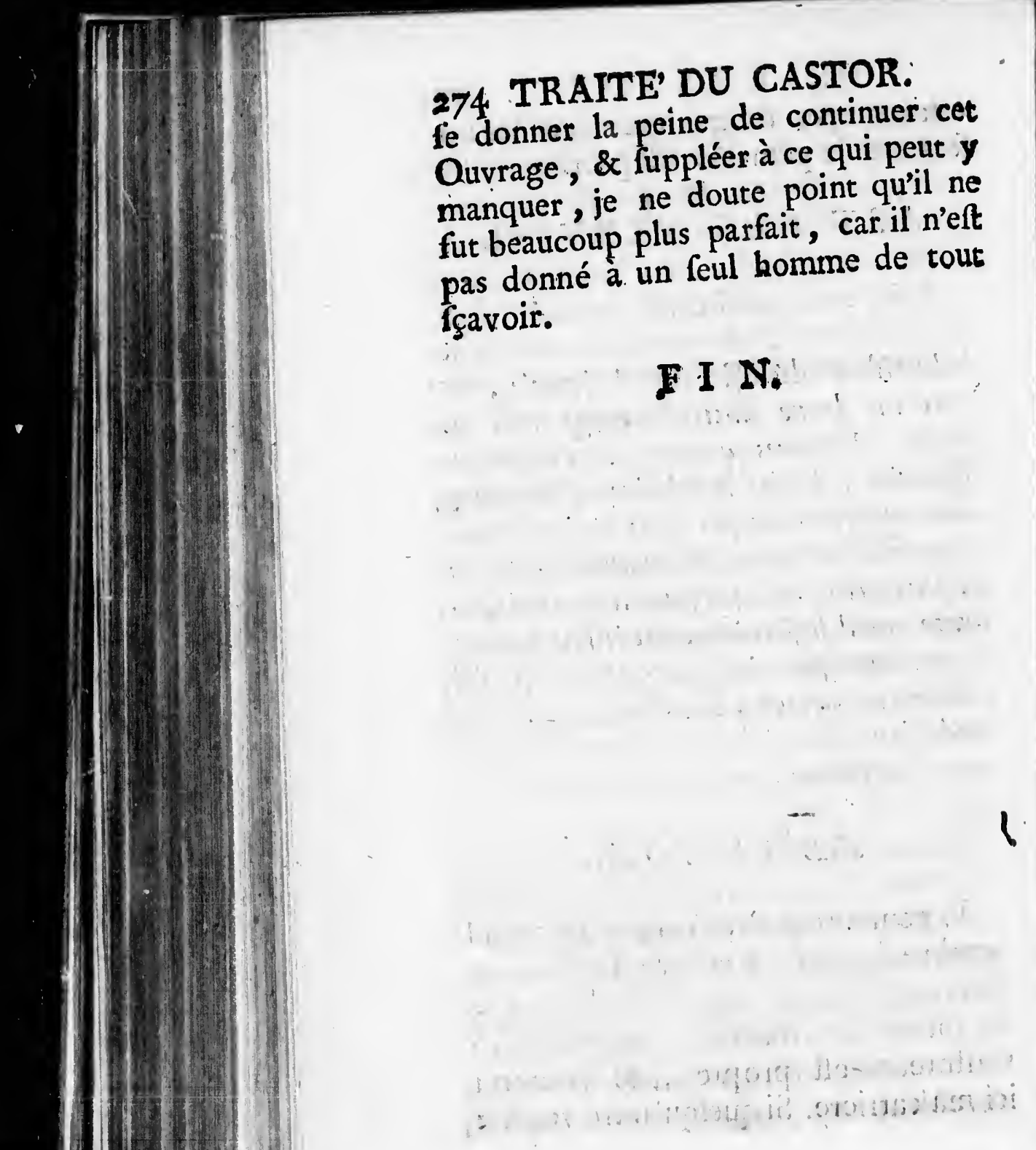




\section{TOR:}

ntinuer cet qui peut $y$ int qu'il ne car il n'elt me de tout

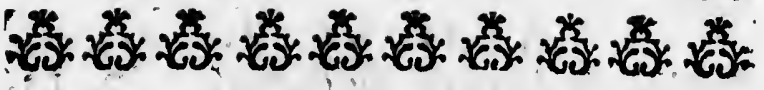

$$
\text { T A B L E }
$$

Des Matieres, contenues dans cet Ouvrage.

\section{P R E' F A C E.}

TXtrait dine Lettre de Mr. Sarrafin;

E à Mr. de Tournefort, touchant l'Anatomie \& la faģon de vivre due Caftor.

Liffe des Manufcrits cités dans Page 6. cet Onvrage:

$$
\text { AVANT-PROPOS. }
$$

\section{Article premier.}

iMotifs gui ont porté l'Auteur à entreprendre cet Ouvrage.

\section{ArticIE II. \& III.}

Differens noms quel'on a donné an Caftor of leur origine. $\quad$ p.7.\&8.

$$
\text { Articie IV. }
$$

Defcription du Caftor. - p. 10: 
276 DES MATIERES. A R T ic L V. Qualité de la chair du Caftor. p. I3:

\section{A R T'TCLE V.I.}

Le Caftor aufsi bideux qu'à craindre à caufe de la force ó de la longueur de fes dents.

A R T I C I E V I I.

Endroit où font placées les poches qui renferment le Caftoreum

- dans le Caftor mále ef femelle. p. I6.

$$
\text { ARTICIE VIII. }
$$

Maniere dont le Caftor mange. p. $2 \mathrm{I}$.

$$
\text { A R T I CLE I X. }
$$

Pays oi l'on trouve des Caftors. p. 23 .

$$
\text { A R T ICIE X. }
$$

Le Caftor recherché à caufe de fa peau, de fa graiffe, de fon fang, de fon poil of de Jes dents. p. 26!.

A R T CIE X I. Utilité de la pean du Caftor. $\quad$ p. 27.

$$
\text { A R T ICIE XII. }
$$

Ütilité de la graiffe de Caftor dans les Maladies des nerfs, dans l'Epilepjie, 'P Apoplexie, la Lé- 
S.

p. I3:

p. 15 .

I.

bes

um

lle. p. I6.

I.

p. $2 \mathrm{I}$.

irs. p. 23.

de

$e$ fon ents. p. $26 . !$

I.

p. 27.

I I.

dans

dans

la Lé-

\section{DES MATIERES. 277}

thargie, les Spafmes o les mouvemens convulfifs. Elle eft bonne pour fortifier of ramollir les nerfs; pour le Vertige, le mal de Dents, l'Afthme, le Vomiffement, les Epreintes; la Diffenterie, les maux de Reins, o les douleurs des Articles.

p. $; 0$.

\section{A RTICLE XIII.}

Le Sang du Caftor eft un remede efficace contre l'Epilepjie.

p. 4 ;

A R T I C LE XIV.

U Jage du Poil du Caftor.

p. $4^{6}$

A R T I C E X X.

U Jages de fes Dents.

p. 47 .

A R T I C I E X.V I. Situation des poches qui contiennent - le Caftoreum.

$$
\text { A r ticie XVII. }
$$

p. 50.

Nature ơ qualité du Caftoreum. p. 5 I.

A R T I C IE XVIII.

Utilité du Caftoreum dans les donleurs de la Surdité, le tintement co le bovirdonnement d'Oreilles, $\mathrm{B} \mathrm{b}$ 


\section{T A B L E}

pour diffiper les abfcès of appaifer les douleurs de la Goutte. Il eft dangereux aux F Fmmes enceintes of caufe fouvent $l$ avortement.

$$
\text { A R I I C I B X I X. }
$$

Le Caftoreum eft utile dans les maladies de la Tête; cauf es par des bumeurs froides; dans l'Epilepfie, pourvî quion l'employe fur le champ. Il foulage ceux qui font fujets aux Trancbées, à la Colique. Les jeunes Femmes doivent éviter fon trop grand ujage, parce quil caufe fouvent la fterilité.

A RTCIE XX.

Le Caftoreum eft efficace contre le mal de Dents.

$$
\text { p. I2.5: }
$$

A T I C IE X X I.

Le Caftoreum remedie aux chûtes du Fondement.

Il caufe l'avortement, of bite l'expulfion du foetus, dans quelque état quill foit. $\quad$ P. I33. 


\section{DES MATIERES. 279}

Artice XXIII.

Le Caftoreum guérit la Gonorrbée. p. 138.

$$
\text { ART I CIE XXIV. }
$$

yorI X. p. 56.

s les spar Epiaploye $\operatorname{cen} x$ ces, à emmes grand uvent

$\mathrm{XX}$. p. 89.

$\times \times 1$.

$$
\text { p. 125: }
$$

$x$ chûtes

X X II.

ơ bîte ans guelp. I33.
Le Caftoreum guérit la Migraine f. difsipe la dureté du Foye: p. I 1 . A r t I CIE X X V.

Le Caftoreum guérit la Sciatique. p. 145.

$$
\text { Articie X X V I. }
$$

Il diffipe la Létbargie, Penflure de la Ratte. Il angmente aufli le lait aux Nourrices.

$$
\text { p. } 151 .
$$

\section{Articie XXVII.}

Le Caftoreum angmente la Memoire, of la rétablit quand on l'a perdue.

A R I ICIE XXVIII.

Le Caftoreum corrige la puanteur de Phaleine:

p. 173. ARTICLE XXIX.

Le Caftoresum eft bon pour la Phrénefie \&o pour la Pleurefie. p. 176. ARTICIE XXX.

Le Caftoreum eft utile dans la $\mathrm{Pa}$ ralifee, dans la Goutte of pour les maladies de la Poitrine. p. I 82. 
280

\section{T A B L E}

ARTICIEXXXI.

Le Caforeum tue les Landes or les Pous.

A T ICIE XXXI p. 195.

Le Caftorenim leve les obftructions des Reins.

p. 200.

A RTicie XXXIII. Le Caftoreum eft bon pour l'Eftomac, of pour faire cefer le Hoquet ; pour les Spafmes, la Céphalalgie of l'A Afoupiffement... Tiré par le nez, il fait ćternuer. il gucrit le Coma, ơ Sa fuméc provoque le fommeil.

p. 203 .

\section{ARticie XXXIV.}

Le Caftorenm excite les Ordinaires, o facilite la fortie des Vuidanges. Il remedic aufí à la fuffocation de Matrice.

\section{A r t ICIE XXXV.}

Le Caftoreum eft utile dans les Tremblemens. Il chaffe le fommeil, fortifie la vñe, ơ diffipe les vertiges. 


\section{$A P P R O B A T I O N$.}

T'Al lâ par ordre de Monfeigneur le Chancelier, un Manufcrit intitulé Caftorologie; ou Traité dans lequct on explique la nature , les proprietés er l'usage duCaftor dans la Médecine, où je n'ai rien trouvé qui puiffe en empê. cher l'Impreflion. Fait à Paris ce 29 A vril $17455^{\circ}$ BRUHIER.

\section{PRIVILEGE DU ROI.}

T OUIs par la grace de Dieu, Roi de France p. 203. $\mathrm{IV}$ ires, danuffop. 218. $\mathbf{X}$

as les

fomdiffipe

p. 245 .

le feillers, les Gens tenans nos Cours de Parlement, Maîtres des Requêtes ordinaires de notre Hôtel, grand Confeil, Prevôt de Paris; Baillifs, Sénéchaux, leurs Liemtenants Civils \& aurres nos Jufticiers qu'il appartiendra. Sa IUT. Norre bien amé Michel EtrenNe Day id fils, Libraite à Paris, nous a fait expofer qu'il défireroit faire imprimer \& donner au Public des Ouvrages qui ont pour titres Cafiorologie, ouTraité dans lequel on explique la nature, les proprietés ón l'usage du Caftor dans la Médecine, par Jean Marius, avec des Obfervations. Méditations fur la vie ón la

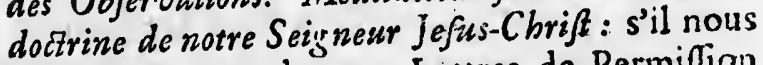
plaifoit lui accorder nos Lettres de Permifion pour ce neceffaires. A cescaufes, voulant favorablement traiter l'Expofant, Nous lui arons permis \& permettons par ces Préfentes de faire 


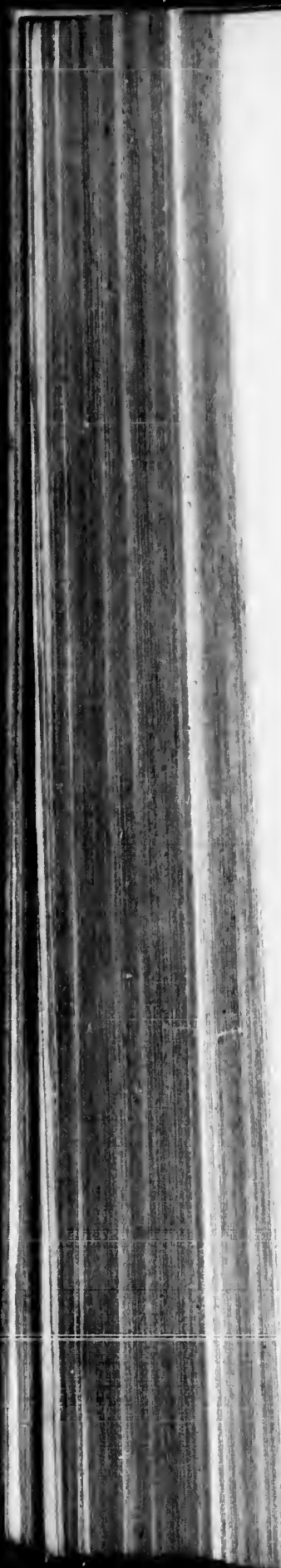

imprimer lefdits Ouvrages, en un ou plufieurs Volumes \& autant de fois que bon lui femblera, \& de les vendre, faite vendre \& débirer par tout notre Royaume, pendant le tems de trois années conlécutives, à compter du jour de la datte des Préfentes. Eaifons deffenfes à tous Libraires Imprimeurs, \& autres Perfonnes de quelque qualité \& condition qu'elles foien, d'en intro. duire d'impreffion étrangere dans aucun lieu de notre obéiffance; à la charge que ces Préfentes feront enregiftrées tour aulong fur le Regittre de la Communauté des Libraires \& Imprimeurs de Paris ; dans trois mois de la datte d'icelles; que l'impreffion deflits Ouvrages fera faite dans notre Royaume \& non ailleurs, en bon papier \& beaux caractéres, conformément à la feuille imprimée \& attachée pour modéle fous le contre fcel des Préfentes, que l'Inpétrant fe conformera en tout aux Réglemens de la Librairie, \& nottamment à celui du Io A vril 1725 , qu'avant que de les expofer en vente les manulcrits \& imprimés qui auront fervi de copie à l'impreffron defdits Ouvrages, feront remis dans le même état ou l'approbation y aura été donnée, ès mains de notre très cher \& féal Chevalier Ie fieur Daguefleau, Chancelier de France, Commandeur de nos Ordres; \& qu'il en fera enfuite remis deux Exemplaires de chacun dans notre Bibliotheque publique, un dans celle de notre Château du Louvre, \& un dans celle de notre très-cher \& féal Chevali er le fieur Dagueffeau, Chancelier de France; le tout à peine de nullité des Préfentes. Du contenu defquelles vous mandons \& enjoignons de faire jouir ledit Expofant ou fes ayans caufes pleinement \& paifiblement, 
plufieurs

emblera,

r par tout

trois an-

le la datte

Libraires

quelque l'en intro. :un lieu de - Préfentes le Regittre mprimeurs e dicelles ; faite dans bon papier à la feuille cous le conrant fe cona Librairie, $172 \mathrm{~s}$, qu'a$s$ manulcrits ie à l'imprefemis dans le été donnée, Chevalier Ie rance, Comen fera enfuire in dans notre elle de notre celle de notre Daguefleau eine de nullité elles vous manledit Expolant $x$ paifiblement,
Cant fouffrit qu'il leur foit fait aucun trouble ou empêchement : Youlons qu'à la copie des Pré. fentes qui feca imprimće tout au long au commenccment où à la fin defdits Ouvrages, foi foit ajoutée comme à l'original. Commandons au premier notre Huiftier ou Sergent, fur ce requis, de faire pour l'execurion d'icelles tous A Etes requis \& neceflaires, fons demander autre Permiffion, \& nonobftant clameur de Haro, Charte Normande \& Lettres à ce contraires ; Car rel eft notre plaifir. Donné à Paris le quatriéne jour du mois de Mars, l'an de grace mil fept cent quarante-fix, \& de notre Régne le trente-unieme. Par le Roi en fon Confeil.

Signé SaInson.

Regiftré fur le Regiftre onze de la Chambre Royale des Libraires \&o Imprimeurs de Paris, No. 558. Fol. 487. conformément aux anciens Réglemens, confirmés par celui du 28 Février 1723. $A$ Paris le 7 Mars 1746.

VINCENT, Syndic. 



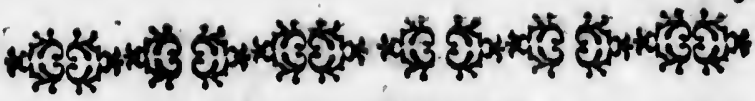

EXPLICATION de la Figure \& des Parties DU CASTOR.

Premiere Figure.

- E Caltor eft repréfenté dans Lla premiere Figure avec la moitié du corps fur la terre, \& l'autre dans l'eau; parce que l'on a obfervé qu'il aime à y plonger fouvent les pattes de derriere \& la queuë.

Secoride Figure.

N. Une des pattes de devant. OO. Le Colon.

P. Le Corcum.

Q. Le Ligament qui attache le Coecum, \& le long duquel plufieurs vaif- 
ij

feaux fe gliffent \& fe perdent dans la membrane de cet inteftin.

RR. Le Cerveau.

S. Legrand Sinus de la Dure mere.

TTTT.Quatre autres Sinus qui en font produits, \& qui féparent le cervelet en trois.

V. Le Cervelet.

Troifiéme Figure.

AA. Sont les Os pubis.

B. Le fond de la Veflie.

CC. Les deux premieres poches, quir font les plus grandes de celles dans. Iefquelles leCaftoreum eft préparế \& content.

DD. Les deux fecondes qui font plus petitcs.

EE. Deux autres pochesd'une troifiéme efpece, qui 
nt $\& \mathrm{fe}$

a memateftin.

la Dure inus qui. uits, \& le cerve-

is.

Veflie. ieres potes plus elles dans. Saftoreum contenu. ndes qui itcs. chesd'une ece, qui font enfermées dans les fecondes.

DE. Quanticé de petits corps ronds, élevés fur la fuperficie de la feconde \&de la troifiéme efpece des poches.

F. L'Ouverture commune à l'inteftin \& all paffage de la verge.

G. Le commencement de la verge.

HH. Les Epididymes.

II. Les Tefticules.

KK. Les Vaiffeatix Spermatiquies préparans.

LL. Les Déférens.

MM. : Les Mufcles cremafters.

YX. L'Os de la verge.

\section{2uatriême Figure.}

Cette Figure repréfente Jes Parties naturelles \& les Poches du Caftoreum d'un Caftor femelle, 
iv deflinées d'après nature, par $\mathrm{Mr}$. Cromwel Mortimer.

A. Les deux Ureteres.

B. Les Ovaires.

C. La Matrice placée fous la Veffie.

D. La Veffie contractée \& vuide.

E. L'Urétre danns un trajet de deux pouces de long.

FF. Les poches duCaftoreum. GG. Les deux Glandes qui ont un orifice commun avecles poches du Caftoreum.

$\mathrm{HH}$. L'Orifice des conduits du Caftoreum.

1. Le Vagin coupé.

K. L'Anus.

L. Une partie de la Queuë. Fin de l'Explication des Figures. 
, par Mr.

res.

:ée fous la

tractée \&

un trajet es de long. Caftoreum. landes qui e commun hes du Caf.

conduits du

pé. des Figures.

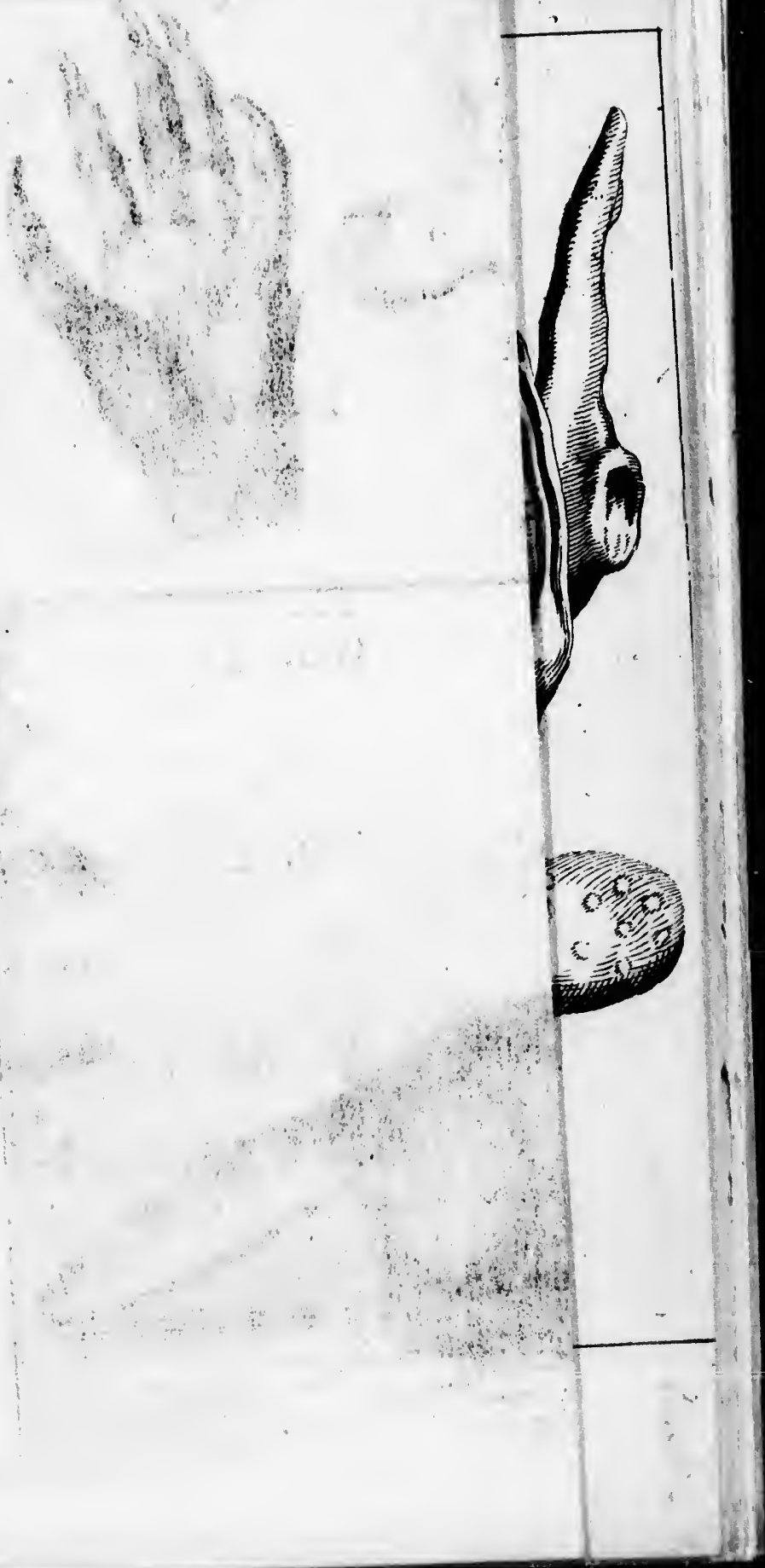


iv

deffinées d'après nature, par $\mathrm{Mr}$. Cromwel Mortimer.

A. Les deux Ureteres.

B. Les Ovaires.

C. La Matrice placée fous la Veffie.

D. La Veffie contractée \& vuide.

E. L'Urétre dạns un trajet de deux pouces de long.

FF. Les poches duCaftoreum. GG. Les deux Glandes qui ont un orifice commun avec les poches du Caf. toretum.

HH. L'Orifice des conduits du Caftoreum.

1. Le Vagin coupé.

K. L'Anus.

L. Une partie de la Quetië. Fin de l'Explication des Figures. 



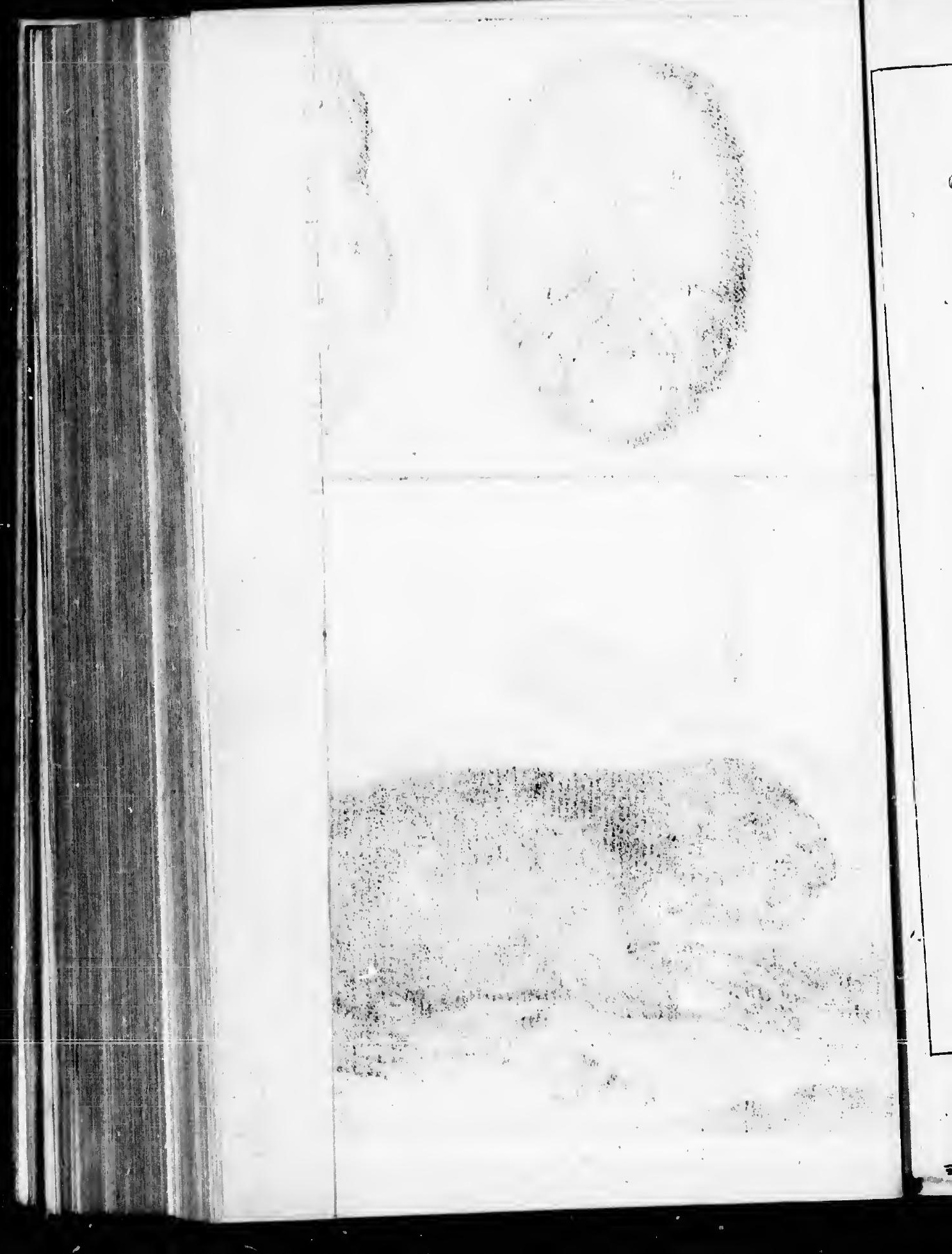




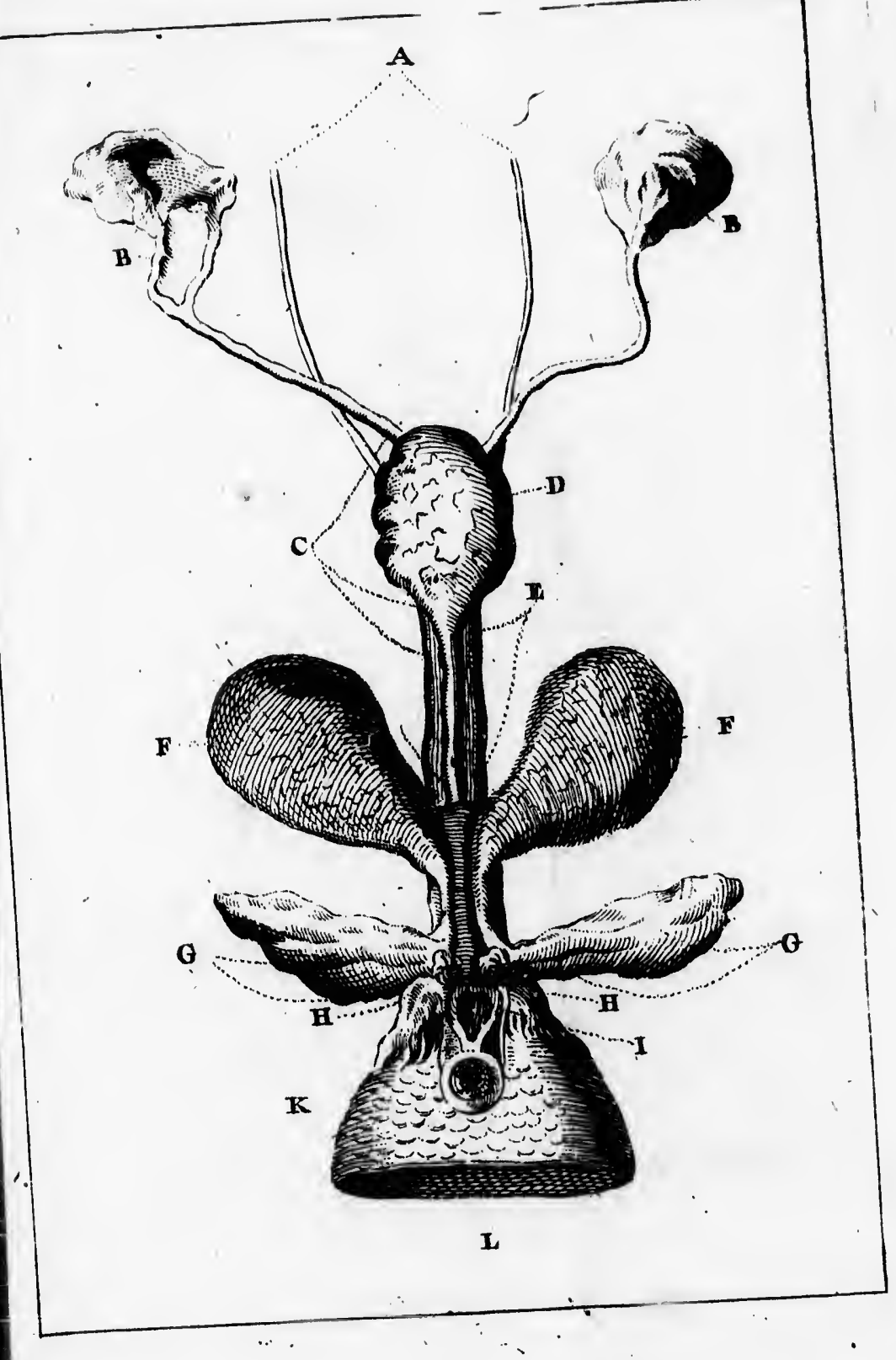




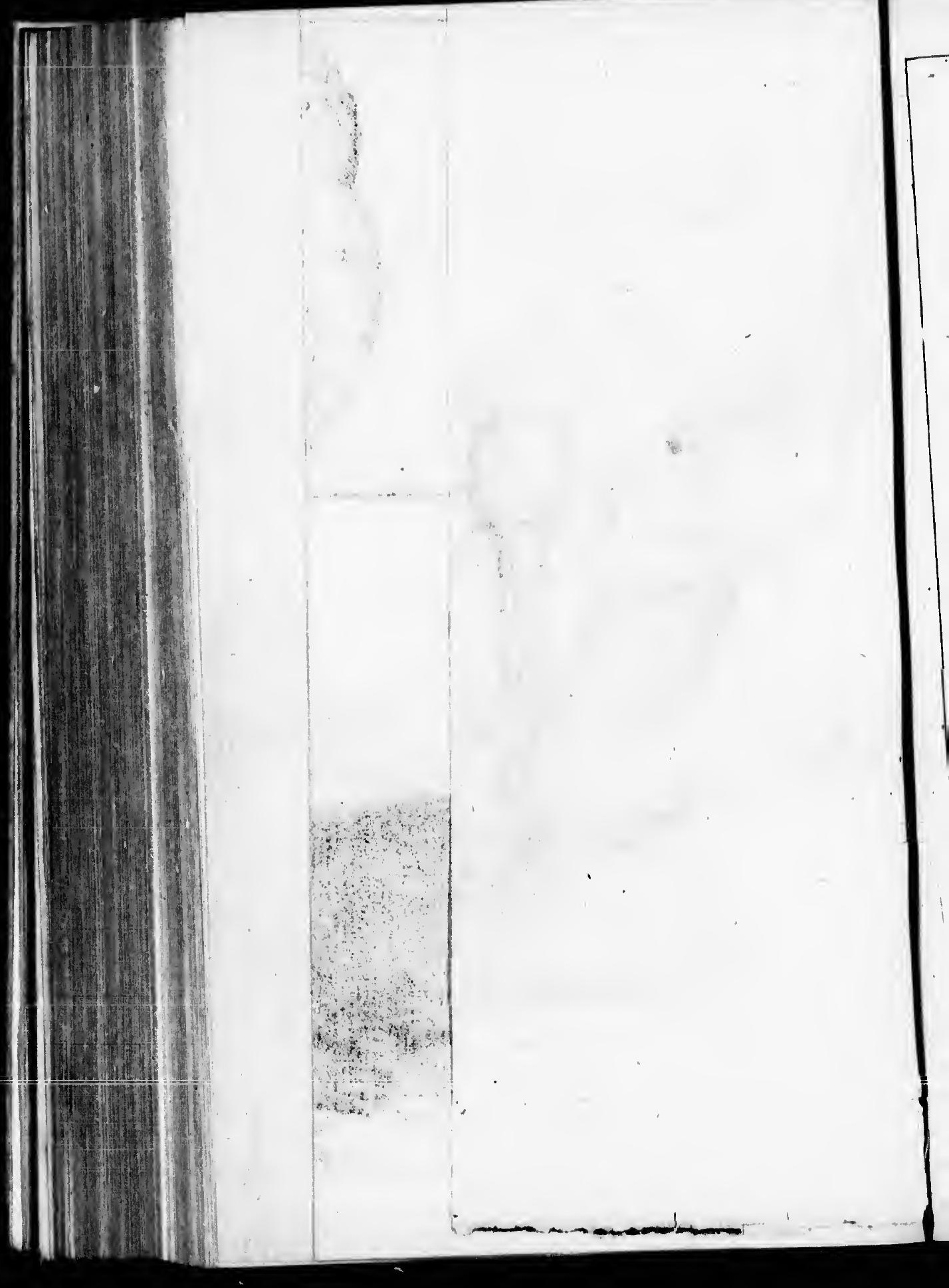




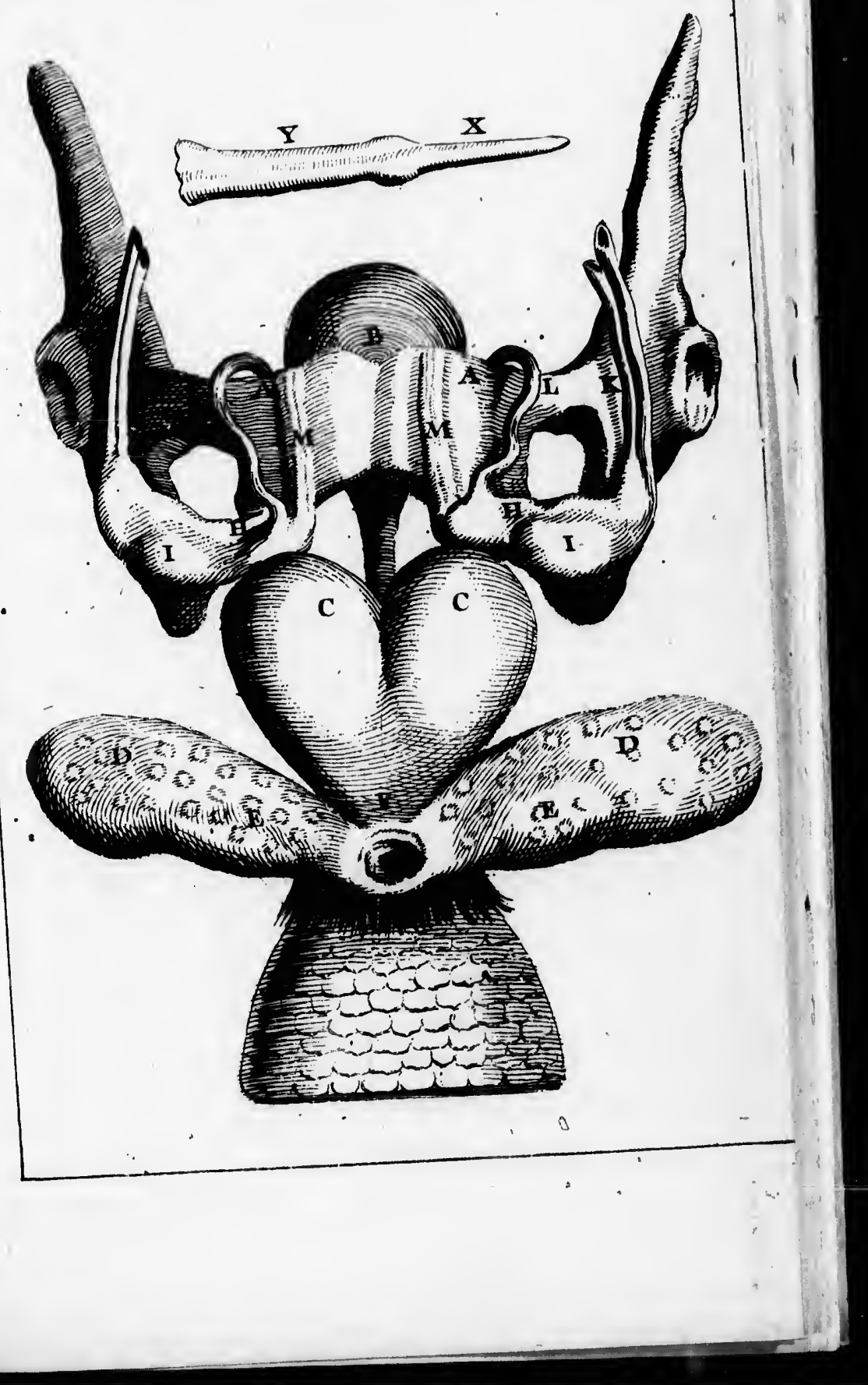




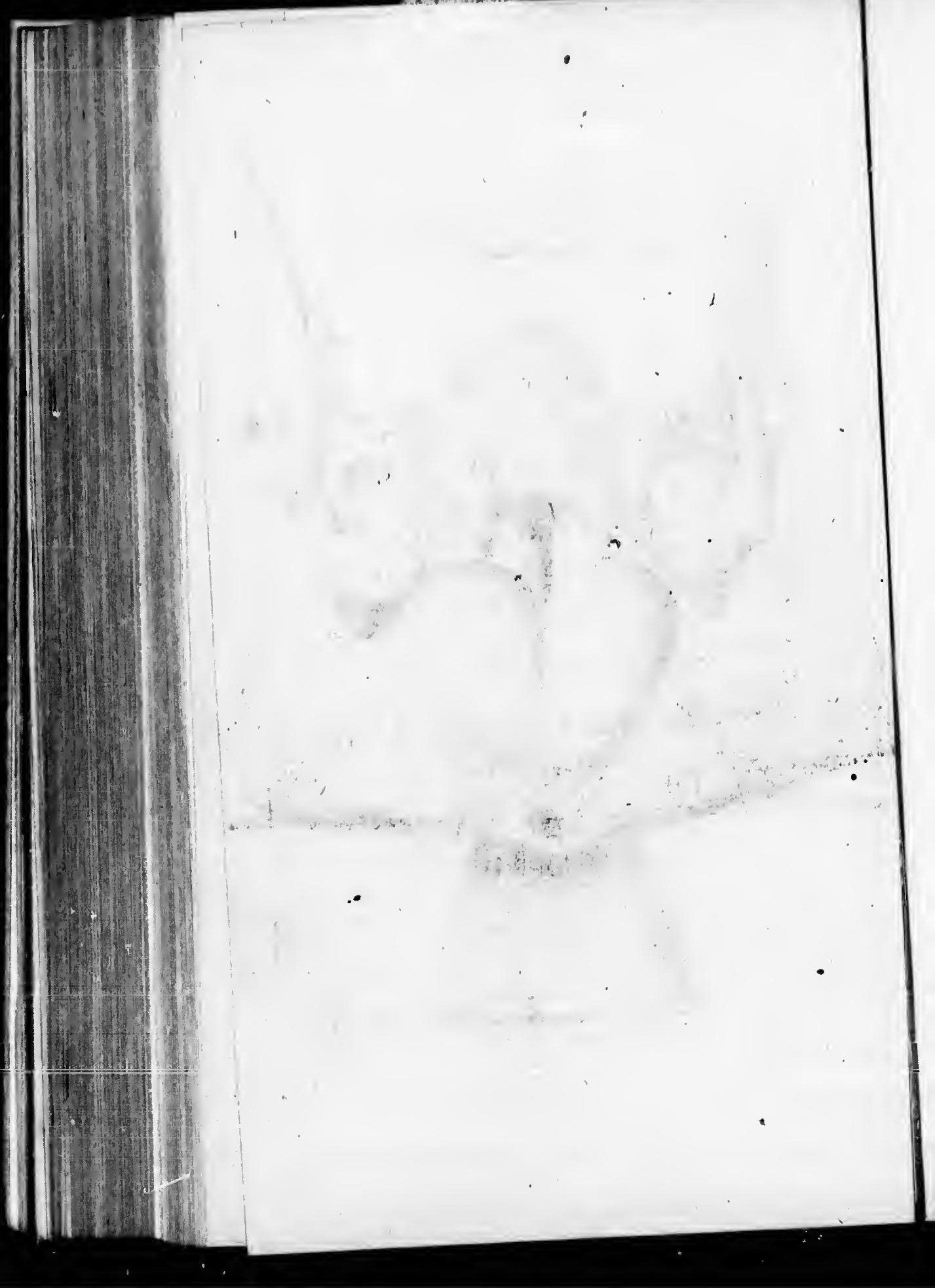





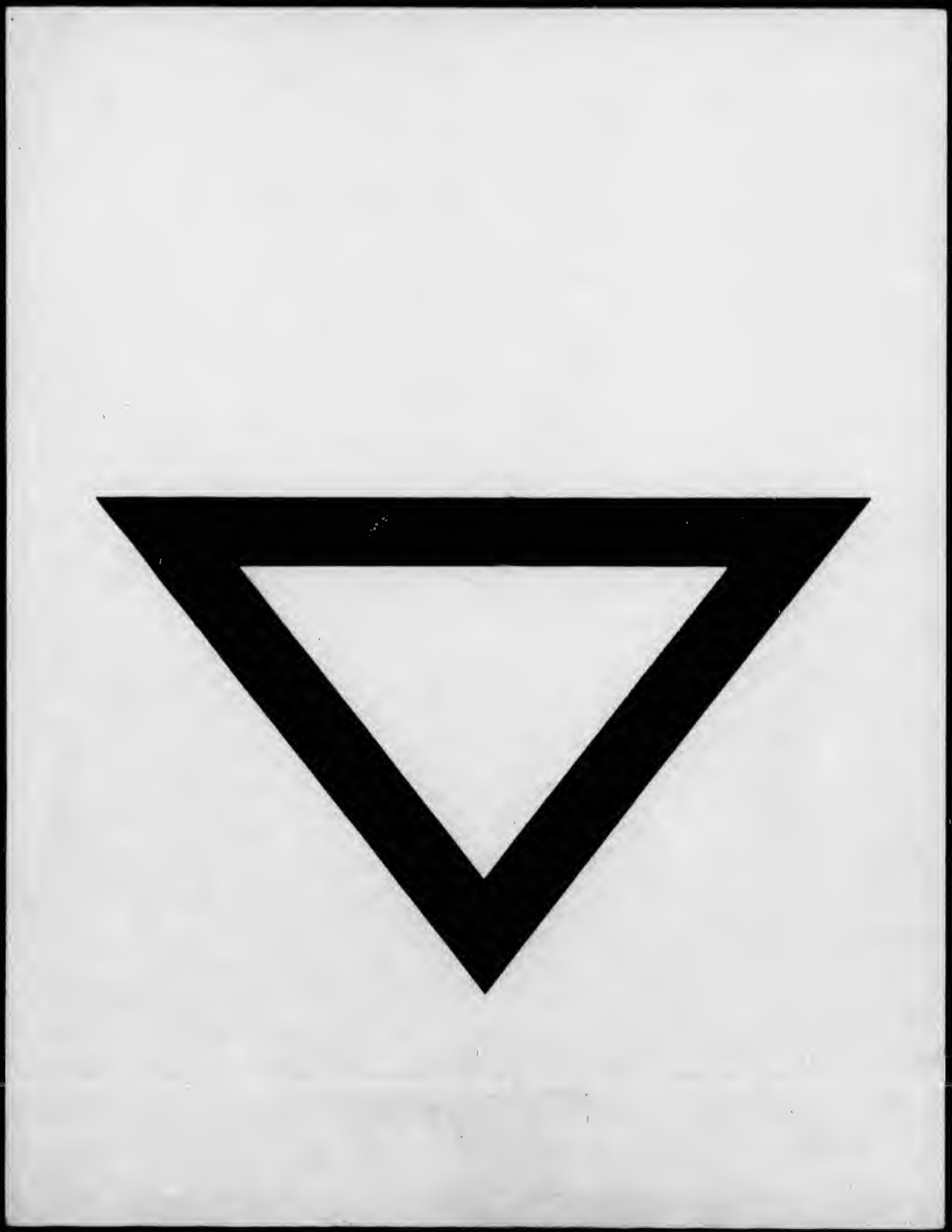

